2. ECN Category

(mark one)

Supplemental

Direct Revision

Change ECN

Temporary

Standby

Supersedure

Cancel/Void
3. Originator's Name, Organization, MSIN, and Telephone No.

A. M. Ermi, Remote Sensing and Sampling Equipment Engineering, L6-37, 376-5099

5. Project Title/No./Work Order No.

Tank 241SY101 Hydrogen Mitigation Test Project / N2045

8. Document Numbers Changed by this ECN (includes sheet no. and rev.) WHC-SD-WM-CSDD-008 Rev. 2

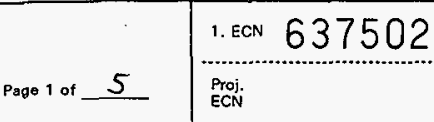

\section{1a. Modification Work}

[] Yes (fill out Blk. 11b)

[X] No (NA Blks. 11b, 11c, 11d)

12. Description of Change 11b. Work Package No.

N/A 11c. Modification Work Complete

N/A

Cog. Engineer Signature \& Date
4. Date

May 20, 1997

[X] Yes [] No TF-97-0581

6. Bldg./Sys./Fac. No.

7. Approval Designator

Tank 241SY101

9. Related ECN No(s). 198629.
SQ

10. Related PO No.

N/A

The previous Rev. 2 document is being replaced by this Rev. 3 document. Numerous changes in field instrumentation and improvements to the graphical interface as requested by Operations are incorporated in this revision. This also resulted in upgrades to the DACS control software (TEST303 to TEST304, and PLC304 to PLC305).

13a. Justification (mark one)

Criteria Change []
As-Found

Design Improvement $[\mathrm{X}] \quad$ Environmental

11d. Restored to Original Condition (Temp. or Standby ECN only)

N/A

13b. Justification Details

Since the issuance of the Rev. 2 document, changes to field instrumentation and improvements to the operator graphical interface have made it necessary to revise the software, and reissue the document to reflect the changes.

Design verification performed by informal review per wHC-CM-6-i, $F P-4, I$

14. Distribution (include name, MSIN, and no. of copies)

See distribution list. 


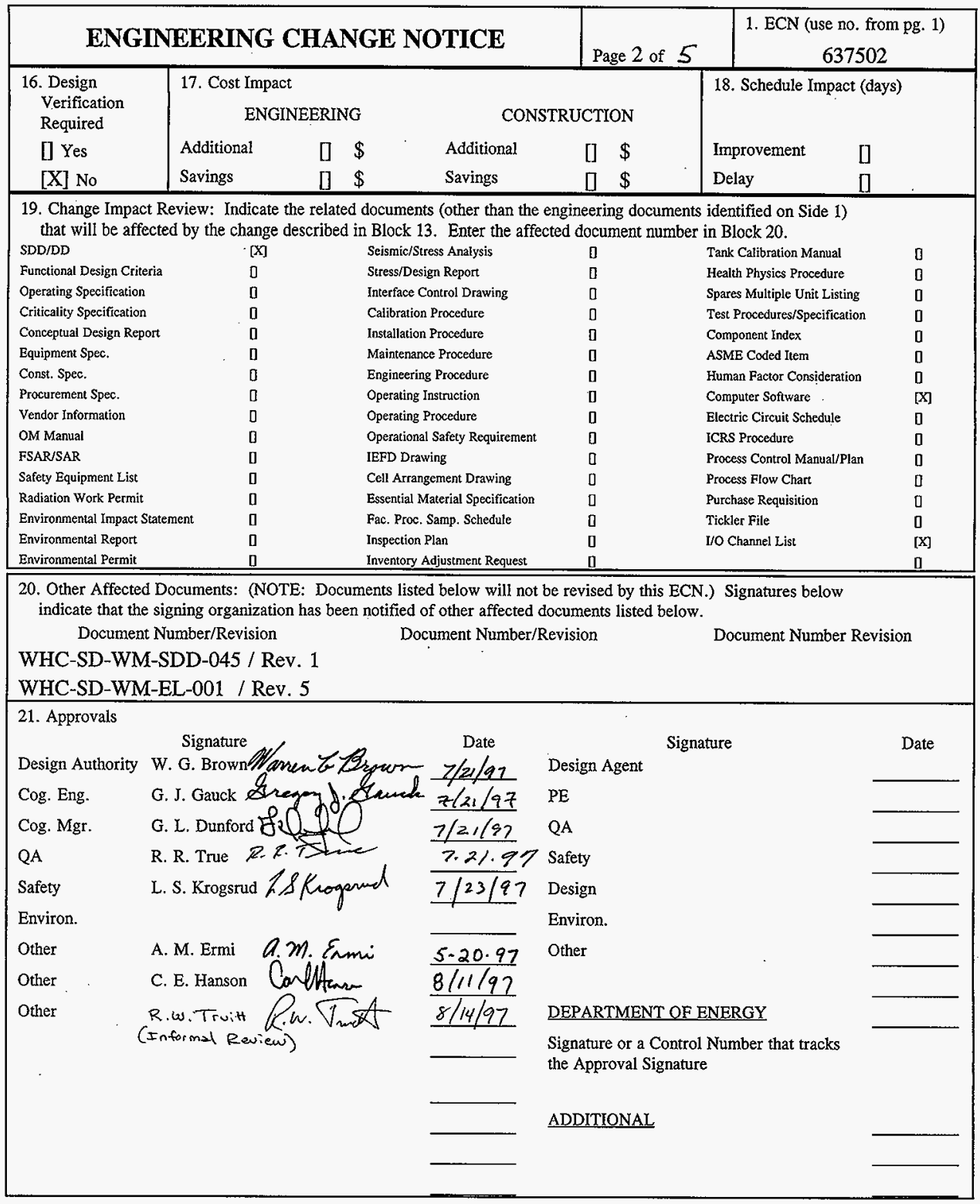




\section{UNREVIEWED SAFETY QUESTION SCREENING/DETERMINATION FORM \\ (Per WHC-IP-0842)}

Page 1 of 3

USQ Tracking No.

TF-97-0581

Rev. 0

AREA: [] East [X] West [] General.

$\begin{array}{lllll}\text { Facility: [] } 242-A & \text { [X] DST } & \text { [] SST } & \text { [] LERF } \\ & \text { [] Aging Waste } & \text { [] Other } & \end{array}$

ECN No. 637502

PCA No. N/A

Work Pkg No. N/A

Other (Specify) HNF-SD-WM-CSDD-008, Rev 3

TITLE: COMPUTER SYSTEM DESIGN DESCRIPTION FOR SY-101 HYDROGEN MITIGATION TEST PROJECT DATA ACOUISITION AND CONTROL SYSTEM (DACS-1); HNF-SD-WMI-CSDD-008, Rev.3, (ECN 637502)

Description of the Proposed Activity/REPORTABLE OCCURRENCE or PIAB:

This ECN changes the computer systems design description support document describing the computers system used to control, monitor and archive the processes and outputs associated with the Hydrogen Mitigation Test Pump installed in SY-101.

Introduction:

There is no new activity or procedure associated with the updating of this reference document. The updating of this computer system design description maintains an agreed upon documentation program initiated within the test program and carried into operations at time of turnover to maintain configuration control as outlined by design authority practicing guidelines. Any changes made to controlled components in the field will be updated after the time of implementation to support the engineers and operators understand, maintain, train to and operate the system.

There are no new credible failure modes associated with the updating of information in a support description document. The failure analysis of each change was reviewed at the time of implementation of the Systems Change Request for a11 the processes changed. This document simply provides a history of implementation and current system status.

\section{Scope:}

This USQ screening examines the CSDD described above, HNF-SD-WM-CSDD-008, Rev 3 and no other.

Authorization Basis:

WHC-SD-WM-ISB-001 Vol 1 Rev 0-M Sec. 6.0 Table 6. Hanford Site Tank Farm Facilities Interim Safety Basis

LA-UR-92-3196, REV 14a, Los Alamos National Laboratory 1995

West Tank Farms Standing Order 97-01 Rev 2

HNF-SSD-TWR-TI-003, Rev 2, Supporting Documentation for Requested Exceptions to Standing Order 96-36 (East) and 96-34 (West)

Conclusion: 
UNREVIEWED SAFETY QUESTION SCREENING/DETERMINATION FORM

(Continued)
Page 2 of 3

USQ Tracking No.

TF-97-0581

Rev. 0

The update and revision of the computer system design description does not represent a USQ and the conditions surrounding the change which occurred in order to change this document have been analyzed in the authorization basis documents. Therefore no USQ determination is required. The incorporation of information into this revision of the Systems Design Description has been examined against the flammable gas JCO 97-01 7atest rev and found not to be applicable because there is no field work associated with this ECN.

\section{References}

DE\&S Hanford Inc., Internat Memo, T.C. Geer to J.H. Wicks and W.M. Funderburke, " CLARIFICATION OF STANDING ORDER 96-36. (EAST) AND 96-34 (WEST)," dated Dec. 2, 1996

Van Vleet, R.J., 1994 "Safety Basis for Activities in Double-Shell Flammable Gas Watch List Tanks," WHC-SD-WM-SARR-002, Westinghouse Hanford Company, Rich? and WA.

Straalsund E.K. \& Mendoza R.E., June 19, 1995, "SYSTEM DESIGN DESCRIPTION FOR SY101 HYDROGEN MITIGATION TEST PROJECT DATA ACQUISITION AND CONTROL SYSTEM (DACS-1)," USQ Screening Against ECN 198628

Gauck, G.J. \& Brown, W.G. February 18, 1997, "SYSTEM DESIGN DESCRIPTION FOR SY-101 HYDROGEN MITIGATION TEST PROJECT DATA ACQUISITION AND CONTROL SYSTEM (DACS-1), "USQ Screening (TF-97-0174) against ECN 637503

USO Screening:

A. Does the PROPOSED ACTIVITY represent a change to the facility as described in the AUTHORIZATION BASIS?

[X] No [] Yes [] N/A

Basis: The document, HNF-SD-WM-CSDD-008, Rev 3, makes no changes to the facility as described in the authorization basis. The hardware system design description is being updated to reflect current status of the DACS system and do not drive any change to the SY-101 tank farm facility. The Safety Assessment, LA-UR-92-3196, REV $14 \mathrm{a}$, Los ATamos National Laboratory 1995, requirements for DACS system hardware and software control testing and verification are discussed in Appendix $S$. The updating of this document is in compliance with the maintaining of current revisions of the software which operates the pump and provides alarms, shutdown sequences and surveillance/archiving functions.

B. Does the PROPOSED ACTIVITY represent a change to procedures as described in the AUTHORIZATION BASIS?
[] No
[] Yes
[X] N/A

Basis: This is not a change to a procedure nor control associated with the operation of the pump or its recording surveitlance devices. 
Rev. 0

C. Does the test or experiment represent a test or experiment not described in the AUTHORIZATION BASIS documentation?
[] No
[] Yes
[X] N/A

Basis: This document up date is not a test nor experiment.

D. Does the PROPOSED ACTIVITY or REPORTABLE OCCURRENCE, impact:

- OSRs or lOSRs?

- Approved IOSR Compliance Implementation Plan?

[X] No [] Yes [] N/A

Basis: There are no changes in any OSR, IOSR, or TSR documents or requirements governing the operation or configuration of this pump control system or this document outlining the systems design descriptions.

E. Does the REPORTABLE OCCURRENCE or PIAB involve analytical errors, omissions, and/or deficiencies in the AUTHORIZATION BASIS?
[] No
[] Yes
[X] N/A

Basis: This is a change to a systems design description document not documentation noting a reportable occurrence or PIAB.

USOE No. 1 G.J. Gauck

USOE No. 2 Warren G Brown

$$
\text { Print Name }
$$

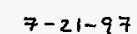
Print Name
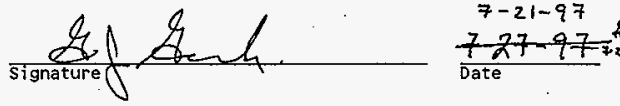

IF "YES", USOE CONTINUE WITH DETERMINATION BELOW

\section{USO DETERMINATION:}

1. Could the PROPOSED ACTIVITY or USO ISSUE significantly increase the frequency of occurrence of an accident previously evaluated in the AUTHORIZATION BASIS?

[] No [] Yes/Maybe

Basis:

2. Could the PROPOSED ACTIVITY or USO Issue significantly increase the consequences of an accident previously evaluated in the AUTHORIZATION BASIS?

[] No [] Yes/Maybe 


\title{
COMPUTER SYSTEM DESIGN DESCRIPTION FOR SY-101 HYDROGEN MITIGATION TEST PROJECT DATA ACQUISITION \& CONTROL SYSTEM (DACS-1)
}

\author{
A. M. Ermi \\ SGN Eurisys Services Corporation, Richland, WA 99352 \\ U.S. Department of Energy Contract DE-AC06-96RL13200 \\ EDT/ECN: 637502 \\ Org Code: $\$ 1200$ \\ UC: 2030 \\ B\&R Code: EW3120072 \\ Charge Code: N2045 \\ Total Pages: 216
}

Key Words: DACS, DATA ACQUISITION AND CONTROL SYSTEM, 241SY101, MIXER PUMP, SOFTWARE, COMPUTER

Abstract: This document provides descriptions of the components and functions of the automated data acquisition and control system (DACS) in support of hydrogen mitigation for waste tank 241SY101 at the Hanford Nuclear Reservation. The system was designed and implemented by Los Alamos National Laboratory, supplied to Westinghouse Hanford Company, and now operated by Lockheed Martin Hanford Corporation.

TRADEMARK DISCLAIMER. Reference herein to any specific commercial product, process, or service by trade name, trademark, manufacturer, or otherwise, does not necessarily constitute or imply its endorsement, recommendation, or favoring by the United States Government or any agency thereof or its contractors or subcontractors.

Printed in the United States of America. To obtain copies of this document, contact: Document Control Services, P.O. Box 950, Mailstop H6-08, Richland WA 99352, Phone (509) 372-2420; Fax (509) 376-4989.
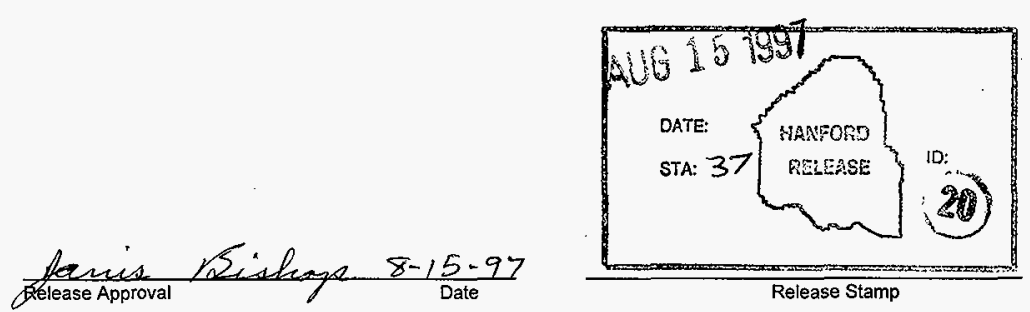
(2) Title

Computer System Design Description for SY-101 Hydrogen Mitigation Test Project Data Acquisition and Control System (DACS-1)

CHANGE CONTROL RECORD

(3) Revision

(4) Description of Change - Replace, Add, and Delete Pages

Rev. 0

(7) EDT 158000, Dec. 22, 1992

Rev. 1

Change title to: "Computer System Design

Description for SY-101 Hydrogen Mitigation Test

Project Data Acquisition and Control System (DACS-1)"

The document was completely re-worked, with numerous changes made in the arrangement of the information and in the level of detail of the information. Information not available at the time Rev. 0 was released is now included in the Rev. 1 document.

Rev. 2 Complete revision per ECN 198629, January 4, 1995

Rev. 3

Complete revision with the installation of revised software TEST-3.04 and PLC-3.05 per ECN 637502, May 20, 1997; "WHC" document prefix changed to "HNF"
Authorized for Release

\begin{tabular}{l|l} 
(5) Cog. Engr. & (6) Cog. Mgr.
\end{tabular}

RW Truitt

RE Bauer

(original signed

8-24-94)

\section{GJ Gauck}

SH Rifaey

(original signed

8-11-95)

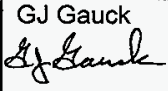

G. L Durford

7. 21.97 .

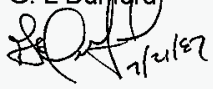


HNF-SD-WM-CSDD-008

Revision 3.0

\section{Computer System Design Description for the SY-101 Hydrogen Mitigation Test Project Data Acquisition and Control System (DACS-1)}

May 1997

Prepared by:

S. O. Smith \& R. W. Truitt, PLCs Plus

and

A. M. Ermi, SGN Eurisys Services Corporation

Prepared for:

G. J. Gauck, Lockheed Martin Hanford Corporation 


\section{TABLE OF CONTENTS}

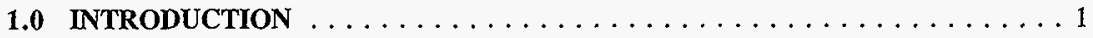

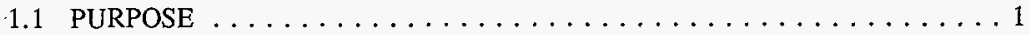

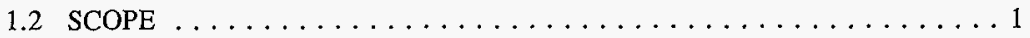

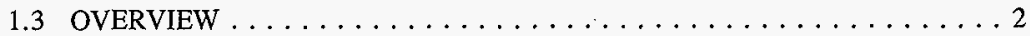

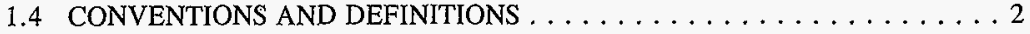

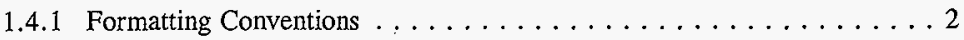

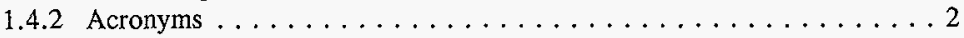

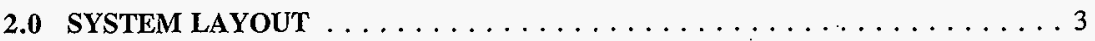

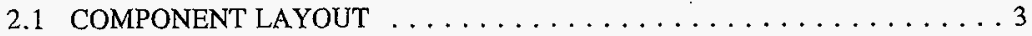

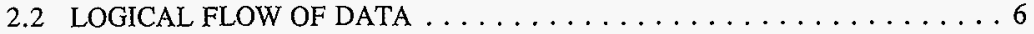

2.3 TASK ALLOCATION TO COMPONENTS $\ldots \ldots \ldots \ldots \ldots \ldots \ldots \ldots$

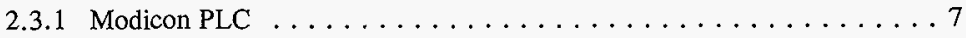

2.3.2 Eaton AF-5000+ Variable Frequency Drives $\ldots \ldots \ldots \ldots \ldots \ldots 7$

2.3.3 TEST Strategy Terminal, STATION5 $\ldots \ldots \ldots \ldots \ldots \ldots \ldots 7$

2.3.4 MOTOR Strategy Terminal, STATION8 $\ldots \ldots \ldots \ldots \ldots \ldots \ldots$

2.3 .5 Backup Station, STATION $7 \ldots \ldots \ldots \ldots \ldots \ldots \ldots \ldots \ldots$

2.3.6 Local RSS Terminals, STATION6, and STATION7 . . . . . . . 8

2.3.7 Remote RSS Terminals, STATION11, STATION13, STATION15, and

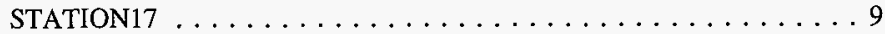

2.3.8 File Server Support, STATION9 $\ldots \ldots \ldots \ldots \ldots \ldots \ldots \ldots \ldots$

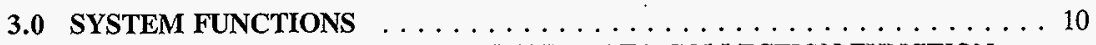

3.1 INSTRUMENT MONITORING AND DATA COLLECTION FUNCTION

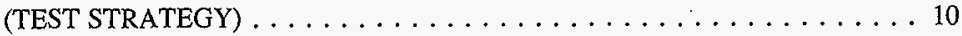

3.1.1 TEST Strategy Communications . . . . . . . . . . . . 10

3.1.1.1 Communications with the Modicon PLC ......... 10

3.1.1.2 Communications with the MOTOR Strategy ......... 11

3.1.1.3 Communications from the TEST Strategy to the RSS

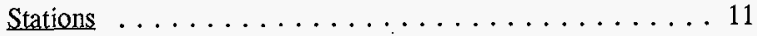

3.1.1.4 Communications from the TEST Strategy to the Data

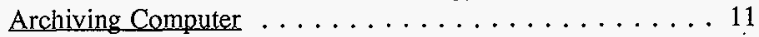

3.1 .2 Data Monitoring . . . . . . . . . . . . . . . . 11

3.1.2.1 Abort Status Monitoring . . . . . . . . . . . 11

3.1.2.2 Tank Measurement Monitoring $\ldots \ldots \ldots \ldots \ldots \ldots \ldots . \ldots \ldots$

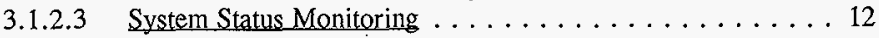

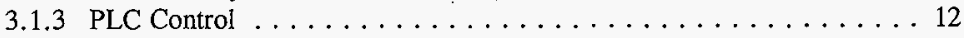

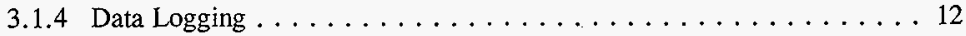

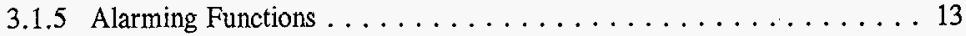


3.2 PUMP CONTROL FUNCTION (MOTOR STRATEGY) $\ldots \ldots \ldots \ldots \ldots 13$

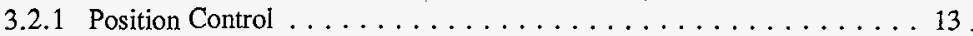

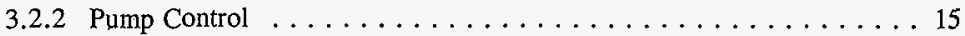

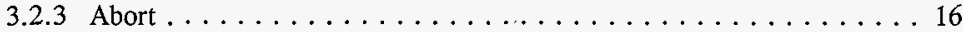

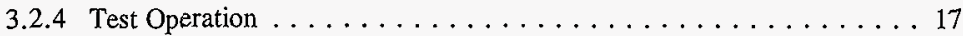

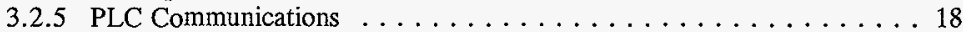

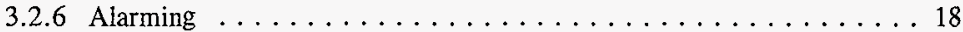

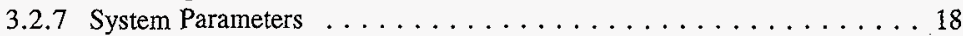

3.3 MODICON PLC FUNCTIONS $\ldots \ldots \ldots \ldots \ldots \ldots \ldots \ldots \ldots \ldots$

3.3.1 Data Collection from the Field $\ldots \ldots \ldots \ldots \ldots \ldots \ldots \ldots \ldots$

3.3 .2 Abort Functions . . . . . . . . . . . . . . . . . 19

3.3.3 Control Points and Alarm Outputs $\ldots \ldots \ldots \ldots \ldots \ldots \ldots$

3.3.4 Test Timers and Enable Logic . . . . . . . . . . . . . . . 20

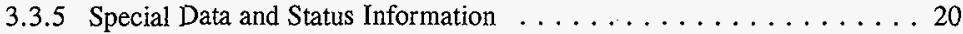

3.4 INSTRUMENTATION . . . . . . . . . . . . . . 20

3.4.1 Mixer Pump Operation Measurements . . . . . . . . . . . 21

3.4.1.1 Mixer Pump Motor Operation .............. 21

3.4.1.2 Discharge Nozzle and Pump Column . . . . . . . . 21

3.4.2 Tank and Waste Measurements . . . . . . . . . . 21

3.4.2.1 Tank and Waste Temperatures . . . . . . . . . . 22

3.4.2.2 Tank Waste Level . . . . . . . . . . . . . . . 22

3.4.2.3 Tank Pressures . . . . . . . . . . . . . . 22

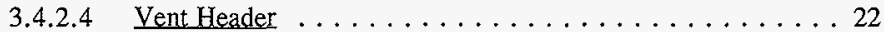

3.4 .2 .5 Gas Concentrations . . . . . . . . . . . . . 22

3.4.2.6 Miscellaneous Tank Measurements . . . . . . . . 23

3.4 .3 Strain Measurements . . . . . . . . . . . . . . 23

3.4 .4 Trailer and Area Monitors $\ldots \ldots \ldots \ldots \ldots \ldots \ldots \ldots$

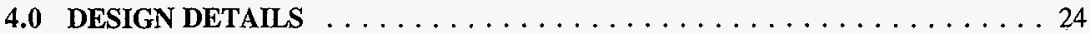
4.1 INSTRUMENT MONITORING AND DATA COLLECTION FUNCTION

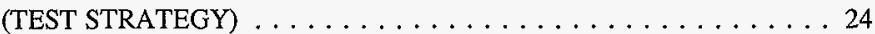

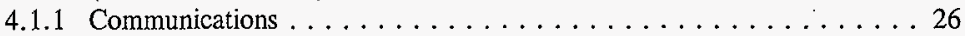

4.1.1.1 Communications between TEST Strategy and the Modicon PLC . . . . . . . . . . . . . 26

4.1.1.2 Communications with the MOTOR Strategy . . . . . . 30

4.1.1.3 Other Network Communications . . . . . . . . . . . . 30

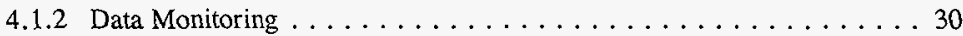

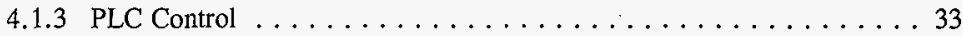

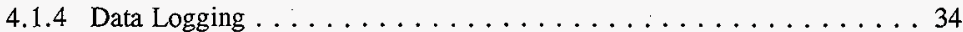

4.1 .5 Alarming Functions $\ldots \ldots \ldots \ldots \ldots \ldots \ldots \ldots \ldots \ldots \ldots \ldots \ldots$ 
4.2 PUMP CONTROL FUNCTION $\ldots \ldots \ldots \ldots \ldots \ldots \ldots \ldots \ldots \ldots \ldots$

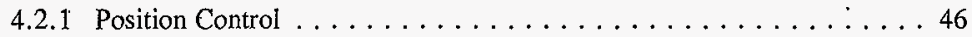

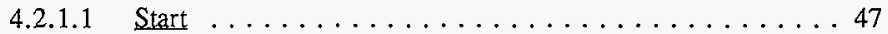

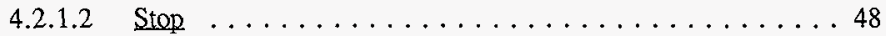

4.2.1.3 AF5000 + Communications . . . . . . . . . . . 50

4.2.1.4 Position Feedback . . . . . . . . . . . . . . 53

4.2.1.5 Direction Control . . . . . . . . . . . . . . 54

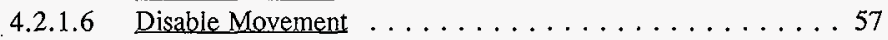

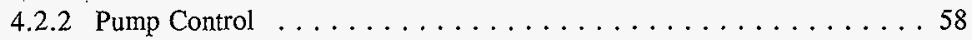

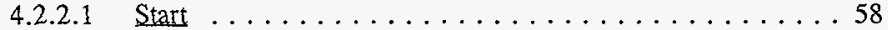

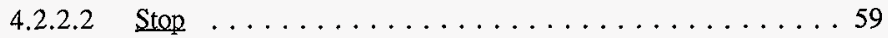

4.2.2.3 AF5000+ Communications . . . . . . . . . . . . 59

4.2.2.4 Parameter Verification . . . . . . . . . . . . . 62

4.2 .3 Abort . . . . . . . . . . . . . . . . . 63

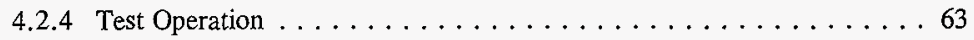

4.2.4.1 Test Creation and Selection . . . . . . . . . . . 64

4.2.4.2 Elapsed Time Calculation . . . . . . . . . . . . . . 67

4.2.4.3 Operator Test Information ... . . . . . . . . 68

4.2.4.4 Test Operation Strategy Details . . . . . . . . . . 69

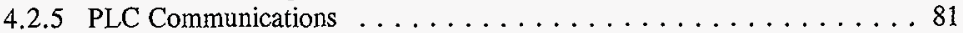

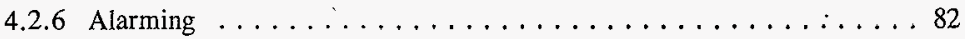

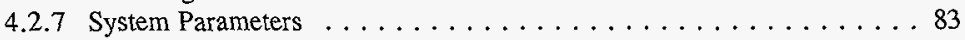

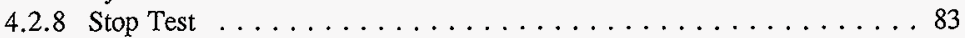

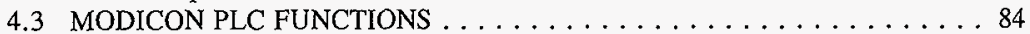

4.3.1 Data Collection From the Field . . . . . . . . . . 85

4.3.1.1 ASCII/BASIC Module Operation ........... 86

4.3.1.2 ASCII/BASIC Module Communications with the Gas Chromatograph ................. 86

4.3.1.3 ASCII/BASIC Module Communications with the RGA5 Computer . . . . . . . . . . . . . . . . 89

4.3.1.4 Thermocouple Module Operation ........... 90

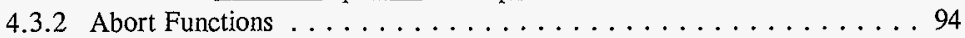

4.3.3 Control Points and Alarm Outputs $\ldots \ldots \ldots \ldots \ldots \ldots \ldots \ldots$

4.3.4 Test Timers and Enable Logic . . . . . . . . . . . . . . . 97

4.3.5 Data Transfer and Status Information . . . . . . . . . . . 98

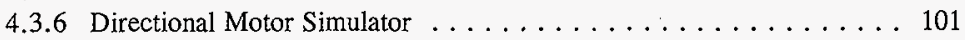

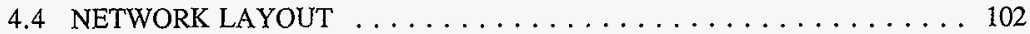




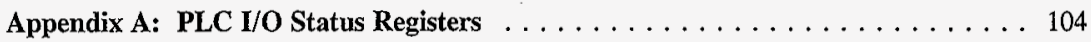
Appendix B: PLC Register List $\ldots \ldots \ldots \ldots \ldots \ldots$ Appendix C: Report and Recipe File Listings . . . . . . . . . . . . . . . 107

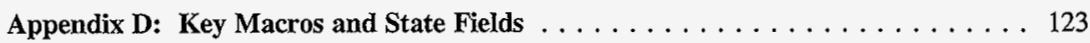
Appendix E: MOTOR Strategy Display List . . . . . . . . . . . . . . . . 124 Appendix $\mathrm{F}:$ Hardware Configurations $\ldots \ldots \ldots \ldots \ldots \ldots \ldots$ Appendix G: Network Configuration Settings . . . . . . . . . . . . . . . 134 Appendix H: Computer Configurations and Software Versions . . . . . . . . 139

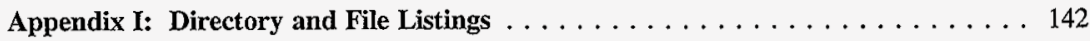
Appendix $\mathrm{J}:$ ASCU/BASIC Listings $\ldots \ldots \ldots \ldots \ldots \ldots \ldots$

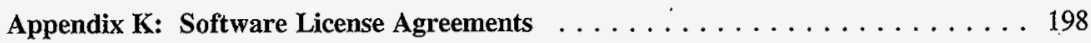
Appendix L: DeCipher Plus and DeTerminal Software . . . . . . . . . . . . . 199 
HNF-SD-WM-CSDD-008

Rev. 3

Page vi

Trademark Credits

Agiler is a trademark of Sysgration Ltd.

$3 \mathrm{Com}$ is a registered trademark of 3 Com Corporation

ARCLINK is a trademark of Datapoint Corporation

ARCNET is a registered trademark of Datapoint Corporation

Bernoulli is a registered trademark of Iomega Corporation

Black Box is a registered trademark of Black Box Corporation

Datataker Plus is a registered trademark of Data Electronics (Aust) Pty. Ltd.

DeCipher Plus is a trademark of Data Electronics (Aust) Pty. Ltd.

DeTerminal is a trademark of Data Electronics (Aust) Pty. Ltd.

DT50, DT200 and DT500 are trademarks of Data Electronics (Aust) Pty. Ltd.

Eaton is a registered trademark of the Eaton Corporation

EMM386 is a trademark of Microsoft Corporation

Ethernet is a trademark of the Xerox Corporation

Expert Mouse is a trademark of Kensington Microware Ltd.

FAMOS is a trademarks of Nicolet Instrument Corporation

Genesis Control Series is a trademark of Iconics, Inc.

Gen-Net is a trademark of Iconics, Inc.

Genius Mouse is a trademark of KYE International Corporation

HP LaserJet is a registered trademark of Hewlett-Packard Company

IBM PC is a trademark of the International Business Machine Corporation

IBM Proprinter is a trademark of the International Business Machine Corporation

Iomega is a registered trademark of Iomega Corporation

Jaz is a registered trademark of Iomega Corporation

Kensington is a registered trademark of Kensington Microware Ltd.

Lotus is a registered trademark of Lotus Development Corporation

Magic I/O is a trademark of Everex Systems, Inc.

Modsoft is a registered trademark of AEG Schneider Automation, Inc.

Modicon, Modbus Plus and 984 PLC are trademarks of AEG Schneider Automation, Inc.

MS-DOS and Windows are registered trademarks of Microsoft Corporation

NETROOM is a trademark of the Helix Software Company, Inc.

Norton DiskLock is a trademark of Symantec Corporation

Nicolet is a registered trademarks of Nicolet Instrument Corporation

SA-85 Modbus Plus Card is a trademark of AEG Schneider Automation, Inc.

Shinko is a trademark of Shinko Technologies, Inc.

SMC is a registered trademark of of Standard Microsystems Corporation

Texas Microsystems is a registered trademark of Texas Microsystems, Inc.

Other product names may be trademarks or registered trademarks of their respective companies and are hereby acknowledged. 


\subsection{INTRODUCTION}

This document provides descriptions of components and tasks that are involved in the computer system for the data acquisition and control of the mitigation tests conducted on waste tank 241-SY-101 at the Hanford Nuclear Reservation. The system was designed and implemented by Los Alamos National Laboratory, supplied to the Westinghouse Hanford Company, and is currently being operated by Lockheed Martin Hanford Corporation. The computers (both personal computers and specialized data-taking computers) and the software programs of the system will hereafter collectively be referred to as the DACS (Data Acquisition and Control System).

\subsection{PURPOSE}

This document reflects the DACS-1 information for the software currently in use in the DACS trailer; TEST strategy "TEST304", MOTOR strategy "MOTOR301", and Modicon ladder logic software "PLC305".

\subsection{SCOPE}

The DACS was designed for hydrogen mitigation testing for waste storage tank 241-SY-101. The mitigation testing uses a pump immersed in the waste tank and is directed at certain angles and operated at different speeds and time durations.

The positioning of the pump and operation of the pump is controlled by the DACS, with the test operators commanding the system. There are many instruments used to monitor process variables within the tank at all times. The DACS collects data from these instruments, displays real-time data for operators and archives the data for later analysis; it also interfaces with control elements and safeguards the operation of the test equipment.

The DACS is composed of several components working in parallel to perform the tasks needed for test operation and monitoring.

There is a variable frequency drive that controls a motor that will move the position of the pump to different angles. A second variable frequency drive controls a motor which drives the pump that circulates the waste.

A PLC (Programmable Logic Controller) interfaces with instrumentation in the waste tank and controls elements for safe operation. This PLC has embedded logic to assure safe operation of the pump and to process data for interfacing to a supervisory networked computer system.

A networked computer system, using a multitasking software shell called Genesis, brings together all data gathered from operator input, the PLC, and the variable frequency drives. The Genesis system is used to collect data from the PLC and from the variable frequency drives controlling the motors. Genesis displays this data in real time and in a graphic format to the operators. The system also stores data to files that can be analyzed at any time and these files are archived for later analysis. 
The Genesis system also is used to control the variable frequency drives' operation from operator requests. There is embedded logic in the system to warn operators of critical conditions and ensure safe operation of the pump motors.

The Genesis system supports peer-to-peer network communications to enable data to be shared between terminals. The Genesis network also supports host communications to multiple supervisory stations, allowing several consoles to access common data.

\subsection{OVERVIEW}

This document provides a description of the system in ever-increasing detail: First the general organization of system components is shown in Section 2, "System Layout." Then, in Section 3, "System Functions," the DACS tasks are broken down and an overview of each component's purpose is given. Finally, in Section 4, "Design Details," the intricacies of how each task is accomplished are supplied.

\subsection{CONVENTIONS AND DEFINITIONS}

This document contains some formalisms to aid in its descriptions. These, as well as acronyms that are used, are given in the sections that follow.

\subsubsection{Formatting Conventions}

The Genesis multitasking software application is embodied in a database referred to as a strategy. Strategies are organized by algorithm blocks, which have a type and a tag name. The block types are denoted by an italic font. The block tag names will be encapsulated in angle brackets; for example, <TAGNAME > .

\subsubsection{Acronyms}

The following acronyms are used:

CSDD Computer System Design Description

DACS Data Acquisition and Control System

FTIR Fourier Transform InfraRed

HLAN Hanford Local Area Network

HSDD Hardware System Design Description

MIT Multi-function Instrument Tree

PLC Programmable Logic Controller

PNL Pacific Northwest Laboratory (Battelle)

$\mathrm{R} \& \mathrm{R} \quad$ Report and Recipe

RSS Remote Supervisory Station

SDD System Design Description

VFD Variable Frequency Drive

WHC Westinghouse Hanford Company 


\subsection{SYSTEM LAYOUT}

The DACS contains several components that function in parallel to perform data collection and analysis, data display, alarm indication, monitoring, pump control, and archiving functions. Each component is carefully chosen, based on its capabilities, to perform a specific task. Their close choreography is required to meet the performance requirements of the system.

The system is designed to collect data from the field, display the data to operators, and $\log$ the data for later analysis. The system has the ability to warn the operators of critical conditions. There are control functions embedded in the system to control the position and operation of the pump. During pump control there are several checks on the critical signals to abort operation when a problem is detected. The system is designed to have enhanced effectiveness by being user friendly, and has built-in protections to make the test operation safe.

Information must be exchanged between components to integrate all of the data and control signals into a workable whole. Communication routines are implemented to read signals and data from the PLC and AF5000 devices and to send control commands to the pump equipment. The display terminals share data over a real-time data network. This network allows multiple users to share information and allows strategies to share critical signals and control commands.

\subsection{COMPONENT LAYOUT}

The DACS is composed of Modicon PLCs, two Eaton AF5000+ variable frequency drives, a Genesis data collection runtime station, a Genesis pump control runtime station, a backup station to each Genesis runtime station, multiple local consoles for the Genesis data collection station, multiple remote consoles for the Genesis data collection station, a file server interface to the local area network and a station in the trailer for access to and programming of the PLC.

The Eaton AF5000 + variable frequency drives are used to control electrical motors. The units have microprocessors that have logic functions specifically designed to control the motor and provide for its safe operation. The reading of parameters and sending of control commands for the variable frequency drives can be done from the front panel of the unit or from serial communication commands. The operating status of the drive can be viewed from the front panel of the unit or it can be requested by a device that supports serial communications.

A driver has been written to communicate with the Eaton AF5000+ variable frequency drives to request data and send control commands. This driver has been specifically designed to function within a personal computer running the Genesis multitasking software.

The Genesis multitasking software is used to display real-time data from the field, perform logic functions, and send commands to the control devices. Each Genesis application 
is embodied in a database which is referred to as a strategy. This strategy contains algorithms that are executed at specific rates. The algorithms in the strategy are graphically selected by placing blocks in the strategy configuration environment. There are different kinds of algorithm blocks that can be used in the strategy to read data from hardware devices and write data to hardware devices. Genesis provides control-based algorithm blocks to build control logic.

Personal computers that use Genesis to update a strategy from hardware devices are considered runtime stations. Real-time displays are dynamically updated from the current values of the parameters in the algorithm blocks in the Genesis strategy. These displays are interactive and are designed to show current signal readings and allow the operators to change operating parameters. The Genesis software is used to bring data from the field together, perform calculations on that data, and then display the results to the operators.

Each Genesis runtime application can share its data to other Genesis stations over a real-time data network called GEN-NET. The GEN-NET is used to transfer selected real-time data and files between personal computers running the Genesis software. The physical layer of the GEN-NET uses ARCNET hardware in a star configuration. All GEN-NET stations are connected to an active hub with coaxial cable.

Two Genesis runtime stations are used to pass data to and from the Modicon PLC. Information is retrieved and sent to the PLC with a communication driver that exeeutes in parallel with the other Genesis runtime functions. One runtime station is called STATION5 on the Genesis GEN-NET. The Genesis strategy executed at this station is called TEST.

The other Genesis runtime station is used for pump control and communicates to the two variable frequency drives used to position and control the pump. This runtime station is called STATION8. It also communicates with the PLC to transfer data from the variable frequency drives. The Genesis strategy that is executed in this station is called MOTOR.

One of the personal computers on the GEN-NET is used as a backup to either STATION5 running the TEST strategy or STATION8 running the MOTOR strategy. This station is called STATION7 on the GEN-NET.

STATION7 can also become a second console to the TEST strategy running in STATION5. As a Remote Supervisory Station (RSS) the console can bring up dynamic displays that update directly from the TEST strategy. STATION6 will serve as a RSS to the TEST strategy at all times.

Four RSS consoles are located outside of the DACS trailer. These are known as STATION11, STATION13, STATION15 and STATION17 to the GEN-NET network software. STATION11 is located in Building MO-278, STATION13 is located in the 306E Building, STATION15 is located at the 2750 Building and STATION17 is located in the office of the software developers. All four remote stations transfer their network data packets over phone lines at 9600 baud using special ARCNET/RS-232 conversion units called Arc-Links. 
The Arc-Links can only recognize odd-numbered network addresses (see 2.3.7), so all of the remote stations have odd numbers. When the remote stations were added, stations in the trailer had been assigned the network addresses 5 through 9 so the remote stations were given the next available odd numbers - 11, 13,15 and 17 .

A personal computer is dedicated to transferring files from the GEN-NET to a file server on the Hanford local area network (HLAN). STATION9 on the GEN-NET is logged into the file server and is operated in a GEN-NET file server mode. This allows files from STATION5 to be transferred to the file server without broadcasting real-time data packets over the HLAN.

STATION1 in the trailer runs the commercial package Modsoft. This software allows the PLC to be programmed and configured. It also allows the PLC registers and coils (single bits) to be viewed and manipulated online, by developers only.

Figure 1 is a diagram of the physical connections between components.

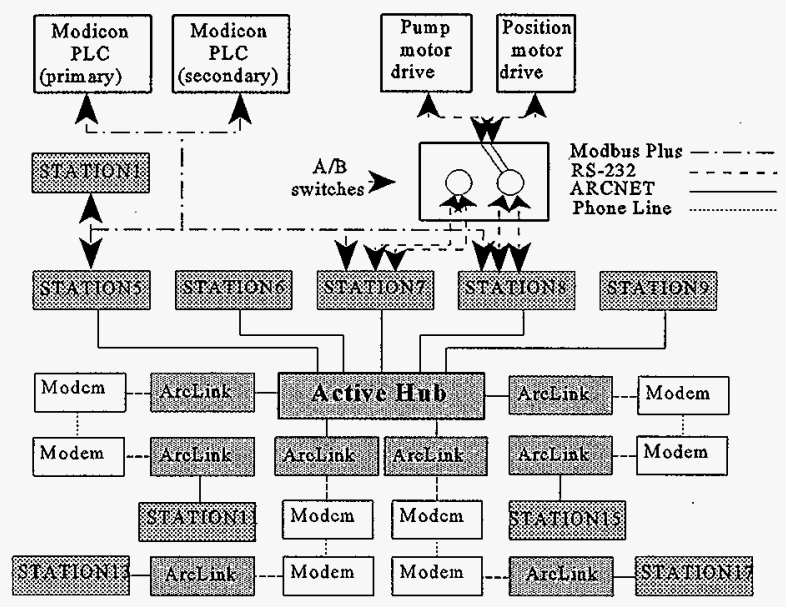

Fig. 1. Diagram of the physical connections between components. 


\subsection{LOGICAL FLOW OF DATA}

Data are retrieved from the PLC registers and status points by the station running the TEST strategy. This updates the TEST strategy algorithm blocks that are used to read data from the PLC. Data are sent back to the PLC from algorithm blocks that are used to write data to the PLC. For backup support STATION7 can run the TEST strategy; for normal operation STATION5 will run the TEST strategy. All discussion related to data flow of the TEST strategy will assume normal operation. For backup operation simply substitute STATION7 for STATION5. The MOTOR strategy is used to communicate bidirectionally with both variable frequency drives. For normal operation STATION8 will run the MOTOR strategy; for backup operation STATION7 can also run the MOTOR strategy. Data which are passed between STATION5 and STATION8 (via registers in the PLC) allow the TEST and MOTOR strategies to share critical data.

The local RSSs linked to the TEST strategy can receive and send values to the TEST strategy. The RSSs outside of the DACS trailer will only be able to receive information from the TEST strategy.

Figure 2 shows the data and control paths between components.

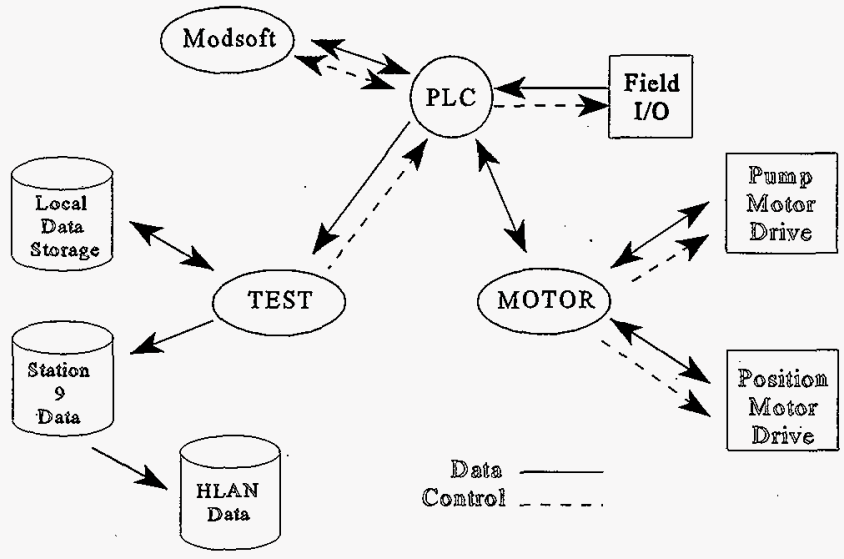

Fig. 2. Data and control paths between components. 


\subsection{TASK ALLOCATION TO COMPONENTS}

Each component performs at least one main task needed for the system. The following section is a breakdown of the tasks that are performed by each component.

\subsubsection{Modicon PLC}

The functions of the Modicon PLC are to input data from the field, to abort the pump when critical channels are beyond their abort limits, to provide control and alarm signals and the logic to generate them, to provide timers and enable logic for pump testing, and to provide data and status information to Genesis.

\subsubsection{Eaton AF-5000+ Variable Frequency Drives}

The variable frequency drives control the motors used to position and operate the pump. Each drive controls its respective motor's critical parameters such as speed, acceleration, deceleration, and maximum speed as well as the starting and stopping of the motor. The drive also monitors current, line voltage, actual speed, and current state of the motor.

The variable frequency drives communicate with the Genesis MOTOR strategy via RS-232 serial communications. Each variable frequency drive has a dedicated COM port for these communications. The drive that controls the pump motor is on COM1, and the drive that controls the directional motor is on COM2. Genesis only acts in a supervisory role in controlling the motors; the drives can run the motors independent of Genesis communication.

A special signal from each drive that indicates when the motor is running is wired directly to a discrete input module. This signal is then used by the PLC for accurate timing of the duration of a test run.

\subsubsection{TEST Strategy Terminal, STATION5}

STATION5 is the primary data acquisition computer and is connected to the Modicon E984 PLC via Modbus Plus. The strategy functions that STATION5 has to perform are: send and retrieve field values from the Modicon E984 I/O drops, write those engineering values to disk as Genesis history files, participate in the watchdog timer with the E984 ladder logic, download abort limits to the PLC and generate operator alarms.

\subsubsection{MOTOR Strategy Terminal, STATION8}

This personal computer is dedicated to running the Genesis Runtime MOTOR strategy. The GEN-NET node name STATION8 is used to reference this component. 
The main task STATION8 performs is to communicate with the AF5000+ variable frequency drives to monitor data from the drives and send commands to them. This is performed with the Eaton AF5000+ Genesis communications driver.

The MOTOR strategy contains logic to control the positioning of the pump. This logic uses operator input, the current status of the pump and directional motors, and the current feedback signal levels of the critical variables in the waste tank to determine what the directional motor should do. This task will command the directional motor's variable frequency drive to move the pump to the operator's desired position when all conditions are correct.

The mixing pump motor is controlled through its variable frequency drive by the logic associated with the pump operation in the MOTOR strategy. The logic uses the current values of the critical variables in the tank to decide if commands from the operators to start or stop the pump motors should be honored. If allowable, commands are sent to change the pump's operating status.

There is logic embedded in the MOTOR strategy to abort the directional or pump motor operation. This task will immediately shut down operation of either motor if any of the abort criteria becomes active. STATION8 will display alarm conditions in the alarm summary and warn the operator with an audible alarm when a signal goes into alarm state.

The tests that are performed on the waste in the tank involve operating the pump at different speeds and at different angles. A test is selected using a display of the MOTOR strategy on the STATION8 console. This selection determines a predetermined set of time durations, speeds, and angles so that the test parameters can be downloaded easily to the active parameters of the position and mixing pump control logic.

PLC communications functions are enabled in this strategy to pass variables to and from the PLC.

\subsubsection{Backup Station, STATION7}

This station can act as the TEST strategy runtime station or the MOTOR strategy runtime station. The tasks that are embedded in each strategy would be performed by this station if it becomes a runtime station. To make this station a runtime station, the position of a manual switch must be changed and the appropriate strategy initiated in the computer.

\subsubsection{Local RSS Terminals, STATION6, and STATION7}

Remote supervisory stations (RSS) allow access to a runtime station strategy through graphic displays that were developed for the strategy. These network stations allow the operator to display and change values in the runtime strategy. All RSS terminals on the GEN-NET will be linked to the station runtime TEST strategy. There are two RSS terminals in the DACS trailer: STATION6 and STATION7 (when it is not operating as a runtime station). 


\subsubsection{Remote RSS Terminals, STATION11, STATION13, STATION15, and STATION17}

These terminals are at a site remote to the DACS trailer. They function just as a RSS terminal in the DACS trailer except that the values in the TEST strategy can not be changed from these terminals. This is done by using a different set of key macros which disable functions that would ordinarily allow access to TEST strategy values.

RSS identification numbers must be unique. The broadcast option uses the low-order bit in the identifier. If the bit has the value 1 , broadcasts are allowed; if it has the value 0 , broadcasts are disabled. The broadcast option is used at DACS, so a 1 is used in the low-order bit making the identifier an odd number and allowing broadcasts to pass through the ARCLINKs. For this reason, all remote RSS terminals using ARCLINKs have odd numbered identification numbers.

\subsubsection{File Server Support, STATION9}

The data files that are logged on STATION5 must be archived. Every two hours the data files are started over and a file transfer program is executed to transfer data files from STATION5 to STATION9. The data files are copied to a 1GB JAZ drive on STATION9 and are transferred to a file server on the HLAN. STATION9 has both an Ethernet card to access the HLAN and an ARCNET card to receive files via GEN-NET. 
HNF-SD-WM-CSDD-008

Rev. 3

Page 10

\subsection{SYSTEM FUNCTIONS}

The tasks that are performed by the DACS are allocated to the/PLC, the Eaton AF5000 + variable frequency drives, or the Genesis supervisory control software. The following sections give an overview of those tasks for each of the components.

\subsection{INSTRUMENT MONITORING AND DATA COLLECTION FUNCTION (TEST STRATEGY)}

The functions of the TEST strategy are to monitor the status and values read from the tank instruments, $\log$ data, generate alarms, and control the PLC. Essential to these functions is communication with the Modicon PLC, with the MOTOR strategy via the PLC, and with other stations on the network. Given below is an overview of these TEST strategy functions and the communication paths needed to accomplish them. The details are reserved for Chapter 4.

\subsubsection{TEST Strategy Communications}

The TEST strategy communicates with the Modicon PLC via the Modbus Plus network protocol. It communicates via the ARCNET with the RSS stations for operator displays, and with the STATION9 data archiving computer. Communication with the STATION8 MOTOR strategy is accomplished via the Modicon PLC and Modbus Plus. The type of data communicated via each of these pathways is discussed briefly below.

\subsubsection{Communications with the Modicon PLC}

All of the tank instrumentation data enter the TEST strategy from the PLC via the Modbus Plus network. These include data such as tank temperature readings, gas measurements, flow measurements, and much more. These data enter the TEST strategy through one of two device blocks called DEV 1 and DEV 2. The device blocks accomplish the mapping between the PLC registers and the Genesis TEST strategy I/O blocks. The device blocks together with the I/O blocks scale the data to engineering units. The data are then available to be logged to the hard disk and displayed on any of a number of user display screens.

In addition to the tank instrumentation data, the PLC will provide status information about the PLC hardware and abort status information about any measurements that have aborts associated with them. It will provide instrument failure status information for selected critical measurements.

The communication with the PLC is a two-way communication, and information is sent from the TEST strategy to the PLC. The TEST strategy sends abort limit values to the 
PLC for use in the abort comparison logic. It will also send an operator-initiated abort reset signal to the PLC, which resets the PLC abort logic.

\subsubsection{Communications with the MOTOR Strategy}

Communications between the MOTOR strategy and the TEST strategy is accomplished via the PLC. There is no direct communication path between the two strategies.

\subsubsection{Communications from the TEST Strategy to the RSS Stations}

Communication with the RSS stations is via ARCNET . These stations can display any of the TEST strategy screens for data monitoring.

\subsubsection{Communications from the TEST Strategy to the Data Archiving Computer}

Data are first logged locally on STATION5 by the TEST strategy. The data are then transferred to the data archiving computer, STATION9. After a successful transfer, the data are then deleted from STATION5. The computers are linked with ARCNET, and the transfer is accomplished by using a GENFXR block located in the TEST strategy. The data archiving computer is networked to both ARCNET and to the HLAN. The data are transferred from STATION5 directly to the network server as well as to the JAZ drive on STATION9.

\subsubsection{Data Monitoring}

Data monitoring is one of the primary functions of the TEST strategy. Tank instrumentation data and system status information are presented on a number of operator display screens. The operator displays fall into four basic categories plus a MAP screen.

The MAP screen shows the organization of all of the other screens in the system. Three of the screen categories are used for monitoring and are discussed below.

\subsubsection{Abort Status Monitoring}

This group of screens include the screen CSMAIN and those below it on the MAP organization screen. These screens allow the operator to monitor critical safety-related measurements. These are measurements that need to be within predetermined limits before the pump can be operated safely. These measurements generally have automatic abort functions located in the PLC that automatically shut off the pump motor when the abort limit is exceeded. They generally have alarms associated with them that alert the operator if their value is approaching the abort limit. The current measurement value, the alarm and abort limits, and the alarm and abort status of these measurements are displayed on the abort monitoring screens. 
HNF-SD-WM-CSDD-008

Rev. 3

Page 12

\subsubsection{Tank Measurement_Monitoring}

These screens include the MSMAIN and ASMAIN screens and the screens below these two on the MAP screen. They allow the operator to view any of the tank instrumentation measurements. Those below MSMAIN allow monitoring of the data in tabular form, on diagrams based on location within the tank, or using graphical representations such as bar graphs. Those below ASMAIN are trend screens. They allow the data to be viewed graphically as it changes through time.

\subsubsection{System Status Monitoring}

These are the screens DACS, IOSTATUS, ABRTENAB, ABRTCHEK, MININ1, MININ2, and ABRTNAME. DACS allows the operator to monitor the status of the trailer power systems and the trailer rack temperatures as well as the outside weather. IOSTATUS allows the operator to monitor the status of the Modicon I/O modules and racks.

ABRTENAB, ABRTCHEK, and ABRTNAME allow the operator to monitor the status of various abort coils and enable/disable any such coils. MININ1 and MININ2 allow the operator to monitor the status of the minimum instruments required to perform a pump run.

\subsubsection{PLC Control}

The TEST strategy provides limited operator control of the PLC. Specifically, from any of the abort monitoring screens (see Section 3.1.2.1) the operator can reset the PLC abort coil. The PLC performs comparisons of certain critical instruments with their abort limits. If one of these measurements exceeds its abort limit then the PLC abort coil is set. The pump cannot run when this coil is set. This abort coil is latched, which means that if a measurement exceeds its abort limit only momentarily the abort coil will remain set even after the measurement has returned to a normal value. The only way to reset the abort coil is via the button on the abort monitoring screens mentioned above.

The TEST strategy is responsible for downloading the abort limits for these measurements to the PLC. This is done once upon startup of the strategy. The only exceptions to these are those limits that change based upon the pump speed. These limits are calculated in the MOTOR strategy and sent to the PLC when a new test is selected.

\subsubsection{Data Logging}

The TEST strategy is responsible for logging data to the hard drive and transmitting the data to the archiving computer, STATION9. The data are used for long-term tank monitoring and to evaluate the results of the pump tests. Approximately 200 data channels are logged. These are stored in 10 history files at intervals ranging from 6 seconds to 5 minutes. 
HNF-SD-WM-CSDD-008

Rev. 3

Page 13

The TEST strategy creates these history files and assigns file names derived from the time and date the file is created. Data are logged until an even-numbered 2-hour boundary is reached (that is, 2:00, 4:00, 6:00, etc.). At this time the current set of history files is closed and a new set is opened. The old set of history files is then transferred to the STATION9 archiving computer and placed on the HLAN. Upon successful transfer the files are deleted from the STATION5 computer disk. If the file transfer is not successful the files remain on the STATION5 disk and another attempt is made 2 hours later. The files accumulate on the STATION5 disk until the network problem is resolved and they can successfully be transferred to STATION9.

\subsubsection{Alarming Functions}

An important function of the TEST strategy is to notify the operator of significant events. This is accomplished by using the alarm features of the Genesis software. The strategy can be set up such that measurements which exceed alarm limits encoded in the strategy blocks cause an audible alarm to sound. Information about the alarm is posted to a special Genesis-provided screen called the Alarm/Event Summary Screen.

The system has been designed to produce alarms when critical tank measurements approach safety limits, when critical instruments fail, when communications have been lost between the TEST strategy and the PLC or the TEST strategy and the MOTOR strategy, and when the PLC has detected an abort condition.

\subsection{PUMP CONTROL FUNCTION (MOTOR STRATEGY)}

The pump is controlled by two variable frequency drives, one for position and one for operation. These variable frequency drives are commanded by the Genesis MOTOR strategy using RS-232 asynchronous communications. This strategy has logic functions that control pump position, pump operation, error checking, operation aborting, test selection, network communications, and alarming.

The following section is a description of each task performed by the MOTOR strategy. Details on how the task is implemented can be found in Section 4.2 of this document.

\subsubsection{Position Control}

The position control portion of the Genesis strategy involves several tasks operating in parallel. The desired pump position is selected by the operator or by the current phase of an automated test. The pump position is controlled by an Eaton AF5000+ variable frequency drive. Parameters are read and set via the Genesis AF5000 driver. The logic portion of the Genesis strategy tells the directional motor to start or stop; the direction of movement is based on the actual position feedback from the PLC. 
HNF-SD-WM-CSDD-008

Rev. 3

Page 14

The starting of the directional motor is controlled by automated logic and enabled by the operator. The automated logic will seek to move the pump within a desired range. When enabied, the logic will set up the direction the pump needs to move and then start the directional motor if the pump is not within the desired range.

The directional motor cannot be started if the pump motor is running. This is a safeguard to ensure equipment is not damaged. At no time are both the directional motor and the pump motor to operate at the same time.

The actual position of the pump must be outside of the desired range for the directional motor to start. If all safeguard conditions are met and the pump is directed to move by the operator, a command is sent to the Eaton AF5000 + variable frequency drive to start movement of the pump.

The directional motor will stop if the actual position of the pump is within the desired range; it will also stop if the actual position exceeds the limits of movement or overshoots the desired range. An abort condition will also cause the directional motor to stop. The operator can manually stop the directional motor from the console or from the stop button on the VFD control panel. If any logic conditions are met that specify halting of the directional motor, a command is sent to the Eaton AF5000 + variable frequency drive to stop the movement of the pump.

Communications to the Eaton AF5000+ variable frequency drive are enabled at all times. Parameters can only be read from and sent to the drive when the drive is powered up and receiving asynchronous communication requests. The communication task is responsible for sending control commands and desired operating conditions to the variable frequency. drive. Feedback status from the directional motor is displayed to the operator and is also passed to the PLC abort logic via Modbus Plus communications.

The current position of the pump is requested from the PLC. When the operator requests a position change, the actual position is compared with the desired position to determine if the directional motor should be started. After being started, it is stopped automatically when it is within range or when it overshoots the desired range. "Within range" is defined by a dead-band of 2 degrees above and below the desired position but this range is adjustable by the operator. When the pump is within this range the directional motor is not started. If the pump is out of the desired range and a request to change the position is made, the direction to move is automatically determined by the position control logic. The direction signal is then passed to the variable frequency drive and the directional motor is started if all critical safety checks are passed.

If for any reason a condition is preventing a successful start of the directional motor an indicator denoted by a question mark will flash on the display. By clicking on the indicator the source of the problem will be displayed to the operator.

When the directional motor is running, limit-checking on the position of the pump assures that the pump will not be moved to a position beyond the maximum bounds set for the pump position. These limits are adjustable by the operator. 
HNF-SD-WM-CSDD-008

Rev. 3

Page 15

The pump can be moved by operator request before or after pump motor operation. There are safeguards in place to disable pump movement during pump operation to protect equipment and test results. There is automated logic that will disable movement after the pump is within the desired range. Any time the directional motor is stopped the movement of the pump is disabled. The logic is set up so the operator must enable position control every time the pump is to be moved.

\subsubsection{Pump Control}

Several tasks that execute in parallel comprise the pump control. The pump is driven by a motor-controlled Eaton AF5000 + variable frequency drive. Commands to start, stop, and change speeds are processed by a Genesis AF5000 communication driver.

Abort logic is provided to ensure safe operation of the pump. Pump operating status is displayed to the operator and passed on to the PLC for abort logic and for STATION5 to data $\log$ critical signals.

An operator request will start the pump provided preventative conditions do not disallow it. An operator can start the pump from the STATION8 console if the directional motor is not operating, all permissives are satisfied, and the enable pump control bit has been set by the operator. If the start logic is satisfied, a command is sent to the Eaton AF5000+ variable frequency drive that controls the pump motor.

If for any reason a condition is preventing a successful start of the pump motor an indicator denoted by a question mark will flash on the display. By clicking on the indicator the source of the problem will be displayed to the operator.

The pump can be halted automatically from the elapsed test timer, an abort condition, or a manual request by an operator. The operator can halt the operation manually by selecting the stop pump button on the STATION8 console or the stop button on the VFD control panel. The stop button on the STATION8 console requires two consecutive presses to prevent accidental stopping of the pump. If the logical conditions to hait the pump motor are met, a command is sent to the Eaton AF5000 + variable frequency drive to stop the pump.

Communications from Genesis to the Eaton AF5000+ variable frequency drive which control the pump motor are enabled at all times, parameters can only be read and sent to the drive when the drive is powered up and receiving asynchronous communication requests. The MOTOR strategy is responsible for sending control commands and desired operating conditions to the pump motor and retrieving feedback status from the pump motor.

The current operating values in the variable frequency drive are compared with the desired operating values set by the operator. If the current operating parameters deviate from the desired operating parameters the operator is warned and the pump is not started. For instance, the desired pump motor speed is compared with the actual pump speed and a warning is displayed to the operator if difference is more than 5 RPM of the desired speed. The acceleration, deceleration, and maximum speed from the pump VFD are also compared with the desired operating conditions. 
The predicted motor current draw is calculated based on the desired speed of the motor and an alarm limit is set on the motor current 10 amps above this limit. The operator will be warned during pump operation if the motor current exceeds this limit. An abort limit is set 20 amps above the predicted current draw. The PLC logic will send an abort command if the motor current exceeds this limit. There is a delay of 6 seconds after the pump is started or changes speeds before this alarm and abort logic come into effect for the motor amps.

\subsubsection{Abort}

The directional motor or pump motor will automatically halt operation if an abort condition becomes active from the abort coil in the PLC, a failure in AF5000+ communications, or a failure in PLC communications to STATION8 or STATION5.

There is limit-checking built into the logic used to safeguard the operation of the pump and directional motors. Feedback signals from the PLC are compared with abort limits and desired operating conditions set by the operator (directly or by test selection). Several instrument signals are also monitored by the PLC to ensure safe operating conditions. The PLC can command the mixing pump control and directional control motors to stop if any of these signals exceed their operating range. There are instrument and motor signals that will cause the abort coil in the PLC to become active, as detailed in Section 4.

\begin{tabular}{|l|l|}
\hline VR232050 & Mixer pump speed high. \\
\hline VR232040 & Mixer pump motor amps high. \\
\hline MIP00001 & Moisture in pump motor oil. \\
\hline TIR12A01 & Mixer pump motor oil temperature A high. \\
\hline TIR12A02 & Mixer pump motor oil temperature B high. \\
\hline ZIMPE143 & Position CW limit switch. \\
\hline ZIMPE144 & Position CCW limit switch. \\
\hline WIR12A01 & Pump support column strain \#1 high. \\
\hline WIR12A02 & Pump support column strain \#2 high. \\
\hline WIR12A03 & Pump support column strain \#3 high. \\
\hline WIR12A04 & Pump support column strain \#4 high. \\
\hline
\end{tabular}


The status of the PLC communications with STATION5 and STATION8 is monitored at all times, and any time if the PLC communications fails both motors will be halted. A failure in communications with either of the AF5000+ variable frequency drives will also cause an abort condition which will stop both motors. If communications to the VFDs is halted it will probably be unlikely that the stop command will be successfully sent to the VFDs. This condition assumes communications has faulted and revived itself. In any case an alarm warning will be indicated to the operator that an abort condition has occurred and which one of the four sources has caused the motors to stop.

\subsubsection{Test Operation}

There are different tests that can be executed by the operators. Each test specifies the position of the pump, the speed of the pump, the duration of pump operation, and the time delay between pump operations, all of which have an effect on the critical feedback signals. The MOTOR strategy is responsible for controlling the pump under stringent guidelines set up by the design engineers.

Each test has a specific number associated with the parameter settings for the test. The test engineer cannot override the test parameters that control the pump unless the mixing pump motor display is used, which is a manual control screen for pump operation. The operator can select the test to be executed from the console and must set the values of the test to the active parameters, by selecting the SET VALUES button from the console. The test operation must then be enabled before starting the test.

When a test is active an elapsed timer keeps track of the overall duration of the test. Another timer keeps track of how long the pump is in operation. An early warning is activated before the elapsed time of pump operation reaches the desired operation time. If either of these elapsed timers reach the desired time during pump operation the test will be aborted and the pump will be stopped. The PLC times pump operation and the overall test time. The desired test time values are passed to the PLC from the test selection with network communications to STATION5.

The pump may become active several times during a test at different positions. The operator will be prompted to move the pump when the desired time of pump operation has been achieved at the current position. After pump operation has been completed at all desired positions, the end of the test is delayed until all critical data are monitored for an appropriate period of time after pump operation is suspended.

During test selection and operation there are several procedures the test engineer must follow to begin the test. The system sets control points on the STATION8 console to different colors to show the operators which procedures have been performed and what functions have been enabled. 


\subsubsection{PLC Communications}

PLC communications are enabled in the MOTOR strategy for several functions. One is to receive the actual position of the pump to be used in the position pump logic. Also the PLC abort coil status is read into the strategy to stop either motor and disallow the start of a motor if it is active. The desired operating parameters and abort levels that are set in the MOTOR strategy are sent to the PLC logic to be used for logic. The current values of the critical variables from the VFDs are also sent to the PLC for abort logic and to be transferred to the TEST strategy for display on STATION5.

\subsubsection{Alarming}

The operators are warned of signals that exceed limits and the status of events with the alarming function of Genesis. When an alarm condition arises the computer drives an amplified audible alarm and the tag name of the signal that caused it is displayed in the lower right corner of the display. A history of alarm conditions can be viewed from the alarm summary.

The alarms set in the motor strategy pertain mostly to the pump motor and the directional motor. There are some additional signals that are received from the PLC that are also alarmed.

Operator activity is also tracked in the alarm/event summary. If a value is changed by the operator, a record of the change is logged into the alarm/event summary.

\subsubsection{System Parameters}

There are special algorithm functions in the MOTOR strategy that are used to execute Report \& Recipe code, and for version tracking. Please refer to Section 4.2 .8 of this document for details on these functions.

\subsection{MODICON PLC FUNCTIONS}

The functions of the Modicon PLC are to input data from the field, to abort the pump when critical channels are beyond their abort limits, to provide control and alarm signals and the logic to generate them, to provide timers and enable logic for pump testing, and to provide data and status information to Genesis. Each of these are discussed functionally in the following sections. The details are in Section 4.3.

\subsubsection{Data Collection from the Field}

Data enter the PLC via any of a number of Modicon input modules. Different types of modules can accept analog voltage or current inputs, thermocouple inputs, digital inputs of 
HNF-SD-WM-CSDD-008

Rev. 3

Page 19

varying levels or ASCII serial inputs. There are corresponding types of modules for data output.

In order to access data from a module, it must be entered into the PLC configuration table known as the Traffic Cop. This involves specifying the module's type, physical location, and the PLC registers which will be used for communication with the module. The physical location is specified in terms of the Modicon $\mathrm{I} / \mathrm{O}$ drop, the $\mathrm{I} / \mathrm{O}$ rack within the drop, and the slot within the rack which contains the module.

For most modules, the PLC I/O hardware places the data into the specified registers. From there, the data can be used within the PLC if further logic operations or abort comparisons are required.

The exceptions to this are the thermocouple input modules and the ASCII/BASIC input modules. Both of these require that PLC logic be provided to program module parameters, control the operation of the modules, and handle the interface between the modules and the PLC. In addition, the ASCII/BASIC module contains a built-in BASIC interpreter. A BASIC program must be loaded into this module to control the input of data into the module as well as the interface between the module and the PLC. The logic and programs which operate these modules will be discussed in Section 4.3.1.1.

The data are copied into a contiguous set of registers before being sent to Genesis. This is done to increase the PLC to Genesis communication efficiency.

\subsubsection{Abort Functions}

The PLC is responsible for providing an automatic pump shutoff signal (known as the abort signal) whenever certain safety-related or other critical measurements exceed predetermined limits. This function is provided in the PLC rather than in Genesis since the response time of the PLC is much faster (on the order of $50 \mathrm{~ms}$ ).

The abort limits are sent to the PLC from Genesis (see Section 3.1.5). The PLC then continually compares the incoming critical measurements to their abort limits and sends the abort signal if any of the limits are exceeded.

\subsubsection{Control Points and Alarm Outputs}

The PLC abort output discussed above is one example of the control and alarm functions of the PLC that is important enough to deserve its own section. The other control outputs provided by the PLC are: a signal which triggers the Nicolet data collection system whenever there are indications of a tank rollover, and a signal which shuts off the VDTT flow meters when a high strain is detected on certain risers.

The PLC also contains a watchdog timer which expects to receive regular updates from Genesis. If communications from Genesis to the PLC fail, a signal is sent which sounds an audible alarm. Also, an oscillating signal is provided from the PLC which resets watchdog timers in Genesis to monitor communication from the PLC to Genesis. 
HNF-SD-WM-CSDD-008

Rev. 3

Page 20

\subsubsection{Test Timers and Enable Logic}

The PLC contains a timer which times the pump tests. The time allowed for the test is sent from Genesis. The PLC timer then runs whenever the pump is running and shuts down the pump whenever the allowed time is exceeded. This provides a backup means for shutting off the pump when the allowed time for the test has elapsed. In most cases, the operator or the MOTOR strategy will have already shut off the pump before the allowed time has elapsed.

The PLC also contains test enable logic. This is a logic mechanism which ensures that the timer is set and abort parameter changes are accomplished before the pump is run.

\subsubsection{Special Data and Status Information}

In most cases, data can be made available to Genesis without any further PLC logic other than the module configuration setup (see Section 3.3.1) and copying to contiguous registers. However, some PLC logic is needed to extract data or status information to be sent to Genesis. The status information provides information about the primary and hot standby PLCs and the I/O drop and module status. By extracting only the information needed in the PLC the amount of I/O between the PLC and Genesis can be reduced.

Also, there is PLC logic which monitors the high-frequency strain alarms for momentary triggers which may otherwise occur too fast to cause an alarm in Genesis.

\subsection{INSTRUMENTATION}

DACS instrumentation provides measurements which can be organized in the following categories: measurements for mixer pump operation, waste tank conditions, riser strain, and DACS trailer status and area monitors. Each of these is discussed in the following sections.

Data enter the DACS via one of four general methods. Knowledge of the method used is necessary in order to determine the resolution of the data.

Most of the analog measurements enter the DACS through Modicon I/O modules which are set up to receive signals ranging from $4-20 \mathrm{~mA}, 1-5$ volts, or $0-5$ volts. These modules digitize the signals to a resolution of 12 bits. The range column of the $\mathrm{I} / \mathrm{O}$ list gives the corresponding range in engineering units. This represents the full range of the input signal. The engineering unit range is used to scale the digitized input, and this scaled value is recorded to disk. The useful range does not always correspond to the full range. In some cases, there is an entry in the subrange column of the channel list which specifies the useful range. If the digitized input signal falls outside of the subrange, the recorded value of the measurement will be pegged at one or the other boundaries of the subrange.

The MIT17B, MIT17C, and tank bottom and side thermocouple measurements enter DACS via Modicon thermocouple modules. These modules are set to produce double 
precision readings with 0.1 degree $F$ resolution as their output which is recorded without any further scaling.

Data from several analytical instruments enter the DACS via Modicon ASCII/BASIC modules. These modules have built-in BASIC interpreters. BASIC programs are written through which the modules communicate with the instruments via RS-232. The data are then placed in Modicon PLC registers in whatever format is agreed upon with the experimenters. This method allows considerable flexibility concerning the ultimate resolution of the data. The GC1, GC2, GC3, FTIR, and Photo NH3 data all enter the DACS via ASCII/BASIC modules.

Data from the variable speed drives (speed, current, and voltage) enter the DACS via the AF5000 device driver. This is the only category of data which does not enter via the PLC.

\subsubsection{Mixer Pump Operation Measurements}

DACS provides measurements which monitor the mixer pump operation. There are measurements for the operating characteristics of the pump motors and for detecting the characteristics and motion of the waste at the pump discharge nozzles and within the pump column.

\subsubsection{Mixer Pump Motor Operation}

These measurements provide information about the operating state of the mixer pump motor and the pump directional motor. Most of these measurements originate with the variable speed drive and first enter the MOTOR strategy over the RS-232 link. There are 12 measurements giving the motor speed (RPM), the motor voltage, current, percent of load voltage frequency and set-point speed for each motor.

In addition there are measurements for mixer pump motor oil temperature and directional motor position which enter via the Modicon PLC. There are also digital signals which detect moisture in the pump motor oil and when the pump rotational position is at one of its limits.

\subsubsection{Discharge Nozzle and Pump Column}

DACS provides a set of measurements for detecting the motion and characteristics of the waste as it moves through the mixer pump. These include measurements for discharge nozzle waste temperature, flow and pressure, nozzle tap pressures, and pump column pressure. There are a total of 16 measurements sampled once every 6 seconds.

\subsubsection{Tank and Waste Measurements}

The bulk of DACS measurements provide information about the characteristics of the tank waste and the conditions inside the tank. 
HNF-SD-WM-CSDD-008

Rev. 3

Page 22

\subsubsection{Tank and Waste Temperatures}

There are two multifunction instrument "trees" (MIT) within the tank called MIT17B and MIT17C. Each of these instrument trees contain 22 thermocouples spaced along the length of the tree for measuring the temperature of the waste at various levels within the tank. Both MIT17B and MIT17C use type K thermocouples. These are sampled by Genesis every 12 seconds.

In addition there are 26 type $J$ thermocouples which measure temperatures around the bottom and side of the inner waste tank. These are sampled every 30 seconds.

\subsubsection{Tank Waste Level}

There is one radar gauge measurement of tank level, a wire level gauge indicating tank level, and a digital measurement which provides a signal if the tank level exceeds a manual set point.

\subsubsection{Tank Pressures}

There are two instruments which measure dome space pressure.

\subsubsection{Yent Header}

There are measurements for vent header flow rate, temperature and relative humidity, and hydrogen concentration.

\subsubsection{Gas Concentrations}

There are three gas chromatographs, called GC1, GC2 and GC3, which provide hydrogen concentration measurements to DACS. These enter the PLC as serial ASCII data through the Modicon ASCII/BASIC modules (see Section 4.3.1.3). The data from GCl and GC2 are compiled together and enter through one of the ASCII-BASIC modules. The GC3 data is compiled with the infrared spectrometer and photo-NH3 data and sent as another ASCII stream which enters the other ASCII/BASIC module (see Section 4.3.1.2). Information sent with the hydrogen concentrations gives the time of the sample, file ID numbers which index the sample, and hydrogen retention time.

An infrared spectrometer provides measurements of $\mathrm{NH} 3$ and $\mathrm{N} 2 \mathrm{O}$ concentrations. This is sent along with the gas chromatograph data and includes the file ID and sample time numbers.

A separate set of measurements monitor the gas chromatograph equipment and the IR spectrometer. This information enters DACS via standard Modicon input modules. 
Four hydrogen monitors which measure hydrogen concentration in various parts of the dome space and the vent header complete the set of gas-measurement equipment.

\subsubsection{Miscellaneous Tank Measurements}

There are measurements for the in-tank camera enclosure pressure and nitrogen supply. There are four fluid velocity measurements for measuring waste movement within the tank.

\subsubsection{Strain Measurements}

There are measurements which provide strain readings for the instrument trees and the pump column. These measure the strain on these trees which can be produced by movement of the tank waste. There are measurements for low- and high-frequency strains. There are a total of 11 low-frequency strain measurements; 4 for the pump column, 3 for riser $1 \mathrm{~B}$, and 2 each for risers $17 \mathrm{C}$ and $17 \mathrm{~B}$. There are also two pump column vibration measurements.

The high-frequency strain measurements (using the same transducers as the lowfrequency strain measurements) are recorded during tank rollover and during pump operation using the Nicolet storage oscilloscope. If these measurements exceed alarm and abort limits, they are sent to the PLC to cause an alarm or abort condition.

\subsubsection{Trailer and Area Monitors}

Environmental measurements provide information about the DACS trailer status. Sensors inside the trailer measure rack temperatures and the power system status. Other devices outside the trailer indicate weather conditions outside the trailer such as air temperature, wind speed and direction, barometric pressure and relative humidity.

There is also an area radiation monitor which provides tank farm radiation readings and alarms. 
HNF-SD-WM-CSDD-008

Rev. 3

Page 24

\subsection{DESIGN DETAILS}

This section presents the details of the DACS design. It includes a discussion of the TEST strategy, the MOTOR strategy, and the PLC, focusing upon how each of these accomplishes their various tasks.

\subsection{INSTRUMENT MONITORING AND DATA COLLECTION FUNCTION (TEST STRATEGY)}

In Section 3.1, the functions of the TEST strategy were discussed, including communications with the Modicon PLC and with the MOTOR strategy, data and status monitoring, alarm generation, data logging, and PLC control. In this section, the details of how these functions are accomplished will be presented.

Some of these functions are accomplished by the TEST strategy blocks, some by the display screens, and some via built-in features of the Genesis system. For those functions that are accomplished via strategy blocks, sample portions of the strategy are shown and explained in the following sections. Figure 3 is a general overview of the TEST strategy that delineates functional regions. This is provided as an aid in placing the sample strategy portions into the context of the strategy as a whole.

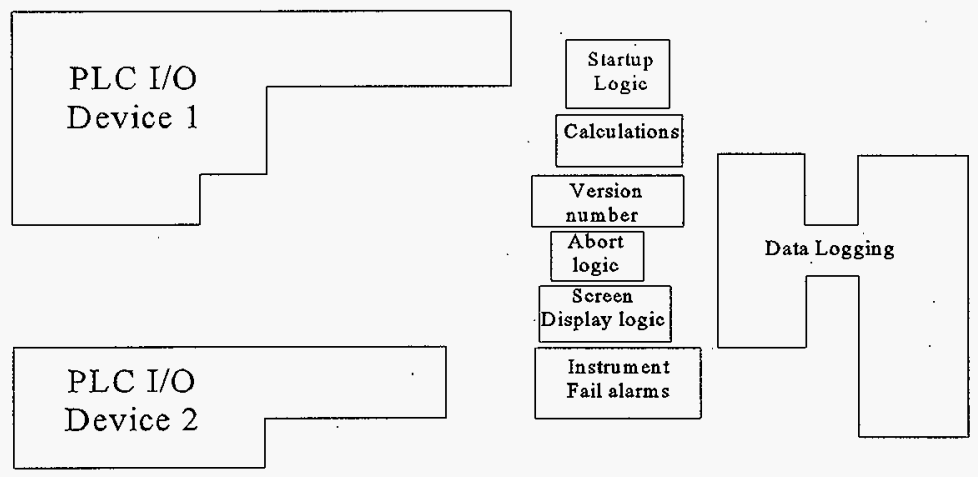

Fig. 3. General overview of TEST strategy functional regions. 
Some of these regions correspond directly to the TEST strategy functions; others are strategy regions that perform supporting roles to these functions. Some brief comments about the regions follow:

- PLC I/O Regions (Device 1 and Device 2): The blocks in these are involved in communications with the Modicon PLC. This will be discussed in detail in Section 4.1.1.1.

The PLC I/O Device 1 regions contains most of the standard instrumentation I/O. It contains the abort limit blocks as well. These blocks are set to the appropriate abort limit values via a report on startup of the strategy (see Section 4.1.3). The values are then sent to the PLC where the actual abort comparison takes place.

The PLC I/O Device 2 region contains I/O for the ASCII/BASIC modules and thermocouple modules. The ASCII/BASIC modules can be used to interface a variety of serial scientific devices (see Section 4.3.1). This region contains blocks that implement the Genesis portion of the Genesis-to-PLC communications watchdog timer (see Section 4.1.5). Input via Device 2 is PLC status information used to monitor the status of the PLC and all of the PLC I/O modules (see Section 4.1.2).

- Startup Logic Region: This region contains blocks that initiate data logging and the downloading of abort limits to the PLC upon startup (see Sections 4.1.4 and 4.1.3).

- Calculations Region: These blocks perform calculations related to providing operator alarms and data logging (see Sections 4.1.4 and 4.1.5).

- Version Number: This in an enlarged dummy logic block whose tag name is set to the current strategy version number.

- Abort Logic Region: This region produces operator alarms when pump problems occur. It also contains the abort coil reset logic (see Section 4.1.5).

- Screen Display Logic Region: This contains logic pertaining to operator displays (see Section 4.1.2).

- Instrument Fail Alarms Region: These blocks provide instrument failure alarms; they will be discussed in Section 4.1.5. 
HNF-SD-WM-CSDD-008

Rev. 3

Page 26

- Data Logging Region: These blocks implement the Data Logging function, to be discussed in Section 4.1.4.

\subsubsection{Communications}

The TEST strategy communicates with the Modicon PLC, with the MOTOR strategy (indirectly), and with the other stations on the ARCNET. The following is a discussion of the details of each of these.

\subsubsection{Communications between TEST Strategy and the Modicon PLC}

The TEST strategy communicates with the Modicon PLC via the Modbus Plus network protocol.

Communications between Genesis and the PLC is accomplished via two device blocks, called DEV 1 and DEV 2. DEV 1 is set to scale 12-bit raw data (0-4095) and DEV 2 is set to scale 16-bit raw data (0-65535). The Modicon PLC uses 16-bit registers, but most of the data from the output modules are 12-bit data. In general, DEV 1 is used for most data, and DEV 2 is used when a full 16-bit PLC register is to be transferred.

Each device block has 16 groups that can be set up to accomplish a mapping between PLC registers and Genesis I/O blocks. For each group to be used, one must specify the type of Genesis I/O block to be connected, the type of PLC register, the starting PLC register address, the Modbus Plus node address of the source data, and the number of connection points within the group. The Genesis I/O block types available are $A I N, A O U T, D I N, D O U T$, PAIN, PAOT, PAIO, PDIN, PDOT, and PDIO. In the above terminology "A" stands for analog, "D" for digital, "P" for packed, "IN" for input, "OUT" or "OT" for output, and "IO" for bidirectional input output. The PLC registers available are: CS (Coil/Status bits-Oxxxxx), IS (Input/Status Bits-1xxxxx), IR (Input Registers-3xxxxx), and HR (Holding Registers- $4 \mathrm{xxxxx}$ ). The starting address specifies the $\mathrm{xxxxx}$ part of the above registers.

The Genesis I/O block and the PLC register type must be compatible. Coil/Status and Input/Status registers must be paired with digital input or output blocks. Input registers must be paired with analog input blocks, and holding registers can be paired with either analog or digital input or output blocks.

The amount of data that can be transferred within one group depends upon the type of I/O block and PLC register that is used. Each group can have up to 16 connections (numbered $0-15$ ). Nonpacked blocks transfer one register or one bit per connection depending on whether the block is analog or digital. Packed blocks can transfer 16 analog registers or 256 (16x16) digital bits. These bits could be 256 coil/status ( $0 \mathrm{xxxx}$ ) bits or 16 holding registers ( $4 \mathrm{xxxx}$ ) interpreted digitally. Packed communication is much more efficient and should be used whenever possible.

The device blocks have several configuration parameters which must be specified. One of these is the device \# parameter. This codes for the memory base address of the SA-85 
interface card. The SA-85 card is the Modbus Plus network interface card which allows the PCs to be connected to the Modbus Plus network. Although the SA-85 card can be set for memory base addresses ranging from C0000-EF800, the Modbus Plus driver only allows four choices: DD000, DD800, DE000, and DE800.

The Scan Task parameter assigns a scan number which corresponds to COM Port number (1 to 4). Although the SA-85 card does not use a COM port, the COM port corresponding to the scan task parameter must be set to INSTALLED in the COMM CNFG menu of the Genesis configurator (under System Configuration). The Scan Period which is defined here determines how often the Modbus Plus driver is executed. The scan task parameter is currently set to 0.5 second.

The device block configuration menu also has parameters for Modbus plus network routing (not used in our system), BCD interpretation of data (also not used) and to specify the bit-order of holding registers (4xxxxx) interpreted bitwise.

Following are the device setup parameters and the group assignments for DEV 1 and DEV 2 for the TEST Strategy:

\section{DEV 1 .}

Device \#

AIN Raw Count-Zero

AIN Raw Range

BCD
2

0

4095

NO
Scan Task

AOUT Raw Count - Zero

AOUT Raw Range

Bit Order
Task 1

0

4095

16-1

\begin{tabular}{|c|c|c|c|c|c|c|c|c|c|c|c|c|c|c|c|c|c|c|c|}
\hline \multirow{2}{*}{ Group } & \multirow{2}{*}{$\begin{array}{l}\text { Ty } \\
\text { Type }\end{array}$} & \multirow{2}{*}{$\begin{array}{l}\text { PLC } \\
\text { Type } \\
\end{array}$} & \multirow{2}{*}{$\begin{array}{c}\text { Register } \\
\text { Range }\end{array}$} & \multicolumn{16}{|c|}{ Connections } \\
\hline & & & & 0 & 1 & 2 & 3 & 4 & 5 & 6 & 7 & 8 & 9 & 10 & 11 & 12 & 13 & 14 & 15 \\
\hline 1 & PAIN & $\mathrm{HR}$ & $402001-402128$ & $y$ & -- & $y$ & $y$ & $y$ & - & - & $y$ & $\mathrm{y}$ & $\mathrm{y}$ & $\mathrm{y}$ & $y$ & $y$ & $\mathrm{y}$ & -- & - \\
\hline 2 & PDIN & $\mathrm{CS}$ & $002001-002256$ & $\mathrm{y}$ & y & $\mathrm{y}$ & $\mathrm{y}$ & -- & -- & -- & - & - & -- & - & -- & -- & - & $-\cdots$ & - \\
\hline 3 & DOUT & $\mathrm{CS}$ & $000241-000256$ & $\mathrm{y}$ & - & $\ldots$ & -- & -- & -- & - & - & -- & $\mathrm{y}$ & - & -- & $\therefore$ & - & -- & - \\
\hline 4 & PAOT & $\mathrm{HR}$ & $400200-400255$ & $\mathrm{y}$ & - & - & $y$ & $y$ & $\mathrm{y}$ & $\mathrm{y}$ & -- & -- & - & - & -- & $\because$ & - & -- & $m$ \\
\hline 5 & PDIO & $\mathrm{CS}$ & $002052-002147$ & $\mathrm{y}$ & $\mathrm{y}$ & $y$ & $\mathrm{y}$ & $\mathrm{y}$ & $\mathrm{y}$ & -- & - & -- & -- & $\cdots$ & -- & $\cdots$ & -- & -- & - \\
\hline 6 & PDIO & $\mathrm{CS}$ & $000476-000731$ & - & - & $y$ & $\mathrm{y}$ & $y$ & $\mathrm{y}$ & -- & -- & -- & -- & - & -- & -- & - & -- & - \\
\hline 7 & PDIO & $\mathrm{CS}$ & $000220-000475$ & $y$ & $\mathrm{y}$ & $y$ & $\mathrm{y}$ & $\mathrm{y}$ & $y$ & $\mathrm{y}$ & $y$ & - & - & -- & -- & -- & -- & $\cdots$ & - \\
\hline 8 & -- & -- & $-\cdots$ & - & -- & -- & -- & -- & - & -- & -- & -- & - & -- & - & $\cdots$ & - & $\because$ & -- \\
\hline 9 & PAIN & HR & $400200-400$ & $y$ & $\mathrm{y}$ & -- & $\mathrm{y}$ & $\mathrm{y}$ & $\mathrm{y}$ & $\mathrm{y}$ & -- & -- & -- & - & - & - & - & - & -- \\
\hline 10 & PDOT & $\mathrm{CS}$ & $002150-002165$ & $\mathrm{y}$ & -- & - & - & -- & - & -- & -- & - & - & - & -- & - & - & -- & 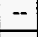 \\
\hline 11 & $\cdots$ & -- & -- & - & -- & -- & - & - & - & -- & -- & - & - & - & - & - & - & - & -- \\
\hline 12 & --- & - & $\cdots$ & - & - & -- & -- & - & $-\rightarrow$ & $\cdots$ & -- & - & -- & -- & -- & - & - & -- & -- \\
\hline 13 & - & $\ldots$ & $\cdots$ & - & -- & -- & - & - & -- & $\because$ & $=$ & $-\cdot$ & - & - & -- & \begin{tabular}{|l|}
-- \\
\end{tabular} & -- & -- & -- \\
\hline 14 & 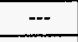 & $\cdots$ & $\cdots$ & -- & -- & -- & -- & -- & $=$ & $=$ & - & - & $\cdots$ & -- & -- & \begin{tabular}{|l|}
- \\
\end{tabular} & -- & - & $\begin{array}{l}-- \\
\end{array}$ \\
\hline 15 & -- & -- & $\cdots$ & - & - & - & -- & -- & -- & -- & $-\because$ & - & $\cdots$ & $\ldots$ & $\ldots$ & $\because$ & -- & -1 & - \\
\hline
\end{tabular}


HNF-SD-WM-CSDD-008

Rev. 3

Page 28

\section{DEV 2}

Device \#

AIN Raw Count-Zero

AIN Raw Range

$\mathrm{BCD}$
2

0

65535

NO
Scan Task

AOUT Raw Count - Zero

AOUT Raw Range

Bit Orcier
Task 1

0

65535

16-1

\begin{tabular}{|c|c|c|c|c|c|c|c|c|c|c|c|c|c|c|c|c|c|c|c|}
\hline \multirow{2}{*}{ Group } & \multirow{2}{*}{$\begin{array}{c}\text { J/O } \\
\text { Type }\end{array}$} & \multirow{2}{*}{$\begin{array}{l}\text { PLC } \\
\text { Type }\end{array}$} & \multirow{2}{*}{$\begin{array}{c}\text { Register } \\
\text { Range }\end{array}$} & \multicolumn{16}{|c|}{ Connections } \\
\hline & & & & 0 & 1 & 2 & 3 & 4 & 5 & 6 & 7 & 8 & 9 & 10 & 11 & 12 & 13 & 14 & 15 \\
\hline 1 & DOUT & $\mathrm{CS}$ & 000213 & $\mathrm{y}$ & - & -- & $\overline{-}$ & $=$ & - & $=$ & -- & -- & $=$ & -- & -- & - & $\therefore$ & -- & $\rightarrow$ \\
\hline 2 & PAIN & $\mathrm{HR}$ & $402129-402256$ & $\mathrm{y}$ & $\mathrm{y}$ & $\mathrm{y}$ & $\mathrm{y}$ & $\mathrm{y}$ & $y$ & $\mathrm{y}$ & $\mathrm{y}$ & $\mathrm{y}$ & $\mathrm{y}$ & $\mathrm{y}$ & $\mathrm{y}$ & $\mathrm{y}$ & $\mathrm{y}$ & $y$ & $\cdots$ \\
\hline $3 *$ & PDIN & HR & $400108-400123$ & $y$ & $y$ & $\mathrm{y}$ & $\mathrm{y}$ & - & $\therefore$ & $\cdots$ & $\cdots$ & - & $\cdots$ & -- & $\cdots$ & -- & -- & -- & -- \\
\hline 4 & PDIN & $\mathrm{CS}$ & $400112-400127$ & $\mathrm{y}$ & $\mathrm{y}$ & $\mathrm{y}$ & $y$ & $=$ & -- & $m$ & - & - & - & -- & + & $+\infty$ & - & -- & -- \\
\hline 5 & PDIN & $\mathrm{CS}$ & $400116-400131$ & $\mathrm{y}$ & $\mathrm{y}$ & $\mathrm{y}$ & $y$ & - & - & $\ldots$ & $\ldots$ & -- & -- & -- & -- & -- & -- & -- & -- \\
\hline 6 & PDIN & $\mathrm{CS}$ & $400120-400135$ & $\mathrm{y}^{\circ}$ & $\mathrm{y}$ & - & - & -- & -- & - & $\cdots$ & - & -- & -- & - & - & -- & -- & - \\
\hline 7 & 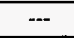 & - & -- & - & $\cdots$ & -- & -- & - & $\because$ & $=$ & -- & -- & $\cdots$ & -- & $-\infty$ & - & - & -- & - \\
\hline 8 & --- & - & $\cdots$ & - & -- & -- & -- & -- & $\cdots$ & - & - & - & $=$ & -- & -- & -- & -- & -- & 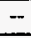 \\
\hline 9 & -- & - & $\cdots$ & - & -- & -- & -- & - & $\cdots$ & - & -- & -- & -- & -- & -- & -- & -- & - & -- \\
\hline 10 & --- & $\ldots$ & $\overline{--}$ & -- & -- & $=$ & - & - & -- & $=$ & - & - & 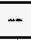 & -- & - & -- & -- & -- & - \\
\hline 11 & -- & - & -- & - & -- & -- & -- & -- & -- & - & 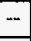 & - & -- & -- & - & -- & -- & - & $\cdots$ \\
\hline 12 & $\ldots$ & - & -- & -- & -- & -- & -- & -- & -- & - & $\cdots$ & $\rightarrow$ & - & $\cdots$ & -- & -- & -- & - & -- \\
\hline 13 & $\cdots$ & -- & -- & + & -- & -- & -- & -- & -- & -- & -- & -- & $\cdots$ & -+ & -- & $\cdots$ & -- & - & -- \\
\hline 14 & 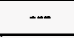 & $=$ & -- & - & -- & -- & -- & -- & -- & -- & - & -- & $\rightarrow$ & $\cdots$ & - & -- & -- & - & -- \\
\hline 15 & -- & -- & --- & - & $\cdots$ & + & - & -- & -- & -- & - & -- & - & -- & -- & - & -- & - & -- \\
\hline 16 & $\cdots$ & -- & $\cdots$ & - & -- & -- & $\cdots$ & -4 & $\cdots$ & -- & -- & -- & -- & -- & - & -- & -- & -- & - \\
\hline
\end{tabular}

*Accurate for corrected Modbus Plus driver. Altemate grouping currently in effect pending Modbus Plus driver update.

ว

Figure 4 shows a portion of the PLC I/O section of the STATION5 strategy. For efficient communications, most I/O is done via packed blocks. The packed blocks are connected to the device block. To allow each channel to have its own tag name and description, regular $A I N$ blocks are connected to the packed blocks as shown in the figure. The I/O blocks are (with few exceptions) organized by device block group such that each horizontal row in the PLC I/O area contains the I/O for one device block group starting with Group 1 at the top. 
HNF-SD-WM-CSDD-008

Rev. 3

Page 29

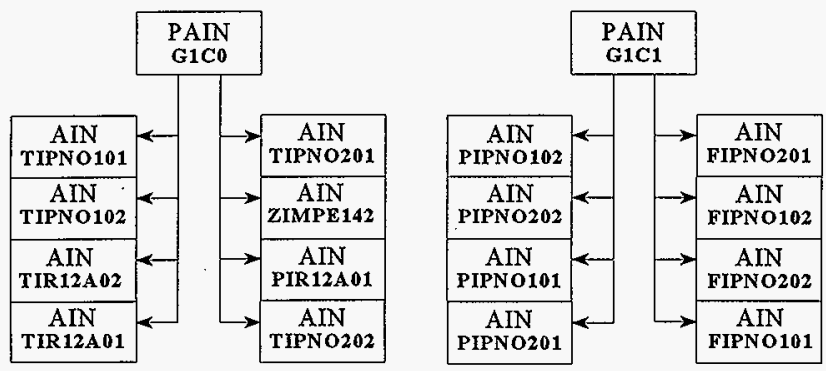

Fig. 4. PLC I/O strategy detail.

The packed blocks are named to reflect their device block group and connection number within the group. Thus, the PAIN block $\langle\mathrm{G} 1 \mathrm{CO}\rangle$ is connected to Group 1, connection 0 of device block 1 . The packed blocks connected to device 1 are named beginning with the letter "G." Those connected to device 2 begin with the letter "H." Thus, a block called "H6C3" would be connected to Group 6, connection 3 of device block 2.

The regular $A I N$ blocks connected to the packed blocks are arranged by connection number of the packed block starting at the upper left and reading down. Thus, in the figure above, <TIPNO101 > is connection 1, <TIPNO102 > is connection 2, <TIR12A01 > is connection 3, <TIR12A02> is connection 4, <TIPNO201> is connection 5, $<$ ZIMPE142> is connection $6,<$ PIR12A01 > is connection 7 , and $<$ TIPNO202 > is connection 8 . This convention has been followed throughout.

The $P A I N$ blocks include range information for the incoming raw values that allow them to be scaled to engineering units. This scaling information is duplicated in the AIN blocks. In addition, the $A I N$ blocks are configured to include the engineering units, the measurement description, alarm values (if any), and scan period.

The scan period specifies the time between measurement updates. Genesis only allows scan periods of $0.05,0.1,0.25,0.5,1,2,6,12$, and 30 seconds. However, the scan period actually achievable depends upon the number of blocks in the system and the communication rate with the PLC. In addition, the overall communication scan period for each communication link must be specified. The scan periods of individual blocks cannot exceed the overall communication scan period. The communication link with the PLC is currently set to a 0.5 second scan period. Most of the measurements are set for 6-, 12-, or 30second scan periods.

There are two cases where additional manipulation is needed to present the data in engineering format. The measurements are $<$ ARMGAMMA $>$ and $<$ PHO-NH3 $\rangle$. The 
HNF-SD-WM-CSDD-008

Rev. 3

Page 30

signal sent to Genesis for <ARMGAMMA > is actually an exponent, so a calculation in a Genesis $F(X)$ block is done to create the actual measurement value from the exponent. The signal $<$ PHO-NH3 $>$ is sent originally as two halves, a most significant and least significant portion. These are combined into one measurement value in the TEST strategy using a $F(X)$ block.

\subsubsection{Communications with the MOTOR Strategy}

There is no direct communication path between the TEST and MOTOR strategies. Instead, communication between them is accomplished via the PLC and Modbus Plus. Data relating to the variable speed drives for pump motor control and directional motor control are sent from the MOTOR strategy to the PLC, then are relayed to the TEST strategy.

AIso, the TEST strategy receives alarm and abort limit values for pump motor speed, pump motor current and pump discharge pressure. These values are calculated in the MOTOR strategy and sent to the PLC. The actual abort and alarm comparisons are done in the PLC, but the calculated limit values are sent from the PLC to the TEST strategy.

Also, both the TEST and MOTOR strategies have watchdog timers to monitor the communication between the strategies and the PLC. When one of these communication paths fails, the other strategy is notified of the communication failure.

\subsubsection{Other Network Communications}

The TEST strategy communicates over the ARCNET to RSS stations for remote screen display information and to the STATION9 computer for data archiving. As mentioned above, the details of the ARCNET configuration can be found in Section 4.4. The data archiving function will be discussed in Section 4.1.4.

\subsubsection{Data Monitoring}

The data and status monitoring functions of the TEST strategy are accomplished by displaying information to the operators on any of a number of displays including Genesisprovided system runtime trend and history displays. In addition to providing the monitoring function, some displays allow the operator to input control signals that can initiate processes in Genesis or ultimately in the PLC. In addition, all displays have a button which, when clicked on with the mouse, allow other displays to be brought up on that particular monitor.

Displays can be brought up independently on the STATION5, STATION6, and STATION7 computers in the DACS trailer, as weil as the four remote stations (STATION11 in Building MO-278, STATION13 in the 306E Building, STATION15 in Building 2750 and STATION17 in the office of the software developers). All data that travel to and from the remote displays (in RSS stations) go through the master computer (STATION5) via ARCNET. 
HNF-SD-WM-CSDD-008

Rev. 3

Page 31

The displays are organized in a hierarchy based on their function; other displays can be accessed from the current one. At the top of the hierarchy is the WELCOME display. This display appears when the system is first brought up. It has buttons that allow access to the MAP, CSMAIN, MSMAIN, and ASMAIN displays.

- The MAP display shows a representation of the hierarchy and allows access to any other display in the system.

- CSMAIN is the overall abort status monitoring display. It allows access to the other displays listed in the "Abort Status Monitoring Screens" table below, which provide more detailed information about the abort status of various instruments. All the members of this group include a button that allows the user to reset the PLC abort coil. This function is discussed in Section 4.1.5.

- MSMAIN has a schematic representation of the tank showing the locations of the various instrument trees. It allows the user to bring up displays that show data from the instruments on these trees. Its buttons allow the user to call up other tank measurement monitoring displays which present the data in a variety of formats. These displays are listed in the "Tank Measurement Monitoring Screens" at the end of this section excluding those indicated as runtime trend screens.

- $\quad$ ASMAIN allows the operator to access runtime trend and history displays. These are displays listed in the "Tank Measurement Monitoring Screens" table below. Runtime trends plot various tank measurements as a function of time, beginning with the point when the screen is first brought up. The graph grows from this point until the time allotted for the graph has passed. After that, the older values are scrolled off the edge of the graph as new values become available. If another screen is brought up on the same display, then the process must start over again. This differs from the system runtime screen discussed below.

Accessible from the MAP display are those displays listed in the "System Status Monitoring and Miscellaneous Screens" table at the end of this section. IOSTATUS and DACS allow monitoring of the PLC racks and modules and the trailer status respectively. The displays named ABRTENAB, ABRTNAME, and ABRTCHEK are used for monitoring and/or enabling/disabling coils used for aborts by the PLC. MININ1 and MININ2 are for convenience and can be used to check minimum instrument status. The "other" displays are non-monitoring screens, MAP and WELCOME, discussed above.

All of the displays have a similar header bar. The header bar has the title, the current time and date, the application name and version number, and buttons that allow the user to bring up the MAP, CSMAIN, MSMAIN, or ASMAIN displays as well as the display one level above in the hierarchy (by pressing the Page Back button). The displays have been designed so that anything in blue can be clicked on with the mouse. These are either buttons 
that bring up another display or measurement values that bring up a tag details sub-window. The tag details sub-window appears at the bottom of the display and gives further information about the measurement.

Genesis provides two other facilities useful for data monitoring. One is the system runtime trend. This allows the display of runtime graphs for up to 20 predefined measurements. These differ from the runtime trend screens discussed above in that the prior data are not lost when the display is exited momentarily.

Additionally, Genesis provides the ability to examine, graphically or in tabular format, any data that are being logged to a history file on the current computer. STATION5 is the only computer that has history files available, so this feature only works on STATION5. Data logging will be discussed further in Section 4.1.4.

\section{TEST Strategy Screens}

Tank Measurement Monitoring Screen

\begin{tabular}{|c|c|c|}
\hline SCREEN & SCREEN TITLE & COMMENTS \\
\hline ASMAIN & Runtime Trend Selection Screen & Selection screen for runtime trend displays \\
\hline GASSUM & Gas Summary & Collected gas concentrations and related items \\
\hline MIT17B & Instrument Tree (1) Riser 17B (MIT) & Tank Temperatures \\
\hline MIT17C & Instrument Tree Riser 17C (MIT) & Tank Temperatures \\
\hline MSMAIN & Main Riser Profile & Selection screen for monitoring displays \\
\hline NEW72HR & Current 72 hour history trend. & History trend - critical measurements \\
\hline OLD72HR & Previous 72 hour history trend. & History trend - critical measurements \\
\hline PUMP & Mixer Pump Riser 12A & Mixer pump instrument readings \\
\hline PUMPOPS & Pump Operations & Runtime trend - pump operation measurements \\
\hline ROLLOVER & Imminent Rollover & $\begin{array}{l}\text { Runtime trends and temperature profiles to } \\
\text { monitor for possible rollover }\end{array}$ \\
\hline SUMMARY & Summary Information & $\begin{array}{l}\text { Vent Header, In-tank parameters, MIT } \\
\text { temperatures }\end{array}$ \\
\hline TBSTC & Tank Bottom and Side Thermocouples & Temperature readings \\
\hline TEMPRFL & MIT Temperature Profiles & Risers $17 \mathrm{~B}$ and $17 \mathrm{C}$ temperature bar graphs \\
\hline
\end{tabular}




\section{Abort Status Monitoring Screens}

\begin{tabular}{||l|l|l|}
\hline \multicolumn{1}{|c|}{ SCREEN } & \multicolumn{1}{c|}{ SCREEN TITLE } & \multicolumn{1}{c|}{ COMMENTS } \\
\hline \hline CSMAIN & Automatic Alarms and Aborts & Overall alarm and abort summary display \\
\hline HVTALARM & Hydrogen-Vent Header Tank & Alarm and abort details \\
\hline MANABRT & Manual Aborts & H2 and NH3 concentrations \\
\hline PUMPALRM & Pump Parameters & Alarm and abort details \\
\hline STRNALM & Strain Gauges & Alarm and abort details \\
\hline TEMPALM & Temperature & Alarm and abort details \\
\hline
\end{tabular}

\section{System Status Monitoring and Miscellaneous Screens}

\begin{tabular}{|l|l|l||}
\hline \multicolumn{1}{|c|}{ SCREEN } & \multicolumn{1}{|c|}{ SCREEN TITLE } & \multicolumn{1}{c|}{ COMMENTS } \\
\hline \hline DACS & DACS Facilities Management & $\begin{array}{l}\text { DACS trailer power, trailer temperature and } \\
\text { weather station }\end{array}$ \\
\hline IOSTATUS & I/O Health Status & Modicon rack and module status \\
\hline MAP & Map & $\begin{array}{l}\text { Shows organization of all screens and allows } \\
\text { operator to call up any screen }\end{array}$ \\
\hline WELCOME & $\begin{array}{l}\text { DST 241-SY-101 Data Acquisition and Control } \\
\text { System (DACS) }\end{array}$ & Screen that appears upon system startup \\
\hline ABRTENAB & Abort Enable Checklist & $\begin{array}{l}\text { Allows enable/disable of PLC abort coils and } \\
\text { indicates coil status }\end{array}$ \\
\hline ABRTCHEK & Abort Limit Checklist & Used for pump run \\
\hline ABRTNAME & Abort Coil Tag Names & $\begin{array}{l}\text { Identifies PLC abort coils and indicates coil } \\
\text { status }\end{array}$ \\
\hline MININ1 & Minimum Instrumentation Checklist \#1 & Convenience \\
\hline MININ2 & Minimum Instrumentation Checklist \#2 & Convenience \\
\hline \hline
\end{tabular}

\subsubsection{PLC Control}

The TEST strategy provides limited control of the PLC. Primarily, it allows the operator to reset the PLC's abort coil. This function was discussed in Section 4.1.2 and the strategy logic to accomplish it will be shown and discussed in Section 4.1.5.

The TEST strategy is also responsible for downloading the abort limits to the PLC. These are the values that the PLC will compare the incoming measurement value with to determine if an abort condition exists. The abort limits are sent via $A I N$ blocks located in the 
HNF-SD-WM-CSDD-008

Rev. 3

Page 34

PLC I/O section of the strategy. These AIN blocks get their values from a report SETLIMS.RPS, which contains the actual abort limit values. This report is run at startup to load the AlN blocks with the abort limit values.

Figure 5 show the startup logic. It shows the mechanism for generating a pulse immediately upon startup as well as a delayed startup pulse. This is implemented by connecting output of the $<\mathrm{ON}>$ DIN block to the $<$ PULON $>$ pul block and the $<$ DELAYON $>$ TON block. The $<$ ON $>$ block is wired to always be 1 . The $<$ OFF $>$ block is wired to be always 0 . Since at startup, the inputs of all blocks are initialized to 0 , the only time the $<$ PULON $>$ and $<$ DELAYON $>$ blocks. will see a 0 to 1 transition on their inputs is at startup. This will trigger the pul block $<$ PULON $>$ and cause the TON block $<$ DELAYON $>$ to produce its output after the programmed 45 -second delay elapses.

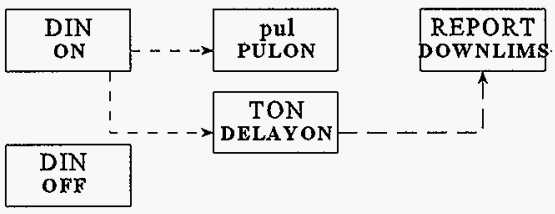

Fig. 5. Startup logic.

The $<$ PULON $>$ block initiates the history file naming the phasing process that was discussed in Section 4.1.4. The TON block <DELAYON $>$ is the block that runs the DOWNLIMS report via the <DOWNLIMS $>$ REPORT block. The 45-second delay is necessary to allow time for Genesis to PLC communication to be established before the abort limits are downloaded.

The $<\mathrm{OFF}>$ block is used to prevent data logging in a HIST block (see section 4.1.4).

\subsubsection{Data Logging}

The TEST strategy is responsible for logging data to the hard disk and sending the data files over the network to the archiving computer.

The data logging portion is accomplished in Genesis by the use of HIST blocks. The files are known in Genesis terminology as history files. Figure 6 shows an overall view of the TEST strategy history/data logging section. More detailed views of portion of this strategy section are shown later. 
The top twelve large blocks of the rightmost column in the diagram above are the HIST blocks. The remainder of the blocks are involved with timing the creation of the history files, phasing the creation of the files and logging of the data to avoid system overload, naming the files, and copying the files automatically over the network and to different directories on the system.
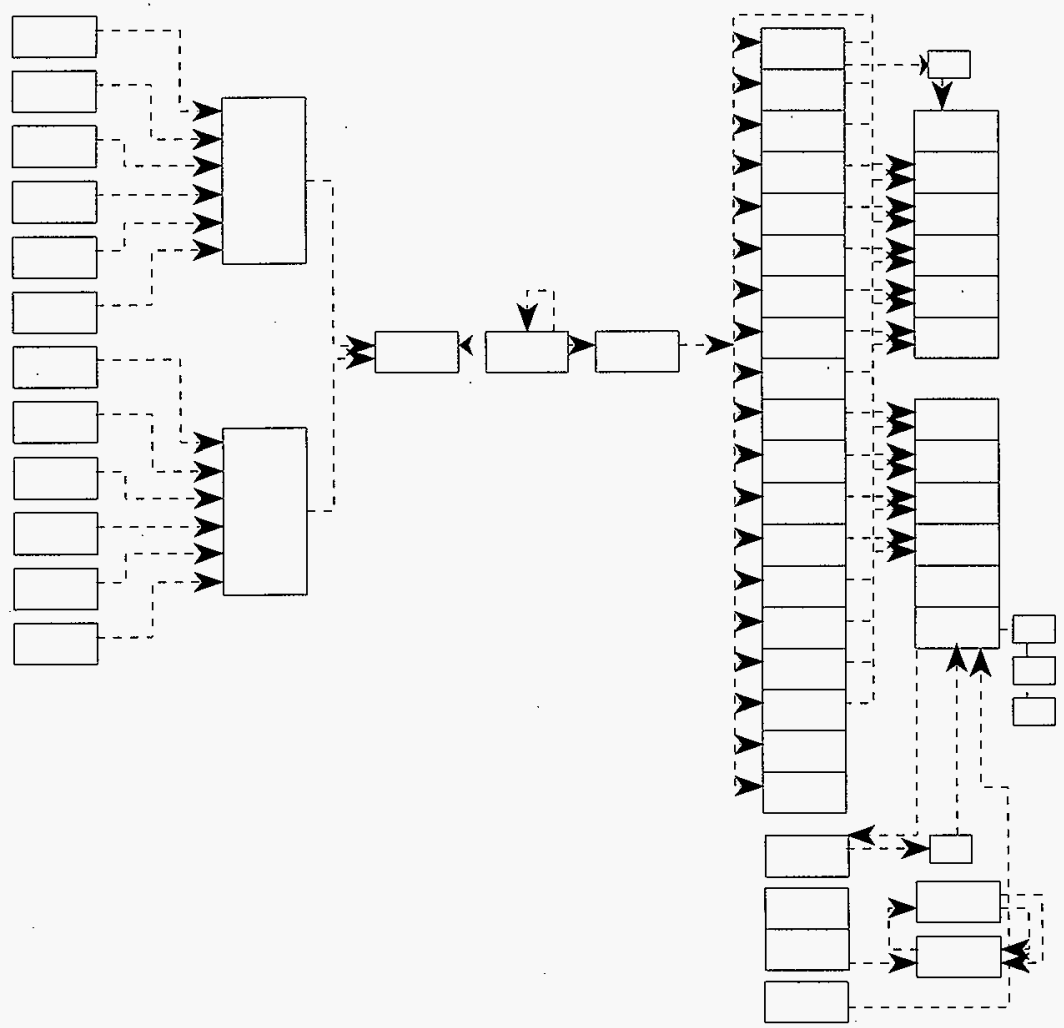

Fig. 6. History data logging overall view. 
HNF-SD-WM-CSDD-008

Rev. 3

Page 36

Two of the twelve HIST blocks are not used for the standard data logging which is described below. The blocks $\langle$ OLD72HR $\rangle$ and $\langle$ NEW72HR $\rangle$ provide a way to have at least 72 hours of readings available which can be viewed using the history display capabilities of Genesis. These history files contain measurements which can characterize the tank status for the time between pump runs when the DACS trailer is not manned.

The functionality of the history section of the strategy is by column, and the general flow of the logic is left to right. The leftmost column consists of TIMER blocks controlling the timing of the opening and closing of the history files. These feed into two OR blocks that feed into a REPORT block. The REPORT block runs a report (HISTFNAM) that creates file names for the about-to-be-opened history files based upon the date and time.

When this process is complete the report sets the pul block, the next block to the right above. This block generates a pulse that causes the SHOT block (the next one over) to generate a one-shot pulse. This pulse starts the TON blocks (the long column of 19 blocks). It is detrimental to start all the history blocks at the same time, so for this reason, the TON (timer-on-delay) blocks lie in-line with every history block. Each TON block has a different delay, spreading the load on the hard disk drive over the total time interval. These delay timer blocks are set to produce their outputs at varying times from the start of the one-shot pulse. They implement the phased stopping and starting of the history files by feeding into the start and stop inputs of the HIST blocks, the rightmost column of blocks. The one exception to this is the $<$ RGA5 > block. It is started when new data is received form the RGA5 computer and stopped after it has logged just one sample. This is done to avoid multiple logging of the same data.

These blocks control the timing of the running of another report (HISTCOPY), which copies history files to two directories on the disk LHIST and IHIST2. The GENFXR block at the bottom of the rightmost column is controlled by the TON blocks. The GENFXR block copies history files over the network. More details concerning this process follow.

Figure 7 shows a portion of the history strategy section that initiates a history file changeover. The system is designed to produce history files that contain 2 hours worth of data each. Every 2 hours throughout the day, the current set of history files is closed and a new set is opened. The timer blocks are set to create a pulse at a specific time of day. In this case, the timer blocks are set to create their pulses on the hour spaced 2 hours apart. When one of the timers goes off, the signal feeds through the $O R$ block and causes the report HISTFNAM to be run.

This report implements the history file-naming convention. The files are named "ymdhFFFF.PRN," where

y is the year, with $2=1992,3=1993$, etc.

$\mathrm{m}$ is the month, numbered $1-9$ and $\mathrm{A}-\mathrm{C}$

$\mathrm{d}$ is the day, numbered $1-9$ and $\mathrm{A}-\mathrm{V}$

h is the hour, numbered $0-9$ and $A-N$, and 
HNF-SD-WM-CSDD-008

Rev. 3

Page 37

FFFF. is the file code that can be any one to four alphanumeric characters.

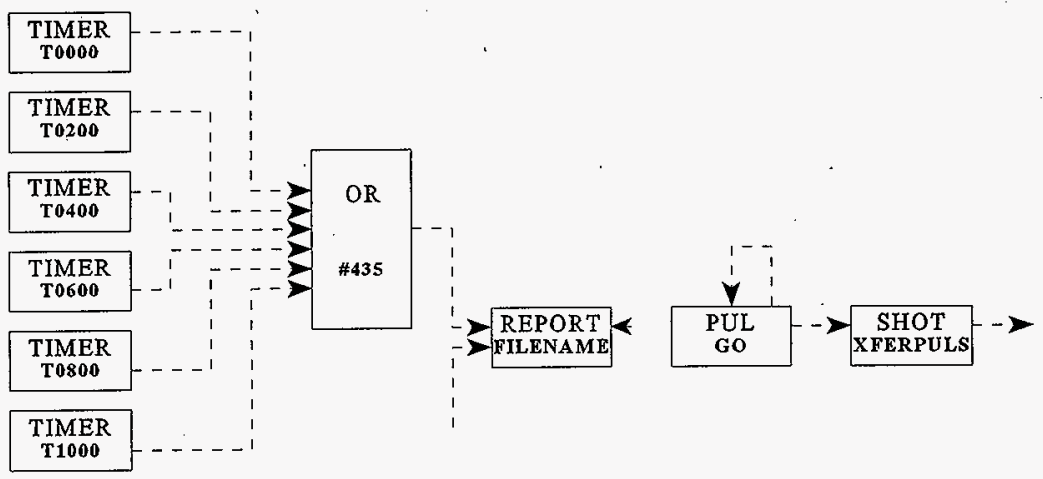

Fig. 7. Timer, report, and pulse portion of history strategy section.

HISTFNAM reads the system time/date and creates these file names. It loads the file name field of the HIST blocks with the new file name. It then sets the PUL block <GO $>$ which in turn initiates the one-shot pulse from the SHOT block $<$ XFERPULS $>$. The HISTFNAM report is run at system startup.

\begin{tabular}{|c|c|c|c|c|c|c|}
\hline \multicolumn{7}{|c|}{ History File Names and Contents } \\
\hline File Name & $\begin{array}{l}\text { Sample } \\
\text { Period }\end{array}$ & \multicolumn{5}{|c|}{ Contents } \\
\hline ymdhPUMP.PRN & 6 or 300 & $\begin{array}{l}\text { PCR12A01, } \\
\text { VR232040, }\end{array}$ & $\begin{array}{l}\text { PDPBASE, } \\
\text { VR232050, }\end{array}$ & $\begin{array}{l}\text { PITNO111, } \\
\text { ZIMPE112, }\end{array}$ & $\begin{array}{l}\text { PITNO110, } \\
\text { ZIMPE142 }\end{array}$ & VR232020 \\
\hline ymdhMIT2.PRN & 12 & $\begin{array}{l}\text { TIR17B09, } \\
\text { TIR 17B14, } \\
\text { TIR17C12, }\end{array}$ & $\begin{array}{l}\text { TIR17B10, } \\
\text { TIR17B15, } \\
\text { TIR17C13, }\end{array}$ & $\begin{array}{l}\text { TIR17B11, } \\
\text { TIR17C09, } \\
\text { TIR17C14, }\end{array}$ & $\begin{array}{l}\text { TLR17B12, } \\
\text { TIR17C10, } \\
\text { TIR17C15 }\end{array}$ & $\begin{array}{l}\text { TLR17B13, } \\
\text { TIR17C11, }\end{array}$ \\
\hline ymdhTBSI.PRN & 300 & $\begin{array}{l}\text { TBSTC01, } \\
\text { TBSTC06, } \\
\text { TBSTC11, }\end{array}$ & $\begin{array}{l}\text { TBSTC02, } \\
\text { TBSTC } 07, \\
\text { TBSTC12, }\end{array}$ & $\begin{array}{l}\text { TBSTC03, } \\
\text { TBSTC08, } \\
\text { TBSTC13 }\end{array}$ & $\begin{array}{l}\text { TBSTC04, } \\
\text { TBSTC09, }\end{array}$ & $\begin{array}{l}\text { TBSTC05, } \\
\text { TBSTC10, }\end{array}$ \\
\hline
\end{tabular}


HNF-SD-WM-CSDD-008

Rev. 3

Page 38

\begin{tabular}{|c|c|c|c|c|c|c|}
\hline \multicolumn{7}{|c|}{ History File Names and Contents } \\
\hline File Name & $\begin{array}{c}\text { Sample } \\
\text { Period } \\
\text { (sec.) }\end{array}$ & \multicolumn{5}{|c|}{ Contents } \\
\hline ymdhGAS-PRN & 150 & $\begin{array}{l}\text { FT-FILE, } \\
\text { FT-NH3C, } \\
\text { PHO-TMME, }\end{array}$ & $\begin{array}{l}\text { FT-TIME, } \\
\text { GC3-TMME, } \\
\text { PHO-NH3, }\end{array}$ & $\begin{array}{l}\text { FT-N2OA, } \\
\text { GC3-FILE, } \\
\text { RGA5TND1, }\end{array}$ & $\begin{array}{l}\text { FT-N2OC, } \\
\text { GC3-RT, } \\
\text { RGA5TND2 }\end{array}$ & $\begin{array}{l}\text { FT-NH3A, } \\
\text { GC3-H2, }\end{array}$ \\
\hline ymdhRGA5.PRN & $\begin{array}{c}\text { per } \\
\text { sample }\end{array}$ & $\begin{array}{l}\text { RG-RUN, } \\
\text { GC1-RT, } \\
\text { FITMSY17, } \\
\text { PDTMSY12, }\end{array}$ & $\begin{array}{l}\text { RG-STAT, } \\
\text { GC2-H2, } \\
\text { TICMSY18, } \\
\text { PITMSY07, }\end{array}$ & $\begin{array}{l}\text { RG-TIME, } \\
\text { GC2-AREA, } \\
\text { PITMSY13, } \\
\text { PITMSY10 }\end{array}$ & $\begin{array}{l}\text { GC1-H2, } \\
\text { GC2-RT, } \\
\text { TIMMSY15, }\end{array}$ & $\begin{array}{l}\text { GC1-AREA, } \\
\text { PITMSY04, } \\
\text { PITMSY 16, }\end{array}$ \\
\hline ymdhMIT3-PRN & 12 & $\begin{array}{l}\text { TIR17B16, } \\
\text { TIR17B21, } \\
\text { TIR17C19, }\end{array}$ & $\begin{array}{l}\text { TIR17B17, } \\
\text { TIR17B22, } \\
\text { TIR17C20, }\end{array}$ & $\begin{array}{l}\text { TIR17B18, } \\
\text { TIR17C16, } \\
\text { TIR17C21, }\end{array}$ & $\begin{array}{l}\text { TIR17B19, } \\
\text { TIR17C17, } \\
\text { TIR17C22 }\end{array}$ & $\begin{array}{l}\text { TIR17B20, } \\
\text { TIR17C18, }\end{array}$ \\
\hline ymdhTBS2.PRN & 300 & $\begin{array}{l}\text { TBSTC14, } \\
\text { TBSTC19, } \\
\text { TBSTC24, }\end{array}$ & $\begin{array}{l}\text { TBSTC15, } \\
\text { TBSTC20, } \\
\text { TBSTC25, }\end{array}$ & $\begin{array}{l}\text { TBSTC16, } \\
\text { TBSTC21, } \\
\text { TBSTC26 }\end{array}$ & $\begin{array}{l}\text { TBSTC17, } \\
\text { TBSTC22, }\end{array}$ & $\begin{array}{l}\text { TBSTC18, } \\
\text { TBSTC23, }\end{array}$ \\
\hline ymdhSTRN.PRN & 150 & $\begin{array}{l}\text { WIR12A01, } \\
\text { WIR17C02, }\end{array}$ & $\begin{array}{l}\text { WIR12A02, } \\
\text { WIR1BA01, }\end{array}$ & $\begin{array}{l}\text { WIR12A03, } \\
\text { WIR1BA02, }\end{array}$ & $\begin{array}{l}\text { WIR12A04, } \\
\text { WIR1BA03 }\end{array}$ & WIR17C01, \\
\hline ymdhVOL.PRN & 12 & $\begin{array}{l}\text { LIR13A01, } \\
\text { PIR11B01, } \\
\text { NITJSY06, } \\
\text { WSWDIR, }\end{array}$ & $\begin{array}{l}\text { FTE50001, } \\
\text { PLR17B04, } \\
\text { NIR17B01, } \\
\text { WSWSPD, }\end{array}$ & $\begin{array}{l}\text { FTE50002, } \\
\text { FTE50003, } \\
\text { WSP1, } \\
\text { TIR12A01, }\end{array}$ & $\begin{array}{l}\text { TT10001, } \\
\text { NIRO5A01, } \\
\text { WSH1, } \\
\text { TIR12A02, }\end{array}$ & $\begin{array}{l}\text { MT10001, } \\
\text { NITKSY06, } \\
\text { WST1, } \\
\text { ENRAF }\end{array}$ \\
\hline ymdhMIT1.PRN & 12 & $\begin{array}{l}\text { TIR17B01, } \\
\text { TIR17B06, } \\
\text { TIR17C03, } \\
\text { TIR17C08 }\end{array}$ & $\begin{array}{l}\text { TIR17B02, } \\
\text { TIR17B07, } \\
\text { TIR17C04, }\end{array}$ & $\begin{array}{l}\text { TIR17B03, } \\
\text { TLR17B08, } \\
\text { TIR17C05, }\end{array}$ & $\begin{array}{l}\text { TRR17B04, } \\
\text { TLR17C01, } \\
\text { TIR17C06, }\end{array}$ & $\begin{array}{l}\text { TIR17B05, } \\
\text { TIR17C02, } \\
\text { TIR17C07, }\end{array}$ \\
\hline NEW72HR.PRN & 300 & $\begin{array}{l}\text { FTE50001, } \\
\text { GC3-H2S, } \\
\text { WYR17C01, }\end{array}$ & $\begin{array}{l}\text { FTY50002, } \\
\text { GC2-H2S, } \\
\text { FTE50003, }\end{array}$ & $\begin{array}{l}\text { PYR17B04, } \\
\text { NIR17B01, } \\
\text { WYR12A01 } \\
\end{array}$ & $\begin{array}{l}\text { PYR11B01, } \\
\text { WYR1BA01, }\end{array}$ & $\begin{array}{l}\text { LIR13A01, } \\
\text { WYR17B01, }\end{array}$ \\
\hline
\end{tabular}

Figure 8 shows some of the TON blocks that implement the phased starting and stopping of the HIST blocks. This phasing is necessary in order to spread out the load on the system imposed by the data logging operations. The system has limited processing time available for data logging as well as limited buffer space for file operations. If the strategy attempts to write too much data at once, this buffer overflows and a system message appears indicating a loss of data. 


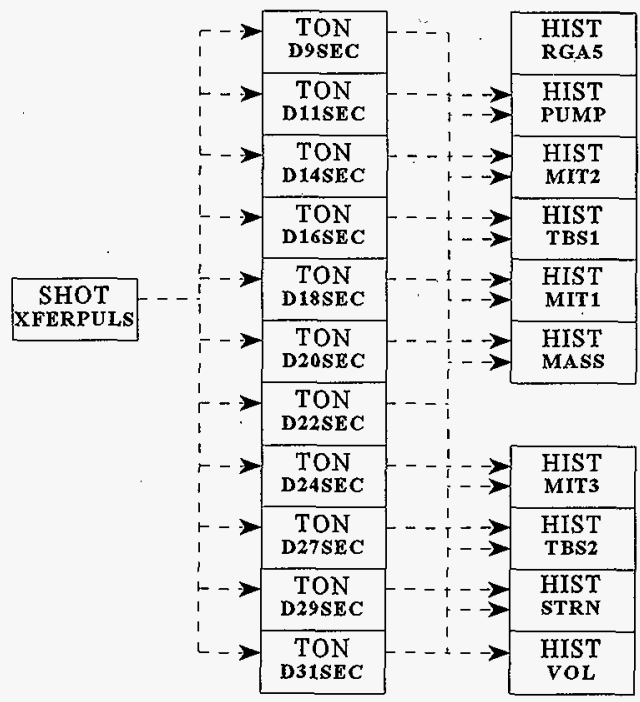

Fig. 8. Phasing and HIST blocks.

Besides the buffer overflow problem, the system resources are strained when files are opened and closed. The phasing scheme is designed to spread out the load on the system as much as possible. The scheme provides that during file changeover, no two files are started or stopped simultaneously. In addition, between changeovers, the sampling of data should be spread out as much as possible. In the current system, no more than two HIST blocks sample their data in any one scan period. The scheme is dependent upon the sample period in the HIIST blocks. If the sample period of any of the blocks is changed, the phasing scheme must be adjusted accordingly. Currently, the changeover occurs as follows:

\begin{tabular}{c|l} 
Second & Action \\
\hline 0 & PUMP Stop \\
1 & PUMP Start \\
5 & MIT2 Stop
\end{tabular}




\begin{tabular}{c|l}
7 & TBS1 Stop, PUMP Sampled \\
9 & MIT2 Start \\
11 & MIT1 Stop \\
13 & PUMP Sampled \\
14 & TBS1 Start \\
16 & GAS Stop \\
18 & MIT1 Start \\
19 & PUMP Sampled \\
21 & MIT2 Sampled \\
22 & GAS Start \\
24 & MIT3 Stop \\
25 & PUMP Sampled \\
29 & MIT3 Start \\
30 & MIT1 Sampled \\
31 & TBS2 Stop, PUMP Sampled \\
33 & STRN Stop, MIT2 Sampled \\
35 & TBS2 Start \\
37 & PUMP Sampled \\
38 & VOL Stop \\
40 & STRN Start \\
41 & MIT3 Sampled \\
43 & VOL Start, PUMP Sampled
\end{tabular}

Given the start times above for each one of the files and the data sampling periods, one can determine when each of the samples are taken. In this case, for a 12-second period, the samples are:

\begin{tabular}{c|l} 
Second & Files Sampled \\
\hline 1 & PUMP \\
2 & TBS1 (every 25th pass beginning with pass 2) \\
4 & MASS (every 25th pass beginning with pass 15) \\
& STRN (every 25th pass beginning with pass 4)
\end{tabular}




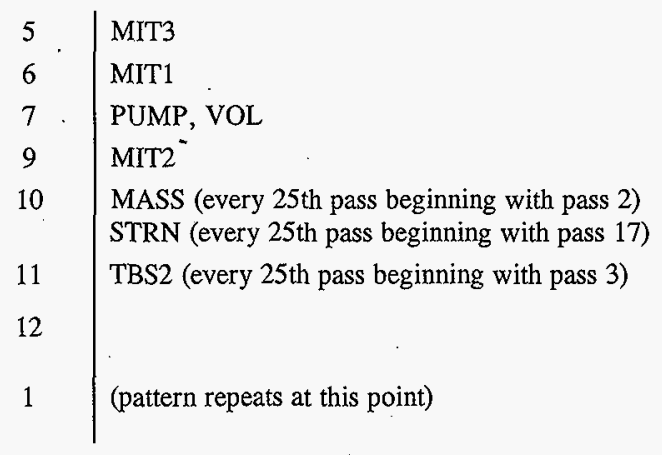

The RGA5 file does not sample regularly as the others do. This file is opened, a sample taken, and closed again only when a new sample is received.

Fig. 9 shows the GENFXR block and an OR block. It also shows a few of the TON blocks. The TON block D1MIN initiates the report, HISTCOPY, 1 minute after the file changeover begins. This report copies the recently closed files to both the $\backslash$ HIST and $\backslash H I S T 2$ directories then deletes them from the ITEST directory. This is done to avoid having history files build up in the directory. The HISTCOPY report renames (using the history file naming convention) copies, then deletes the alarm and event summary files.

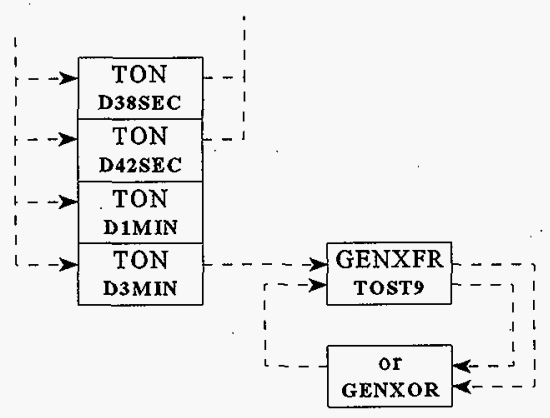

Fig. 9. GENFXR detail.

The GENFXR block is set up to copy the history files over the network. This block is initiated 3 minutes after a file changeover begins. The first pass attempts to copy files from 
the \HIST directory to the IHIST directory on drive C: of STATION9. If this file transfer is successful, the files are deleted from the \HIST directory on STATION5.

The OR block detects one of two status outputs: either successful transfer or failure. In either case, it means that the first operation is complete. This signal is used to initiate the second file transfer operation in the GENFXR block. This time, files are copied from the IHIST2 directory over the network to the Jaz drive (Drive E:) of STATION9. Once again, the files are deleted from the STATION5 directory if the transfer is successful.

The history file ymdhRGA5 differs from the others in that a new sample is logged only when a new reading is received by Genesis. This avoids duplication of samples in the file. The instruments are set to produce a new sample every three minutes. If the instruments are not working properly or if there is some other problem, no data will be logged and the file could be empty. The file is still closed every two hours no matter how many samples have been taken during that time.

A discussion of the logic which implements this follows. The $F(X)$ block, $<$ FILEUPDT $>$, continually scans the $<$ RG-RUN $>$ tag. The value of this tag will change whenever a new sample is received. The <FILEUPDT $>$ block contains logic to compare the previous value of $<$ RG-RUN $>$ with the current value. It sets one of its outputs (DO3) to be high (1) if the current and previous scans are equal, and low (0) otherwise. When this output transitions from 0 to 1 , it starts a 45 second timer (TON block < RGSTLOG $>$ ). When the 45 seconds have elapsed, the sample is logged (by starting data logging for the $<$ RGA5 > HIST block. This 45 second delay is to insure that the value of PHO-NH3 which is calculated from MSB and LSB portions, has enough time to execute before the values are logged.

The HIST blocks <OLD72HR > and <NEW72HR> provide a way to have at least 72 hours of readings available which can be viewed using the history display capabilities of Genesis. These history files contain measurements which can characterize the tank status for the time between pump runs when the DACS trailer is not manned. Only $\langle$ NEW72HR $\rangle$ is set to actually log data. When a 72 hour period has elapsed the tag $<$ CHNG72OK $>$ is set. The report HISTCOPY.RPS detects this and copies the file NEW72.PRN to OLD72.PRN. New data is then logged to the NEW72.PRN file. The data in the OLD72.PRN file can be examined using the history file display capabilities of Genesis.

\subsubsection{Alarming Functions}

Operators are notified of significant events by using the alarm capabilities of the Genesis software. Genesis provides a special screen called the alarm/event summary screen. Alarms, operator actions, and other system events are posted to this screen as they occur. In addition, the PC speaker sounds when an alarm arrives. These speakers have been amplified in the trailer producing an effective audible alarm. The operator must hit a keyboard key to silence the alarm. Information about the alarm can be found on the alarm/event summary screen. From there the alarms can be acknowledged by the operator. 
Most of the alarms are generated by measurement I/O blocks. The alarm values are programmed into the block and the alarm priority is set. When the measurement value exceeds one of the alarm limits the alarm occurs. Other alarms require additional strategy logic. Portions of the TEST strategy related to the alarming function are shown in Fig. 10 and discussed below:
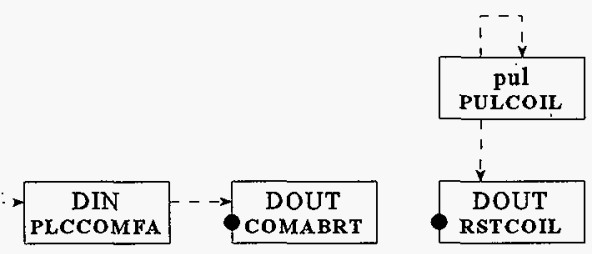

Fig. 10. Abort logic detail.

This strategy section is responsible for causing a Genesis alarm if a PLC communication failure is detected. It also contains logic for resetting the PLC abort coil.

Since the PLC abort coil remains latched following an abort, the operator needs some means of resetting the coil after the problem has been resolved. This is provided by the $<$ PULCOIL $>$ and <RSTCOIL > blocks shown above. When the Reset Abort Coil buttons on the abort coil status screens (see Section 4.1.2) are clicked upon, they cause the $<$ PULCOIL $>$ block to produce a pulse. This is sent via the $<$ RSTCOIL $>$ digital output block to the PLC where it causes a reset of the PLC abort coil, as well as all of the individual aborts in the PLC.

The <PLCCOMFA > block is set when Genesis detects a communication failure from the PLC to Genesis. This can be detected by the Modicon driver and accessed by a connection to the FAIL bit of an I/O block. The <PLCCOMFA $>$ block causes a Genesis alarm whenever this condition occurs. It also attempts to send this information to the PLC so that the abort coil can be set. This is accomplished via the $<$ COMABRT $>$ block shown above. This is useful in the unlikely event that the communication failure has been only one way and the PLC has not detected a corresponding Genesis to PLC failure.

Figure 11 shows a portion of the strategy that generates instrument failure alarms. These blocks generate alarms when a critical instrument reads at or near zero indicating a possible instrument failure. They are also wired to the instrument failure detection 
mechanisms in the PLC (see Section 4.3.2) and cause an alarm when the PLC detects an instrument failure as well.

Each of the $O R$ blocks shown in Fig. 11 implements an instrument fail alarm for the measurements whose names correspond most closely to the names of the $O R$ blocks. In most cases, the measurement name has an $I$ in place of the $Z$ in the above names.

Four of these instrument failure alarm blocks have to be handled differently. These are the ones shown as $\langle$ GC1-INST $\rangle$, $\langle$ GC2-INST $\rangle,\langle$ GC3-INST $\rangle$; $<$ NH3-INST $\rangle$, and $<$ FT-INST $>$ in Fig. 11. These originate from the gas measurement equipment and arrive at the PLC after having traveled through several other computers and devices. An instrument failure in this case could mean either a failure of the instrument itself or of the communication pathways involved in getting the measurement to the PLC.

The first case is handled by detecting when the measurements involved read zero. This is slightly complicated by the fact that $\langle\mathrm{GC} 1-\mathrm{H} 2\rangle,\langle\mathrm{GC} 2-\mathrm{H} 2\rangle$ and $\langle\mathrm{GC} 3-\mathrm{H} 2\rangle$ already have low alarm values associated with them, so separate blocks ( $<\mathrm{GCl}$-ZVAL $>$, $<$ GC2-ZVAL $>$, and $<$ GC3-ZVAL $>$ ) have been provided to detect the zero case.

The second case is handled by the logic shown in Fig. 12. It is used to detect a failure in the communications path between the instrument and the PLC. The gas measuring equipment sends a value to the PLC known as the File ID. This value is incremented (independently for FTIR, PHOTO NH3, GC1, GC2 and GC3 data) whenever a new measurement has been taken. The $F(X)$ block, <FILEUPDT $>$, receives this file ID from the measurements. As long as the current value is equal to the previous value, the TON blocks are allowed to run. When a new File ID arrives, the TON blocks are reset. If the TON blocks ever reach their predefined timeout values, the instrument failure alarm occurs. The block < RGSTLOG > is used to start the RGA5 data logging. It was discussed in section 4.1.4.

Values for FTIR, PHOTO NH3, GC1, GC2, and GC3 are forced to zero by Genesis if the TON blocks time out. This is an obvious indication to operators that the instrument has a problem. The gas values are actually forced to zero in the PLC ladder logic by use of a PDOT block (G10CO). As soon as updated data is sent to the PLC from the gas equipment, the TON blocks will reset and the display will indicate valid readings. 
HNF-SD-WM-CSDD-008

Rev. 3

Page 45

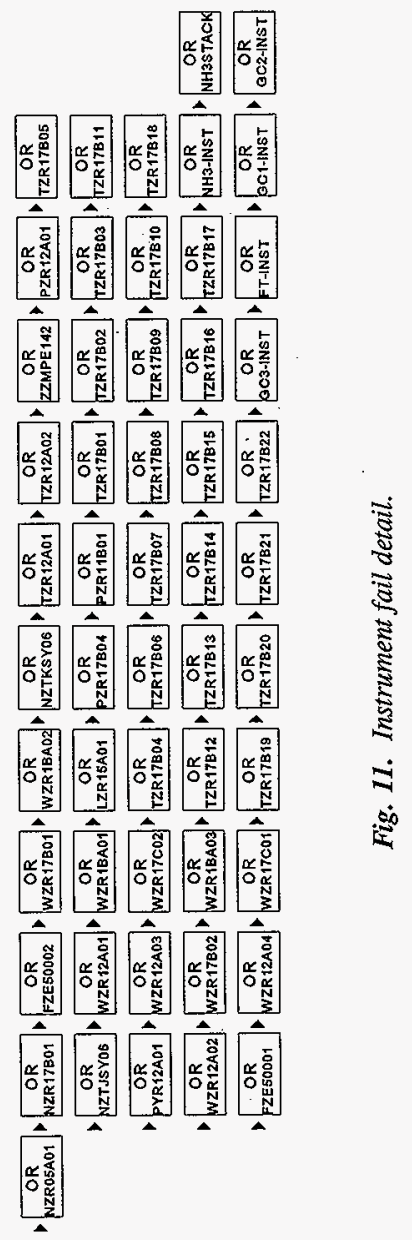


HNF-SD-WM-CSDD-008

Rev. 3

Page 46

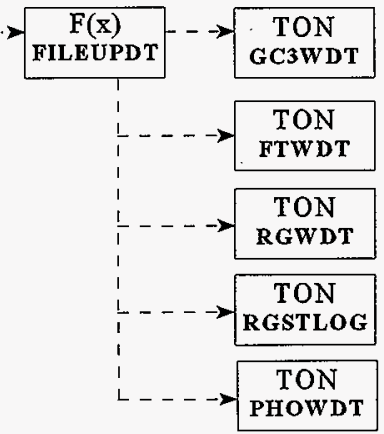

Fig: 12. Communication pathway failure detection.

\subsection{PUMP CONTROL FUNCTION}

The signals that actually control the pump are assigned by the Eaton AF5000+ variable frequency drives. There is one drive to control the motor that positions the pump and one drive to control the motor that operates the pump. These variable frequency drives receive commands in the form of ASCII strings from a communication driver. This ASCII driver is imbedded in the Genesis MOTOR strategy and is represented by two AF5000+ hardware communication device blocks, one for each VFD.

There are several different tasks that are performed in parallel to control the position and operation of the pump. The results of these tasks are sent as commands to the variable frequency drives or as indications to the operators. The following subsections of Section 4.2 supply the details of how the separate tasks of position control, pump control, aborting, and test operation are implemented in the MOTOR strategy. These will be followed by discussions of PLC communications, alarms, system parameters, and indication of failure of executing tasks.

\subsubsection{Position Control}

The following are the details related to controlling the position (i.e., direction) of the pump. 


\subsubsection{Start}

The directional motor can move the pump only if the actual position is outside the desired range, the actual position is within the safe boundary, the pump is not running, and the operator enables the pump to move. The following tags of the MOTOR strategy are used to execute the start of the directional motor.

$\begin{array}{llll}\text { ABORTOR } & \text { BACKWARD } & \text { DISMOVE } & \text { DMOTOR } \\ \text { FORWARD } & \text { FSTRTDEL } & \text { GOFORWRD } & \text { GOREVERS } \\ \text { HILIMAND } & \text { LOLIMAND } & \text { NOTRUN } & \text { POSCNTRL } \\ \text { POSITION } & \text { PRUN } & \text { PSTOP } & \text { RSTRTDEL } \\ \text { START } & \text { STARTAND } & \text { STARTSHT } & \text { STRTAND }\end{array}$

When the output of the one shot block <STARTSHT $>$ goes high, the directional motor will be commanded to start by setting <DMOTOR.start> high. <STARTSHT> is set high when the output of the small logic and block $<$ STARTAND $>$ goes high. $<$ STARTAND $>$ and <STRTAND $>$ are used as the safeguard to disable a start of movement under improper conditions. All of the following conditions must be true before the directional motor can be started.

- $\quad$ ABORTOR.QNOT> is high if no abort condition is active.

- $\quad$ SSTART.DOUT $>$ is high indicating a start request is active from the direction control logic.

- $\quad<$ HILIMAND.QNOT > is high indicating the position of the pump is not beyond the maximum boundary.

- < LOLIMAND.QNOT> is high indicating the position of the pump is not beyond the minimum boundary.

- $\quad$ <DISMOVE.QNOT > is high indicating position control is not disabled.

- $\quad<$ PSTOP.DOUT $>$ is high indicating that pump motor is stopped.

- $\quad<$ PRUN.QNOT $>$ is high indicating the pump motor is not running. 
HNF-SD-WM-CSDD-008

Rev. 3

Page 48

The small logic or block <START> is the block that will go high when the directional motor is successfully requested to move. <START> has two inputs to move the pump forward or backward.

- $\quad<$ FSTRTDEL.DOUT > goes high when the pump is to move in the forward direction. <FSTRTDEL > will go high when both of the following inputs are true.

- $<$ GOFORWARD.DOUT > which goes high when the pump is to go forward.

- <DMOTOR.forward > is high when the position motor is set to move in the forward direction.

- $\quad<$ RSTRTDEL.DOUT > goes high when the pump is to move in the reverse direction. < RSTRTDEL > will go high when both of the following inputs are true.

- <GOREVERS.DOUT > which goes high when the pump is to go backward.

- $\quad$ DMOTOR.reverse $>$ is high when the position motor is set to move in the reverse direction.

\subsubsection{Stop}

The directional motor will be stopped automatically if the position of the pump is within the desired range, the position of the pump exceeds the safe boundary, or an abort condition arises. The directional motor also can be stopped by an operator request from the STATION8 console.

The following signals are involved with the stop task in the MOTOR strategy.

$\begin{array}{llll}\text { BUTPULSE } & \text { DISP1 } & \text { DMOTOR } & \text { FOROVER } \\ \text { FOVRSTOP } & \text { GOSTOP } & \text { HILIMIT } & \text { LOLIMIT } \\ \text { REVOVER } & \text { ROVRSTOP } & \text { STOP } & \text { STOP2 }\end{array}$

The output of the small logic or block <STOP2 > controls <DMOTOR.stop >, which commands the directional motor to halt if the signal transitions from 0 to 1 .

$<$ STOP.DOUT $>$ is also a small logic or block to help compile stop conditions. $<$ STOP2.DOUT $>$ will go high if any one of the following conditions become true. 
- $\quad<$ STOPTEST.DOUT > which goes high when the operator requests to stop the pump, an abort condition occurs, or the pump operation time reaches the desired time.

- <GOSTOP.DOUT> goes high, which is automatically set when the pump position comes within the desired range while the directional motor is moving.

- $\quad$ <FOVRSTOP.DOUT > goes high, which indicates an overshoot condition while the pump is moving forward.

- $\quad<$ ROVRSTOP.DOUT > goes high, which indicates an overshoot condition while the pump is moving in reverse.

- $\quad<$ HILIMIT.DOUT > goes high, which indicates the actual pump position has exceeded the maximum boundary. This will be discussed in further detail in the position feedback task in section 4.2.1.4.

- <LOLIMIT.DOUT > goes high, which indicates the actual pump position has exceeded the minimum boundary. This will be discussed in further detail in the position feedback task in section 4.2.1.4.

- $\quad<$ BUTPULSE.DOUT > goes high, which indicates the operator requested the motor to stop.

Each time the position motor is stopped the movement is disabled by the output of $<$ STOP2 $>$ setting input 1 of $<$ DISP1 $>$ high to execute the macro DISMOV1. The macro DISMOV1 simply forces <DISMOVE > high. The disable movement task will be discussed in further detail in section 4.2.1.6.

An overshoot condition causes the directional motor to stop operation. This condition is recognized when $<$ POSCNTRL.DO2 $>$ goes high and the pump is moving forward or <POSCNTRL.DOUT $>$ goes high and the pump is moving in reverse.

The small logic and block <FOROVER > goes high to drive the one-shot block $<$ FOVRSTOP $>$ that stops the directional motor when all three of the following conditions are true.

- $\quad<$ DMOTOR.inforwd $>$ is high, indicating the motor is moving in the forward direction.

- $\quad<$ POSCNTRL.DO2 > is high when the actual position is beyond the desired range and the motor should be moved in reverse to achieve the desired position.

- $<$ DMOTOR.inrun $>$ is high, indicating the directional motor is running. 
HNF-SD-WM-CSDD-008

Rev. 3

Page 50

The small logic and block <REVOVER> goes high to drive the one-shot block $<$ ROVRSTOP $>$ that stops the directional motor when all three of the following conditions are true.

- $\quad<$ DMOTOR.inrevers $>$ is high, indicating the motor is moving in the reverse direction.

- $\quad<$ POSCNTRL.DOUT > is high when the actual position is beyond the desired range and the motor should be moved in forward to achieve the desired position.

- $\quad$ DMOTOR.inrun > is high, indicating the directional motor is running.

\subsubsection{AF5000+ Communications}

The AF5000 device driver is a communication task that runs in parallel with all other Genesis tasks. The device driver is responsible for sending information to and collecting information from the variable frequency drive. The device block with the tag name $<$ DMOTOR $>$ processes all communications for the variable frequency drive controlling the directional motor.

The following signals are used to perform the AF5000+ communications to the position motor.

$\begin{array}{llll}\text { AF5COMFA } & \text { COMMOR } & \text { DACCEL } & \text { DATSPEED } \\ \text { DDECEL } & \text { DFAULT } & \text { DFORWARD } & \text { DLINE } \\ \text { DMAXSPD } & \text { DMOTOR } & \text { DREADY } & \text { DREVENAB } \\ \text { DREVERSE } & \text { DRUN } & \text { DSTOP } & \text { VR232070 } \\ \text { VR232080 } & \text { VR232090 } & \text { VR232100 } & \text { VR232110 } \\ \text { VR232120 } & \text { GOFORWRD } & \text { GOREVERS } & \text { STARTSHT }\end{array}$

STOP2

The following tags are used to issue commands to the variable frequency drive to change operating value and operating condition.

\begin{tabular}{|l|l|l||}
\hline \multicolumn{1}{|c|}{ TAG } & \multicolumn{1}{c|}{ VARIABLE } & \multicolumn{1}{c|}{ DESCRIPTION } \\
\hline \hline GOFORWRD & forwrd.do0 & Changes direction of motor to forward \\
\hline GOREVERS & revers.do0 & Changes direction of motor to reverse \\
\hline STARTSHT & start.do0 & Causes motor to start \\
\hline STOP2 & stop.do0 & Causes motor to halt \\
\hline
\end{tabular}


The following tags are used as directional motor feedback signals from the AF5000+ device block. Some of these signals are passed to STATION5 with the PLC communication task and some are used for parameter verification.

\begin{tabular}{|l|l|l||}
\hline \multicolumn{1}{|c|}{ TAG } & \multicolumn{1}{c|}{$\begin{array}{c}\text { AF5000+ } \\
\text { Variable }\end{array}$} & \multicolumn{1}{c|}{ Description } \\
\hline \hline COMMOR.INP1 & ACCEL.fail & Indicates a failure in communications \\
\hline DACCEL & ACCEL.inp & Desired acceleration rate \\
\hline DDECEL & DECEL.inp & Desired deceleration rate \\
\hline VR232090 & FREQ.inp & Stator frequency high range \\
\hline DLINEV & LINEV.hrng & Line voitage \\
\hline VR232070 & LOAD.inp & Motor load \\
\hline DMAXSPD & MAXSPD.inp & Maximum speed \\
\hline VR232100 & MOTORA.inp & Motor current \\
\hline VR232080 & MOTORV.inp & Motor voltage \\
\hline VR232120 & SPDSET.inp & Desired speed of motor \\
\hline VR232110 & SPEED.inp & Actual speed of motor \\
\hline DATSPEED & inatspd.di0 & Actual speed is within $\pm 5 \%$ of desired speed \\
\hline DFAULT & infault.di0 & Variable frequency drive is faulted \\
\hline DFORWARD & inforward.di0 & Direction of motor movement is forward \\
\hline DREADY & inready.di0 & Drive is ready to run \\
\hline DREVERSE & inrevers.di0 & Direction of motor movement is reverse \\
\hline DRUN & inrun.di0 & Drive is running \\
\hline DSTOP & instoppd.di0 & Drive is stopped \\
\hline DREVENAB & reven.di0 & Reverse enable \\
\hline \hline
\end{tabular}


The following is a list of variables in the AF5000+ device block <DMOTOR>

\begin{tabular}{|l|l||}
\hline \multicolumn{1}{|c|}{ Variable } & \multicolumn{1}{c|}{ Description } \\
\hline \hline ACCEL & Desired acceleration rate \\
\hline DECEL & Desired deceleration rate \\
\hline FREQ & Stator frequency \\
\hline LINEV & Line voltage \\
\hline LOAD & Motor load \\
\hline MAXSPD & Maximum speed \\
\hline MOTORA & Motor current \\
\hline MOTORV & Motor voltage \\
\hline SPDSET & Desired speed of motor \\
\hline SPEED & Actual speed of motor \\
\hline forwrd & Changes direction of motor to forward \\
\hline inatspd & Actual speed is within $\pm 5 \%$ of desired speed \\
\hline infault & Variable frequency drive is faulted \\
\hline inforward & Direction of motor movement is forward \\
\hline inready & Drive is ready to run \\
\hline inrevers & Direction of motor movement is reverse \\
\hline inrun & Drive is running \\
\hline instoppd & Drive is stopped \\
\hline reven & Reverse enable \\
\hline revers & Changes direction of motor to reverse \\
\hline start & Causes motor to start \\
\hline stop & Causes motor to halt \\
\hline & \\
\hline
\end{tabular}


HNF-SD-WM-CSDD-008

Rev: 3

Page 53

If a failure of communications arises from the VFD, the parameter $<$ DMOTOR.ACCEL. fail > will go high which is passed on <COMMOR $>$ which alarms $<$ AF5COMFA $>$. Communications failure is an abort condition which causes either motor drive to be automatically stopped as discussed further in the abort task section 4.2.3.

\subsubsection{Position Feedback}

There are maximum limits set on the actual position of the pump. The actual position signal comes from the block <POSITION $>$. The high-alarm value of $<$ POSITION $>$ is set to 190 degrees, and the low-alarm value is set to 15 degrees.

The following signals are integral to the position feedback task in the MOTOR strategy.
ANION
HILIMAND
HILIMIT
INBAND
LOLIMAND
LOLIMIT
POSITION

The high-alarm bit from < POSITION > will go high when the actual position exceeds the high alarm value. This high-alarm bit is passed on to a small logic and block $<$ HILIMAND >, which is used to disable the start of the directional motor.

The output of $<$ HILIMAND $>$ must be low for the directional. motor to be enabled to start.

- $\quad<$ POSITION.HALM $>$ is high indicating the pump has exceeded the maximum boundary.

- $\quad<$ DMOTOR.inforwrd $>$ is high indicating the variable frequency drive is enabled to move the directional motor forward.

The high-alarm bit from $<$ POSITION $>$ is currently passed to a small logic and block < HILIMIT>, which is used to stop the directional motor and disable movement of the pump if it is running and the actual position exceeds the high limit. The output of $<$ HILIMIT $>$ is passed to the block $\langle\mathrm{STOP}\rangle$, which will cause the directional motor to stop. The output of $<$ HILIMIT $>$ will go high when the following three conditions are true.

- $\quad<$ POSITION.HALM $>$ is high, indicating the pump has exceeded the maximum boundary.

- $\quad<$ DMOTOR.inrun $>$ is high, indicating the directional motor is running.

- $<$ DMOTOR.inforwrd $>$ is high, indicating the directional motor will move forward when it is started. 
The low-alarm bit from < POSITION > will go high when the actual position is less than the low-alarm value. This low-alarm bit is passed on to a small logic and block <LOLIMAND>, the output of which must be low for the directional motor to be enabled to start. The output of <LOLIMAND $>$ will go high when both of the following conditions are true.

- $\quad<$ POSITION.LALM $>$ is high, indicating the pump has exceeded the minimum boundary.

- $\quad<$ DMOTOR.inrevers $>$ is high, indicating the variable frequency drive is enabled to move the directional motor in reverse.

The low-alarm bit from <POSITION > is also passed to a small logic and block $<$ LOLIMIT > , which is used to stop the directional motor and disable movement of the pump, if it is running and the actual position falls below the low limit. The output of $<$ LOLIMIT $>$ is passed to the block $<$ STOP $>$, which will cause the directional motor to stop. The output of <LOLIMIT > will go high when the following three conditions are true.

- $\quad$ POSITION.LALM > is high, indicating the pump has fallen below the minimum boundary.

- $\quad<$ DMOTOR.inrun > is high, indicating the directional motor is running.

- $\quad<$ DMOTOR.inrevers $>$ is high, indicating the directional motor will move in reverse when it is started.

The position feedback alarming is disabled on startup of Runtime by controlling the inhibit alarm bit of <POSITION > by <ANTON.QNOT> which will go low 10 seconds after the strategy is started. When the feedback position is within the deadband of the desired position <INBAND > is set high.

\subsubsection{Direction Control}

The actual pump position is monitored from the PLC by STATION8 with the block called $<$ POSITION $>$. The output of the block <POSITION $>$ is passed to the DGAP control block $<$ POSCNTRL $>$ as the measured process variable.

The DGAP block <POSCNTRL > is used to control forward movement or reverse movement of the directional motor based on the comparison of desired position with actual 
HNF-SD-WM-CSDD-008

Rev. 3

Page 55

position. The $D G A P$ block is an on-off control block that sets two digital outputs to various states depending on where the measured position is in relationship to the deadband. Figure 13 is a diagram of these two outputs.

The high gap and low gap of the DGAP block <POSCNTRL> is set to a 2-degree dead band around the desired position.

The first output of the $D G A P$ block $<$ POSCNTRL.DOUT $>$ goes high when the measured position is less than the desired position minus the lowgap offset. The output goes to a oneshot block < GOFORWRD $>$, used to start forward movement of the pump.

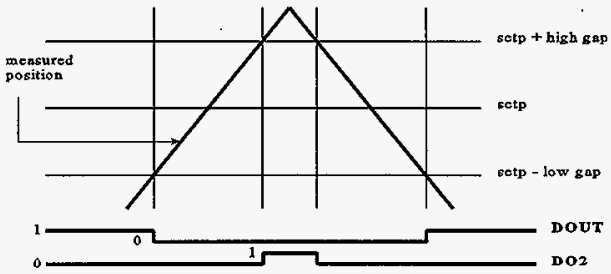

Fig 13. DGAP block output

The output of <GOFORWRD> will stay high for 15 seconds unless the block is reset. The reset of the block <GOFORWRD $>$ is controlled by the inverse of the small logic and block $<$ FORWARD $>$. When the output of $<$ FORWARD $>$ is low, the output of $<$ GOFORWRD $>$ will always be low and will not start forward movement.

The block <FORWARD> has two inputs that must go high for the output to go high to allow the pump to move forward.

- The output of $<$ DISMOVE $>$ must be low. This is the bit used to disable movement mentioned in the disable movement task.

- The output of <NOTRUN > must be high, which is the inverse of the feedback signal from the directional motor variable frequency drive that goes high when the motor is running.

When the output of <GOFORWRD $>$ is allowed to go high it sets $<$ DMOTOR. forwrd $>$ high, which commands the variable frequency drive to move the motor forward when it is running. The output of $<$ GOFORWRD $>$ also starts a 6-second time-on delay block <FSTRTDEL $>$.

The 6-second delay of <FSTRTDEL > is to ensure that the forward command is sent to the variable frequency drive before the motor is commanded to start. The output of $<$ FSTRTDEL $>$ sets a small logic or block $<$ START $>$ high, which is the beginning of the start task of position control.

The second output of the DGAP block <POSCNTRL.DO2> goes high when the measured position is greater than the desired position plus the high-gap offset. The output goes on to a one-shot block <GOREVERS > used to start reverse movement of the pump.

The output of <GOREVERS $>$ will stay high for 15 seconds unless the block is reset. The reset of the block <GOREVERS $>$ is controlled by the inverse of the small logic 
and block $<$ BACKWARD $>$. When the output of $\angle B A C K W A R D>$ is low the output of $<$ GOREVERS $>$ will always be low and will not start reverse movement.

The block < BACKWARD> has two inputs that must go high for the output to go high and allow the pump to move backward:

- The output of <DISMOVE > must be low. This is the bit used to disable movement mentioned in the disable move task.

- The output of <NOTRUN > must be high. This is the inverse of the feedback signal from the directional motor variable frequency drive that goes high when the motor is running.

When the output of <GOREVERS > is allowed to go high it sets $<$ DMOTOR.revers $>$ high, which tells the variable frequency drive to move the motor in reverse when it is running. The output of <GOREVERS $>$ also starts a 6-second time-on delay block < RSTRTDEL $>$.

This delay ensures that the reverse command is sent to the variable frequency drive before the motor is commanded to start. The output of $<$ RSTRTDEL $>$ sets a small logic or block <START $>$ high, which, as noted above, imitates the position control task.

An overshoot condition causes the directional motor to stop operation. This condition is recognized when <POSCNTRL.D02> goes high and the pump is moving forward or $<$ POSCNTRL.DOUT $>$ goes high and the pump is moving in reverse.

The small logic and block <FOROVER $>$ goes high to drive the one-shot block $<$ FOVRSTOP $>$ that stops the directional motor when all three of the following conditions are true:

- $\quad$ DMOTOR.inforwrd $>$ is high, indicating the motor is moving in the forward direction.

- $\quad<$ POSCNTRL.DO2 > is high when the actual position is beyond the desired range and the motor should be moved in reverse to achieve the desired position.

- $\quad$ CDMOTOR.inrun > is high, indicating the directional motor is running.

The small logic and <REVOVER > goes high to drive the one-shot block $<$ ROVRSTOP $>$ that stops the directional motor when all three of the following conditions are true: 
HNF-SD-WM-CSDD-008

Rev. 3

Page 57

- <DMOTOR.inrevers > is high, indicating the motor is moving in the reverse direction.

- $\quad<$ POSCNTRL.DOUT $>$ is high when the actual position is beyond the desired range and the motor should be moved forward to achieve the desired position.

- $\quad<$ DMOTOR.inrun $>$ is high, indicating the directional motor is running.

\subsubsection{Disable Movement}

The pump is disabled from moving unless the operator enables movement from the console. Each time the pump stops or goes beyond the desired range the pump is disabled from moving automatically.

The following tags in the MOTOR strategy are used to execute the disable movement task.

$\begin{array}{llll}\text { DISMOV } & \text { DISMOV1 } & \text { DISP1 } & \text { PBPOSAN2 } \\ \text { DISMOVE } & \text { DISP1 } & \text { INBAND } & \text { ON } \\ \text { STOP2 } & & & \end{array}$

The $D I N$ block <DISMOVE > must have a 0 value in order to start the directional motor; This is the value set when the operator enables pump movement from the STATION8 console. The value of $\langle$ DISMOVE $>$ is set to 1 any time the directional motor is stopped or when the MOTOR strategy is first started. This is accomplished with two custom macros in EXTRA.KMS. The macro DISMOVO is used to set $<$ DISMOVE.DOUT $>$ low and the macro DISMOV1 is used to set <DISMOVE.DOUT $>$ high which will disable movement of the pump.

The following signal will execute the macro DISMOV0.

- $\quad<$ PBPOSAN2.DOUT > which goes high if the operator selects to position the pump during a full integrated test.

The movement of the pump is also enabled manually by the operator from the DDISPLAY display.

The following signals will execute the macro DISMOV1.

- $\quad<$ STOP2.DOUT $>$ will go high any time the directional motor is stopped.

- <ON.DOUT > when the MOTOR strategy is first started. 
HNF-SD-WM-CSDD-008

Rev. 3

Page 58

- $\quad$ DISMOV1.DOUT > which goes high any time there is a problem with starting the position motor, the position motor is not running, and the position of the pump is not within the desired deadband.

The function block <DISMOV > is used to stop the directional motor and disable movement when the position of the pump is within the desired range. This block also checks the disable movement bit from <DISMOVE.DOUT> the forward movement bit from $<$ POSCONTRL.DOUT $>$, and the reverse movement bit from <POSCNTRL.D02>. When all three conditions are not true an internal control bit $\langle\mathrm{DRl}\rangle$ starts an internal counter $<$ AR $1>$. This counter is used to delay the stop of the pump by 2 seconds after the position is within the dead band. This allows the pump to move closer to the desired position before shutting down movement. When the internal counter reaches 2 seconds the directional motor is commanded to stop and movement is disabled by control bit <DISMOV.DOUT>.

The function block <DISMOV $>$ also has a logic equation to determine if the pump is within the desired range. <DISMOV.D02 $>$ is passed to $<$ INBAND $>$, which is used to indicate the pump is within the dead band range of 2 degrees.

\subsubsection{Pump Control}

The following are the details related to controlling the operation of the mixing pump to actually mix the contents of the tank.

\subsubsection{Start}

The AF5000+ device block variable <PMOTOR.start > requires a transition from 0 to 1 to start operation of the pump motor. The <PMOTOR.start $>$ variable is driven by the output of the block with the tag name $<$ PBSTRTDN $>$. < PBSTRTDN $>$ will go high when the operator successfully starts a fully integrated test for pump operation. Test operation will be explained in detailed sections to follow.

The following blocks are involved with the start pump control task. 


\subsubsection{Stop}

The AF5000 + device block variable <PMOTOR.stop > requires a transition from 0 to 1 to stop operation of the pump motor. The <PMOTOR.stop $>$ variable is driven by the output of a small logic or block with the tag name $<$ STOPTEST $>$.

The $<$ STOPTEST $>$ block will go high when the pump operation is stopped automatically from an abort condition, from the elapsed time exceeding the desired times, the operator manually stopping pump operation, or failure in communications to either VFD.

The following blocks are involved with the stop pump control task.

PMOTOR STOPTEST

\subsubsection{AF5000+ Communications}

The AF5000+ device driver is a communication task that runs in parallel with all other Genesis tasks. The device driver is responsible for sending information to and collecting information from the variable frequency drive. The device block with the tag name $<$ PMOTOR > processes all communications for the variable frequency drive controlling the pump motor.

The following signals are used to perform the communications task for the pump control.

$\begin{array}{llll}\text { AF5COMFA } & \text { COMMOR } & \text { EQUPSPD } & \text { PACCEL } \\ \text { PATSPEED } & \text { PDECEL } & \text { PFAULT } & \text { PFORWARD } \\ \text { PLINEV } & \text { PMAXSPD } & \text { PMOTOR } & \text { PREADY } \\ \text { PREVENAB } & \text { PREVERSE } & \text { PRUN } & \text { PSTOP } \\ \text { VR232020 } & \text { VR232030 } & \text { VR232040 } & \text { VR232050 } \\ \text { VR232060 } & \text { VSDRS232 } & & \end{array}$

The following tags are used to issue commands to the variable frequency drive to change operating values and operating conditions.

\begin{tabular}{|l|l|l||}
\hline \multicolumn{1}{|c|}{ TAG } & \multicolumn{1}{|c|}{$\begin{array}{c}\text { AF5000+ } \\
\text { Variable }\end{array}$} & \multicolumn{1}{c|}{ Description } \\
\hline \hline COMMOR.QNOT & forwrd.do0 & Changes direction of motor to forward \\
\hline PBSTRTDN & start.do0 & Causes motor to start \\
\hline STOPTEST & stop.do0 & Causes motor to halt \\
\hline
\end{tabular}


HNF-SD-WM-CSDD-008

Rev. 3

Page 60

The following tags are used as pump feedback signals from the AF5000+ device block. Some of these signals are passed to STATION5 with the PLC communication task, and some are used for parameter verification.

\begin{tabular}{||l|l|l||}
\hline \multicolumn{1}{|c|}{ TAG } & \multicolumn{1}{|c|}{$\begin{array}{c}\text { AF5000+ } \\
\text { Variable }\end{array}$} & \multicolumn{1}{c||}{ Description } \\
\hline \hline COMMOR.INP2 & ACCEL.fail & Indicates a failure in communications \\
\hline PACCEL & ACCEL.inp & Desired acceleration rate \\
\hline PDECEL & DECEL.inp & Desired deceleration rate \\
\hline VR232030 & FREQ.hrng & Stator frequency high range \\
\hline PLINEV & LINEV.inp & Line voltage \\
\hline VSDRS232 & LOAD.inp & Motor load \\
\hline PMAXSPD & MAXSPD.inp & Maximum speed \\
\hline VR232040 & MOTORA.inp & Motor current \\
\hline VR232020 & MOTORV.inp & Motor voltage \\
\hline VR232060 & SPDSET.inp & Desired speed of motor \\
\hline VR232050 & SPEED.inp & Actual speed of motor \\
\hline VSDRS232 & LOAD.inp & VSD\% load \\
\hline PATSPEED & inatspd.di0 & Actual speed is within $\pm 5 \%$ of desired speed \\
\hline PFAULT & infault.di0 & Variable frequency drive is faulted \\
\hline PFORWARD & inforward.di0 & Direction of motor movement is forward \\
\hline PREADY & inready.di0 & Drive is ready to run \\
\hline PREVERSE & inrevers.di0 & Direction of motor movement is reverse \\
\hline PRUN & inrun.di0 & Drive is running \\
\hline PSTOP & instoppd.di0 & Drive is stopped \\
\hline PREVENAB & reven.di0 & Reverse enable \\
\hline
\end{tabular}


The following is a list of variables in the AF5000+ device block $<$ PMOTOR $>$.

\begin{tabular}{|l|l||}
\hline \multicolumn{1}{|c|}{ Variable } & \multicolumn{1}{c|}{ Description } \\
\hline \hline ACCEL & Desired acceleration rate \\
\hline DECEL & Desired deceleration rate \\
\hline FREQ & Stator frequency \\
\hline LINEV & Line voltage \\
\hline LOAD & Motor load \\
\hline MAXSPD & Maximum speed \\
\hline MOTORA & Motor current \\
\hline MOTORV & Motor voltage \\
\hline SPDSET & Desired speed of motor \\
\hline SPEED & Actual speed of motor \\
\hline forwrd & Changes direction of motor to forward \\
\hline inatspd & Actual speed is within $\pm 5 \%$ of desired speed \\
\hline infault & Variable frequency drive is faulted \\
\hline inforward & Direction of motor movement is forward \\
\hline inready & Drive is ready to run \\
\hline inrevers & Direction of motor movement is reverse \\
\hline inrun & Drive is running \\
\hline instoppd & Drive is stopped \\
\hline reven & Reverse enable \\
\hline revers & Changes direction of motor to reverse \\
\hline start & Causes motor to start \\
\hline stop & Causes motor to halt \\
\hline
\end{tabular}


If a failure of communications arises from the VFD the parameter $<$ PMOTOR.ACCEL.fail > will go high which is passed on <COMMOR $>$ which alarms $<$ AF5COMFA $>$. Communications failure is an abort condition which should cause either motor drive to be automatically stopped as discussed further in the abort task section 4.2.3.

\subsubsection{Parameter Verification}

The following blocks are used for parameter verification in the MOTOR strategy.

$\begin{array}{llll}\text { CALCUR } & \text { RCALDISP } & \text { RCURABR } & \text { TCURALRM } \\ \text { CURPRED } & \text { DISPRABT } & \text { DISPRALM } & \text { DISPRPRE } \\ \text { EQUPSPD } & \text { VR232050 } & \text { VR232060 } & \end{array}$

The function block <EQUPSPD > contains an equation to compare the desired speed set in the variable frequency drive $\langle$ VR232060 $>$ with the actual speed $<$ VR232050 $>$. The variable <EQUPSPD.DRl $>$ will be high if the actual speed is within $5 \%$ of the desired speed. This will be displayed to the operator as a light green indication on the pump speed bar graphs.

The desired speed value is passed to the function block <CALCURR > uses $<$ CURPRSPD $>$ as the desired speed and automatically calculates the predicted motor current, which is passed to <CURPRED $>$.

The predicted motor current plus $20 \%$ is passed to $<$ CURALRM $>$ as the alarm limit. The output of $\langle$ CURALRM $\rangle$ sets the high alarm value of $\langle$ VR232040 $>$ and is passed to the PLC for the high motor alarm.

The predicted motor current plus $40 \%$ is passed to <CURABRT> as the abort limit. The output of $<$ CURABRT $>$ is passed to the PLC as the abort limit for motor current.

The desired pump speed is also passed to the function block $<$ CALDISPR $>$ which automatically calculates the predicted discharge pressure, which is passed to <DISPRPRE > for operator display.

The predicted discharge pressure plus $20 \%$ is passed to $<$ DISPRALM $>$ as the alarm limit, and the output of $<$ DISPRALM $>$ is passed to the PLC to set the high alarm value of the discharge pressure signal.

The predicted discharge pressure plus $40 \%$ is passed to $<$ DISPRABT $>$ as the abort limit, and the output of $<$ DISPRABT $>$ is passed to the PLC as the abort limit for the discharge pressure. 


\subsubsection{Abort}

Certain conditions are monitored continuously in the MOTOR strategy as abort criteria to stop both motors automatically. Also abort conditions will prevent the start of either motor.

The following blocks are involved with the abort task.

$\begin{array}{llll}\text { A5ABRT } & \text { ABORT } & \text { ABORTOR } & \text { ABORTPUL } \\ \text { COMMOR } & \text { NODEFAIL } & \text { PLCFAIL } & \end{array}$

The current abort status is indicated by the small logic or block <ABORTOR $>$ which has the following input conditions.

- $\quad<$ ABORT.DOUT $>$ is high if the abort coil in the PLC is active.

- <COMMOR.DOUT > is high if either VFD has a failure in communications to the MOTOR strategy.

- <NODEFAIL.DOUT > is high if a failure in communications from STATION5 to the PLC is recognized.

- <PLCFAIL.DOUT > is high if a failure of communications to the PLC is recognized from the MOTOR strategy.

The output of $<A B O R T O R>$ is passed to a small logic pulse block $<$ ABORTPUL $>$ which is passed on to <STOPTEST $>$ which will stop either VFD with a communication command.

$<$ COMMOR $>$ is a small logic or block with two inputs from each hardware device block. If communications to either variable frequency drive goes bad, indicated by a fail bit of the first parameter selected from each hardware device block, <COMMOR.DOUT $>$ will go high. This signal is passed to the PLC with the digital output block $<$ A5ABRT $>$.

\subsubsection{Test Operation}

This section provides the details of the actual test operation, including their selection, how the elapsed time is calculated, and the information provided to the operator. 


\subsubsection{Test Creation and Selection}

The following blocks are related to test creation and selection.

$\begin{array}{llll}\text { ANGLECHG } & \text { CHANGED } & \text { CHGCHK1 } & \text { CLRMESS } \\ \text { DECELCHG } & \text { DELPUL } & \text { HRSCHG } & \text { INFILE } \\ \text { MANUAL } & \text { MAXINDX } & \text { MINSCHG } & \text { NEXTINDX } \\ \text { NEXTPUL } & \text { OACCEL } & \text { OANGLE } & \text { ODECEL } \\ \text { OHRS } & \text { OLDTEST } & \text { OMINS } & \text { ORESTIM } \\ \text { OSECS } & \text { OSPEED } & \text { PBTESTNO } & \text { PREVPUL } \\ \text { RESCHG } & \text { SAVEPUL } & \text { SECSCHG } & \text { SPEEDCHG } \\ \text { TESTCHG } & \text { TESTSET } & \text { TESTSET2 } & \text { UACCEL } \\ \text { UANGLE } & \text { UDECEL } & \text { UHRS } & \text { UMINS } \\ \text { UMSG1 } & \text { URESTIM } & \text { USECS } & \text { USPEED } \\ \text { UTESTNO } & & & \end{array}$

- All test setups are in a file called USERSET.TDF (TDF stands for Test Data File). The test setups can be accessed from the pump operation display PUMPRUN. There is a display called TESTSET which allows the creation and modification of the test setup file USERSET.TDF. This display is not part of the STATION8 menu system but can be accessed via the F1 function key. The TESTSET display calls report and recipe code which performs basic operations on the test setup file such as test setup loading, scrolling, insertion and deletion.

The details of all of this are described below.

USERSET.TDF file format. This is an ASCII file which contains records with the following information for each test setup:

test number (or end of file marker)

angle (degrees)

pump speed (RPM)

test duration (hours minutes seconds)

pump motor acceleration (RPM/Sec)

pump motor deceleration $(\mathrm{RPM} / \mathrm{Sec})$

test description

Reset overall test timer indication $(1=$ yes, $0=$ no) 
HNF-SD-WM-CSDD-008

Rev. 3

Page 65

The format for each record is:

tt.t aaa.a rrrr.r hh mm ss Ccc.c ddd.d eeeeeeeeeeeeeeeeeeee $f$

where tt.t is the test number, aaa.a is the angle, rrrr.r is the pump speed, hh is test duration hours, $\mathrm{mm}$ is test duration minutes, ss is test duration seconds, ccc.c is pump motor acceleration, ddd.d is pump motor deceleration, e...e is the test description and $f$ is reset overall timer indication.

Each record is separated by a carriage return/line feed. The end of file record has 999 as the test number.

The reset overall test timer field is used to indicate whether the overall test time should be reset at the beginning of a test. This allows for multiple-angle tests; the timer should be reset for the first of the series of tests and not for the subsequent tests.

TESTSET Screen. The TESTSET screen is used to create and maintain the setup file USERSET.TDF. It contains data entry fields for the above parameters as well as buttons to save and delete test setups, and buttons to go to the previous or next record in the file. A test setup can also be loaded by typing the test number in the test number data entry field. There is an indication on the screen telling whether or not the current test number exists in the file.

The buttons on the screen initiate the execution of reports which do the actual file manipulation. The Save Test button executes the report SAVE.RPS, the Delete Test button, DELETE.RPS, the Next button, NEXT.RPS, and the Previous button, PREV.RPS. In addition, there are reports CLRMESS.RPS, ULOAD.RPS and ILOAD.RPS. These reports are discussed in the next section.

Reports for test setup file manipulation. SAVE.RPS is executed by clicking on the Save Test button on the TESTSET screen. It inserts the test setup which has been entered into the data entry fields on that screen into the USERSET.TDF file. The new setup is inserted so as to keep the records in numeric order by test number. If a record already exists with the same test number, it is replaced.

DELETE.RPS is executed by clicking on the Delete Test button on the TESTSET screen. It deletes the current test from the file, if it exists in the file.

NEXT.RPS loads the setup for the next test (in numeric order). This setup is displayed on the screen. It is executed by clicking on the Next button on the TESTSET screen or the up-arrow button on the PUMPRUN screen. If the current test is not in the test setup file, the next button will load the next test from the last test loaded which was in the file.

PREV.RPS works the same as NEXT.RPS only the previous test setup (in numeric order) is loaded. It is executed by clicking on the Previous button, or the down-arrows. 
ILOAD.RPS loads the first setup in the test setup file and initializes the housekeeping blocks in the strategy. It is executed upon strategy startup.

ULOAD.RPS loads the setup for the current test number. It is executed when the strategy blocks detect that the user has entered a new test number.

CLRMESS.RPS clears the message field on the TESTSET screen. The reports SAVE and DELETE produce messages on the TESTSET screen giving the status of the save or delete operation. These messages are cleared by CLRMESS after a delay. It is executed by the strategy block CLRMESS going high. This bit is controlled from within the SAVE and DELETE reports.

SETOLD.RPS sets a set of strategy blocks corresponding to all of the test setup parameters to be equal to the current test setup parameters. This allows the strategy to detect when the user changes a parameter. It is executed from within any of the above reports which load a new predefined test setup.

Strategy Blocks. The reports are run from the report blocks $<$ TESTSET $>$ and $<$ TESTSET2 > . <TESTSET > executes SAVE.RPS from input 1, DELETE.RPS from input 2 and CLRMESS.RPS from input 3. <TESTSET2 > executes ULOAD.RPS from input 1, NEXT.RPS from input 2, PREV.RPS from input 3, and ILOAD.RPS from input 4.

The test setups are loaded into a set of AIN and DIN blocks called $<$ UTESTNO $>$, $<$ UANGLE $\rangle,\langle$ USPEED $\rangle,\langle$ UHRS $\rangle,\langle$ UMINS $\rangle,\langle$ USECS $\rangle,\langle$ UACCEL $\rangle$, $<$ UDECEL > , <UDESC > and <URESTIM >. There is a corresponding set of blocks with the first letter of " $O$ " instead of " $U$ " (except for the one corresponding to $<$ UTESTNO > , which is called <OLDTEST> and the one corresponding to <UDESC > which is called $<$ TDESC $>$ ). These sets of blocks are set to be equal when a new test. setup is loaded (see SETOLD.RPS above). A set of alarm blocks detects when any of the pairs of blocks contain differing values. This indicates that the user has changed a setup parameter and this information is displayed on the screens. In addition, if the test number is changed, the report ULOAD.RPS is executed to load in the setup corresponding to the new test number if it exists. The block <INFILE > is maintained by the reports. It is 1 if the current test is in the file, 0 otherwise. The blocks $<$ NEXTINDX $>$ and $<$ MAXINDX $>$ are maintained by the reports. They keep track of the record number of the current test and the record number of the highest numbered test in the file respectively. The block <UMSG1 > is used by the reports to display messages in the message field of the TESTSET screen. The block $<$ CHANGED $>$ is 1 if any of the test setup parameters have been changed since last loaded and 0 if not. The block manual is set when a test setup is actually loaded for use if either $<$ CHANGED $>$ is 1 or $<$ INFILE $>$ is 0 . This indicates that a setup is being used that was not predefined. 
HNF-SD-WM-CSDD-008

Rev. 3

Page 67

\subsubsection{Elapsed Time Calculation}

There are two elapsed timers that are used during test operation. The overall timer for test operation keeps track of the total test time. There is a second timer to time pump operation time.

The following blocks are integral is performing the elapsed time calculation task.

$\begin{array}{llll}\text { DF65535 } & \text { DFLT0 } & \text { DISP4 } & \text { PB30SEC } \\ \text { PBCALSEC } & \text { PBDNTM } & \text { PBHR } & \text { PBMIN } \\ \text { PBRAMP } & \text { PBRAMPHL } & \text { PBSEC } & \text { PBSPLIT } \\ \text { RESETPB } & \text { RSECPB } & \text { SPLITPB } & \text { TSTRUNNG }\end{array}$

The $R A M P$ block $<\mathrm{RSECPB}>$ totals the test time while a test is in operation. When ramp rate 1 becomes active the output of $\angle$ RSECPB $>$ increments by one every second.

A test is in operation when the $r$ flip-flop block $<$ TSTRUNNG $>$ is high. This signal controls $<$ RSECPB.RPIO $>$, which activates ramp rate 1 . The elapsed timer $<$ RSECPB $>$ is reset at the beginning of test operation by $<$ RESTPB $>$ which is set high with the RR code PBSETVAL.RPS when a new test is selected. The elapsed test time is broken down from seconds into hours, minutes, and seconds by the function block $<$ SPLITPB $>$.

There is a second elapsed timer used to keep track of the pump operation time at each position. The RAMP block <PBRAMP > totals the time the pump is in operation. When ramp rate 1 becomes active, the output of $\angle$ PBRAMP $>$ increments by one every second.

The pump is in operation when the rs flip-flop block <TSTRUNNG > is high. This signal controls <RSECPB.RPIO $>$, which activates ramp rate 1.

The elapsed timer $<$ PBRAMP $>$ is reset at the beginning of pump operation by $<$ SETVALDN $>$ which goes high when the test values have been successfully set. The high limit of $<$ PBRAMP $>$ is controlled by $<$ PBRAMPHL $>$ which will pass either the value 0 from $\langle$ DFLT0 $>$ or the maximum pump operation time from $<$ DF65535 $>$. $<$ PBRAMPHL $>$ will pass the value of $<$ DF65535 $>$ when $<$ SETVALDN $>$ is high when the test values are successfully loaded.

The desired pump operation time is set during test selection by setting the test values. The AIN blocks $<$ PBHR $>,<$ PBMIN $>$, and $<$ PBSEC $>$ contain the desired minutes and seconds for pump operation. The outputs of these blocks are passed to a function block $<$ PBCALSEC $>$, which merges the values into one desired pump operation time value in seconds. This value is passed to the function block $<$ PBSPLIT $>$, which is used to stop pump operation when the elapsed time from $<$ PBRAMP $>$ exceeds the desired time from $<$ PBCALSEC $>$. 
The control bit <PBSPLIT.DOUT> will go high when the elapsed time exceeds the desired time and is passed to the DIN <PBDNTM $>$. The output of this block resets the rs flip-flop block $<$ PBRSFF $>$ mentioned above. The output of $<$ PBDNTM $>$ is passed to logic which stops pump operation by setting $<$ STOPTEST $>$ high. $<$ PBSPLIT $>$ also breaks seconds of pump operation into hours, minutes, and seconds for operator display.

The desired pump operation times are reset by the output of <STOPTEST $>$ executing the macro RESPTIM which is referenced in $\langle$ DISP4 $\rangle$.

The alarm block $<\mathrm{PB} 30 \mathrm{SEC}>$ is used to warn the operator 30 seconds before the end of pump operation. The high alarm value of $\langle$ PB30SEC $\rangle$ is set by the second analog output of <PBCALSEC > which is set to 30 less than the desired pump operation time during test operation and to a very large number when a test is not in operation.

\subsubsection{Operator Test Information}

The PUMPRUN screen can be used for any test. The operator actions required for the PUMPRUN screen are discussed below. The operations are:

1) Select a test setup or manually enter a pump test configuration

2) Set the selected test values (set values).

3) Position the pump (if required)

4) Enable the pump test.

5) Start the pump test.

6) Stop the pump test (performed automatically when the preset time elapses or at any time by the operator.

Test Setup. Tests can be selected by typing the test number in the Test entry field on the screen. This will access the USERSET.TDF file to load the parameters for this test into the other fields (see 4.2.4.1). These values can be used as is, or can be changed by entering different values into any of the fields. If new values are entered the test is considered to be a manual test. A message will appear in the lower left corner of the screen indicating that the test values have been changed.

Set Values. The test parameters do not take effect until the SET VALUES button is pressed. The button is only effective if it is green in color. Pressing SET VALUES begins the pump test process, copying the test setup parameters to operational parameters. After the SET VALUES button is pressed the STOP TEST button will turn green. This button will abort the current test and return the system to the test setup mode. This can be done at any time, however the button functions differently if the pump is actually running (see below). After the SET VALUES button is pressed the POSITION PUMP button will turn green if the pump is not oriented at the specified angle. Otherwise the ENABLE TEST button will turn green. If there is a problem with setting the values, a flashing yellow question mark will appear at 
the bottom of the screen. Clicking on this question mark will bring up a screen showing what the problem was. Similar problem screens exist for all of the operations.

Position Pump: Pressing this button will cause the directional motor to begin to orient the pump to the desired angle. The current angle and the directional motor speed (in RPMs), as well as a directional motor running indicator are displayed above the button. When the pump is in position the POSITION PUMP button will turn gray and the ENABLE TEST button will turn green. As with all of the buttons, if there is a problem with pump positioning, clicking on the flashing question mark will bring up a problem screen.

Enable Test. This button enables a pump test. At this time test times and pump speed based alarm and abort limit values are sent to the PLC. The START TEST button will turn green. The operator has 60 seconds to start the test after the enable button is pressed. If the 60 seconds elapses, the ENABLE TEST button will once again turn green.

Start Test. This button starts the pump. The elapsed time indication on the screen will begin to increment and the pump motor running indicator will turn green. The pump speed is also displayed. The legend for the STOP TEST button will change to read ENABLE STOP.

Stop Test. This button functions to reset the system when the pump is not running. It returns the system to the test setup mode (SET VALUES button is green). When the pump is running, the legend for this button is ENABLE STOP. When clicked upon, the legend of the button will change to STOP TEST. After two seconds, the button will begin to flash. At this point, the user has five seconds to click the button again. This will stop the pump and reset the system to the test setup mode. If the 5 seconds elapses, the legend will change once again to ENABLE STOP. The pump will stop automatically when the specified time for the test has elapsed. There is also a timer in the PLC to shut off the pump as a backup to this. The STOP TEST button gives the operator a means to manually stop the pump before the allotted time has elapsed. When the pump is stopped either manually or at the end of the time allotted, the system will return to the test setup mode.

\subsubsection{Test Operation Strategy Details}

There is logic within the MOTOR strategy for indication of test operation status. There are status bits for test values set correctly, pump at desired position, test enabled to start, and test running. If a function is selected by an operator and the task was not successfully executed there is logic to indicate what the problem is. The following sections describe each main task execution and status feedback for indication of success of operation.

Set Test Values. The desired test values selected by the operator must be downloaded to the control parameters in the MOTOR strategy. This is done by the operator 
HNF-SD-WM-CSDD-008

Rev. 3

Page 70

with the set values button. The blocks in the following table are related to the set test values task.

NORUN

SETTEST

VALSET
PBENABLE

SETVALDN
PBREPORT

STOPTEST
PBSETAND

TSTRUNNG

The small logic pulse block <SETTEST > starts the execution of the set values task. Its output is passed to the small logic and block <PBSETAND $>$ which has the following input conditions to be true before executing the RR code PBSETVAL.RPS by setting input 1 of <PBREPORT $>$ high.

- $\quad<$ SETTEST.DOUT $>$ is set high by the operator to set the test values.

- $\quad<$ PBENABLE.QNOT $>$ is high if a test is not already enabled.

- $\quad$ TSTRUNNG.QNOT > is high if a test is not in progress.

- $\quad<$ NORUN.DOUT $>$ is high if both the pump motor and position motor are stopped.

- $\quad$ VALSET.QNOT > is high if the test values are not already set.

At the end of the RR code PBSETVAL.RPS <SETVALDN> is set high to indicate the test values are successfully set. <SETVALDN $>$ has a pulsed output and sets the $r$ slipflop block <VALSET> high. <VALSET.DOUT> is the status bit used to indicate that the test values have been successfully set. <VALSET > is reset when $<$ STOPTEST > goes high when a test is stopped.

Problem with Setting Test Values. If the test values are requested to be set and the task is not successfully completed then the blocks in the following table are used to indicate what the problem with setting test value variables is.

DISP3

PBPROB

SETPROB
NORUN

PDISP

SETPROBA
NOSEPROB

RSETPROB

SETPROBR
PBBUTSTP

SEDISP 
The $r$ flip-flop block <SETPROB $>$ is used to indicate a problem with setting the test values. $<$ SETPROB $>$ is set high if the output of $<$ SETPROBA $>$ is high and the reset input $<$ SETPROBR $>$ is low.

$<$ SETPROBA $>$ is a small logic and block with the following inputs.

- $\quad$ SSETTEST.DOUT $>$ is high if the test values are requested to be set.

- $\quad<$ NORUN.DOUT $>$ is high if both motors are stopped.

- $\quad$ VALSET.QNOT > is high if the test values are not set.

$<$ SETPROBR $>$ will reset $<$ SETPROB $>$ if any of the following conditions are true.

- <RSETPROB.DOUT > which is set high by the operator to reset the problem indication.

- $\quad<$ PBBUTSTP.DOUT $>$ which goes high when the operator manually stops a test.

- $\quad<$ NOSEPROB.DOUT > which is a small logic and block with the following input conditions.

- <PBENABLE.QNOT > is high when a test is not enabled.

- <TSTRUNNG.QNOT > is high when a test is not running.

- <NORUN.DOUT > is high when both motors are stopped.

When $<$ SETPROB $>$ goes high $<$ PBPROB $>$ is set high which indicates a test operation problem. The small logic and block $<$ SEDISP $>$ is used to bring up the problem indication display for setting test values. When $\angle$ SETPROB $>$ is high and the operator sets $<$ PDISP $>$ high to view the problem the display SETPROB is brought up via the display block $<$ DISP3 $>$.

Position Pump Selection. When the test values are set the desired pump position is compared with the actual position. If the pump is not at the desired position the pump will need to be positioned before a test can be enabled. The blocks in the following table are the key variables in the pump position selection. 
HNF-SD-WM-CSDD-008

Rev. 3

Page 72

$\begin{array}{llll}\text { ABORTOR } & \text { INPOSI } & \text { NORUN } & \text { PBENABLE } \\ \text { PBPOSAN2 } & \text { PBPOSAND } & \text { PBPOSPMP } & \text { POSSET } \\ \text { TSTRUNNG } & \text { VALSET } & & \end{array}$

$<$ PBPOSPMP $>$ starts the execution of the pump position selection. Its output is passed to the small logic and block <PBPOSAND $>$ which together with $<$ PBPOSAN2 $>$ has the following input conditions before <PBPOSAN2> will start the pump position control by executing the macro DISMOV0 as discussed earlier in the disable movement task section.

- $\quad<$ TSTRUNNG.QNOT $>$ which is high if a test is not running.

- $\quad<$ ABORTOR.QNOT > which is high if an abort conditions is not active.

- $\quad$ PBENABLE.QNOT > is high if a test is not enabled.

- <VALSET.DOUT > is high if the test values are set.

- <NORUN.DOUT > is high if both motors are stopped.

- $\quad<$ PBPOSPMP.DOUT $>$ goes high when the operator selects to position the pump.

- $\quad<$ POSSET.QNOT $>$ which is an AND block with the following input conditions.

- $\quad<$ VALSET.DOUT > is high when the test values are set.

- <INPOSI.DOUT > which is high when the pump is at the desired position.

Problem with Position Pump Selection. If the pump position selection does not successfully execute, the blocks in the following täble are used to indicate what the problems with the position pump variables are.

$\begin{array}{llll}\text { ABORTOR } & \text { DISP3 } & \text { NOPOPROB } & \text { NORUN } \\ \text { PBBUTSTP } & \text { PBENABLE } & \text { PBPOSPMP } & \text { PBPROB } \\ \text { POSDISP } & \text { POSPROB } & \text { POSPROBA } & \text { POSPROBR } \\ \text { POSSET } & \text { RPOSPROB } & \text { TSTRUNNG } & \text { VALSET }\end{array}$


The rs flip-flop block $<$ POSPROB $>$ is used to indicate a problem with selecting to position the pump. $<$ POSPROB $>$ is set high if the output of $<$ POSPROBA $>$ is high and the reset input $<$ POSPROBR $>$ is low. $<$ POSPROBA $>$ is a small logic and block with the following inputs.

- $\quad<$ PBPOSPMP.DOUT $>$ is set high by the operator to position the pump.

- $\quad<$ POSSET.QNOT > which is high when the pump is not in position or the test values are not set.

- $\quad<$ NORUN.DOUT $>$ is high when both motors are stopped.

- <VALSET.DOUT > is high if the test values have been set.

$<$ POSPROBR $>$ will reset $<$ POSPROB $>$ if any of the following conditions are true.

- $\quad<$ RPOSPROB.DOUT $>$ which is set high by the operator to reset the problem indication.

- $\quad$ PBBUTSTP.DOUT> which goes high when the operator manually stops a test.

- $\quad<$ NOPOPROB.DOUT $>$ which is a small logic and block with the following input conditions.

- $\quad<$ ABORTOR.QNOT $>$ which is high if no abort condition is active.

- $\quad<T S T R U N N G . Q N O T>$ is high if a test is not running.

- $\quad$ PBENABLE.QNOT $>$ is high if a test is not enabled.

- <VALSET.DOUT > is high if the test values are set.

- <NORUN.DOUT > is high if both motors are stopped.

When $<$ POSPROB $>$ goes high $<$ PBPROB $>$ is set high which indicates a test operation problem. The small logic and block $<$ POSDISP $>$ is used to bring up the problem indication display for position pump selection. When $<P O S P R O B>$ is high and the operator sets $<$ PDISP $>$ high to view the problem the display $<$ POSPROB $>$ is brought up via the display block $<$ DISP $3>$. 
Position Pump Operation Problem. When the position motor is to be started to position the pump and a problem prevents the actual movement of the pump, the blocks in the following table are used to indicate what the problem with position pump operation variables is.

$\begin{array}{llll}\text { ABORTOR } & \text { DDISP } & \text { DISMOV1 } & \text { DISMOVE } \\ \text { DISP1 } & \text { DISP3 } & \text { DMDISP } & \text { DMPROB } \\ \text { DMPROBD } & \text { IDMPROBR } & \text { DRUN } & \text { DSTOP } \\ \text { ENMOVPUL } & \text { ENMOVTON } & \text { HILIMAND } & \text { HOLDENMO } \\ \text { INBAND } & \text { LOLIMAND } & \text { NODMPROB } & \text { PBDMPROB } \\ \text { PBPROB } & \text { PBPROB2 } & \text { PDISP } & \text { POSDISP } \\ \text { PRUN } & \text { PSTOP } & \text { RDMPROB } & \end{array}$

The $r$ flip-flop block $<\mathrm{DMPROB}>$ is used to indicate a problem with positioning the pump. $<$ DMPROB $>$ is set high if the small logic pulse block $<$ ENMOVPUL $>$ is high and the reset input $<$ DMPROBR $>$ is low. <ENMOVPUL $>$ is set high by $<$ ENMOVTON $>$ which delays <HOLDENMO > for 4 seconds. <HOLDENMO > stays high for 5 seconds after the pump is requested to move by $<$ DISMOVE $>$ going low. $<\mathrm{DMPROBR}>$ will reset $<\mathrm{DMPROB}>$ if any of the following conditions are true.

- $\quad<$ RDMPROB.DOUT $>$ which is set high by the operator to reset the problem indication.

- $\quad$ NODMPROB.DOUT > which is a small logic and block with the following input conditions.

- $\quad$ INBAND.QNOT > which indicates the pump is not within the desired position.

- $\quad<$ ABORTOR.QNOT $>$ which is high if no abort condition is active.

- $\quad$ HILIMAND.QNOT > is high if the pump position is not beyond the high range.

- <LOLIMAND.QNOT > is high if the pump position is not beyond the low range.

- $\quad<$ PSTOP.DOUT $>$ is high if the pump motor is stopped.

- $\quad<$ PRUN.QNOT $>$ is high pump motor is not running. 
HNF-SD-WM-CSDD-008

Rev. 3

Page 75

If there is a problem indicated by $\angle D M P R O B>$ and the test values are set and the pump is not in position < PBDMPROB $>$ goes high which is then passed to < PBPROB $>$ through $<$ PBPROB2 $>$. The small logic and block $<$ DMPROBDI $>$ is used to bring up the problem indication display for positioning the pump. When $\angle$ PBDMPROB $>$ is high and the operator set $<$ PDISP $>$ high to view the problem and there is no problem with the position selection from <POSDISP.QNOT $>$, the display DMPROB will be brought up via the display block $<\mathrm{DISP} 3>$.

The small logic and block <DISMOV1 > will execute the macro DISMOV1 to disable movement of the pump. <DISMOV1 $>$ has the following input conditions.

- <DISMOVE.QNOT > is high if movement is enabled.

- $\quad<$ DRUN.QNOT $>$ is high if the position motor is not running.

- $\quad$ DSTOP.DOUT > is high if the position motor is stopped.

The small logic and block <DMDISP $>$ is used to bring up the problem indication display for positioning the pump. When $\angle D M P R O B>$ is high and the operator sets $<$ DDISP $>$ high to view the problem from the MOTOR display the display DMPROB is brought up via the display block $\langle$ DISP 1$\rangle$.

Test Enable. Before test operation can be started a test must be enabled. The enable task is used to check the values set for a test to ensure proper test operation. The blocks in the following table are the variables involved with the test enable function.

$\begin{array}{llll}\text { BPOSGATE } & \text { CHKCOLOR } & \text { DO1-6DEV } & \text { DO1-7DEV } \\ \text { DO1DEV } & \text { DO2DEV } & \text { DO3DEV } & \text { DO4DEV } \\ \text { DO5DEV } & \text { DO6DEV } & \text { DO7DEV } & \text { ENCHECK } \\ \text { NORUN } & \text { PBCHK1 } & \text { PBCHKCLR } & \text { PBENABLE } \\ \text { PBENAND } & \text { PBENOR } & \text { PBENREST } & \text { PBENRSRS } \\ \text { PBENTIMO } & \text { PBENTON } & \text { POSORBUM } & \text { RSCHECK } \\ \text { RSCHECKR } & \text { STOPTEST } & \text { TSTRUNNG } & \end{array}$

The small logic pulse block <CHKCOLOR > starts the execution of the test enable task. Its output is passed to the small logic and block $<$ PBCHKCLR $>$ which works with $<$ PBENAND $>$ to require the following input conditions before a test can be enabled by setting < PBENABLE $>$ high.

- $<$ CHKCOLOR.DOUT > which is set high by the operator to enable a test.

- $\quad<$ NORUN.DOUT > is high if both motors are stopped. 
- $\quad$ TSTRUNNG.QNOT > is high if a test is not running.

- $\quad$ PBBENABLE.QNOT > is high if a test is not enabled.

- $\quad$ POSORBUM.DOUT > is high if the pump is in position.

- $\quad<$ DO1-7DEV.QNOT $>$ is high when all of the following conditions are not active. $<\mathrm{DO} 1-6 \mathrm{DEV}>$ is also used to compile the conditions.

- $\quad$ PBCHK1.DALM $>$ is high when the PLC test time does not match the desired test time.

- $<$ BPOSGATE.DOUT $>$ is high if the pump is not in position.

- $\quad$ DO1DEV.DALM $>$ is high if the pump is not in position.

- $\quad$ DO2DEV.DALM > is high if the desired pump speed does not match the pump speed in the VFD.

- <DO3DEV.DALM > is high if the desired pump acceleration does not match the acceleration set in the VFD.

- <DO4DEV.DALM > is high if the desired pump deceleration does not match the deceleration set in the VFD.

- $\quad$ DO5DEV.DALM $>$ is high if the desired pump maximum speed does not match the VFD feedback.

- <DO6DEV.DALM > is high if the set speed alarm does not match the PLC feedback.

- <DO7DEV.DALM > is high if the pump speed abort limit does not match the PLC feedback.

The test enable bit $<$ PBENABLE $>$ is reset when $<$ PBENOR $>$ has one of the following input conditions are true.

- $\quad<$ STOPTEST.DOUT $>$ goes high when a test is stopped. 
HNF-SD-WM-CSDD-008

Rev. 3

Page 77

- $\quad<$ PBENREST.DOUT $>$ is a 4 second time delay of the small logic and block $<$ PBENTIMO $>$. $<$ PBENTIMO $>$ has the following input conditions.

- $\quad$ PBENTON.DOUT > will go high if a test is enabled and a test is not started within 60 seconds.

- <TSTRUNNG.QNOT > is high if a test is not running.

$<$ ENCHECK $>$ is a status bit used to enable color control on the test operation displays for critical parameters. This bit comes from the $r s$ flip-flop block $<$ RSCHECK $>$ which is set high by $<$ PBCHKCLR $>$ and reset by $<$ RSCHECKR $>$ which will go high when any of the following conditions go high.

- $\quad<$ SETVALDN.DOUT > goes high when the test values are set.

- $\quad<$ STOPTEST.DOUT $>$ goes high when a test is stopped.

Problem with Test Enable. If the test enable function was desired but not successfully completed the blocks in the following table are used to indicate what the problem with the test enable variables is.

$\begin{array}{llll}\text { CHKCLRTN } & \text { DISP3 } & \text { DO1-7DEV } & \text { NOPENAB } \\ \text { NORUN } & \text { PBBUTSTP } & \text { PBENABLE } & \text { PBENADIS } \\ \text { PBENRSRS } & \text { PBPROB } & \text { PDISP } & \text { PENAB } \\ \text { PENABA } & \text { PENABR } & \text { POSORBUM } & \text { RPENAB } \\ \text { TSTRUNNG } & & & \end{array}$

The $r$ flip-flop block $<\mathrm{PENAB}>$ is used to indicate a problem with enabling a test. $<$ PENAB $>$ is set high if the output of $<$ PENABA $>$ is high and the reset input $<$ PENABR $>$ is low. $<$ PENABA $>$ is a small logic and block with the following inputs.

- $\quad$ PBENABLE.QNOT $>$ is high if a test is not enabled.

- $\quad<$ NORUN.DOUT > is high if both motors are stopped.

- $\quad<$ CHKCLRTN.DOUT $>$ will go high 1 second after the operator tries to enable a test. 
HNF-SD-WM-CSDD-008

Rev. 3

Page 78

- $\quad<$ POSORBUM.DOUT $>$ is high if the pump is in position.

$<$ PENABR $>$ will reset $<$ PENAB $>$ if any of the following conditions are true.

- $\quad<$ RPENAB.DOUT $>$ which is set high by the operator to reset the problem indication.

- $\quad<$ PBBUTSTP.DOUT $>$ which goes high when the operator manually stops a test.

- <NOPENAB.DOUT > which is a small logic and block with the following input conditions.

- <DO1-7DEV.QNOT $>$ is high if no problem exists with the feedback parameters.

- $\quad<$ NORUN.DOUT $>$ is high if both motors are stopped.

- $\quad$ TSTRUNNG.QNOT > is high if a test is not running.

- <POSORBUM.DOUT > is high if the pump is at the desired position.

- $\quad<$ PBENRSRS.DOUT $>$ is high if the test enable has timed out.

When $<$ PENAB $>$ goes high, $<$ PBPROB $>$ is set high which indicates a test operation problem. The small logic and block $<$ PBENADIS $>$ is used to bring up the problem indication display for enabling a test. When $\angle \mathrm{PENAB}\rangle$ is high and the operator sets <PDISP > high to view the problem the display, PBENPROB is brought up via the display block $<$ DISP $3>$.

Test Start. After test parameters are downloaded and a test is enabled the operator can start a test which will operate the pump for a desired period of time. The blocks in the following table are related to the test start task.

$\begin{array}{llll}\text { ABORTOR } & \text { NORUN } & \text { PBENABLE } & \text { PBENTON } \\ \text { PBSPLIT } & \text { PBSTRAN2 } & \text { PBSTRAND } & \text { PBSTRTDN } \\ \text { PBSTTEST } & \text { PLCPBENA } & \text { STOPTEST } & \text { TSTRUNNG }\end{array}$

VALSET 
HNF-SD-WM-CSDD-008

Rev. 3

Page 79

The small logic pulse block < PBSTTEST > starts the execution of the test start task. Its output is passed to the small logic and blocks $<$ PBSTRAND $>$ and $<$ PBSTRAN2 $>$ which must have the following input conditions true before starting a test.

- $\quad<$ PLCPBENA.DOUT $>$ which is high if the test enable status bit is high in the PLC.

- $\quad$ <PBSTTEST.DOUT > is set high by the operator to start a test.

- $\quad<$ PBENABLE.DOUT $>$ is high if a test is enabled.

- $\quad$ TSTRUNNG.QNOT > is high if a test is not running.

- $\quad$ VALSET.DOUT > is high if the test values are set.

- $\quad<$ NORUN.DOUT $>$ is high if both motors are stopped.

- $\quad$ ABBORTOR.QNOT > is high if no abort condition is active.

- $\quad$ PBENTON.DO2 $>$ is high when the test enable has not timed out.

- $\quad$ PBSPLIT.DO3 > is high if the elapsed test time is not greater than or equal to the desired time.

The output of $<$ PBSTRAN2 $>$ is passed onto $<$ PBSTRTDN $>$ which starts the pump motor and sets the $r$ slip-flop block <TSTRUNNG > high. <TSTRUNNG> is reset from <STOPTEST $>$ when a test is stopped.

Problem with Starting a Test. If the start of a test is not permitted, the blocks in the following table are used to indicate problems with the start test variables.

$\begin{array}{llll}\text { ABORTOR } & \text { DISP3 } & \text { NOPSPRO2 } & \text { NOPSPROB } \\ \text { NORUN } & \text { PBBUTSTP } & \text { PBENABLE } & \text { PBENTON } \\ \text { PBPROB } & \text { PBSPLIT } & \text { PBSTTEST } & \text { PLCPBENA } \\ \text { PSDISP } & \text { PSPROB } & \text { PSPROBA } & \text { PSPROBR } \\ \text { RPSPROB } & \text { TSTRUNNG } & \text { VALSET } & \end{array}$


The $r$ flip-flop block $<$ PSPROB $>$ is used to indicate a problem with starting a test. $<$ PSPROB $>$ is set high if the output of $<$ PSPROBA $>$ is high and the reset input $<$ PSPROBR $>$ is low. $<$ PSPROBA $>$ is a small logic and block with the following inputs.

- $\quad<$ PBSTTEST.DOUT $>$ is set high by the operator to start a test.

- <TSTRUNNG.QNOT > is high if a test is not running.

- $\quad<$ PBENABLE.DOUT $>$ is high if a test is enabled.

$<$ PSPROBR $>$ will reset $<$ PSPROB $>$ if any of the following conditions are true.

- $\quad<$ RPSPROB.DOUT $>$ which is set high by the operator to reset the problem indication.

- $\quad<$ PBBUTSTP.DOUT $>$ which goes high when the operator manually stops a test.

- $\quad<$ NOPRPRO2.DOUT $>$ which is a small logic and block that works with $<$ NOPSPROB $>$ to compile the following input conditions.

- $\quad$ PBENABLE.DOUT $>$ is high if a test is enabled.

- $\quad$ PLCPBENA.DOUT > is high if the test enable bit in the PLC is high.

- <ABORTOR.QNOT> is high if no abort condition is active.

- <VALSET.DOUT > is high if the test values are set.

- <NORUN.DOUT > is high if both motors are stopped.

- $\quad$ PBENTON.DO2 > is high if the test enable did not time out.

- $\quad$ PBSPLIT.DO3 $>$ is high if the elapsed test time is less than the desired time.

When $<$ PSPROB $>$ goes high $<$ PBPROB $>$ is set high which indicates a test operation problem. The small logic and block $<$ PSDISP $>$ is used to bring up the problem indication display for starting a test. When $\angle$ PSPROB $>$ is high and the operator sets $<$ PDISP $>$ high to view the problem the display PSPROB is brought up via the display block $\langle$ DISP3 $>$. 


\subsubsection{PLC Communications}

The MOTOR strategy has communications directly to the PLC for update and control of registers and bits in the PLC. The following table is a list of tags that are used for communications to the PLC.

\begin{tabular}{|c|c|c|c|}
\hline $\begin{array}{l}\text { PLC } \\
\text { REGISTER }\end{array}$ & TAGNAME & DESC & BLQCK TYPE \\
\hline 242 & ST8WDRES & WATCHDOG BIT & DIGITAL OUTPUT \\
\hline 249 & PBENAB & PHASE B TEST ENABLE TO PLC & DIGITAL OUTPUT \\
\hline 251 & A5ABRT & AF5000 COMM ABORT & DIGITAL OUTPUT \\
\hline $2001-2016$ & $\mathrm{~J} 2 \mathrm{CO}$ & & PAK DIGITAL INPUT \\
\hline 2015 & ZIMPE144 & CCW POSITION LIMIT & DIGITAL INPUT \\
\hline 2016 & ZIMPE143 & CW POSITION LIMIT & DIGTTAL INPUT \\
\hline $2017-2032$ & $\mathrm{~J} 2 \mathrm{C} 1$ & & PAK DIGITAL INPUT \\
\hline 2017 & MIP00001 & MOISTURE IN PUMP MOTOR OIL & DIGITAL INPUT \\
\hline $2033-2048$ & $\mathrm{~J} 2 \mathrm{C} 2$ & & PAK DIGITAL INPUT \\
\hline 2042 & ABORT & PLC ABORT COL SET & DIGITAL INPUT \\
\hline 2043 & PLCPBENA & TEST ENABLE FROM PLC & DIGTTAL INPUT \\
\hline 2044 & PLCWD & WATCH DOG FROM PLC & NOT \\
\hline 2048 & NODEFAIL & STATION5 COMM FAIL & DIGITAL INPUT \\
\hline $40208-40215$ & $\mathrm{I} 2 \mathrm{Cl}$ & & PAK ANALOG OUTPUT \\
\hline 40208 & SWCABRT & PUMP CURRENT ABORT & SWCH \\
\hline 40209 & DISPRABT & DISCH PRESSURE ABORT & ANALOG INPUT \\
\hline 40210 & PBCALSEC & DESIRED HOURS FROM GENESIS & FX \\
\hline 40211 & SWCALRM & PUMP CURRENT ALARM & SWCH \\
\hline 40212 & PBCALSEC & DESIRED SECONDS FROM GENESIS & FX \\
\hline 40213 & SWCSPDAB & PUMP SPEED ABORT SET & SWCH \\
\hline 40214 & SWCSPDAL & PUMP SPEED ALARM SET & SWCH \\
\hline 40215 & VR232020 & PUMP MOTOR VOLTAGE & ANALOG INPUT \\
\hline $40216-40223$ & $12 \mathrm{C} 2$ & & PAK ANALOG OUTPUT \\
\hline 40216 & VR232080 & ROTATION MOTOR VOLTAGE & ANALOG INPUT \\
\hline 40217 & VR232100 & ROTATION MOTOR CURRENT & ANALOG INPUT \\
\hline 40218 & VR232110 & ROTATION MOTOR SPEED & ANALOG INPUT \\
\hline 40219 & VR232040 & PUMP MOTOR CUंRRENT & ANALOG INPUT \\
\hline 40220 & VR232050 & PUMP MOTOR SPEED & ANALOG INPUT \\
\hline 40223 & DISPRALM & DISCH PRESSURE ALARM & ANALOG INPUT \\
\hline $42001-42008$ & $\mathrm{~J} 1 \mathrm{C} 0$ & & PAK ANALOG INPUT \\
\hline 42003 & TIR12A02 & MLX PUMP MOTOR OIL TEMP 2 & ANALOG INPUT \\
\hline 42004 & TIR12A01 & MIX PUMP MOTOR OIL TEMP 1 & ANALOG INPUT \\
\hline $42129-42136$ & $\mathrm{I} 1 \mathrm{CO}$ & & PAK ANALOG INPUT \\
\hline
\end{tabular}


HNF-SD-WM-CSDD-008

Rev. 3

Page 82

$\begin{array}{lll}42131 & \text { POSITION } & \text { POSITION FROM PLC } \\ 42217-42224 & \text { I1C11 } & \\ 42217 & \text { PLCAMPAL } & \text { FROM PLC, AMPS ALARM LIMTT } \\ 42218 & \text { PLCAMPAB } & \text { FROM PLC, AMPS ABORT LIMT } \\ 42219 & \text { PLCDPRAL } & \text { FROM PLC, DISCH PRESS ALARM } \\ 42220 & \text { PLCDPRAB } & \text { FROM PLC, DISCH PRESS ABORT } \\ 42221 & \text { HPSPDLIM } & \text { HIGH SPEED ABORT LIMIT } \\ 42222 & \text { VRO5OHAV } & \text { HIGH SPEED ALARM LIMIT } \\ 42223 & \text { PLCTIADD } & \text { PLC DESIRED HOURS } \\ 42224 & \text { PLCTIADD } & \text { PLC DESIRED SECONDS } \\ 42225-42232 & \text { I1C12 } & \\ 42231 & \text { PLCCURAB } & \text { FROM PLC, PUMP CURRENT ABORT } \\ 42232 & \text { PLCCURAL } & \text { FROM PLC, PUMP CURRENT ALARM }\end{array}$

ANALOG INPUT

PAK ANALOG INPUT ANALOG INPUT ANALOG INPUT ANALOG INPUT ANALOG INPUT ANALOG INPUT ANALOG INPUT ANALOG INPUT ANALOG INPUT PAK ANALOG INPUT ANALOG INPUT ANALOG INPUT

To report a failure in the PLC, the DIN block < PLCFAIL > will alarm in the MOTOR strategy. <PLCFAIL > receives the signal from <PLCFAIL2 > which is a small logic or block that has three input conditions.

- $\quad<$ PLCWDON.DOUT > goes high if the PLC toggle bit <PLCWD stays high for more than 2 seconds.

- $\quad<$ PLCWDOFF.DOUT > goes high if the PLC toggle bit $<$ PLCWD $>$ stays low for more than 2 seconds.

- $\quad$ I1C0.FAIL > which will go high if there is a failure in communications in the ModPlus Genesis driver.

\subsubsection{Alarming}

All algorithm blocks with an alarm priority greater than 0 are enabled as alarming signals. If an alarm level is exceeded the tag and description will show up in the alarm summary to tell the operator which signal is in alarm. Refer to the data dictionary of the MOTOR strategy for all alarm signals with alarm priorities greater than 0 . 


\subsubsection{System Parameters}

There are several Report blocks used to execute $R \& R$ code. Following is a list of Report blocks in the strategy with the R\&R code that each block serves. Refer to Appendix $\mathrm{C}$ for a description of each R\&R code.

\begin{tabular}{||l|l|l|l|l|}
\hline \multicolumn{1}{|c|}{ TAG } & \multicolumn{1}{c|}{ SOURCE1 } & SOURCE2 & SOURCE3 & SOURCE4 \\
\hline \hline TESTSET2 & ULOAD & NEXT & PREV & ILOAD \\
\hline PBREPORT & PBSETVAL & & & \\
\hline TESTSET & SAVE & DELETE & CLRMESS & \\
\hline INITENAB & INTTENAB & & & \\
\hline
\end{tabular}

The $d$ flip-flop block in the center of the database contains the version of the strategy as its tag name. For example, $\langle\mathrm{V} 3.00\rangle$ would be the tag name for version 3.00 of the strategy. The block <VERSION> contains the version number in the descriptive field.

\subsubsection{Stop Test}

The stop test task will stop operation of either motor and reset operator status feedback. The following blocks are used for the stop test task.

ABORTPUL

DISP4

PBBUTSTP

PBDNTM STOPTEST

The operator can manually stop a test by setting <PBBUTSTP $>$ high. The output of $<$ PBBUTSTP $>$ is passed to $<$ STOPTEST $>$ which stops the motors and resets the desired pump operation time with the macro RESPTIM in the display block <DISP4 $>$. $<$ STOPTEST $>$ also resets the operator feedback status bits for test operation. $<$ STOPTEST > also is controlled by <ABORTPUL.DOUT > which goes high if an abort condition becomes active. <PBDNTM.DOUT > goes high if the elapsed pump operation time exceeds the desired time and sets <STOPTEST $>$ high. 


\subsection{MODICON PLC FUNCTIONS}

The Modicon PLC is responsible for inputting data from the field instrumentation, providing an abort signal when the values of critical measurements exceed their abort limits, providing control signals to field instruments, providing a timer and enable logic for pump operation, sending data and status information to Genesis and providing a directional motor simulation. Details of these functions will be presented in the following sections.

Access to and programming of the PLC is provided by the program Modsoft. Modsoft is run on STATION1 in the DACS trailer and communicates with the PLC via the Modbus Plus network.

Using Modsoft, the PLC I/O configuration can be defined, the PLC registers can be allocated and named, and the ladder logic can be produced. All of this can be done offline and later downloaded to the PLC, or can be done online in the PLC as it operates. The latter is not a wise policy for making permanent changes, but can be useful for debugging ladder logic.

Modsoft allows the ladder logic programmer to impose a structure on the ladder logic for ease of understanding. It allows the programmer to break the ladder logic into modules known as objects and to connect the objects using flow control logic. Each object can contain any number of ladder logic networks. This structure is converted by Modsoft to an equivalent flat nonstructured form when the logic is downloaded to the PLC. In addition, the ladder logic can be distributed in different logic segments. The segments provide another way to organize the ladder logic program. The logic in each segment can be set to be solved either on each pass or conditionally. Also, an I/O drop can be associated with a segment; the drop inputs and outputs are processed when the associated segment is active.

The current PLC program has logic in the first four segments. The first segment contains only the hot standby block. This block controls the hot standby functions of the PLCs. The second segment contains most of the operational logic and will be discussed extensively below. The third segment contains the block copy logic for creating the Genesis I/O region. The fourth segment contains the directional motor simulator logic.

Segment two is the only segment in which the logic is divided into objects. It currently has seven objects (P000, P001, and P003 through P007) which execute sequentially (no control structures mediating them). Their functions are listed below:

- P000 (15 Networks) - PLC status logic, test timer and enable logic, instrument control logic.

- P001 (1 Network) - PLC rack and module status logic.

- P003 (64 Networks) - Abort logic and instrument fail logic.

- P004 (10 Networks) - RGA5 ASCII/BASIC module control logic. 
- P005 (13 Networks) - GC3 and FTIR ASCII/BASIC module control logic.

- P006 (5 Networks) - High frequency strain alarm filtering.

- P007 (54 Networks) - Thermocouple module setup and control logic.

Modsoft has a documentation feature which allows information about the PLC configuration and ladder logic to be either saved to a file or printed.

\subsubsection{Data Collection From the Field}

The PLC is responsible for collecting data from the field instruments. These data enter the PLC through any of a number of Modicon I/O modules. There are several different types of modules which accept different types of input. The modules used in the system and their descriptions are listed below. Both input and output modules are listed in this table. The output modules are used for various control functions discussed in Sections 4.3.2 and 4.3.3.

\begin{tabular}{||l|l|l||}
\hline \multicolumn{1}{|c|}{ Modiule } & \multicolumn{1}{|c|}{ Description } & \multicolumn{1}{c|}{ Signals Accepted } \\
\hline \hline B875-101 & 8-channel analog input & Configurable for various voltage or current input ranges \\
\hline B827-024 & 32-channel digital input & 24-V digital input \\
\hline B885-002 & ASCIU/BASIC module & RS-232 serial ASCII data \\
\hline B829-016 & 16-channel digital input & 5-V TTL digital input \\
\hline B883-200 & Thermocouple module & Thermocouple types B, E, J, K, N, R, S, \& T \\
\hline B865-002. & TTL Register input & 5-V digital output \\
\hline B824-016 & 16-chan. digital output & 24-V digital output \\
\hline B828-016 & 16-chan. digital output & 5-V TTL digital output \\
\hline
\end{tabular}

Each of these modules has a physical location and a set of registers through which it communicates to the PLC. This location and the exact registers used for communication are specified in the configuration module of the Modsoft program. For all but the B885 ASCII/BASIC module and the B883 thermocouple module, this is all that needs to be done in order for the PLC to have access to the data from these modules. Both the ASCII/BASIC module and the thermocouple require additional ladder logic to set up and operate the module. The operation of these modules will be discussed in the next two sections.

Most of the measurements from the field enter the system through the B875 analog input module. This module can be set to accept inputs with differing characteristics. Commonly used in this system are 1-5 V, 0-5 V and 4-20 mA signals. These inputs are digitized with 12 bits of resolution. This 12-bit value is stored in the lower order 12 bits of the Modicon register corresponding to that channel. The most significant bit of the same 
register is the out-of-range bit. The B875 module will set this bit if it detects an incoming signal which is out of the range specified when the module is set up. For example, if the module has been set to receive 1 to $5-\mathrm{V}$ inputs and then receives an input of $0 \mathrm{Vs}$, it will set the out-of-range bit. This out-of-range bit is used for instrument failure detection, a topic which is discussed in Section 4.3.5.

\subsubsection{ASCL/BASIC Module Operation}

The Modicon B885 ASCII/BASIC Module allows ASCII data from a computer or from analytical equipment to be read into the Modicon PLC. The ASCII data are presented via one of two RS-232 ports on the front of the module. The module contains a strippeddown BASIC interpreter. BASIC programs can be written that read the ASCII data from the ports and pass it to the PLC via the command interface registers.

The Module has two operational modes: RUN and PROGRAM. These are selected via a switch on the front panel. In PROGRAM mode, the module communication parameters can be set and the BASIC interpreter accessed for programming. In the RUN mode, the module is under the control of the PLC ladder logic via the command/status registers or under control of its own internal scheduler. These are used to determine which BASIC program stored in the module's memory to execute, and when.

Details of the module configuration, programming, and operation are given in the Modicon B885 ASCII/BASIC Module User Guide.

The DACS uses two ASCII/BASIC Modules: one for the RGA5 gas data (RGA5), and one for gas chromatograph, infrared spectrometer and photo gas concentration data (GC3) (see Appendix J for complete file listings). Both of these require a BASIC program to read the ASCII stream, strip off unwanted characters, format the data for the PLC registers, and send this data to the PLC. They also require ladder logic to control and monitor the operation of the BASIC programs, receive the data from the interface registers, and place it in the appropriate final destination registers.

The BASIC programs and ladder logic are therefore quite similar in concept but differ due to the differing data formats and conventions used by the devices. The RGA5 ladder logic is in Segment 2, Object P004 and the gas chromatograph ladder logic is in Segment 2, Object P005.

\subsubsection{ASCII/BASIC Module Communications with the Gas Chromatograph}

The gas monitoring computer sends its data to the ASCII/BASIC module as a stream of ASCII characters beginning with a STX (start of transmission) character and followed by 14 four-digit ASCII encoded numbers separated by carriage returns ( $\omega$ ) (see table below). These communication parameters are: 1200 Baud, 8 bits, 1 stop bit, no parity.

The BASIC program (filename GC3.BAS) in the ASCII/BASIC module is responsible for reading these incoming characters, interpreting them, placing them in 
registers and sending them to the PLC through the module's command/data register interface.

\begin{tabular}{|l|l|c|}
\hline \multicolumn{2}{|c|}{ GC3 Data Format } \\
\hline \multicolumn{1}{|c|}{ Label } & \multicolumn{1}{|c|}{ Description } & Value Transmitted \\
\hline \hline STX & Start of Transmission & 2 \\
\hline GC3-TIME & GC3 Time of Sample & nnnn \\
\hline GC3-AREA & GC3 Peak area & nnnn \\
\hline GC3-RT & GC3 H2 Retention Time & nnnn \\
\hline GC3-H2 & GC3 H2 Concentration & nnnn \\
\hline GC3-FILE & GC3 File ID & nnnn \\
\hline FT-TIME & FTIR Time of Sample & nnnn \\
\hline FT-N2OA & FTIR N2O Area & nnnn \\
\hline FT-N2OC & FTIR N2O Concentration & nnnn \\
\hline FT-NH3A & FTIR NH3 Area & nnnn \\
\hline FT-NH3C & FTIR NH3 Concentration & nnnn \\
\hline FT-FILE & FTIR File ID & nnnn \\
\hline PHO-TIME & Photo NH3 Time of Sample & nnnn \\
\hline PHO-MSB & Photo NH3 Conc. - most significant byte & nnnn \\
\hline PHO-LSB & Photo NH3 Conc. - least significant byte & nnnn \\
\hline
\end{tabular}

nnnn $\omega=$ four ASCII numeric characters followed by a carriage return.

The PLC ladder logic is responsible for running the BASIC program, issuing commands to read the status of the module, and to read data from the module and placing the data into the proper registers so it can be sent to Genesis.

Communication between the PLC and the BASIC module is through the 6 input and 6 output interface registers assigned to the module during configuration. In addition, there is an array of 100 registers internal to the BASIC module which can be accessed by the PLC (up to 5 at a time) through these interface registers. There are also eight status bits which can be set or reset directly by the BASIC program and read by the PLC along with the hardware status bits.

In general, the normal sequence of operation of the system is as follows (for more specifics, see the ladder logic comments, the BASIC program listing and the ASCII/BASIC module manual): 
HNF-SD-WM-CSDD-008

Rev. 3

Page 88

\section{PLC Operation}

1. The ladder logic checks the ASCII/BASIC module status register. If there is an error condition, it resets the module. If the BASIC program is not running, it issues the command to run the BASIC program.

2. The ladder logic continues to monitor the status register for error conditions and checks the data ready user flag (GC3_SND8). This is the signal from the BASIC program that a set of data has been read and is ready to be transferred to the PLC.

3. When the data ready flag has been received, the ladder logic goes through a sequence of commands which transfer the data from the ASCII/BASIC module's internal register array. The data are transferred one to four registers at a time and stored in registers in the PLC for transference to Genesis. The 14 data items to be transferred are stored in the ASCII/BASIC module's internal registers 0-13. The PLC ladder logic issues 7 commands in sequence to transfer these 14 data items.

4. The ladder logic sets the ASCII/BASIC module's internal register 30 to 1 (data transfer complete flag). This is the signal to the BASIC program that the data transference is complete.

5. Go to step 1 .

\section{BASIC Program Operation}

1. The program is initialized by the PLC ladder logic. It immediately sets the data ready flag to zero (although it should already be zero) and the data transfer complete register (register 30) to zero.

2. The program reads characters from serial port I until a STX character is received. The start of transmission character signals the beginning of the gas data stream.

3. After the STX is received, the program reads 14 numeric values and stores them in internal registers 0 through 13 .

4. The program sets the data ready flag [SND(8)], indicating to the PLC that there is a set of data in the registers to be transferred.

5. The program waits until the data transfer complete flag is set (Register 30). This will indicate that the PLC has transferred the data. 
HNF-SD-WM-CSDD-008

Rev. 3

Page 89

6. The program clears the data ready flag, then exits. When the PLC detects that the program has exited, it will rerun the program.

\subsubsection{ASCII/BASIC Module Communications with the RGA5 Computer}

Following is the data format for the RGA5 ASCII/BASIC module communication:

Run=nnn, Stream =cccccccC, Date $=\mathrm{nn}-\mathrm{nn}-\mathrm{nn}, \mathrm{Time}=\mathrm{nn}: \mathrm{nn}$
$\mathrm{H} 2 \mathrm{~A}=\mathrm{nnnn} . \mathrm{n}, \mathrm{H} 2 \mathrm{~A}$ Area=nnnnnnnnn, H2ART=nnn, H2Arf=nnnnn.n
$\mathrm{H} 2 \mathrm{~B}=\mathrm{nnnn} . \mathrm{n}, \mathrm{H} 2 \mathrm{~B}$ Area=nnnnnnnnn, H2BRT=nnn, H2Brf=nnnnn.n

where, $\mathrm{n}=$ any numeric character and $\mathrm{c}=$ any printable ASCII character. Run is the run number and is incremented by one with each data stream. Stream is set to Tank, Flush or Calib to indicate the source of the data. The BASIC program only looks at the first character of this field. Date is the sample date. This is ignored by the BASIC program. Time is the time of sample in the format hours:minutes. $H 2 A$ is the GC-1 hydrogen concentration in ppm. H2A Area is the GC-1 hydrogen peak area. H2ART is the GC-1 hydrogen retention time in seconds. $H 2 A$ if is the GC-1 hydrogen retention factor. This is ignored by the BASIC program. $H 2 B$ refers to the same information as above except it pertains to GC-2 instead of GC-1. The numeric data will be right justified with leading zeros inserted to preserve the field widths.

The communications parameters are: 1200 baud, 8 bits, no parity, 1 stop bit. The stream must enter the ASCII module via port B. The XON/XOFF protocol should be enabled.

The BASIC program operates by searching the ASCII stream for the word "Run", indicating the start of the data. It then issues reads to the ASCII message processor to input the data. After the data has been input, the program places the data into contiguous registers to be read by the PLC. In some cases a datum is placed unchanged into a register. In other cases, the data is scaled or manipulated in some way in order to make it fit into a 16 bit register. The PLC is then notified that data is available. When it has read the data, it notifies the BASIC program that the data has been read. The program then exits and is run anew by the PLC.

The issuing of ASCII read messages by the program means that these message formats must be loaded into the memory of the ASCII portion of the ASCII/BASIC module. The following are the ASCII read message formats:

$\begin{array}{lll}\text { RMSG1 : } & 10 & \mathrm{~S} 0, \mathrm{D} 3 \\ \text { RMSG2 : } & 10 & \mathrm{~S} 1, \mathrm{~A} 1 \\ \text { RMSG3 : } & 10 & \mathrm{~S} 2 \\ \text { RMSG4 : } & 10 & \mathrm{~S} 2, \mathrm{D} 2, \mathrm{D} 2\end{array}$


HNF-SD-WM-CSDD-008

Rev, 3

Page 90

$\begin{array}{lll}\text { RMSG5: } & 10 & \text { S4,F6.1 } \\ \text { RMSG6: } & 10 & \text { S6, D1, D4, D4 } \\ \text { RMSG7: } & 10 & \text { S9,D3 } \\ \text { RMSG8: } & 10 & \text { S10 } \\ \text { RMSG9: } & 10 & \text { S10, F6.1 } \\ \text { RMSG10: } & 10 & \text { S12, D1, D4, D4 } \\ \text { RMSG11: } & 10 & \text { S15, D3 } \\ \text { RMSG12: } & 10 & \text { S16 }\end{array}$

In addition, the program uses the prefix capability of the ASCII module to determine the beginning point of the ASCII reads. The prefix instructs the ASCII message processor to ignore all incoming characters until the prefix string is read, then begin the formatted read.

In this case, the prefix string of the module must be set to "=." The command to be issued is: PR\# 3Dh. Also, the delimiter character should be set to null: DL\# 0.

The program must be loaded into RAM 2 of the ASCII/BASIC module.

\subsubsection{Thermocouple Module Operation}

The B883 thermocouple modules receive thermocouple inputs from the MIT17B and MIT17C tank temperatures, and the tank bottom and side thermocouples. Three groups of modules are used: three modules to input the MIT17B tank temperatures (22 measurements), three modules to input the MIT17C tank temperatures (22 measurements), and three to input the tank bottom and side temperatures ( 26 measurements). These modules require ladder logic to set up and operate the modules.

The ladder logic can be broken into three major sections: (1) creation of the setup table and command table, (2) configuring the module, and (3) operating the module. The configuration of the three modules of each group is the same so only two setup tables are needed. The following is an overview of the ladder logic needed to operate one of the modules.

Figure 14 shows a portion of the ladder logic used to create the thermocouple module setup table. Since no predefined constants are available in ladder logic, the contents of the configuration table must be created from scratch when the PLC is first brought online. The SUB blocks are used to load the values in the top node of the SUB blocks into the registers indicated in the bottom node of the SUB blocks. These registers form the setup table. They are grouped in threes, since these represent command parameters which will later be sent to the thermocouple modules. In the figure the $\# 0301-\# 0000-\# 0000$ sequence is the thermocouple module STOP command, and the $\# 0290-\# 0000-\# 0000$ sequence is the thermocouple module ENTER CONFIGURATION MODE command. A complete list of the available commands can be found in the thermocouple module manual. 


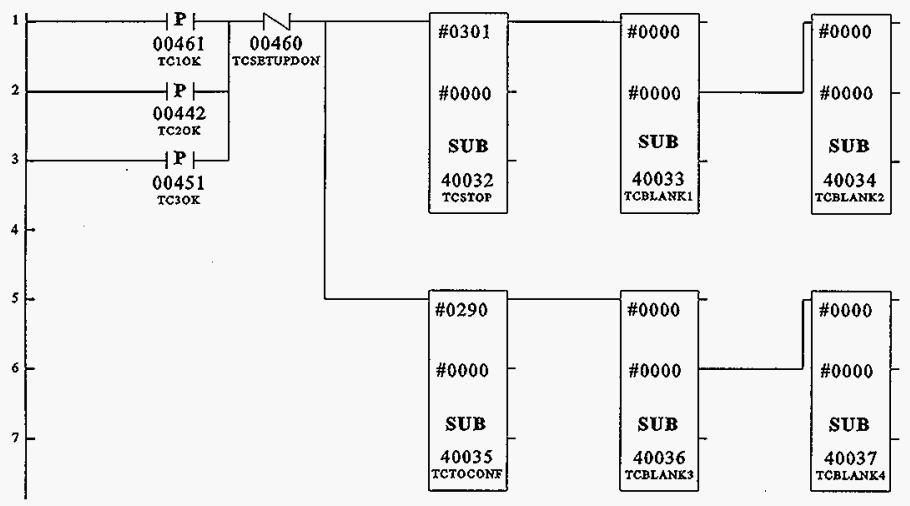

Fig. 14. Ladder logic for thermocouple setup table creation.

The setup table, when complete, contains a set of commands which will be issued sequentially to each module in the group during configuration mode. These commands will configure the module, giving it the thermocouple type to expect upon input and the data format in which to report the channel values. Each channel must be configured separately so, although in our case all of the, channels are configured the same, we must still set the configuration parameters for each channel.

Figure 15 shows a portion of the ladder logic for command table creation. The command table is a list of commands which will be issued to the module one after another when the system is in operational mode. In our case, the command table consists of 10 read channel value commands, one for each of the ten channels available on a single module. In this case, $A D D$ blocks are used to set the channel parameters. The 984A PLCs do not allow constants larger than 999 in a block, so, for example, the "read channel one value" command, 1001, is created by adding 2 to 999 . 


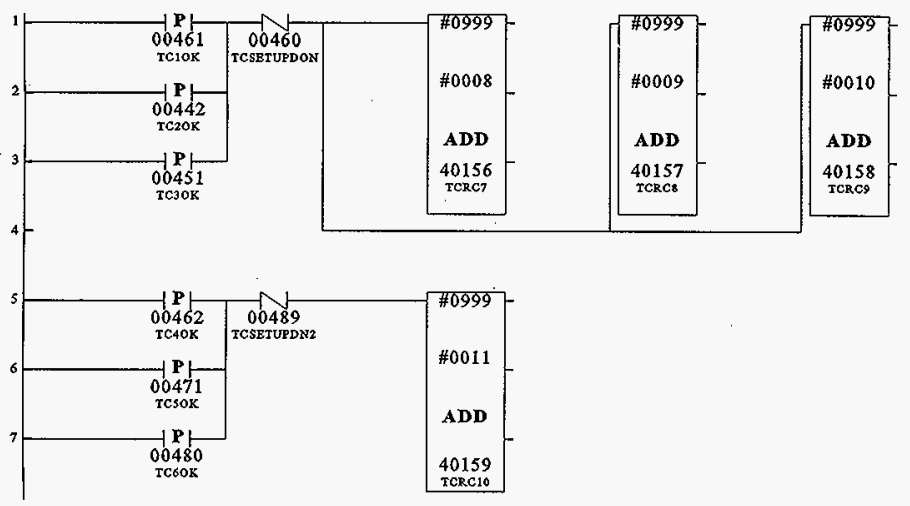

Fig. 15. Ladder logic for thermocouple command table creation.

After these two tables have been created, the modules must then be configured according to the commands now in the setup table. Figure 16 shows the logic which issues these configuration commands. Register 40173 is the setup table pointer. This logic will load the three register command sequences into the command registers, 40091-40093, incrementing the setup table pointer each time. This is done until the end of the setup table is reached and coil 435 is set, indicating that configuration is done. The next set of commands is issued when coil 434 goes high indicating that the previous command has been accepted by the module. The setup sequence can also be initiated when a module first comes online (coil 461 goes high) or after an error has occurred (coil 437 goes high).

After the configuration is complete, the thermocouple modules enter operation mode. In this mode, the commands in the command table are executed. When the end of the table is reached, the system resets the command table pointer to the beginning of the table and goes through the table again. The command table consists of commands to read each of the 10 thermocouple data values one after the other.

In Figure 17, register 40150 is the beginning of the command table. Register 40171 is the index into the command table, and register 40172 is the register which receives the value pointed to by the combination of 40150 plus the offset in 40171 . This value is loaded into the thermocouple module command interface register, 40091, thereby issuing the command. 


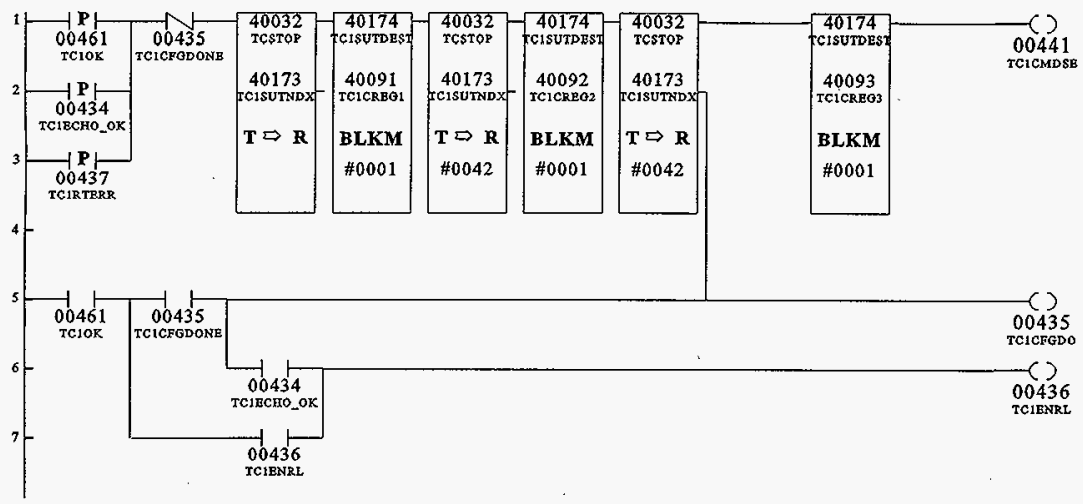

Fig. 16. Ladder logic for configuring thermocouple modules.

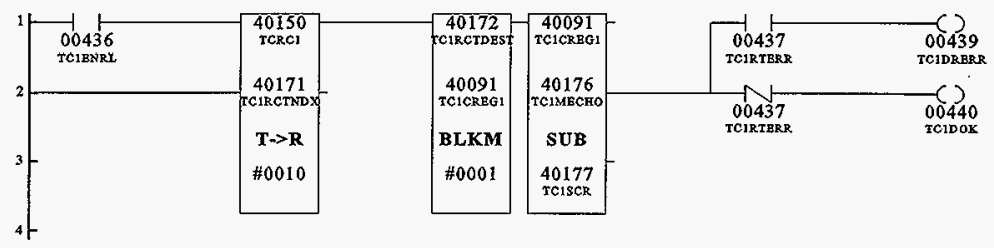

Fig. 17. Thermocouple operation: extraction of commands from command table.

Figure 18 shows the ladder logic for reading the data values from the module after the read channel value command has been issued and successfully echoed. Register 40160 is the index to a table called the data value table. This table is where the thermocouple temperature values are stored after they are read. Register 30277 is the interface register which contains the data value from the module. This is placed in the position in the table given by register 40160 . This register is automatically incremented. The $A D D$ block increments the command table index so that the next command can be issued. If the end of the table has been reached, the $S U B$ blocks are activated. These blocks reset the value table index and the command table index to the beginnings of their respective tables so the process can repeat. 


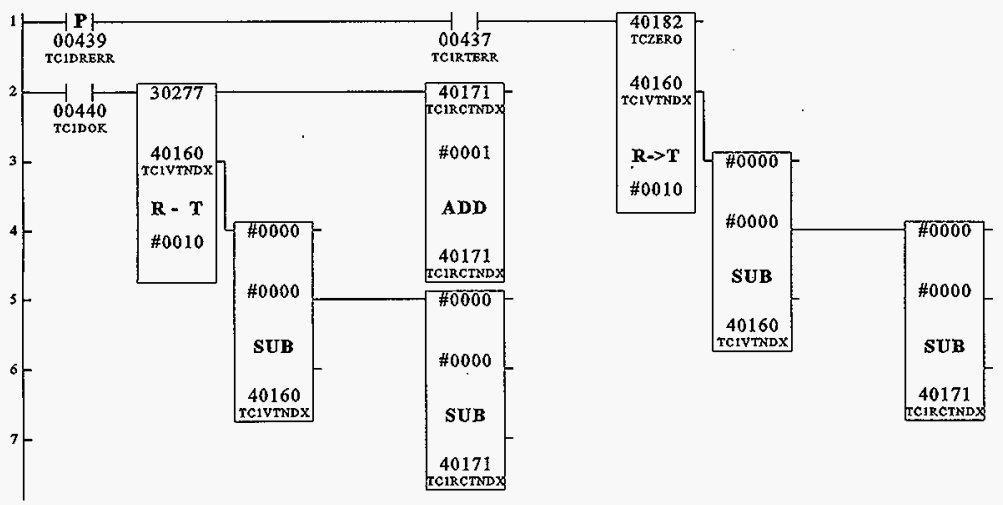

Fig. 18. The thermocouple modules reading thermocouple data values.

The upper pathway is activated when there is an error (coil 437, runtime error, is high). This places a zero into the data value table and resets the data value pointer and the command table pointer.

\subsubsection{Abort Functions}

One of the primary monitoring functions of the Modicon 984 PLC in the DACS system is to check for over- or under-range conditions on various safety parameters. These parameters are sensed by the 984 series I/O at drops or I/O stations distributed around tank 241-SY-101 at surface level, and then transferred to the 984 PLC crate inside the DACS trailer. Once received by the PLC, these critical values are stored in 30xxx registers. These are two-byte registers that function as repositories for incoming data. Current values of the important parameters are now loaded in the PLC, and are ready for comparison with limit values. This comparison takes place in the ladder logic in the PLC and is of the form below in Figure 19. Register A is the current value register.

Register $B$ is the $40 x x x$ register containing the limit to be compared with the current value. Register $\mathrm{C}$ is the $40 \mathrm{xxx}$ register containing the difference between the values in $\mathrm{A}$ and $\mathrm{B}$. The subtract block actually has three outputs available for user logic. The top output is

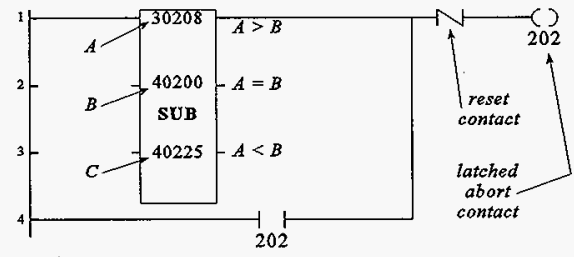

Fig. 19. Abort limit testing. 
activated if A is greater than B. This is the case in which the limit abort logic is mainly interested. With this line high and the reset contact sense in the nonreset condition, the latched abort contact 202 is closed. When it closes, the contact sense in the bottom leg holds or latches the contact closed. Nothing can interrupt power to contact 202 except if the reset contact should close. The reset contact in the above diagram is a "not" of the true reset contact. This means that if the reset contact is open, the ladder element conducts power (is closed).

Values for the abort and alarm limits stored in the 4xxxx registers are written from the TEST strategy in STATION5 to the PLC.

In the PLC, there exists ladder logic similar to the above for every limit abort parameter; however, the latched abort contact is distinct for each parameter. The reset contact is common to all the logic. Figure 20 shows how the many abort contacts are OR'ed together to set a single abort contact. Here the reset contact is identical to that in the previous diagram and all other limit abort logic. The composite abort contact is held closed by the latching leg containing the sense of contact 021 . It can only be reset by making the reset contact close. This is done from Genesis. Notice below that the abort contact 202 from the logic above is represented as only one of many such contacts combined to set the composite abort contact.

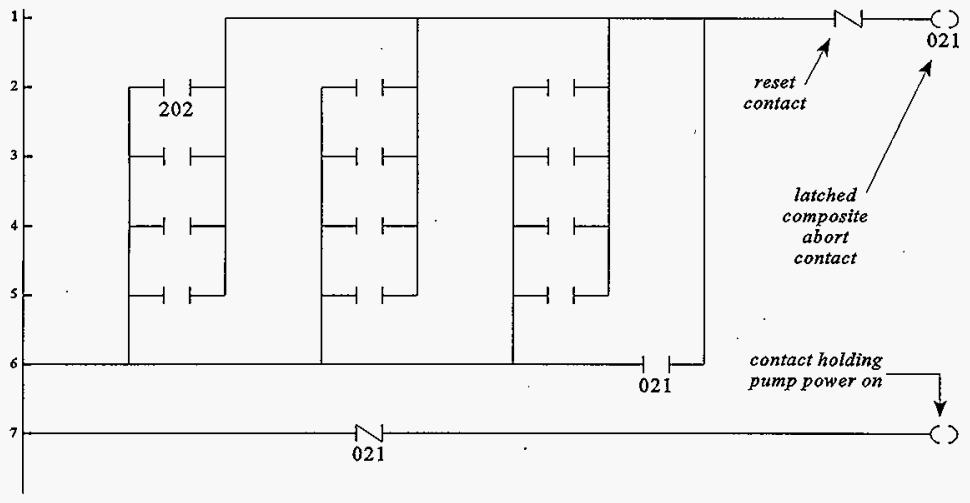

Fig. 20. Composite abort contact.

When the latched composite abort contact closes, there is a contact shown in the bottom right-hand corner of the logic above that is opened upon an abort. This power contact is directly connected to a digital output Modicon module that normally holds the 
power breaker to the pump and directional motors closed. When this contact is opened, the power to the motors is interrupted.

When any of the latched abort contacts closes, a display in STATION5 called CSMAIN shows the class of the abort along with the alarm limit value, the abort limit value, and a button to another screen with more detail on the abort.

The class of the abort will be one of the following:

High $\mathrm{H} 2$ Concentration

High Pump Flow

High Duration Limit

High Pump Discharge Pressure

High Pump Motor Oil Temperature

High Pump Column Strain

Low Pump Column Gas Pressure

VDTT Column Strain
High Waste Tank Level

High Pump Speed

High Waste Temperature

High Pump Motor Current

High Pump Motor Oil Moisture

High Pump Column Vibration

MIT Column Strain

Low Ventilation Flow

High Tank Dome Pressure

There is also an indicator of the status of the PLC abort coil and a reset button for it. The text on this screen signifying the class of the abort becomes red if a tag in its class has caused an abort. If the operator presses the button next to a class, another more detailed screen is called up. On this next level of display tag names, tag descriptions, alarm and abort limit values, tag current values, and units are listed. In addition, there is an indicator that other alarms or abort conditions exist as well as an indicator for the PLC abort contact.

As a safety factor, the composite abort contact is read by the Genesis strategy in STATION8. The tag name of the particular block holding this state is <LIMABORT>. When the MOTOR strategy in STATION8 detects a problem, a report executes that issues stop commands to both the pump motor drive and the directional motor drive.

\subsubsection{Control Points and Alarm Outputs}

The PLC provides a few control and alarm signals other than the pump motor shutoff signal. They are: a signal which triggers the Nicolet data collection system and a signal which causes an audible alarm to sound when communications from either Genesis STATION5 or STATION8 stops. 
The Nicolet trigger signal is set whenever any of the following occur: (1) there is a high-frequency strain alarm condition, (2) there is a low frequency strain alarm condition, or (3) the pump motor is running. The Nicolet system captures high-speed strain data. This allows the system to be triggered during a tank rollover.

Figure 21 shows the Genesis to PLC watchdog timer ladder logic. Genesis sends an alternating digital signal which comes into on PLC coil 213 . This signal alternately resets one of the two timers while allowing the other to run. If communication from Genesis ceases, one of the two timers will be stuck in the run state and will eventually time out, setting coil 20. This coil is wired to an audible alarm circuit, which produces an alarm when the coil is set.

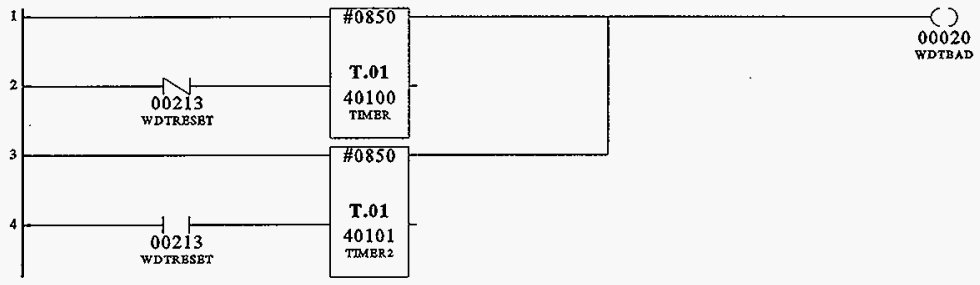

Fig. 21. Genesis to PLC watchdog timer.

\subsubsection{Test Timers and Enable Logic}

The PLC contains ladder logic which implements a test enable mechanism and timer for timing pump tests. Figure 22 shows this logic.

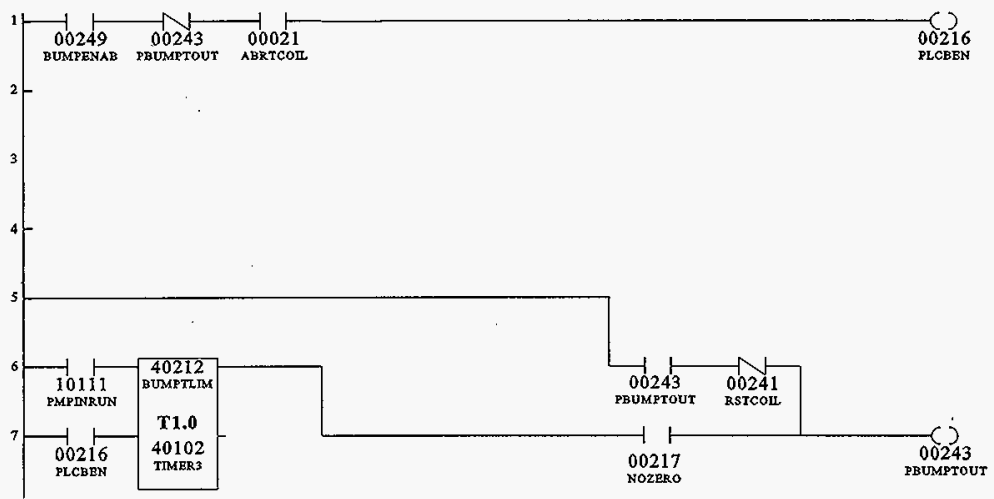

Fig. 22. Test enable and timer logic for pump bump. 
HNF-SD-WM-CSDD-008

Rev. 3

Page 98

The pathway in the upper part of the figure is the test timer enable mechanism. The test enable signal originates from STATION8. The operator presses the test enable button on one of the pump run screens. The enable signal is passed from the MOTOR strategy to the PLC where it becomes coil 249. This enable signal starts the test timer as long as there is no abort current in the PLC logic (indicated by coil 21). The enable signal must remain set continuously in STATION8 for the duration of the run. Coil 243 causes the timer to reset when the test time has elapsed regardless of the state of the enable from STATION8. This coil is also incorporated into the pump abort logic, causing the pump to shut off when the allowed test time has elapsed.

The timer block is set to time the duration of a pump run and will shut off the pump if the elapsed time exceeds the allowed time. The allowed time is loaded into register 40212 by the Motor strategy. The elapsed time is in register 40102 . The timer will run only if the test has been enabled (coil 216 is high) and the pump is running (input 10111 is high). If the allowed time elapses the output of the timer will go high. This sets coil 243 high provided that coil 217 is high. Coil 217 is set only if the timer count and elapsed time are both nonzero. This prevents the timer from causing an abort condition before the test has begun.

\subsubsection{Data Transfer and Status Information}

Most data to be transferred from the PLC to Genesis is organized into contiguous blocks before transfer. This increases the efficiency of the data transfer. This is accomplished in segment 3 of the ladder logic by using block moves.

Other than the ASCII/BASIC module data and the thermocouple data discussed in Sections 4.3.1.1 and 4.3.1.2, there is one other case in which additional PLC processing is needed to prepare data for Genesis. This is required to slow down the possibly momentary high-frequency strain alarms so that Genesis can have enough time to detect them before they disappear.

Figure 23 shows the PLC ladder logic used to extend the duration of the highfrequency strain alarms. An alarm can appear as a high on any of the input register 10193, 10195,10197 , etc. When a positive-going pulse is detected on any of these channels, and if an extended alarm is not already present for that channel, coil 167 is set. This coil indicates that a new alarm has arrived.

In addition, one of the coils $209-215$ is set and latched. The coil set is the one corresponding to the alarm received. These are the coils which are sent to Genesis to become the high-frequency strain alarms. The incoming signal on the $10 \mathrm{xxx}$ register could have been just a momentary signal that disappeared before the alarm was transferred to Genesis. The latching mechanism ensures that the alarm will remain long enough to be sent to Genesis.

To reset the latches, a timer block is provided. This timer will begin to run if an alarm is received and will time out after 2 seconds causing any latched alarms to be reset. If a second alarm is received before the timer has timed out, the timer count will be reset and the timer will continue to run. This ensures that all latched alarms will remain latched for at least 2 seconds. 
HNF-SD-WM-CSDD-008

Rev. 3

Page 99
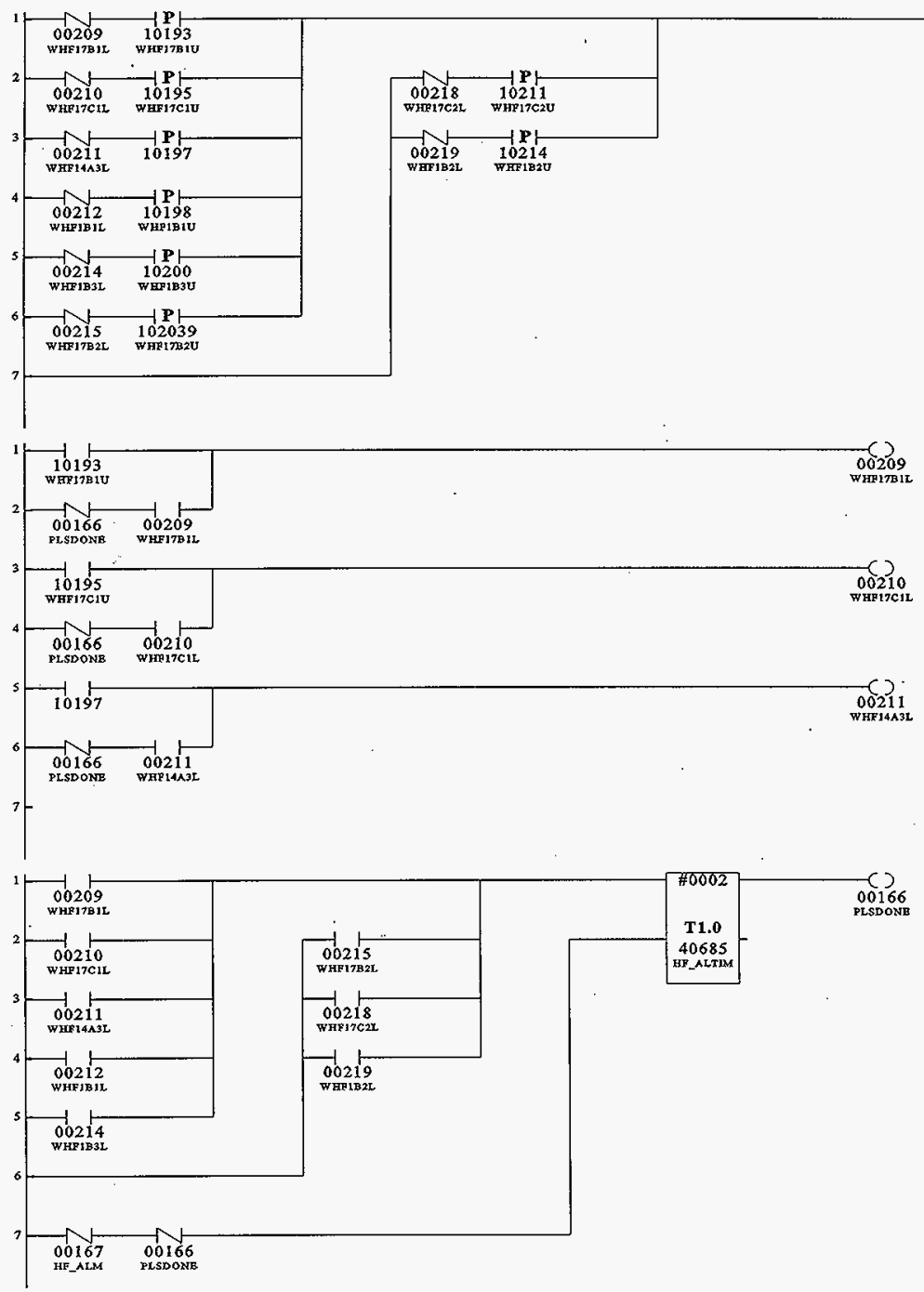

Fig. 23. High-frequency strain alarm monitoring logic. 
The PLC also provides status information to Genesis. It provides a signal which monitors the PLC and the hot standby PLC. This signal is 1 if both PLCs are okay, and 0 if either of them is offline. This information comes from extracting information from the PLC status table which begins at register 40301. Refer to the Modsoft PLC manual "Modicon 984 Programmable Controller Systems Manual" for the details of the status table.

The PLC also provides information to Genesis about the health status of I/O modules in the system. The following four conditions must be met for a module to indicate good health:

- The slot has been configured in the Traffic Cop.

- The slot contains a module with the correct personality.

- Valid communications exist between the module and the $\mathbf{J} 890$.

- Valid communications exist between the $\mathrm{J} 890$ and the 984 PLC.

Module health is stored in registers in the Modicon PLC. Different PLCs use different registers. To standardize access to this information, a STAT block is added to the ladder logic. During runtime, the status information is moved to registers defined by the STAT block.

None of the drops are full of modules. Thus, not all of the status registers are of use. A STAT block register contains the $\mathrm{I} / \mathrm{O}$ health of one crate (alternately referred to as a rack) of modules on a drop. All told, 13 racks are currently in use.

To minimize the communication load, the status registers that correspond to existing racks are copied into a set of transmit registers. It is the transmit registers that Genesis views.

The movement of the STAT registers to the transmit registers is accomplished by using BLKMs (block moves). The order of the STAT registers is by drop (1 through 32) and by rack ( 1 through 5 ) within each drop. Only in cases where two crates have been used within a given drop are the registers contiguous and thus can be handled by a single block move, as shown in Figure 24.

To streamline communication, the Genesis TEST strategy gathers the transmit registers in as packed data. The 13 registers fit within 13 packed digital inputs (PDIN) fanned out from DEV 4, GC11 (group 11). The names of the PDIN blocks reflect the drop and crate numbers of the involved modules. The drop number is prefaced by $\mathrm{D}$, the crate number is prefaced by an $\mathrm{R}$ (for Rack). Thus, the PDIN block for drop 2 crate 1 modules is named D2R1. 
HNF-SD-WM-CSDD-008

Rev. 3

Page 101

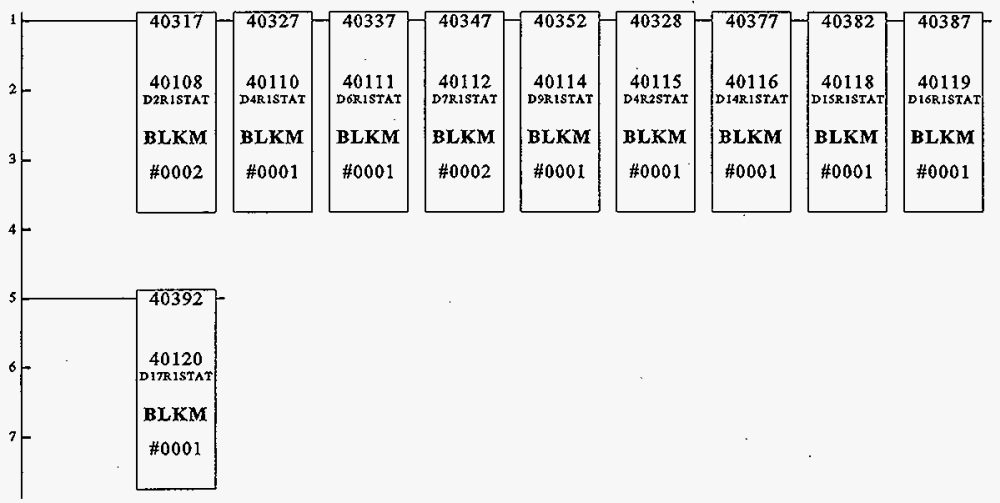

Fig. 24. Block moves for transmitting I/O health status.

Each PDIN block contains 16 bits. Each block represents modules $1-11$ in a given crate (plus 5 unused bits). Because Modicon defines its bits opposite of Genesis, this corresponds to bits 16 through 6 in Genesis. (The data also require byte swapping, which is provided in DEV 4.) Note that alarms for PDIN blocks are reported by bit number.

Display of the I/O health is available on the graphic IOSTATUS. Each point in the matrix is tied to the PDIN block bit corresponding to the module's health. Thus, the matrix point for drop 2 crate 1 slot (or module) 4 is tied to D2Rl.DO13.

Good health is indicated by a green OK; bad health is indicated by a red BAD. On startup of Genesis, the graphic will show all the modules in bad health until one scan of transmit registers has been made. The scan rate of the transmit registers is 30 seconds.

A complete table of these PLC I/O status registers is given in the "I/O Health Status Implementation Table" in Appendix A.

\subsubsection{Directional Motor Simulator}

Segment four of the PLC program contains the directional motor simulator logic. This logic simulates the rotation of pump in the lab environment. This logic receives the directional motor acceleration setting, the directional motor speed setpoint and whether or not the motor is in forward or reverse from the Motor strategy. It then increments or decrements the value of ZIMPE112, the position indication. 
The simulator is enabled by setting coil 171 to 0 using Modsoft. It also requires the real position encoder (ZIMPE112) be at 0. If there is a non-zero reading for ZIMPE112, then the simulation is disabled and the real value is passed to Genesis.

The simulation logic calculates the number of seconds required to move the directional motor 1 degree. This calculation is based upon the directional motor simulated speed (RPM). The value is calculated using a value of 13.09 degrees for each revolution of the pump motor.

\subsection{NETWORK LAYOUT}

The GEN-NET network is composed of eight GEN-NET network stations with ARCNET in a star configuration, as illustrated in Figure 25.

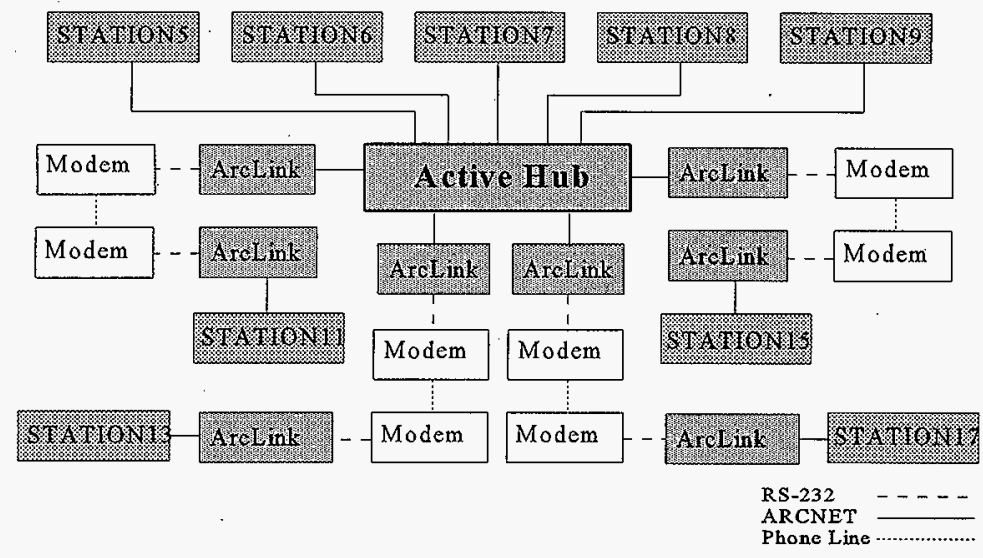

Fig. 25. GEN-NET network configuration

The Genesis system allows peer-to-peer communications between Genesis applications. STATION5 serves data to all other stations on the GEN-NET. STATION6, STATION7, STATION11, STATION13, STATION15 and STATION17 all link directly to STATION5 and share the database TEST strategy running on STATION5. These stations accomplish this by running Remote Supervisory Software with the TEST strategy on each station. 
HNF-SD-WM-CSDD-008

Rev. 3

Page 103

STATION5 uses GEN-NET software to enable networking to a Runtime master station. STATION8 is connected to the network for offline file transfer but is not connected when the motor Standby is running.

STATION7 normally serves as a Remote Supervisory Station but is also used as a backup for STATION5 or STATION8. In this instance STATION7 serves as a Runtime master station.

STATION9 acts as a file server on the network to store data files. STATION9 is also connected to the HLAN and is connected to a file server using Novell software.

Figure 26 shows the current network data flow.

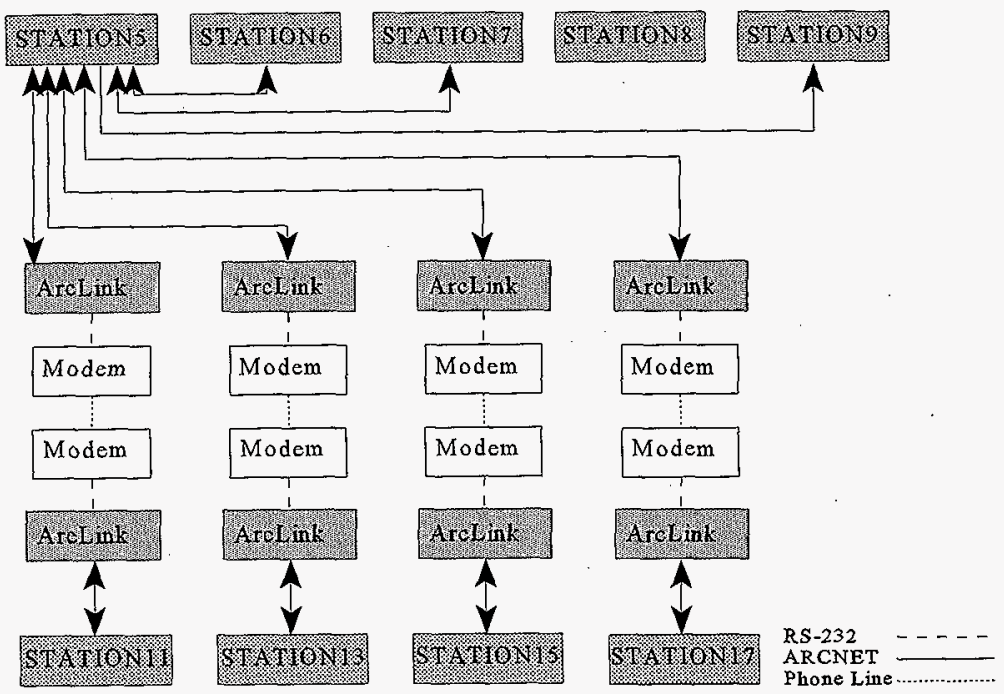

Fig. 26. Network data flow.

Each station is addressed on the GEN-NET by the network card address on the ARCNET. A station name is linked to a physical address in the GEN-NET software. Refer to Appendix $\mathrm{G}$ for details on the network layout. 


\section{Appendix A: PLC I/O Status Registers}

The Modicon $1 / 0$ health status alarms Genesis when a module is no longer in good health. In Section 4.3.5, the facility for Genesis determining the health of the I/O modules in the system was discussed. This included the conditions for good health, the STAT blocks used in the ladder logic to define the module health registers that are transmitted to Genesis, and the PDIN blocks in the Genesis strategy that receive them.

The following is a complete list of the PLC registers and their corresponding. Genesis strategy variable names.

\begin{tabular}{|c|c|c|c|c|c|c|}
\hline \multicolumn{7}{|c|}{ Table B-I. I/O Health Status Implementation Table } \\
\hline Drop & Rack & Slot & $\begin{array}{r}\text { STAT } \\
\text { block } \\
\text { Register }\end{array}$ & $\begin{array}{l}\text { Transmit } \\
\text { Register }\end{array}$ & PDIN NAME & Output \\
\hline \multirow[t]{4}{*}{$\overline{2}$} & $\overline{1}$ & & 40317 & $40 \overline{108}$ & $\overline{\mathrm{H}} \overline{\mathrm{CO} 0}$ & \\
\hline & & 4 & & & & Do13 \\
\hline & & 5 & & - & & D012 \\
\hline & & 6 & & & & Do11 \\
\hline \multirow[t]{3}{*}{2} & 2 & & 40318 & 40109 & $\mathrm{H} 3 \mathrm{C} 1$ & \\
\hline & & 3 & & & & DO14 \\
\hline & & 4 & & & & DO13 \\
\hline \multirow[t]{5}{*}{4} & 1 & & 40327 & 40110 & $\mathrm{H} 3 \mathrm{C} 2$ & \\
\hline & & 4 & & & & D013 \\
\hline & & 5 & & & & D012 \\
\hline & & 6 & & & & DO11 \\
\hline & & 7 & & & & Do10 \\
\hline \multirow[t]{6}{*}{4} & 2 & & 40328 & 40115 & $\mathrm{H} 3 \mathrm{C} 3$ & \\
\hline & & 3 & & & & D014 \\
\hline & & 4 & & & & D013 \\
\hline & & 5 & & & & D012 \\
\hline & & 6 & & & & D011 \\
\hline & & 7 & & & & Do10 \\
\hline \multirow[t]{5}{*}{6} & 1 & & 40337 & 40111 & $\mathrm{H} 3 \mathrm{C} 3$ & \\
\hline & & 4 & & & & D013 \\
\hline & & 5 & & & & DO12 \\
\hline & & 6 & & & & D011 \\
\hline & & 7 & & & & Do10 \\
\hline
\end{tabular}


HNF-SD-WM-CSDD-008

Rev. 3

Page 105

\begin{tabular}{|c|c|c|c|c|c|c|}
\hline \multirow[t]{5}{*}{8} & 1 & & 40347 & 40112 & $\mathrm{H} 4 \mathrm{CO}$ & \\
\hline & & 4 & & & & Do13 \\
\hline & & 5 & & & & DO12 \\
\hline & & 6 & & & & DO11 \\
\hline & & 7 & & & & Do10 \\
\hline \multirow[t]{4}{*}{8} & 2 & & 40348 & 40113 & $\mathrm{H} 4 \mathrm{C} 1$ & \\
\hline & & 3 & & & & DO14 \\
\hline & & 4 & & & & DO13 \\
\hline & & 5 & & & & DO12 \\
\hline \multirow[t]{5}{*}{9} & 1 & & 40352 & 40114 & $\mathrm{H} 4 \mathrm{C} 2$ & \\
\hline & & 4 & & & . & DO13 \\
\hline & & 5 & & & & DO12 \\
\hline & & 6 & & & & D011 \\
\hline & & 7 & & & & DO10 \\
\hline \multirow[t]{6}{*}{13} & 1 & & 40372 & 40120 & $\mathrm{H} 6 \mathrm{CO}$ & \\
\hline & & 4 & & & & D013 \\
\hline & & 5 & & & & DO12 \\
\hline & & 6 & & & & DO11 \\
\hline & . & 7 & & & & DO10 \\
\hline & & 8 & & & & DO9 \\
\hline \multirow[t]{4}{*}{14} & 1 & & 40377 & 40116 & $\mathrm{H} 5 \mathrm{CO}$ & \\
\hline & & 4 & & & & DO13 \\
\hline & & 5 & & & & Do12 \\
\hline & & 6 & & & & DO11 \\
\hline \multirow[t]{6}{*}{14} & 2 & & 40378 & 40117 & $\mathrm{H} 5 \mathrm{C} 1$ & \\
\hline & & 3 & & & & DO14 \\
\hline & & 4 & & & & DO13 \\
\hline & & 5 & & & & DO12 \\
\hline & & 6 & & & & DO11 \\
\hline & & 7 & & & & Do10 \\
\hline \multirow[t]{5}{*}{15} & 1 & & 40382 & 40118 & H5C 2 & \\
\hline & & 4 & & & & D013 \\
\hline & & 5 & & & & $\mathrm{DO} 12$ \\
\hline & & 6 & & & & D011 \\
\hline & & 7 & & & & DO10 \\
\hline \multirow[t]{6}{*}{16} & 1 & & 40387 & 40119 & $\mathrm{H} 5 \mathrm{C} 3$ & \\
\hline & & 4 & & & & DO13 \\
\hline & & 5 & & & & Do12 \\
\hline & & 6 & & & & DO11 \\
\hline & & 7 & & & & DO10 \\
\hline & & 8 & & & & Do9 \\
\hline
\end{tabular}




\section{Appendix B: PLC Register List}

The Modsoft program allows a symbol table to be created. This symbol table allows the programmer to assign symbolic names and comments to the registers used by the PLC. The symbol table is accessed under the Utility Menu of Modsoft. A hard copy print-out can be obtained by using the File I/O and Export menu choices once the symbol table has been called up.

The symbol table is essential for the ladder logic programmer. It is the definitive record of which PLC registers have been used and which are available for use. Any entry in the symbol table which has a symbolic name has been used by the PLC. If there is no entry in the symbol table for a register, or if there is a register entry without a symbolic name, that register is available for use.

It is essential that the symbol table be kept up to date. Any change which adds or deletes PLC registers (including adding I/O modules) must be reflected in the symbol table also. 


\section{Appendix C: Report and Recipe File Listings}

Report and Recipe (R\&R) code is controlled by the state of bits in the strategy. These bits are connected to REPORT blocks which reference the code as a source file.

$R \& R$ code is composed of a command and function set provided by the $R \& R$ software option. These commands and functions must follow a syntax format explained in the R\&R Option document provided by Iconics.

Following is a description of each R\&R code's function for the MOTOR and TEST strategies and when it is executed. Refer to the code itself for details on how the functions are carried out.

\section{MOTOR Strategy Reports}

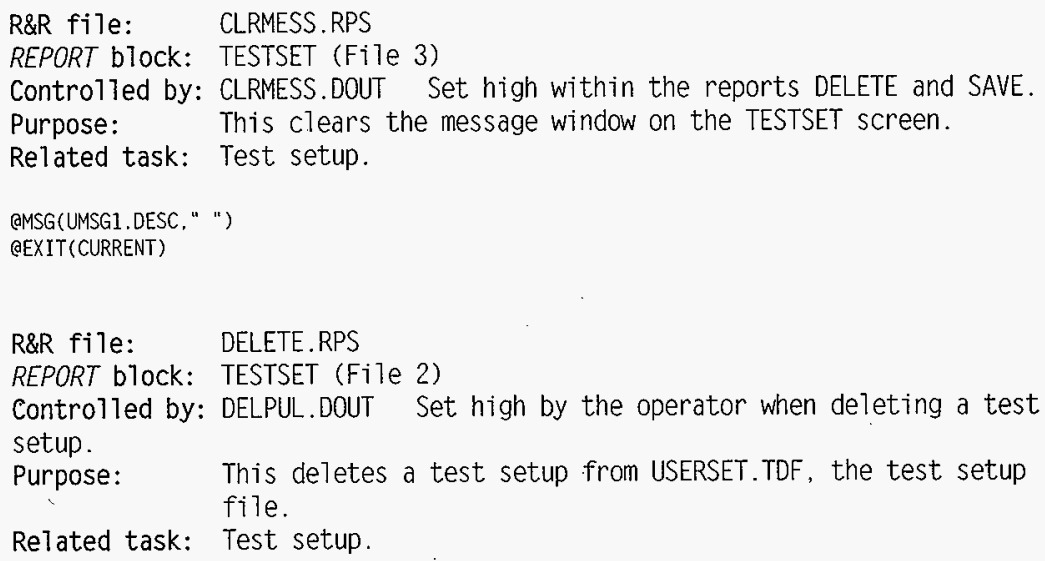


HNF-SD-WM-CSDD-008

Rev. 3

Page 108

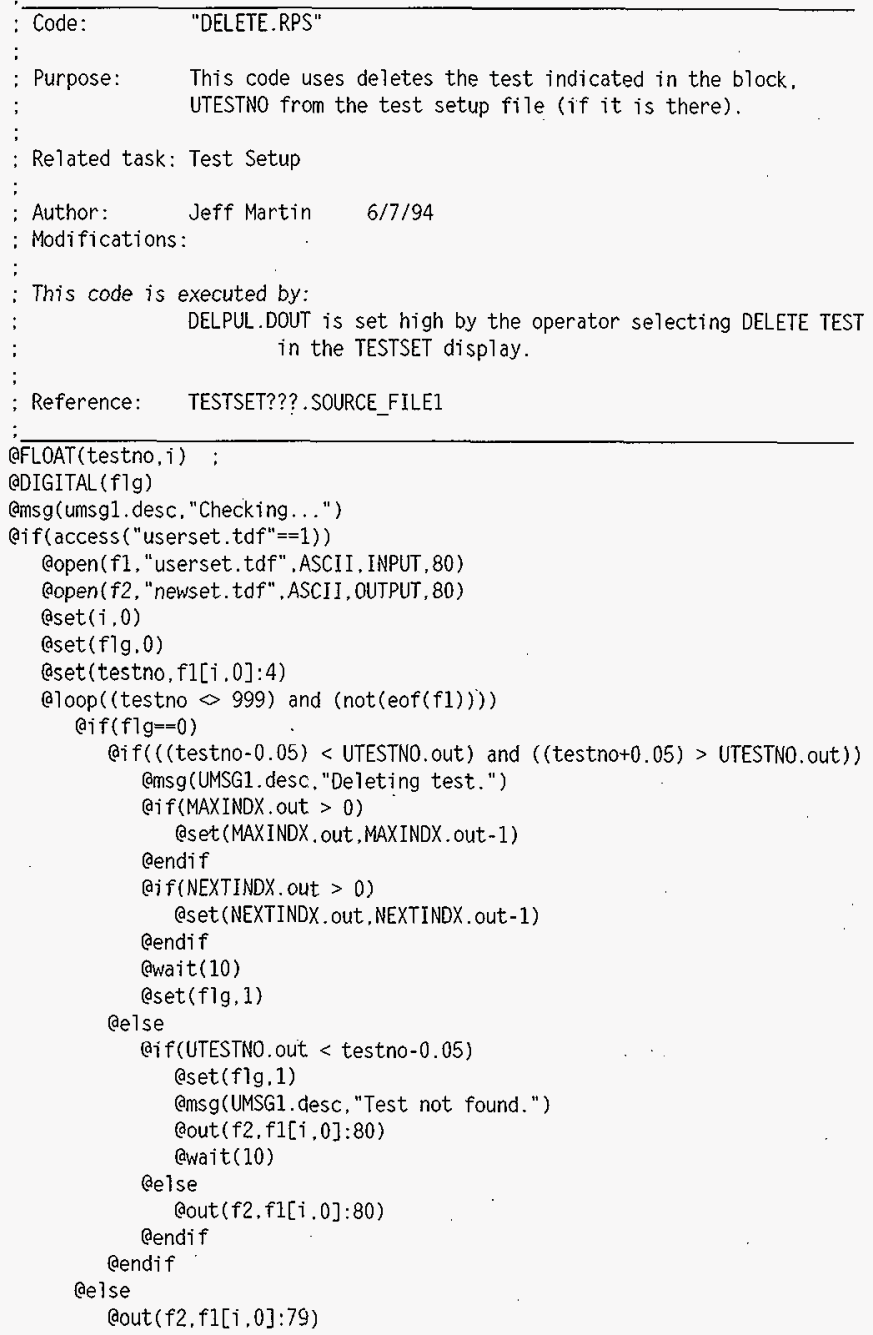




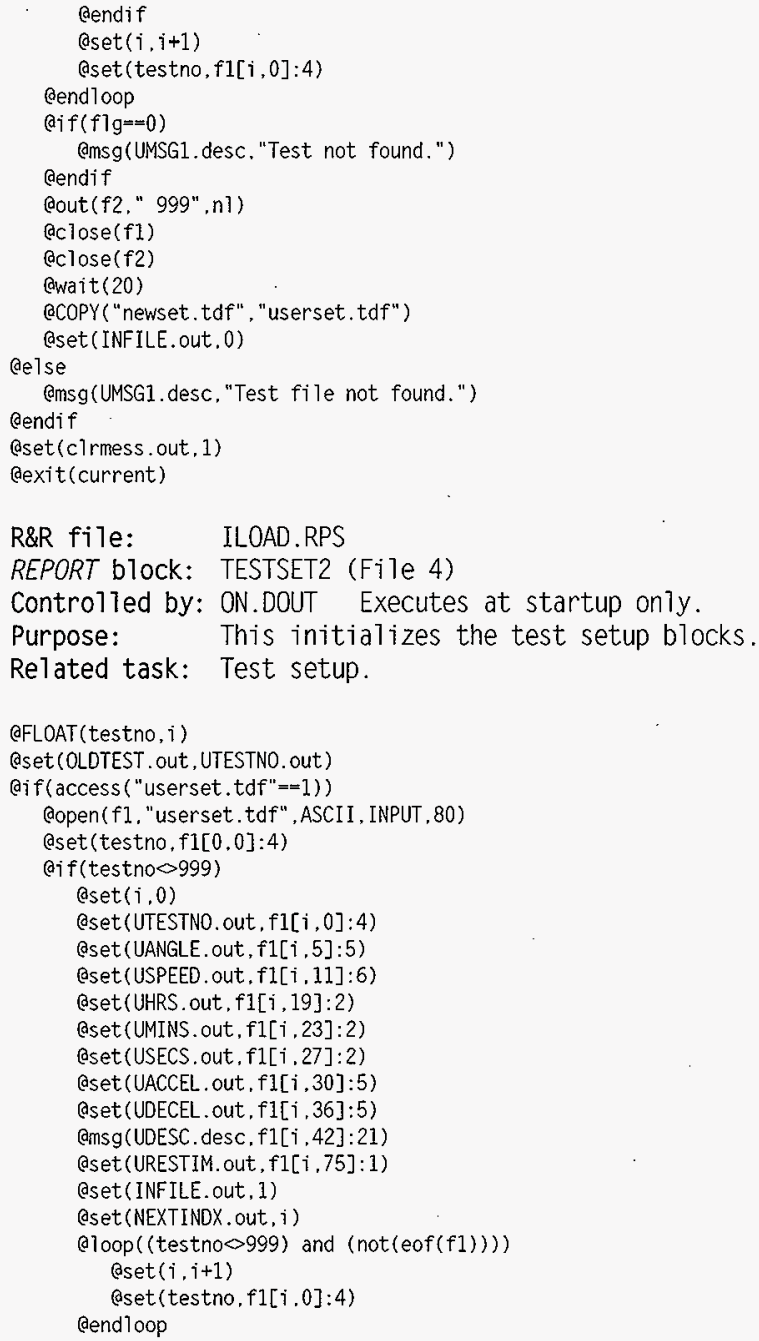




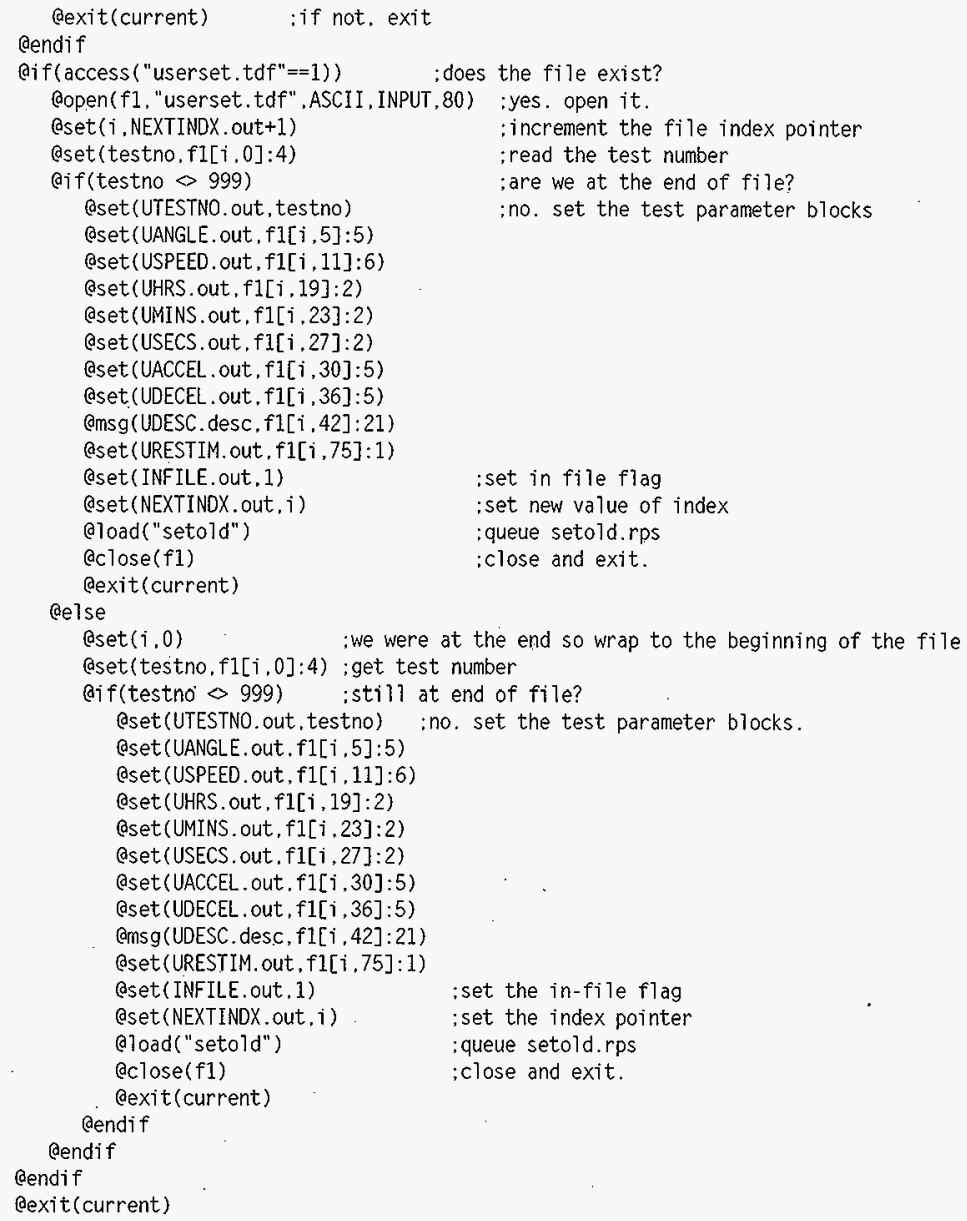


HNF-SD-WM-CSDD-008

Rev. 3

Page 112

R\&R fi]e: PBSETVAL.RPS

REPORT block: PBREPORT (File 1)

Controlled by: SETTEST.DOUT Set high by the operator selecting to set values.

Purpose: $\quad$ This code will download the desired test values to the critical parameters in the MOTOR.

Related task: Set test values

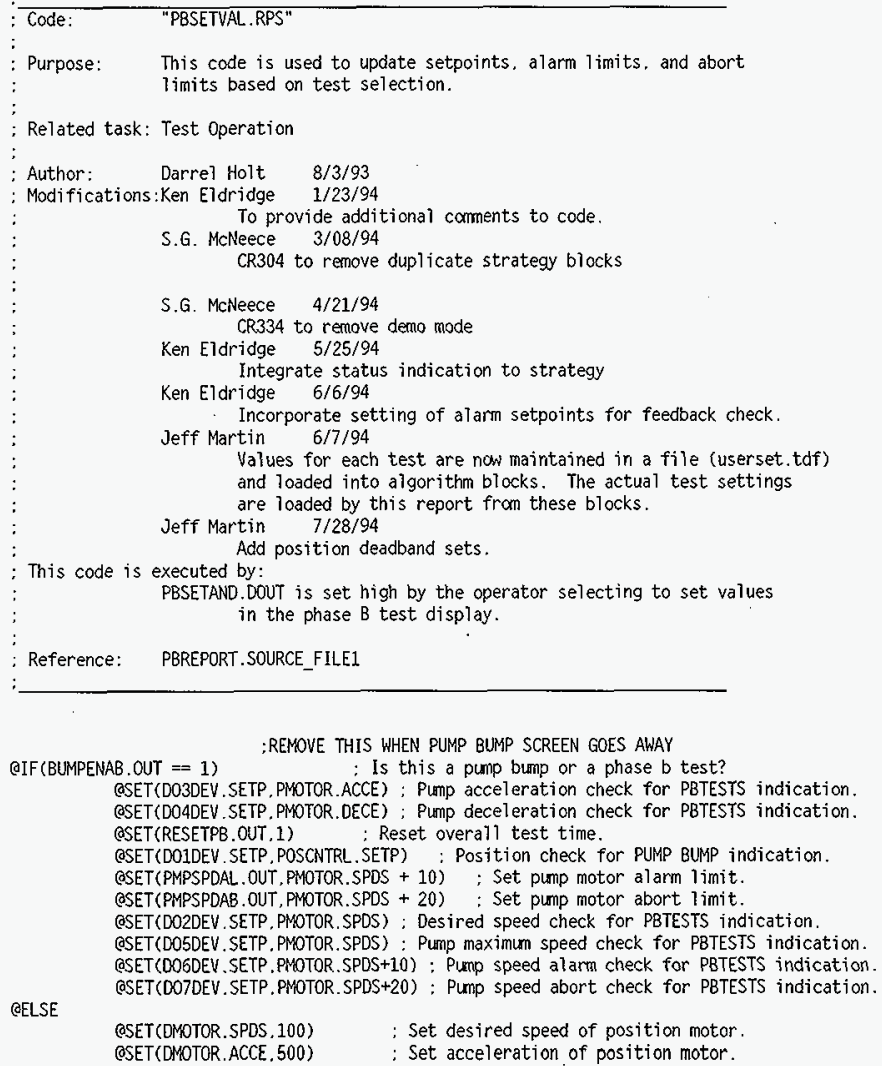


HNF-SD-WM-CSDD-008

Rev. 3

Page 113

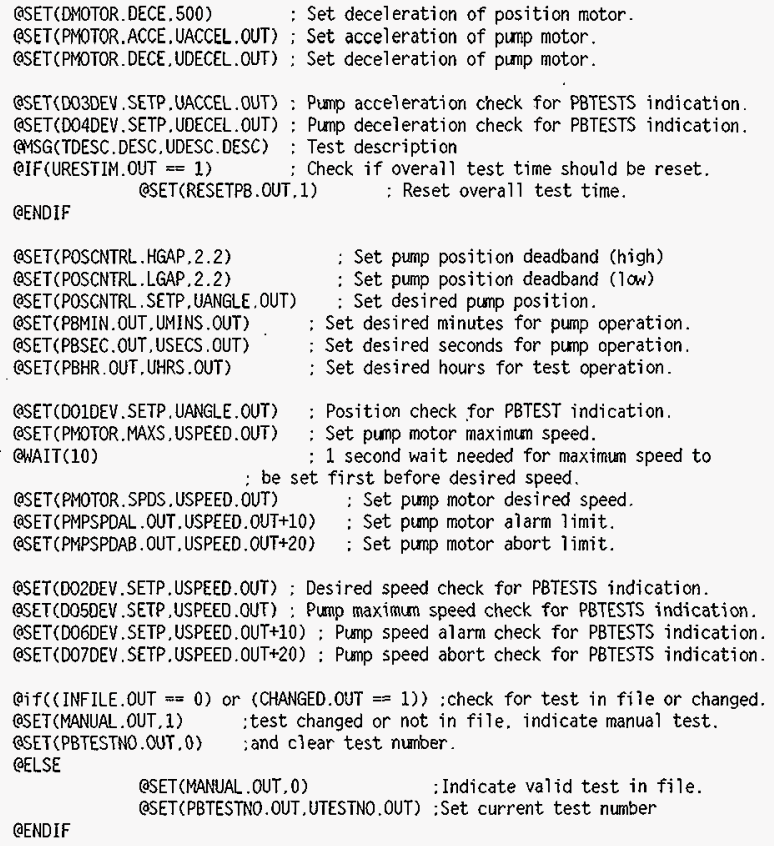

OSET(DO20EV.SETP.USPEED.OUT): Desired speed check for PBTESTS indication. BSET(DO5DEV.SETP,USPEED.OUT) : PUmp maximum speed check for PBTESTS indication. GSET(D06DEV.SETP, USPEED.OUT+10) : Punp speed alarm check for PBTESTS indication. CSET(D07DEV.SETP.USPEED OUT+20) : PLmp speed abort check for PBTESTS indication.

Oif ( (INFILE.OUT $=0$ ) or (CHANGED.OUT $=1$ )) :check for test in file or changed. (OSET(MANUAL.OUT.1) :test changed or not in file, indicate manual test. QSET(PBTESTNO.OUT.O) :and clear test number.

CELSE

QSET(MANUAL.OUT, 0) :Indicate valid test in file.

OENDIF QSET(PBTESTNO.OUT, UTESTNO.OUT) : Set current test number

BENOIF

CSET(SETVALDN.OUT.1) : Set indication that values are set successfully 
R\&R file: $\quad$ PREV.RPS

REPORT block: TESTSET2 (File 3)

Controlled by: PREVPUL.DOUT Set high by the operator when using the up arrow button to access the previous test in the test setup file.

Purpose: This accesses the previous test in the test setup file. Related task: Test setup.

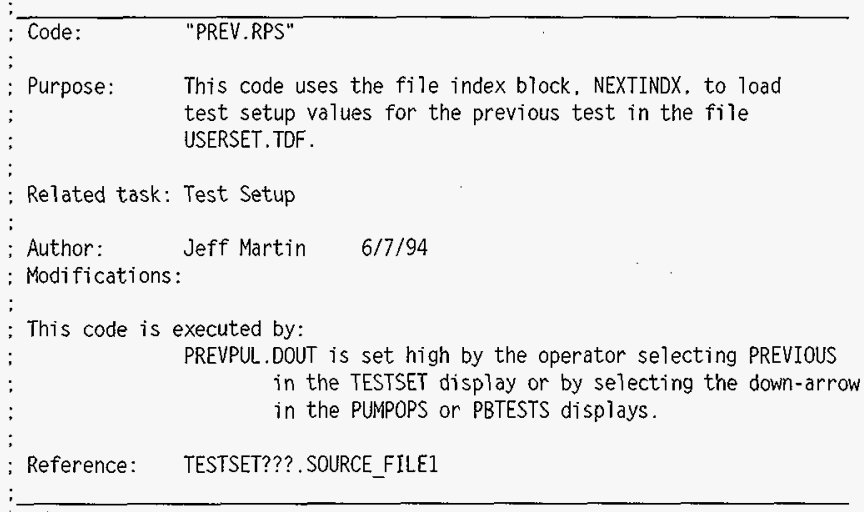

QFLOAT(testno. $i$ ) ; setup local variable, testnumber and $j$ - record index. aif (MAXINDX. Out $=0$ ) ; if maxindx is 0 . there is either no setup file Bexit(current)

eendif aif(access ("userset, $t d f "==1$ ))

(aopen(f1. "userset.tdf", ASCII.INPUT, 80) ;if test setup file exists, open it. aset( $i$,NEXTINDX.out) :get the index for the current test.

(aif $(j=0) \quad$; are we at the beginning?

aset(i.MAXINDX.out) :if so, set the new index to the end of the file $i f(i \circ 0)$ (dset $(i, j-1)$ dendif

(ae) se aset (i.NEXTINDX.out-1) :we're not at the beginning, so decrement index pointer Cendif

eset(testno, $f 1[i, 0]: 4)$;read the next number for the 'previous' record. Qif(testno $\triangle 999)$ is it the end of file pointer? aset(UTESTNO.out.testno) ;if not, set the test value blocks in the strategy @set (UANGLE. out, f1[i,5]:5). 
HNF-SD-WM-CSDD-008

Rev. 3

Page 115

(aset (USPEED . out, $f 1[i, 11]: 6$ )

(aset(UHRS. out, fl $[i, 19]: 2$ )

aset (UMINS out. $f 1[i, 23]: 2$ )

aset (USECS. out, $f 1[i, 27]: 2$ )

(aset (UACCEL . out, fi[i, 30]:5)

eset (UDECEL . out, $f 1[i, 36]: 5$ )

(amsg(UDESC.desc, $f 1[i, 42]: 21$ )

aset (URESTIM. out, f1[i.75]:1)

(aset(INFILE.out.1) ; set the in-file indication

(aset(NEXTINDX,out, 1 ) ; set the new current record index

(Bload("setold") ;queue setold.rps

(eclose(f1) ;close and exit

(exit (current)

dendif

(exit (current)

R\&R file: SAVE.RPS

REPORT block: TESTSET (File 1)

Controlled by: SAVEPUL.DOUT Set high by the operator to save a test setup. Purpose: $\quad$ This saves a test setup in the test setup file. Related task: Test setup.

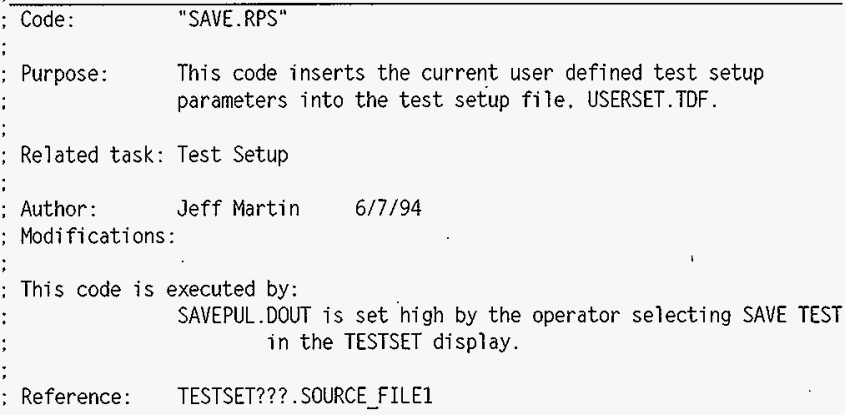

(aFLOAT(testno,i) :setup local variables, testno is the test number read from ; the file. $i$ is the record index into the file

GDIGITAL(flg) :setup local variable. flg is set when the new test setup ihas been inserted.

emsg(umsg1.desc. "Saving...") ; write message to display

(aif (access("userset.tdf" $=1$ )) ; check to see if USERSET.TOF exists 


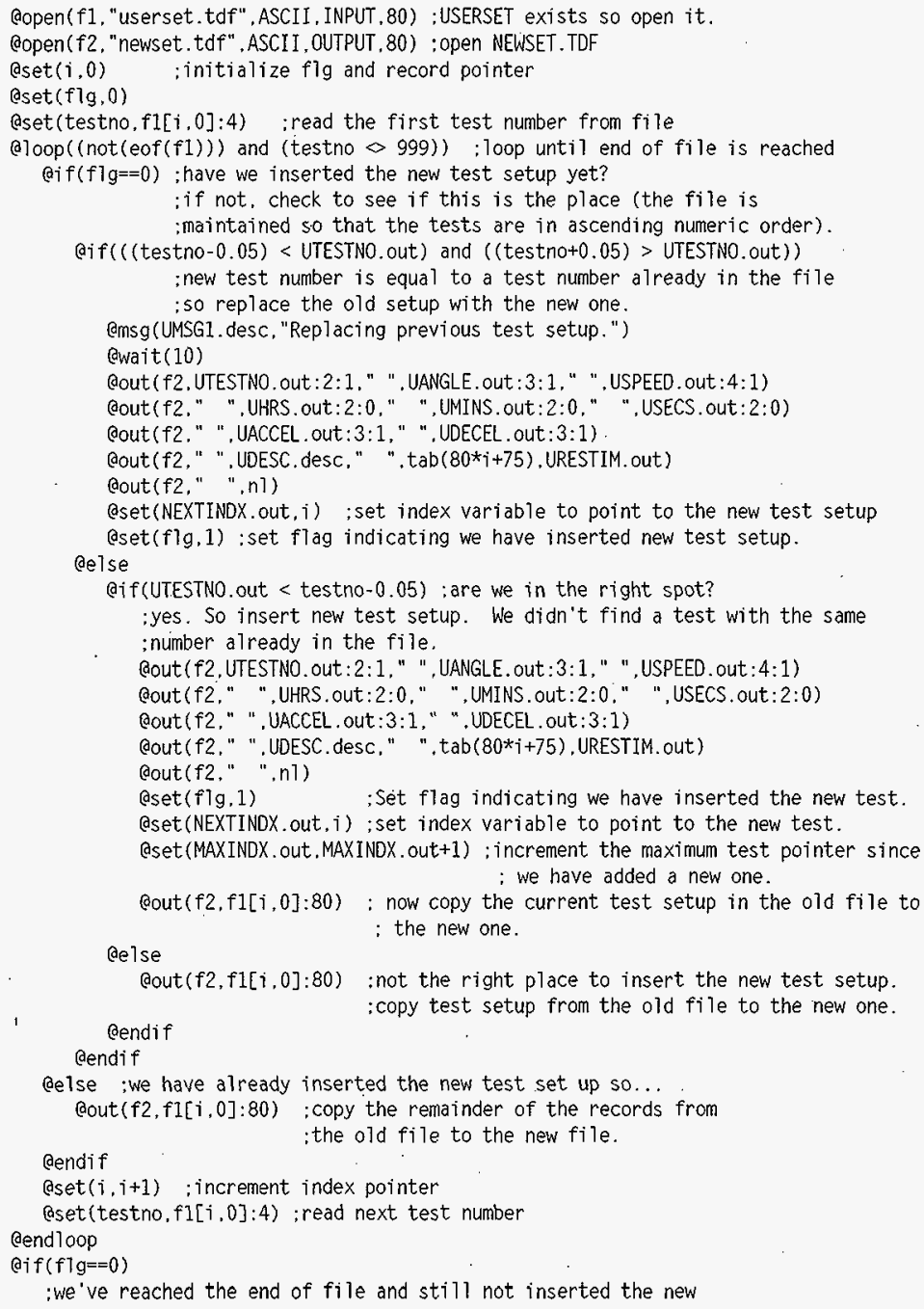


:test. That means we need to insert it at the end.

(aout ( $f 2$,UTESTNO. out: $2: 1$, " ".UANGLE . out: $3: 1, "$ ".USPEED .out: $4: 1$ )

gout (f2," ".UHRS. out:2:0," ".UMINS.out:2:0," ".USECS. out: $2: 0$ )

Cout (f2." ". UACCEL.out:3:1." ".UDECEL.out:3:1)

(dout (f2," ",UDESC. desc, " ", tab $\left(80^{\star} i+75\right)$,URESTIM.out)

Qout (f2," ",nl)

- (eset(NEXTINDX.out,i) : set index pointer variable to new test

aset (MAXINDX. out, MAXINDX out+1) ;increment maximum test index pointer Qendif

Eout (f2." $\left.999^{\prime \prime}, \mathrm{nl}\right)$; append the end of file marker to the new test file

aclose $(f 1) \quad ;$ close the old setup file and the new setup file

(aclose(f2)

ewait(20) ;wait 2 seconds then copy the new file to the old file.

(aCOPY ("newset.tdf", "userset.taf")

Qset(INFILE.out.1) ; set the infile flag indicating that the current test

- is in the setup file.

aelse

(aload("setold") :queue setold.rps

; the file didn't exist, so create it and add the current setup.

(eopen (f2, "userset.tdf". ASCII , OUTPUT, 80)

cout (f2, UTESTNO out:2:1." ",UANGLE. out: $3: 1, "$ ",USPEED .out:4:1)

cout (f2," ",UHRS out: $2: 0, "$ ",UMINS out: $2: 0, "$ ",USECS out: $2: 0$ )

Cout (f2," ".UACCEL.out:3:1," ",UDECEL .out: $3: 1$ )

gout (f2," ", UDESC.desc," ",tab(75), URESTIM. out)

cout $(f 2, "$ " "nl)

Bout (f2," $999 ", n\}$ )

(aset(MAXINDX.out, 1) ; set the maximum index to 1

Gset(NEXTINDX.out.0) :set the current index to 0 - the first record.

(aclose (f2)

eset(INFILE.out,1) ; the current test is in the file.

(eload("setold") ;queue setold.rps

aendif

@msg(umsg1.desc, "Save Complete.") ;write message to display.

aset(c7rmess.out.1) :run clrmess.rps after a delay.

exit(current) ;exit

R\&R file: $\quad$ SETOLD.RPS

REPORT block: None

Controlled by: Called from the reports SAVE, ILOAD, ULOAD, NEXT, PREV.

Purpose: $\quad$ This code updates the old test parameter blocks whenever a new test becomes the active test. This allows the check for test parameter changes to be made.

Related task: Test setup.

(ASET (OANGLE.OUT, UANGLE. OUT)

(ASET (OSPEED. OUT. USPEED. OUT)

(ASET (OHRS. OUT, UHRS.OUT) 


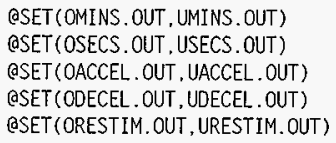

R\&R. file: ULOAD.RPS

REPORT block: TESTSET2 (File 1)

Controlled by: TSTCHG.DOUT Set whenever a new test number is entered by the operator on the TESTSET, PBTESTS or PUMPRUN screens.

Purpose: This loads the selected test from the test setup file. .

Related task: Test setup.

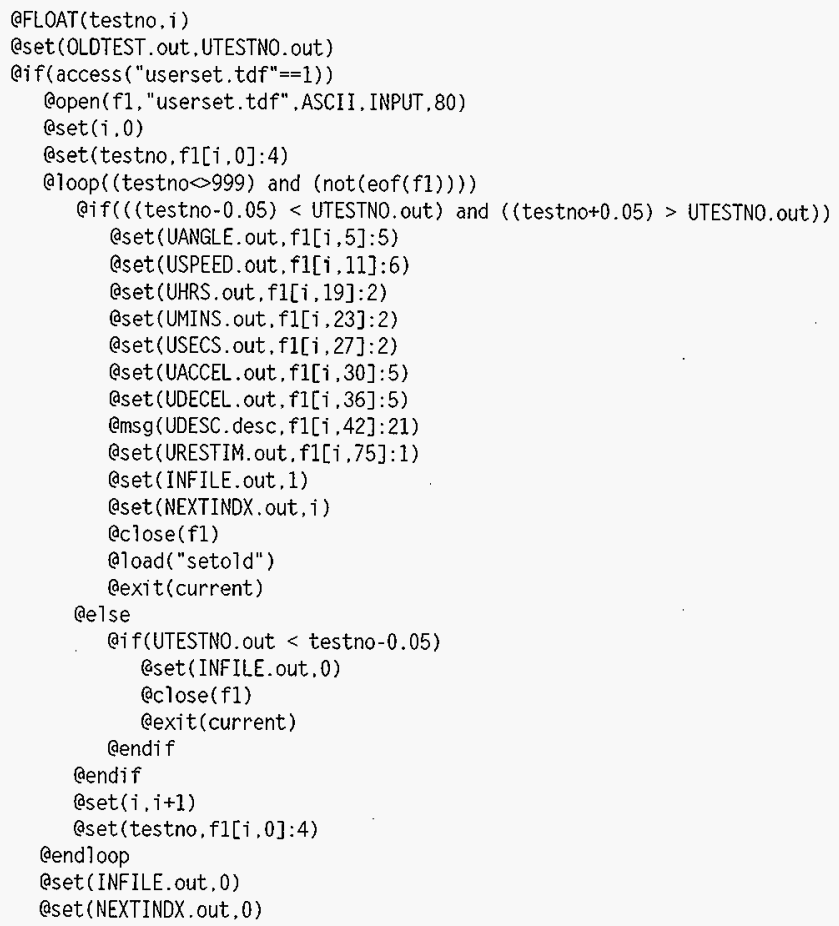




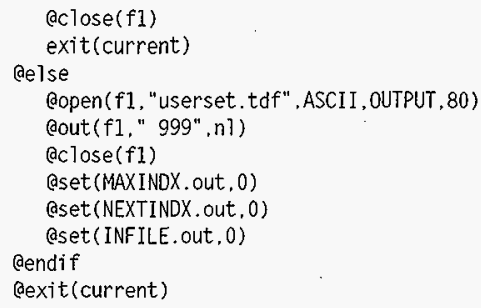

\section{TEST Strategy Reports}

R\&R file: HISTCOPY.RPS

REPORT block: FILENAME (File 4)

Controlled by: DIMIN.DOUT Set high one minute after the beginning of a history file changeover.

Purpose: $\quad$ This copies history files from the TEST directory to the HIST and HIST2 directories.

Related task: History file transfer.

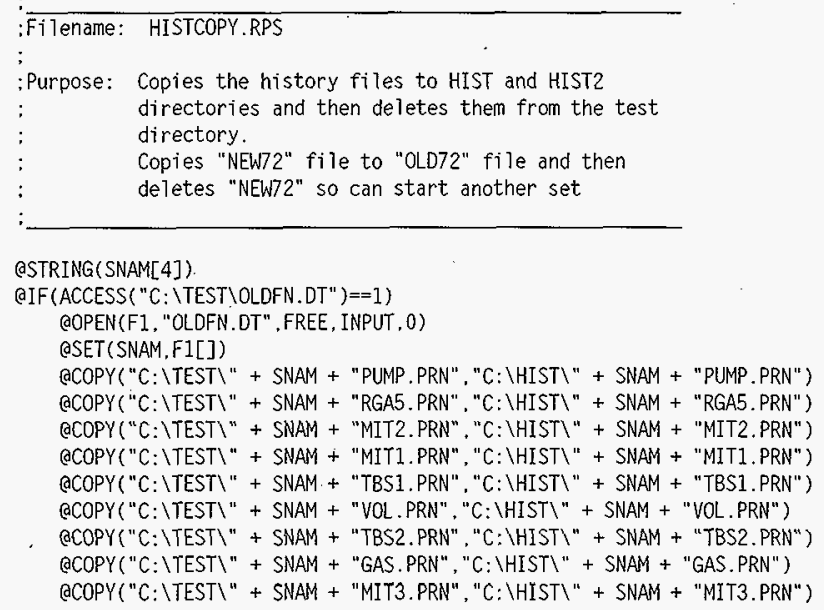




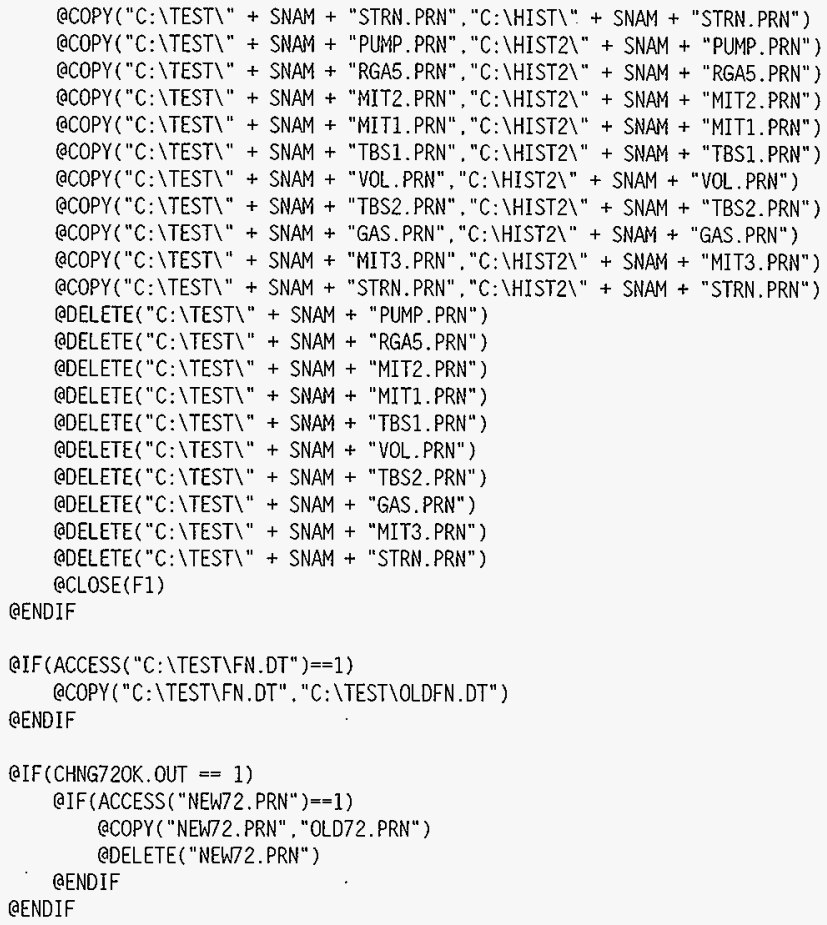

Purpose: This renames the history files based upon the time and date. Related task: History file transfer:

QFLOAT (MNUM, ONUM, HNUM)

BSTRING(YSTR[1].MSTR[1],OSTR[1], HSTR[1])

BOPEN(FI, "STORE. DT", ASCII , OUTPUT, 8)

BOUT(F1,DATE(YY),DATE(MM), DATE(DD), DATE (HH))

BCLOSE(FI)

QOPEN(F1, "STORE.DT", ASCII , INPUT .8) 


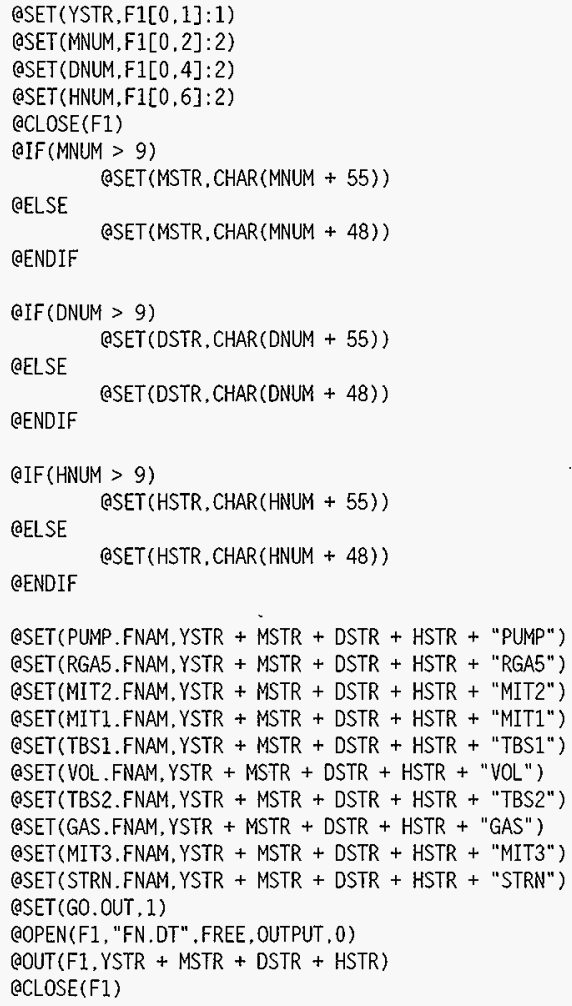


HNF-SD-WM-CSDD-008

Rev. 3

Page 123

\section{Appendix D: Key Macros and State Fields}

GENESIS software has several predefined key macros. The TEST and MOTOR strategies utilize a key macro definition file to redefine one of the key macros, the auto/manual function. RSS stations outside the DACS trailer do not have the redefined auto/manual function enabled. The text file EXTRA.KMS was created to disable $<$ F9 $>$ and add <Alt-F9> as the auto/manual macro. The text file is compiled with KEYMAC EXTRA to create EXTRA.KML. This compiled file must be contained in the MOTOR and TEST directories where the respective strategies are contained. The following is the listing of EXTRA.KMS:

DISMOV $1=$ ON(DISMOVE. OUT) .

DISMOV0 $=$ OFF(DISMOVE.OUT).

CHKCLR $1=$ ON $($ CHKCOLOR.OUT $)$.

SETTES $1=$ ON(SETTEST. OUT).

RESPTIM =DOWNLD_PT(0,PBHR.OUT) DOWNLD_PT(0,PBMIN.OUT)

DOWNLD_PT(0,PBSEC.OUT)

DOWNLD_PT(0,PMPSPDAL.OUT) DOWNLD_PT(0,PMPSPDAB.OUT)

DOWNLD_PT(0,DO5DEV.SETP) DOWNLD_PT'(0,DO6DEV.SETP).

$[\mathrm{F} 9]=\mathrm{DISABLE}$.

$[$ Alt-F9] $=\mathrm{A} / \mathrm{MO}$.

State fields are useful to tie words to analog or discrete values. The text file STATES.SFS was modified to create a state field for the displays linked to the MOTOR strategy:

- <Enable-Disable Move > is used to indicate and control the enabling of the position motor.

If a state field is revised (by editing STATES.SFS and compiling it with the command STATECMP STATES), the display connection in the display builder must be redone in order for the changes to come into effect. 


\section{Appendix E: MOTOR Strategy Display List}

The following list of displays are currently implemented on STATION8 and are dynamically linked to the MOTOR strategy. (See Section 4.1.2 for a list and discussion of the TEST strategy displays).

\begin{tabular}{|l|l||}
\hline \multicolumn{2}{|c|}{ Table F-1. Station Displays } \\
\hline Display & \multicolumn{1}{c|}{ Functions } \\
\hline DMPROB & Help screen - positioning problem display. \\
\hline MAINMENU & Menu display to select other displays. \\
\hline PBENPROB & Help screen - Test enable problem display. \\
\hline PSPROB & Help screen - Test start problem display. \\
\hline PUMPRUN & Combined directional/run pump operation display. \\
\hline SETPROB & Help screen - Test values set problem display. \\
\hline TESTSET & User test setup display. \\
\hline EXIT & Runtime exit display \\
\hline
\end{tabular}




\section{Appendix F: Hardware Configurations}

The following is a list of all cards and their settings on all computer stations in the DACS trailer. The addresses below ("Addr" column) are in hexadecimal. The printer ports are multiplexed; the port on the multiplexer is noted in the "Destination" column; the ARCNET star configuration ports are also noted here.

There are other standard IRQs that are being used by the system in addition to those noted in the tables: IRQ 0 (system timer), IRQ 1 (keyboard), IRQ 2 (cascade from higher IRQs), IRQ 6 (floppy disk), IRQ 8 (clock), IRQ 13 (80486DX), and IRQ 14 (hard disk).

\section{Computer \#1 (Texas Microsystems, in the DACS trailer)}

running ModSoft; directly connected to the PLC

\begin{tabular}{|c|c|c|c|c|c|}
\hline Slot & Card & Port(s) & IRQ & Addr & Destination \\
\hline 1 & Kensington & 9-pin $\sigma^{4}$ & 10 & 338 & Bus mouse \\
\hline 2 & (empty) & & & & \\
\hline 3 & SA-85 & 9-pin $?$ & & $\mathrm{C} 000$ & Modbus Plus, 984E \\
\hline 4 & (empty) & & & & \\
\hline 5 & Texas Micro & $\begin{array}{l}\text { 15-pin } 9 \\
\text { 9-pin }+9\end{array}$ & & & $\begin{array}{l}\text { V2VGA Video } \\
\text { not used }\end{array}$ \\
\hline 6 & (empty) & & & & \\
\hline 7 & CPU (80486) & $\begin{array}{l}\text { 9-pin } 0^{x} \\
25 \text {-pin }+\end{array}$ & & & $\begin{array}{l}\text { not used } \\
\text { not used }\end{array}$ \\
\hline 8 & Magic I/O & $\begin{array}{l}\text { 9-pin } 0^{x} \\
25-\text { pin } q\end{array}$ & $\begin{array}{l}4 \\
7 \\
\end{array}$ & $\begin{array}{l}3 F 8 \\
378\end{array}$ & $\begin{array}{l}\text { not used } \\
\text { LaserJet printer (port 6) }\end{array}$ \\
\hline 9 & 1/O jumper & $\begin{array}{l}\text { 9-pin } 0^{x} \\
25-\text { pin } q\end{array}$ & 3 & $2 \mathrm{~F} 8$ & $\begin{array}{l}\text { PLC A/B switch (rack 13) } \\
\text { not used }\end{array}$ \\
\hline 10 & (empty) & & & & \\
\hline 11 & (empty) & & & & \\
\hline 12 & (empty) & & & & \\
\hline 13 & SCSI controlier & 37-pin 9 & 11 & 330 & not used \\
\hline 14 & (empty) & & & & \\
\hline
\end{tabular}

${ }^{1}$ Connected through $\mathrm{T}$-connector going to Computer $\# 4$ and to rack 8 , where the cable is curled up near Computer \#9. The card in not being used. 


\section{Computer \#2 (Texas Microsystem, in the DACS trailer)}

used for gas monitoring

\begin{tabular}{|c|c|c|c|c|c|}
\hline Slot & Card & Port(s) & IRQ & Addr & Destination \\
\hline 1 & Kensington bus mouse & 9-pin $\sigma^{4}$ & 10 & 338 & not used \\
\hline 2 & (empty) & & & & \\
\hline 3 & 3Com Ethernet & $\begin{array}{l}\text { 15-pin }{ }^{+} \\
\text {BNC }+9\end{array}$ & & & $\begin{array}{l}\text { TLC fanout buffered } \\
\text { repeater } \\
\text { not used }\end{array}$ \\
\hline 4 & (empty) & & & & \\
\hline 5 & Texas Micro & $\begin{array}{l}\text { 15-pin } 9 \\
9 \text {-pin } q\end{array}$ & & & $\begin{array}{l}\text { V2VGA Video } \\
\text { not used }\end{array}$ \\
\hline 6 & (empty) & & & & \\
\hline 7 & CPU (80486) & $\begin{array}{l}\text { 9-pin } o^{x} \\
\text { 25-pin } q\end{array}$ & $\begin{array}{l}4 \\
7\end{array}$ & $\begin{array}{l}3 \mathrm{~F} 8 \\
378\end{array}$ & $\begin{array}{l}\text { mouse } \\
\text { LaserJet printer (port 2) }\end{array}$ \\
\hline 8 & I/O jumper & 9-pin & 3 & $2 \mathrm{~F} 8$ & not used \\
\hline 9 & (empty) & & & & \\
\hline 10 & 3Com Ethernet & $\begin{array}{l}\text { 15-pin } q \\
\text { BNC } 9\end{array}$ & 5 & 300 & $\begin{array}{l}\text { not used } \\
\text { Rack } 10 \text { GMS computer }\end{array}$ \\
\hline 11 & (empty) & & & & \\
\hline 12 & (empty) & & & & \\
\hline 13 & SCSI controller & 37-pin $q$ & 11 & 330 & not used \\
\hline 14 & (empty) & & & & \\
\hline
\end{tabular}


Computer \#3 (Texas Microsystem, in the DACS trailer)

Utility station; HLAN drop; communicates with ASCII/BASIC module

\begin{tabular}{|c|l|l|l|l|l|}
\hline \hline Slot & \multicolumn{1}{|c|}{ Card } & \multicolumn{1}{|c|}{ Port(s) } & MRQ & Addr & \multicolumn{1}{|c|}{ Destination } \\
\hline 1 & Kensington bus mouse & 9-pin ơ & 12 & 338 & bus mouse \\
\hline 2 & Iomega host adaptor & 37-pin o & 5 & & $\begin{array}{l}\text { Switch box; branch 2 } \\
\text { (Bernoulli) }\end{array}$ \\
\hline 3 & 3Com Ethernet II & $\begin{array}{l}\text { RF } \\
\text { connector } \\
\text { RF } \\
\text { connector }\end{array}$ & 5 & 300 & $\begin{array}{l}\text { terminated (jumpered to } \\
\text { Hanford LAN }\end{array}$ \\
\hline 4 & (empty) & 11)
\end{tabular}


Computer \#4 (Texas Microsystem, in the DACS trailer)

High speed strain gauge data (Nicolet system)

\begin{tabular}{|c|c|c|c|c|c|}
\hline Slot & Card & Port(s) & $\mathbf{R R Q}$ & Addr $\mathbf{r}$ & Destination \\
\hline 1 & Kensington bus mouse & $9-$ pin $\sigma^{\pi}$ & 12 & 338 & bus mouse \\
\hline 2 & Iomega host adaptor & 37-pin $\sigma^{4}$ & 5 & & $\begin{array}{l}\text { Switch box; branch } 1 \\
\text { (Bernoulli) }\end{array}$ \\
\hline 3 & GPIB-AT & IEEE-488 & 10 & 280 & Nicolet system \\
\hline 4 & (empty) & & & & \\
\hline 5 & Texas Micro & $\begin{array}{l}\text { 15-pin }+ \\
9 \text {-pin } 9\end{array}$ & & & $\begin{array}{l}\text { V2VGA Video; Shinko } \\
\text { multiplx. } \\
\text { not used }\end{array}$ \\
\hline 6 & (empty) & & & & \\
\hline 7 & CPU (80486) & $\begin{array}{l}\text { 9-pin } 0^{x} \\
25-\text { pin } 9\end{array}$ & & & $\begin{array}{l}\text { not used } \\
\text { not used }\end{array}$ \\
\hline 8 & Magic I/O & $\begin{array}{l}\text { 9-pin } 0^{x} \\
25-\text { pin } ?\end{array}$ & $\begin{array}{l}4 \\
7\end{array}$ & $\begin{array}{l}3 \mathrm{~F} 8 \\
378\end{array}$ & $\begin{array}{l}\text { not used } \\
\text { LaserJet printer (port 3) }\end{array}$ \\
\hline 9 & I/O jumper & $\begin{array}{l}\text { 9-pin } o^{\pi} \\
25-\text { pin } q\end{array}$ & 3 & $2 \mathrm{~F} 8$ & $\begin{array}{l}\text { not used } \\
\text { not used }\end{array}$ \\
\hline 10 & (empty) & & & & \\
\hline 11 & (empty) & & & & \\
\hline 12 & (empty) & & & & \\
\hline 13 & SCSI controller & 37-pin + & 11 & 330 & not used \\
\hline 14 & (empty) & & & & \\
\hline
\end{tabular}




\section{Computer \#5 (Texas Microsystem, in the DACS trailer)}

STATION5, running the Genesis TEST strategy

\begin{tabular}{|c|c|c|c|c|c|}
\hline Slot & Card & Port(s) & IRQ & Addr & Destination \\
\hline 1 & (empty) & & & & \\
\hline 2 & Kensington bus mouse & 9-pin $\sigma^{x}$ & 12 & 338 & bus mouse \\
\hline 3 & SA-85 & 9-pin + & & D800 & Modbus Plus, 984E \\
\hline 4 & (empty) & & & & \\
\hline 5 & Texas Micro & $\begin{array}{l}\text { 15-pin }+9 \\
9-\text { pin } q\end{array}$ & & & $\begin{array}{l}\text { V2VGA Video; Shinko } \\
\text { multiplx. } \\
\text { not used }\end{array}$ \\
\hline 6 & (empty) & & & & \\
\hline 7 & CPU (80486) & $\begin{array}{l}\text { 9-pin } \sigma^{x} \\
\text { 25-pin } q\end{array}$ & & & $\begin{array}{l}\text { not used } \\
\text { not used }\end{array}$ \\
\hline 8 & Magic I/O & $\begin{array}{l}\text { 9-pin } 0^{x} \\
\text { 25-pin } 9\end{array}$ & 7 & 378 & $\begin{array}{l}\text { not used } \\
\text { Genesis C key; Black Box } \\
\text { data switch; Proprinter \#3 } \\
\text { (port 1) }\end{array}$ \\
\hline 9 & I/O jumper & $\begin{array}{l}\text { 9-pin } 0^{x} \\
\text { 25-pin } q\end{array}$ & $\begin{array}{l}4 \\
3\end{array}$ & $\begin{array}{l}3 \mathrm{~F} 8 \\
2 \mathrm{~F} 8\end{array}$ & $\begin{array}{l}\text { Dual } A B C \text { box }(A) \\
\text { mouse }\end{array}$ \\
\hline 10 & SMC ARCNET & $\mathrm{BNC}$ & 5 & $2 \mathrm{E} 0$ & ARCNET hub (port 5) \\
\hline 11 & (empty) & & & & \\
\hline 12 & (empty) & & & & \\
\hline 13 & (empty) & & & & \\
\hline 14 & (empty) & & & & \\
\hline
\end{tabular}




\section{Computer \#6 (Texas Microsystem, in the DACS trailer)}

STATION6, Remote Supervisory Station for the TEST strategy

\begin{tabular}{|c|c|c|c|c|c|}
\hline Slot & Card & Port(s) & IRQ & Addr & Destination \\
\hline 1 & (empty) & & & & \\
\hline 2 & (empty) & & & & \\
\hline 3 & (empty) & & & & \\
\hline 4 & (empty) & & & & \\
\hline 5 & Texas Micro & 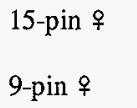 & & & $\begin{array}{l}\text { V2VGA Video; Shinko } \\
\text { multiplx. } \\
\text { not used }\end{array}$ \\
\hline 6 & (empty) & & & & \\
\hline 7 & CPU (80486) & $\begin{array}{l}\text { 9-pin or } \\
25 \text {-pin }+9\end{array}$ & $\begin{array}{l}4 \\
7\end{array}$ & $\begin{array}{l}3 \mathrm{~F} 8 \\
378\end{array}$ & $\begin{array}{l}\text { mouse } \\
\text { Genesis RSS key; Black Box } \\
\text { data switch; Proprinter \#3 } \\
\text { (port 1) }\end{array}$ \\
\hline 8 & (empty) & & & & \\
\hline 9 & SMC ARCNET & $\mathrm{BNC}$ & 5 & $2 \mathrm{E} 0$ & ARCNET hub (port 6) \\
\hline 10 & (empty) & & & & \\
\hline 11 & (empty) & & & & \\
\hline 12 & (empty) & & & & \\
\hline 13 & (empty) & & & & \\
\hline 14 & (empty) & & & & \\
\hline
\end{tabular}


HNF-SD-WM-CSDD-008

Rev. 3

Page 131

Computer \#7 (Texas Microsystem, in the DACS trailer)

STATION7, Backup for STATION5 or STATION8

\begin{tabular}{|c|c|c|c|c|c|}
\hline Slot & Card & Port(s) & IRQ & Addr & Destination \\
\hline 1 & (empty) & & & & \\
\hline 2 & Kensington bus mouse & 9-pin $\sigma^{x}$ & 12 & 338 & bus mouse \\
\hline 3 & SA-85 & $9-$ pin 9 & & D800 & Modbus Plus, 984E \\
\hline 4 & (empty) & & & & \\
\hline 5 & Texas Micro & $\begin{array}{l}\text { 15-pin }+ \\
9-\text { pin }+\end{array}$ & & & $\begin{array}{l}\text { V2VGA Video; Shinko } \\
\text { multiplx. } \\
\text { not used }\end{array}$ \\
\hline 6 & (empty) & & & & \\
\hline 7 & CPU (80486) & $\begin{array}{l}\text { 9-pin } 0^{7} \\
25-\text { pin } 9\end{array}$ & & & $\begin{array}{l}\text { not used } \\
\text { not used }\end{array}$ \\
\hline 8 & Magic I/O & $\begin{array}{l}\text { 9-pin } \sigma^{4} \\
\text { 25-pin }+9\end{array}$ & 7 & 378 & $\begin{array}{l}\text { not used } \\
\text { Genesis RT key; Black Box } \\
\text { data switch; Proprinter \#3 } \\
\text { (port 2) }\end{array}$ \\
\hline 9 & I/O jumper & $\begin{array}{l}\text { 9-pin } 0^{x} \\
25-\text { pin } 9\end{array}$ & $\begin{array}{l}4 \\
3\end{array}$ & $\begin{array}{l}3 \mathrm{~F} 8 \\
2 \mathrm{~F} 8\end{array}$ & $\begin{array}{l}\text { mouse } \\
\text { Dual } \mathrm{ABC} \text { box }(\mathrm{C})\end{array}$ \\
\hline 10 & SMC ARCNET & $\mathrm{BNC}$ & 5 & $2 \mathrm{E} 0$ & ARCNET hub (port 7) \\
\hline 11 & (empty) & & & & \\
\hline 12 & (empty) & & & & \\
\hline 13 & (empty) & & & & \\
\hline 14 & (empty) & & & & \\
\hline
\end{tabular}


HNF-SD-WM-CSDD-008

Rev. 3

Page 132

Computer \#8 (Texas Microsystem, in the DACS trailer).

STATION8, running the Genesis MOTOR strategy

\begin{tabular}{|c|c|c|c|c|c|}
\hline Slot & Card & Port(s) & IRQ & Addr & Destination \\
\hline 1 & (empty) & & & & \\
\hline 2 & Kensington bus mouse & 9-pin $0^{x}$ & 12 & 338 & bus mouse \\
\hline 3 & SA-85 & 9-pin + & & $\mathrm{D} 800$ & Modbus Plus, 984E \\
\hline 4 & Everex $\mathrm{I} / \mathrm{O}$ & $\begin{array}{l}\text { 9-pin or } \\
\text { 25-pin }+9\end{array}$ & 7 & 278 & $\begin{array}{l}\text { not used } \\
\text { Proprinter \#8 }\end{array}$ \\
\hline 5 & Texas Micro & $\begin{array}{l}\text { 15-pin }+9 \\
9 \text {-pin 우 }\end{array}$ & & & $\begin{array}{l}\text { V2VGA Video; Shinko } \\
\text { multiplx. } \\
\text { not used }\end{array}$ \\
\hline 6 & (empty) & & & & \\
\hline 7 & CPU (80486) & $\begin{array}{l}\text { 9-pin o } \\
\text { 25-pin } 9\end{array}$ & & & $\begin{array}{l}\text { not used } \\
\text { not used }\end{array}$ \\
\hline 8 & Magic I/O & $\begin{array}{l}\text { 9-pin } \sigma^{\pi} \\
\text { 25-pin }+9\end{array}$ & 7 & 378 & $\begin{array}{l}\text { not used } \\
\text { Genesis C key; LaserJet } \\
\text { printer multiplx. (port } 8 \text { ) }\end{array}$ \\
\hline 9 & I/O jumper & $\begin{array}{l}\text { 9-pin } \sigma^{x} \\
\text { 25-pin }+\end{array}$ & $\begin{array}{l}4 \\
3\end{array}$ & $\begin{array}{l}3 \mathrm{~F} 8 \\
2 \mathrm{~F} 8\end{array}$ & $\begin{array}{l}\text { Dual } A B C \text { box }(B) \\
\text { mouse }\end{array}$ \\
\hline 10 & (empty) & & & & \\
\hline 11 & SMC ARCNET & $\mathrm{BNC}$ & 5 & $2 \mathrm{E} 0$ & not used \\
\hline 12 & (empty) & & & & \\
\hline 13 & (empty) & & & & \\
\hline 14 & (empty) & & & & \\
\hline
\end{tabular}


HNF-SD-WM-CSDD-008

Rev. 3

Page 133

Computer \#9 (Texas Microsystem, in the DACS trailer)

STATION9, stores data files and moves them to a HLAN file server

\begin{tabular}{|c|c|c|c|c|c|}
\hline Slot & Card & Port(s) & IRQ & Addr & Destination \\
\hline 1 & Kensington bus mouse & 9-pin $\sigma^{x}$ & 10 & 338 & bus mouse \\
\hline 2 & (empty) & & & & \\
\hline 3 & 3Com Ethernet II & $\begin{array}{l}\text { RF connector } \\
\text { RF connector }\end{array}$ & 5 & 300 & $\begin{array}{l}\text { terminated (jumpered to } \\
\text { slot 11) } \\
\text { Hanford LAN }\end{array}$ \\
\hline 4 & (empty) & & & & \\
\hline 5 & Texas Micro & $\begin{array}{l}\text { 15-pin }+ \\
9 \text {-pin } \dot{9}\end{array}$ & & & $\begin{array}{l}\text { V2VGA Video; Shinko } \\
\text { multiplx. } \\
\text { not used }\end{array}$ \\
\hline 6 & (empty) & & & & \\
\hline 7 & CPU (80486) & $\begin{array}{l}\text { 9-pin } \sigma^{x} \\
25-\text { pin } q\end{array}$ & $\begin{array}{l}4 \\
7\end{array}$ & $\begin{array}{l}3 \mathrm{~F} 8 \\
378\end{array}$ & $\begin{array}{l}\text { not used } \\
\text { Genesis RT key }\end{array}$ \\
\hline 8 & I/O jumper & $\begin{array}{l}\text { 9-pin } \sigma^{x} \\
\text { 25-pin } 9\end{array}$ & & & $\begin{array}{l}\text { not used } \\
\text { not used }\end{array}$ \\
\hline 9 & Iomega host adaptor & 37-pin $\sigma^{4}$ & 5 & & Bernoulli drive \\
\hline 10 & SMC ARCNET & $\mathrm{BNC}$ & 3 & $2 \mathrm{E} 0$ & ARCNET hub (port 4) \\
\hline 11 & 3Com Ethernet II & 15-pin + & & & not used (jumpered to slot 3 ) \\
\hline 12 & (empty) & & & & \\
\hline 13 & (empty) & & & & \\
\hline 14 & (empty) & & & & \\
\hline
\end{tabular}


HNF-SD-WM-CSDD-008

Rev. 3

Page 134

\section{Appendix G: Network Configuration Settings}

Station name: STATION5

Function: Runtime Master Station

Network settings

Memory Buffer Address: D980

I/O Port Address: 2e0

IRQ: 5

Data Check Mode: CRC-16

Network address: 5

Node fail time: 20

Watchdog message rate: 8

Performance monitor rate: 4

Network scan time: 1

Message retry count: 3

Transmit Timeout: 8

Primary ACK setting: 80

Net Alarm Squelch After Startup: 0

Net Alarm Squelch During Startup: 10

Net Alarm Buffer size: 4096

Transmit Buffer Full Level: 80

RX Buffers: 32,32,16,16,32

Rename Duplicates on file transfer: Yes

Alarm broacicasts: ENABLE

Station name: STATION6

Function: Local RSS

Network settings

Memory Buffer Address: D980

I/O Port Address: 2e0

IRQ: 5

Data Check Mode: CRC-16

Network address: 6

Node fail time: 20

Watchdog message rate: 8

Performance monitor rate: 4

Network scan time: 1

Message retry count: 3

Transmit timeout: 8

Primary ACK Setting: 80

Network point database size: 300

RSS master identification: MANUAL

RSS auto reconfiguration: ENABLED

RSS Master Node Name: STATION5 
Station name: STATION7

Function: Local RSS

Network settings

Memory Buffer Address: D980

I/O Port Address: $2 \mathrm{e} 0$

IRQ: 5

Data Check Mode: CRC-16

Network address: 7

Node fail time: 20

Watchdog message rate: 8

Performance monitor rate: 4

Network scan time: 1

Message retry count: 3

Transmit timeout: 8

Primary ACK Setting: 80

Network point database size: 300

RSS master identification: MANUAL

RSS auto reconfiguration: ENABLED

RSS Master Node Name: STATIONS

Station name: STATION8

Function: Runtime Master

Network settings

Memory Buffer Address: D980

I/O Port Address: $2 \mathrm{e} 0$

IRQ: 5

Data Check Mode: CRC-16

Network address: 8

Node fail time: 20

Watchdog message rate: 8

Performance monitor rate: 4

Network scan time: 1

Message retry count: 3

Transmit Timeout: 8

Primary ACK setting: 80

Net Alarm Squelch After Startup: 0

Net Alarm Squelch During Startup: 10

Net Alarm Buffer size: 512

Transmit Buffer Full Level: 10

RX Buffers: $8,8,4,4,8$

Rename Duplicates on file transfer: Yes

Alarm broadcasts: DISABLE 


\author{
Station name: STATION9 \\ Function: DOS file server \\ Network settings \\ Memory Buffer Address: D980 \\ I/O Port Address: $2 \mathrm{e} 0$ \\ IRQ: 5 \\ Data Check Mode: CRC-16 \\ Network address: 9 \\ Node fail time: 20 \\ Watchdog message rate: 8 \\ Performance monitor rate: 4 \\ Network scan time: 1 \\ Transmit Timeout: 8 \\ Primary ACK setting: 80 \\ Rename Duplicates on file transfer: Yes
}

Station name: STATION11

Function: Remote RSS

Network settings

Memory Buffer Address: CC00

I/O Port Address: 300

IRQ: 5

Data Check Mode: CRC-16

Network address: 11

Node fail time: 20

Watchdog message rate: 8

Performance monitor rate: 4

Network scan time: 4

Message retry count: 3

Transmit timeout: 8

Primary ACK Setting: 80

RSS master identification: MANUAL

RSS auto reconfiguration: DISABLED

RSS Master Node Name: STATION5 
HNF-SD-WM-CSDD-008

Rev. 3

Page 137

Station name: STATION13

Function: Remote RSS

Network settings

Memory Buffer Address: CC00

I/O Port Address: 300

IRQ: 5

Data Check Mode: CRC-16

Network address: 13

Node fail time: 20

Watchdog message rate: 8

Performance monitor rate: 4

Network scan time: 6

Message retry count: 3

Transmit timeout: 8

Primary ACK Setting: 80

RSS master identification: MANUAL

RSS auto reconfiguration: DISABLED

RSS Master Node Name: STATION5

Station name: STATION15

Function: Remote RSS

Network settings

Memory Buffer Address: CCOO

y/O Port Address: $2 \mathrm{e} 0$

IRQ: 5

Data Check Mode: CRC-16

Network address: 15

Node fail time: 20

Watchdog message rate: 8

Performance monitor rate: 4

Network scan time: 4

Message retry count: 3

Transmit timeout: 8

Primary ACK Setting: 80

RSS master identification: MANUAL

RSS auto reconfiguration: DISABLED

RSS Master Node Name: STATION5 
HNF-SD-WM-CSDD-008

Rev. 3

Page 138

Station name: STATION17

Function: Remote RSS

Network settings

Memory Buffer Address: $\mathrm{CC} 00$

VO Port Address: $2 \mathrm{e} 0$

IRQ: 5

Data Check Mode: CRC-16

Network address: 17

Node fail time: 20

Watchdog message rate: 8

Performance monitor rate: 4

Network scan time: 4

Message retry count: 3

Transmit timeout: 8

Primary ACK Setting: 80

RSS master identification: MANUAL

RSS auto reconfiguration: DISABLED

RSS Master Node Name: STATION5 
HNF-SD-WM-CSDD-008

Rev. 3

Page 139

\section{Appendix H: Computer Configurations and Software Versions}

See Appendix $\mathrm{G}$ for a general description of the functions and network setup parameters (ARCNET VO Port, Memory Address, and IRQ) of the stations in the network.

All stations are running DOS, site standard version. The versions of Iconics software that are in use are:

- Genesis (GEN-6C and GEN-RT) 3.72

- Remote Supervisory System (RSS) 3.72

- GEN-NET 3.64

- $\quad$ Report \& Recipe option (RRCOMBO) 3.62

The following table gives the parameters for the setup of the ARCNET cards and the Iconics software packages that are on the stations. GEN-NET and RSS serial numbers are provided as well, for those stations that have that software.

\begin{tabular}{||c|c|c|c|c||}
\hline \multicolumn{1}{c|}{} & $\begin{array}{c}\text { ARCNET } \\
\text { Hub } \\
\text { Port }\end{array}$ & $\begin{array}{c}\text { ARCNET } \\
\text { I/O Port } \\
\text { Address }\end{array}$ & $\begin{array}{c}\text { ARCNET } \\
\text { Board IRQ }\end{array}$ & Iconics Software \\
\hline \hline STATION5 & 5 & $2 \mathrm{E} 0$ & 5 & GEN-6C, GEN-NET, R\&R \\
\hline STATION6 & 6 & $2 \mathrm{E} 0$ & 5 & RSS, R\&R \\
\hline STATION7 & 7 & $2 \mathrm{E} 0$ & 5 & GEN-6RT, GEN-NET, R\&R \\
\hline STATION8 & N/A & $2 \mathrm{E} 0$ & 5 & GEN-6C, GEN-NET, R\&R \\
\hline STATION9 & 4 & $2 \mathrm{E} 0$ & 3 & GEN-NET \\
\hline STATION11 & 2 & 300 & 5 & RSS, R\&R \\
\hline STATION13 & 8 & 300 & 5 & RSS, R\&R \\
\hline STATION15 & 1 & $2 \mathrm{E} 0$ & 5 & RSS, R\&R \\
\hline STATION17 & 3 & $2 \mathrm{E} 0$ & 5 & RSS, R\&R \\
\hline
\end{tabular}


HNF-SD-WM-CSDD-008

Rev. 3

Page 140

The directory organization on the computers is the same for the following directories:

- I(Root directory) - AUTOEXEC.BAT and CONFIG.SYS system boot files

- IDOS - MS-DOS system files

- IMOUSE - Mouse driver

- INETROOM3 - Expanded Memory Manager

Where directories differ between stations, the following table shows what those directories contain.

\begin{tabular}{|c|c|c|}
\hline Station Name & Directory & Contents \\
\hline \multirow[t]{2}{*}{ STATIONS } & IGEN372 & $\begin{array}{l}\text { Genesis system, GEN-NET, AF5000+/Genesis } \\
\text { driver, Modicon/Genesis driver, RRCOMBO } \\
\text { option, Help system files }\end{array}$ \\
\hline & ITEST & $\begin{array}{l}\text { TEST strategy files, related displays, } R \& R \text { code, } \\
\text { key macro files, state field files, startup batch } \\
\text { files }\end{array}$ \\
\hline \multirow[t]{2}{*}{ STATION6 } & IGEN372 & $\begin{array}{l}\text { RSS software, AF5000+/Genesis driver, } \\
\text { Modicon/Genesis driver, RRCOMBO option, } \\
\text { Help system files }\end{array}$ \\
\hline & ITEST & $\begin{array}{l}\text { TEST strategy files, related displays, R\&R code, } \\
\text { key macro files, state field files, startup batch files }\end{array}$ \\
\hline \multirow[t]{2}{*}{ STATION7 } & IGEN372 & $\begin{array}{l}\text { RSS software, GEN-NET, AF5000+/Genesis } \\
\text { driver, Modicon/Genesis driver, RRCOMBO } \\
\text { option, Help system files }\end{array}$ \\
\hline & ITEST & $\begin{array}{l}\text { TEST strategy files, related displays, R\&R code, } \\
\text { key macro files, state field files, startup batch files }\end{array}$ \\
\hline \multirow[t]{2}{*}{ STATION8 } & $1 \mathrm{GEN} 372$ & $\begin{array}{l}\text { Genesis system, GEN-NET, AF5000+/Genesis } \\
\text { driver, Modicon/Genesis driver, RRCOMBO } \\
\text { option, Help system files }\end{array}$ \\
\hline & IMOTOR & $\begin{array}{l}\text { MOTOR strategy files, related displays, } R \& R \\
\text { code, key macro files, state field files, startup } \\
\text { batch files }\end{array}$ \\
\hline
\end{tabular}


HNF-SD-WM-CSDD-008

Rev. 3

Page 141

\begin{tabular}{|lll|}
\hline STATION9 & IGEN372 & GEN-NET \\
& INETWARE & Novell networking software (???) \\
\hline STATION11 & IGEN372 & $\begin{array}{l}\text { RSS software, AF5000+/Genesis driver, } \\
\text { Modicon/Genesis driver, RRCOMBO option, } \\
\text { Help system files }\end{array}$ \\
& ITEST & $\begin{array}{l}\text { TEST strategy files, related displays, R\&R code, } \\
\text { key macro files, state field files, startup batch files }\end{array}$ \\
\hline STATION13 & IGEN372 & $\begin{array}{l}\text { RSS software, AF5000+/Genesis driver, } \\
\text { Modicon/Genesis driver, RRCOMBO option, }\end{array}$ \\
& ITEST & $\begin{array}{l}\text { Help system files } \\
\text { TEST strategy files, related displays, R\&R code, } \\
\text { key macro files, state field files, startup batch files }\end{array}$ \\
\hline STATION15 & IGEN372 & $\begin{array}{l}\text { RSS software, AF5000+/Genesis driver, } \\
\text { Modicon/Genesis driver, RRCOMBO option, }\end{array}$ \\
& Help system files \\
& TEST strategy files, related displays, R\&R code, \\
& key macro files, state field files, startup batch files \\
\hline STATION17 & IGEN372 & $\begin{array}{l}\text { RSS software, AF5000+/Genesis driver, } \\
\text { Modicon/Genesis driver, RRCOMBO option, } \\
\text { Help system files }\end{array}$ \\
& ITEST & $\begin{array}{l}\text { TEST strategy files, related displays, R\&R code, } \\
\text { key macro files, state field files, startup batch files }\end{array}$ \\
\hline & &
\end{tabular}




\title{
Appendix I: Directory and File Listings
}

\section{DACS STATION 5 DIRECTORY LISTINGS}

\author{
Volume in drive $C$ is MS-DOS 5 \\ Volume Serial Number is $1 \mathrm{C} 9 \overline{\mathrm{B}}-5752$ \\ 175841280 bytes free \\ Directory of $C:{ }^{*}$. BAT, *. SYS

$\begin{array}{llrrr}\text { AUTOEXEC BAT } & 230 & 07-25-95 & 2: 29 p \\ \text { ALMCOPY BAT } & 87 & 11-06-96 & 12: 29 a \\ \text { CONFIG SYS } & 440 & 01-26-95 & 10: 02 a \\ \text { RENAME72 } & \text { BAT } & 411 & 03-08-94 & 1: 35 p \\ \text { RUNTIME BAT } & 1155 & 05-25-95 & 2: 12 p\end{array}$

Directory of $\mathrm{C}: \backslash \mathrm{GEN} 372$

\begin{tabular}{llrrr} 
& \multicolumn{2}{c}{$<$ LIR> } & $08-03-94$ & $9: 21 a$ \\
GENCFG & NCF & 276 & $05-03-94$ & $9: 21 a$ \\
GENR & $08-95$ & $9: 12 a$ \\
GENNET & ONL & 442 & $05-24-95$ & $9: 12 a$ \\
GENNET & NDB & 171 & $05-24-95$ & $9: 12 a$ \\
CONFIG & EXE & 637000 & $02-24-94$ & $3: 27 a$ \\
GENCFG & NBC & 1015 & $08-27-92$ & $5: 02 p$ \\
AINDET & GSP & 2995 & $02-24-94$ & $3: 27 a$ \\
GENESIS & GSP & 1109 & $02-24-94$ & $3: 27 a$ \\
ALM & GSP & 2649 & $02-24-94$ & $3: 27 a$ \\
GENESIS & BAT & 19 & $08-03-94$ & $10: 09 a$ \\
ALMSUM & GSP & 2244 & $02-24-94$ & $3: 27 a$ \\
AMBDET & GSP & 2449 & $02-24-94$ & $3: 27 a$ \\
ANALOG & MNU & 3377 & $02-24-94$ & $3: 27 a$ \\
AOUTDET & GSP & 2113 & $02-24-94$ & $3: 27 a$ \\
BOOT & GSP & 3450 & $02-15-95$ & $11: 29 a$ \\
BUTTONS & SMB & 1320 & $02-24-94$ & $3: 27 a$ \\
CALC & GSP & 3633 & $02-24-94$ & $3: 27 a$ \\
CALC2 & GSP & 4408 & $02-24-94$ & $3: 27 a$ \\
CALC3 & GSP & 2502 & $02-24-94$ & $3: 27 a$ \\
CART & SMB & 245 & $02-24-94$ & $3: 27 a$ \\
CIRCUITS SMB & 44898 & $02-24-94$ & $3: 27 a$ \\
CNT & GSP & 2703 & $02-24-94$ & $3: 27 a$ \\
CONTROL & MNU & 10065 & $02-24-94$ & $3: 27 a$ \\
CTLOET2 & GSP & 3044 & $02-24-94$ & $3: 27 a$ \\
CTLDET3 & GSP & 2580 & $02-24-94$ & $3: 27 a$ \\
DGAP & GSP & 3003 & $02-24-94$ & $3: 27 a$
\end{tabular}




\begin{tabular}{|c|c|c|c|}
\hline DGAP2 & GSP & $2593 \quad 02-24-94$ & $3: 27 a$ \\
\hline DIGDET & GSP & $2946 \quad 02-24-94$ & $3: 27 a$ \\
\hline DIGITAL & MNU & $4434 \quad 02-24-94$ & $3: 27 a$ \\
\hline DIR & GSP & $4139 \quad 02-24-94$ & $3: 27 a$ \\
\hline DISPOIR & GSP & $4234 \quad 02-24-94$ & $3: 27 a$ \\
\hline DISPSAV & GSP & $1001 \quad 02-24-94$ & $3: 27 a$ \\
\hline DISPSEC & GSP & $980 \quad 02-24-94$ & $3: 27 a$ \\
\hline DOTDET & GSP & $2064 \quad 02-24-94$ & $3: 27 a$ \\
\hline DTIMDET & GSP & $2588 \quad 02-24-94$ & $3: 27 a$ \\
\hline DYNAMIC & MNU & $14019 \quad 02-24-94$ & $3: 27 a$ \\
\hline EMPTY & GSP & $845 \quad 02-24-94$ & $3: 27 a$ \\
\hline EPSON_MX & PRP & $36 \quad 02-2$ & $3: 27 a$ \\
\hline EPSON_MX & PTR & $2048 \quad 02-24-94$ & $3: 27 a$ \\
\hline EXIT & GSP & $1021 \quad 02-24-94$ & $3: 27 a$ \\
\hline EXTASCII & FNT & $1536 \quad 02-24-94$ & $3: 27 a$ \\
\hline FF1 & GSP & $2190 \quad 02-24-94$ & $3: 27 a$ \\
\hline FF2 & GSP & $233502-24-94$ & $3: 27 a$ \\
\hline FILEUTIL & GSP & $1296 \quad 02-24-94$ & $3: 27 a$ \\
\hline GNET_OLD & KML & $\begin{array}{lll}510 & 02-24-94\end{array}$ & $3: 27 a$ \\
\hline GRAPHIC & MNU & $262702-24-94$ & $3: 27 a$ \\
\hline HCURS & GSP & $415 \quad 02-24-94$ & $3: 27 a$ \\
\hline HDWDET & GSP & $1954 \quad 02-24-94$ & $3: 27 a$ \\
\hline HELP & GSP & $1217 \quad 02-24-94$ & $3: 27 a$ \\
\hline HELP1 & GSP & $121702-16-95$ & $3: 01 p$ \\
\hline HELP2 & GSP & 121702 & 3:01p \\
\hline HELP3 & GSP & $121702-$ & $3: 01 p$ \\
\hline HELP4 & GSP & $121702-16-95$ & $3: 01 p$ \\
\hline HELP5 & GSP & $1210 \quad 02-24-94$ & $3: 27 a$ \\
\hline HELPo & GSP & $1156 \quad 02-24-94$ & $3: 27 a$ \\
\hline HGLSTMEN & GSP & $1344 \quad 02-24-94$ & $3: 27 a$ \\
\hline HGREP & GSP & $781 \quad 02-24-94$ & $3: 27 a$ \\
\hline HGREPLST & GSP & $1688 \quad 02-24-94$ & $3: 27 a$ \\
\hline HGREPMEN & GSP & $1408 \quad 02-24-94$ & $3: 27 a$ \\
\hline HISMON & GSP & $246302-24-94$ & $3: 27 a$ \\
\hline HISREP & GSP & 1588 & $3: 27 \mathrm{a}$ \\
\hline ST & MNU & 15746 & $3: 27 \mathrm{a}$ \\
\hline HISTB & GSP & $\begin{array}{llll}1862 & 02-24-94\end{array}$ & $3: 27 a$ \\
\hline HISTLST & GSP & $203802-24-94$ & $3: 27 a$ \\
\hline HISTMEN1 & GSP & $2029 \quad 02-24-94$ & $3: 27 a$ \\
\hline HTBREP & GSP & $\begin{array}{lll}1226 & 02-24-94\end{array}$ & $3: 27 a$ \\
\hline ICONS & ICN & $\begin{array}{lll}66267 & 02-24-94\end{array}$ & $3: 27 a$ \\
\hline IDB & GSP & $2674 \quad 02-24-94$ & $3: 27 a$ \\
\hline IDBAIN & GSP & $2739 \quad 02-24-94$ & $3: 27 a$ \\
\hline IDBAIO & GSP & $\begin{array}{lll}3137 & 02-24-94\end{array}$ & $3: 27 a$ \\
\hline IDBAO & GSP & $2070 \quad 02-24-94$ & $3: 27 a$ \\
\hline IDBDIN & GSP & $438102-2$ & $3: 27 a$ \\
\hline IDBDINB & GSP & $1574 \quad 02-24-94$ & $3: 27 a$ \\
\hline IDBDIO & GSP & $4831 \quad 02-24-94$ & $3: 27 a$ \\
\hline IDBDIOB & GSP & $\begin{array}{lll}1644 & 02-24-94\end{array}$ & $3: 27 a$ \\
\hline IOBDOT & GSP & $280902-24-94$ & $3: 27 a$ \\
\hline
\end{tabular}


HNF-SD-WM-CSDD-008

Rev. 3

Page 144

\begin{tabular}{|c|c|c|c|}
\hline IDBDOTB & GSP & $1325 \quad 02-24-94$ & $3: 27 a$ \\
\hline IDBENTRY & GSP & $\begin{array}{lll}663 & 02-24-94\end{array}$ & $3: 27 a$ \\
\hline IDBSIO & GSP & $1480 \quad 02-24-94$ & $3: 27 a$ \\
\hline IDBSTG & GSP & $127102-24-94$ & $3: 27 a$ \\
\hline IDBSTGO & GSP & $1309 \quad 02-24-94$ & $3: 27 a$ \\
\hline KB & TBL & $339202-24-94$ & $3: 27 a$ \\
\hline KEYHELP & EXE & $3926102-24-94$ & $3: 27 a$ \\
\hline XEYMAC & EXE & $34201 \quad 02-24-94$ & $3: 27 a$ \\
\hline LIBRARY & MNU & $347102-24-94$ & $3: 27 a$ \\
\hline LISTMAIN & GSP & $363 \quad 02-24-94$ & $3: 27 a$ \\
\hline LISTMENU & GSP & $165702-24-94$ & $3: 27 a$ \\
\hline LOGIC & GSP & $2843 \quad 02-24-94$ & $3: 27 \bar{a}$ \\
\hline LOGO & DAT & $902-24-94$ & $3: 27 a$ \\
\hline MACROS & MNU & $2282 \quad 02-24-94$ & $3: 27 a$ \\
\hline MATH & GSP & $2602 \quad 02-24-94$ & $3: 27 a$ \\
\hline MATH2 & GSP & $2506 \quad 02-24-94$ & $3: 27 a$ \\
\hline MEMSYS & MNU & $\begin{array}{lll}853 & 02-24-94\end{array}$ & $3: 27 \mathrm{a}$ \\
\hline METACONF & EXE & $69599 \quad 02-24-94$ & $3: 27 a$ \\
\hline METACONF & MNU & $\begin{array}{lll}3859 & 02-24-94\end{array}$ & $3: 27 a$ \\
\hline MNEMONIC & MNU & $\begin{array}{lll}8335 & 02-24-94\end{array}$ & $3: 27 a$ \\
\hline MOUSE & OPT & $4118 \quad 02-24-94$ & $3: 27 a$ \\
\hline PAI01 & GSP & $3453 \quad 02-24-94$ & $3: 27 a$ \\
\hline PAIO2 & GSP & $\begin{array}{lll}3453 & 02-24-94\end{array}$ & $3: 27 a$ \\
\hline PAI03 & GSP & $3888 \quad 02-24-94$ & $3: 27 a$ \\
\hline PAOUT & GSP & $3143 \quad 02-24-94$ & $3: 27 a$ \\
\hline PASSWORD & GSP & $1794 \quad 02-24-94$ & $3: 27 a$ \\
\hline PDIN & GSP & $\begin{array}{lll}5661 & 02-24-94\end{array}$ & $3: 27 a$ \\
\hline PDOUT & GSP & $4171 \quad 02-24-94$ & $3: 27 a$ \\
\hline PLOT & GSP & $465 \quad 02-24-94$ & $3: 27 a$ \\
\hline PLOTMEN & GSP & $2405 \quad 02-24-94$ & $3: 27 a$ \\
\hline PULNOT & GSP & $2322 \quad 02-24-94$ & $3: 27 a$ \\
\hline RAMP & GSP & $3525 \quad 02-24-94$ & $3: 27 a$ \\
\hline README & 354 & $761106-17-92$ & $3: 54 a$ \\
\hline RUNTIME & EXE & $\begin{array}{l}401424 \\
02-24-94\end{array}$ & $3: 27 a$ \\
\hline SEL & GSP & $\begin{array}{lll}3718 & 02-24-94\end{array}$ & $3: 27 a$ \\
\hline SEQ & GSP & $2131 \quad 02-24-94$ & $3: 27 a$ \\
\hline SET_EMS & EXE & $12857 \quad 06-17-92$ & $3: 54 a$ \\
\hline SIM & GSP & $3038 \quad 02-24-94$ & $3: 27 a$ \\
\hline SLOGIC & GSP & $236002-24-94$ & $3: 27 a$ \\
\hline SORTIDBM & GSP & $1976 \quad 02-24-94$ & $3: 27 a$ \\
\hline SORTMAIN & GSP & $2164 \quad 02-24-94$ & $3: 27 a$ \\
\hline SORTMENU & GSP & $\begin{array}{lll}1128 & 02-24-94\end{array}$ & $3: 27 a$ \\
\hline SPULLNOT & GSP & $\begin{array}{lll}1503 & 02-24-94\end{array}$ & $3: 27 a$ \\
\hline STANDARD & CFN & $18899 \quad 02-24-94$ & $3: 27 a$ \\
\hline STANDARD & HLS & $1908 \quad 02-24-94$ & $3: 27 a$ \\
\hline STANDARD & $\mathrm{KML}$ & $544 \quad 02-24-94$ & $3: 27 a$ \\
\hline STAT1 & GSP & $2271 \quad 02-24-94$ & $3: 27 a$ \\
\hline STAT2 & GSP & $2053 \quad 02-24-94$ & $3: 27 \mathrm{a}$ \\
\hline STATECMP & EXE & $2856102-24-94$ & $3: 27 a$ \\
\hline STRING & MNU & $1027 \quad 02-24-94$ & $3: 27 a$ \\
\hline
\end{tabular}


HNF-SD-WM-CSDD-008

Rev. 3

Page 145

\begin{tabular}{|c|c|c|c|c|}
\hline SUPMAC & MNU & 2461 & $02-24-94$ & $3: 27 a$ \\
\hline $\mathrm{SWCH}$ & GSP & 2925 & $02-24-94$ & $3: 27 a$ \\
\hline SYSCONF & GSP & 3011 & $02-24-94$ & $3: 27 \mathrm{a}$ \\
\hline SYSCONF & MNU & 15280 & $02-24-94$ & $3: 27 a$ \\
\hline SYSCONF2 & GSP & 2891 & $02-24-94$ & $3: 27 a$ \\
\hline SYSPERF & GSP & 2325 & $02-24-94$ & $3: 27 \mathrm{a}$ \\
\hline TD & GSP & 3086 & $02-24-94$ & $3: 27 a$ \\
\hline TESTHDW & EXE & 11969 & $06-17-92$ & $3: 54 a$ \\
\hline TIMERS & GSP & 2363 & $02-24-94$ & $3: 27 a$ \\
\hline TOT & GSP & 3285 & $02-24-94$ & $3: 27 a$ \\
\hline TPO & GSP & 3658 & $02-24-94$ & $3: 27 a$ \\
\hline TREND & GSP & 467 & $02-24-94$ & $3: 27$ a \\
\hline TRENDLST & GSP & 2042 & $02-24-94$ & $3: 27 \mathrm{a}$ \\
\hline TRENDMEN & GSP & 1990 & $02-24-94$ & $3: 27 a$ \\
\hline TRENDREP & GSP & 3400 & $02-24-94$ & $3: 27 a$ \\
\hline TUNE & GSP & 3152 & $02-24-94$ & $3: 27 \mathrm{a}$ \\
\hline TUNE2 & GSP & 3156 & $02-24-94$ & $3: 27 a$ \\
\hline TUNE3 & GSP & 2935 & $02-24-94$ & $3: 27 a$ \\
\hline TUNE4 & GSP & 2432 & $02-24-94$ & $3: 27 \mathrm{a}$ \\
\hline USER & GSP & 3967 & $02-24-94$ & $3: 27 a$ \\
\hline USER2 & GSP & 3090 & $02-24-94$ & $3: 27 \mathrm{a}$ \\
\hline$X C$ & GSP & 3543 & $02-24-94$ & $3: 27 a$ \\
\hline XLATE & EXE & 78445 & $02-24-94$ & $3: 27 a$ \\
\hline CTLDET & GSP & 2896 & $02-24-94$ & $3: 27 a$ \\
\hline ELECTRIC & SMB & 2837 & $02-24-94$ & $3: 27 a$ \\
\hline FACEPLAT & SMB & 15558 & $02-24-94$ & $3: 27 a$ \\
\hline HPPJET & PRP & 36 & $05-08-92$ & $3: 53 a$ \\
\hline HPPJET & PTR & 2560 & $05-08-92$ & $3: 53 a$ \\
\hline IBMPRO & PRP & 36 & $09-17-90$ & $3: 32 a$ \\
\hline IBMPRO & PTR & 2048 & $09-17-90$ & $3: 32 a$ \\
\hline NEWUET & PRP & 82 & $05-08-92$ & $3: 53 a$ \\
\hline NEWJET & PTR & 2560 & $05-08-92$ & $3: 53 a$ \\
\hline README & 353 & 6763 & $05-08-92$ & $3: 53 a$ \\
\hline READPTR & ME & 562 & $05-08-92$ & $3: 53 a$ \\
\hline XROX 4020 & PRP & 82 & $05-08-92$ & $3: 53 a$ \\
\hline XROX4020 & PTR & 2560 & $05-08-92$ & $3: 53 a$ \\
\hline HEATEXCH & SMB & 846 & $02-24-94$ & $3: 27 a$ \\
\hline LOGIC & $S M B$ & 1353 & $02-24-94$ & $3: 27 a$ \\
\hline MODICON & 350 & 282 & $04-03-92$ & $3: 50 a$ \\
\hline MODICON & DES & 2418 & $04-03-92$ & $3: 50 a$ \\
\hline MODICON & DRV & 7038 & $04-03-92$ & $3: 50 a$ \\
\hline MODICON & MNU & 14762 & $04-03-92$ & $3: 50 a$ \\
\hline MACHINE & SMB & 1841 & $02-24-94$ & $3: 27 \mathrm{a}$ \\
\hline MISC & SMB & 1680 & $02-24-94$ & $3: 27 a$ \\
\hline MOTORS & SMB & 396 & $02-24-94$ & $3: 27 a$ \\
\hline PRESS & SMB & 1755 & $02-24-94$ & $3: 27 a$ \\
\hline STATES & SFL & 642 & $02-24-94$ & $3: 27 a$ \\
\hline DOSNODE & PWD & 226 & $02-18-94$ & 5:01p \\
\hline DOSPWD & EXE & 113849 & $02-18-94$ & $5: 01 p$ \\
\hline DOSPWD & MNU & 959 & $02-18-94$ & 5:01p \\
\hline
\end{tabular}




\begin{tabular}{|c|c|c|c|}
\hline$E G A$ & DEV & $13450 \quad 02-18-94$ & $5: 01 p$ \\
\hline GCOPY & BAT & $33 \quad 01-15-92$ & $3: 52 a$ \\
\hline GCOPY & EXE & $145747 \quad 02-18-94$ & $5: 01 p$ \\
\hline GEN_NET & OPT & $6155101-15-92$ & $3: 52 \mathrm{a}$ \\
\hline GENCEXIT & GSP & $928 \quad 02-18-94$ & $5: 02 p$ \\
\hline GENCFG & GNF & $265 \quad 02-18-94$ & $1: 36 a$ \\
\hline GENCFG & MNU & $3393402-18-94$ & 5:01p \\
\hline GENCFGB & MNU & $2419001-15-92$ & $3: 52 a$ \\
\hline GENCMDR & BAT & $46 \quad 01-15-92$ & $3: 52 a$ \\
\hline ENCMDR & $D O C$ & $591202-18-94$ & $5: 02 p$ \\
\hline NCMDR & EXE & $260257 \quad 02-18-94$ & $5: 02 p$ \\
\hline NCMDR & GSP & $948 \quad 02-18-94$ & $5: 02 p$ \\
\hline NCMDR & HLP & $23280 \quad 02-18-94$ & $5: 02 p$ \\
\hline ECMDR & MNU & $768202-18-94$ & $5: 020$ \\
\hline ENCMDR & NDX & $625 \quad 02-18-94$ & $5: 02 p$ \\
\hline GENCMDR & OPT & $\begin{array}{lll}43487 & 02-18-94\end{array}$ & $5: 02 p$ \\
\hline GENCMDR2 & GSP & $\begin{array}{lll}860 & 02-18-94\end{array}$ & $5: 02 p$ \\
\hline GENCOMP & EXE & $4406902-18-94$ & $5: 01 p$ \\
\hline GENCONF & EXE & $91957 \quad 02-18-94$ & 5:01p \\
\hline GENMON & EXE & $1648702-18-94$ & $5: 01 p$ \\
\hline GN_CA & OPT & $66311 \quad 01-1$ & $3: 52 a$ \\
\hline$G N \_C B$ & OPT & $9108901-$ & $3: 52 a$ \\
\hline GN_CFA & OPT & $99255 \quad 01-15-92$ & $3: 52 a$ \\
\hline $\mathrm{GN}^{-} \mathrm{CFB}$ & OPT & $12403301-$ & $3: 52 a$ \\
\hline GN_COMM & OPT & $35453 \quad 02-18-94$ & $5: 02 p$ \\
\hline GN_DB & $\mathrm{OPT}$ & $86329 \quad 0$ & $3: 52 \mathrm{a}$ \\
\hline GN_DCA & OPT & $77441 \quad 01-15-92$ & $3: 52 a$ \\
\hline GN_DCB & $\mathrm{OPT}$ & $10223501-15-92$ & $3: 52 a$ \\
\hline GN_DCFA & OPT & $11089701-15-92$ & $3: 52 a$ \\
\hline GNDCFB & OPT & $135675 \quad 01-15-92$ & $3: 52 a$ \\
\hline GN_DFA & OPT & $9499101-15-92$ & $3: 52 \mathrm{a}$ \\
\hline GN_DFB & OPT & $11927301-15-92$ & $3: 52 a$ \\
\hline GN_DRVR & OPT & $\begin{array}{lll}67307 & 02-18-94\end{array}$ & $5: 02 p$ \\
\hline GN_FTP & OPT & $5221902-18-94$ & $5: 02 p$ \\
\hline GN_INTF & OPT & $32731 \quad 02-18-94$ & $5: 02 p$ \\
\hline GN_INTFB & $\mathrm{OPT}$ & $56305 \quad 01-15-92$ & $3: 52 a$ \\
\hline GN_TIMER & EXE & $13851 \quad 02-18-94$ & 5:01p \\
\hline GN_TIMER & SYS & $1856 \quad 02-18-94$ & 5:01p \\
\hline GNETOIR & GSP & $676 \quad 02-18-94$ & 5:01p \\
\hline GNETMON & GSP & $2073 \quad 02-18-94$ & $5: 01 p$ \\
\hline GNETMON2 & GSP & $2045 \quad 02-18-94$ & $5: 01 p$ \\
\hline GNFXEXIT & GSP & $972 \quad 02-18-94$ & $5: 01 p$ \\
\hline GNFXR1 & GSP & $1053 \quad 02-18-94$ & $5: 01 p$ \\
\hline GNFXR2 & GSP & $1043 \quad 02-18-94$ & $5: 01 p$ \\
\hline GNFXR3 & GSP & $1024 \quad 02-18-94$ & $5: 01 p$ \\
\hline GNFXR4 & GSP & $82702-18-94$ & $5: 01 p$ \\
\hline LOGO_NET & DAT & $\begin{array}{ll}9 & 02-18-94\end{array}$ & $1: 36 a$ \\
\hline PS110RST & EXE & $15259 \quad 02-18-94$ & 5:01p \\
\hline README & DOC & $591201-15-92$ & $3: 52 \mathrm{a}$ \\
\hline HOW_OPT & EXE & $1593102-18-94$ & 5:01p \\
\hline
\end{tabular}


HNF-SD-WM-CSDD-008

Rev. 3

Page 147

\begin{tabular}{|c|c|c|c|}
\hline UNPACK & EXE & $29378 \quad 02-18-94$ & $1: 36 a$ \\
\hline STATES & SFS & $91302-24-94$ & $3: 27 a$ \\
\hline DXFTOGRP & EXE & $58777 \quad 10-31-91$ & $1: 31 a$ \\
\hline GRPTODXF & EXE & $39665 \quad 10-31-91$ & $1: 31 a$ \\
\hline RRCOMBO & OPT & $73309 \quad 04-28-93$ & $3: 26 a$ \\
\hline TANKS & SMB & $1890 \quad 02-24-94$ & $3: 27 a$ \\
\hline VALVES & SMB & $236402-24-94$ & $3: 27$ a \\
\hline VATS & SMB & $3741 \quad 02-24-94$ & $3: 27 a$ \\
\hline HPLSRJII & PRP & $\begin{array}{ll}36 & 09-17-90\end{array}$ & $3: 32 a$ \\
\hline HPLSRJII & PTR & $256009-17-90$ & $3: 32 a$ \\
\hline CONFMSMI & $\mathrm{COM}$ & $1487 \quad 02-18-94$ & $5: 01 p$ \\
\hline CONF104 & FNT & $\begin{array}{lll}7168 & 02-18-94\end{array}$ & $5: 01 p$ \\
\hline BOOT & BAT & $79 \quad 02-18-94$ & $5: 01 p$ \\
\hline CONFIG & PRM & $407 \quad 08-03-94$ & $10: 09 a$ \\
\hline AUTOCAD & $D O C$ & $998410-31-91$ & $1: 31 a$ \\
\hline SHUTTLE & SMB & $48419 \quad 10-31-91$ & $1: 31 \mathrm{a}$ \\
\hline REC & GSP & 226610 & $3: 41 a$ \\
\hline RRTEST & EXE & $68794 \quad 10-07-91$ & $3: 41 \mathrm{a}$ \\
\hline README & 341 & $243410-07-91$ & $3: 41 \mathrm{a}$ \\
\hline TEST & GIF & $2201901-$ & $11: 25 p$ \\
\hline RSSBOOT & GSP & 345002 & $11: 29 a$ \\
\hline STANDARD & HLP & $137301-$ & $4: 16 p$ \\
\hline AF 5000 & DRV & $3506604-29-94$ & $3: 52 a$ \\
\hline AF5000 & AIF & $1695905-12-92$ & $3: 52 \mathrm{a}$ \\
\hline AF 5000 & DES & $448 \quad 05-05-92$ & $3: 52 a$ \\
\hline AF5000 & DOC & $3171605-12-92$ & $3: 52 a$ \\
\hline AF5000 & MNU & $81205-06-92$ & $3: 52 a$ \\
\hline MODPLUS & DES & $448 \quad 02-09-94$ & $3: 38 a$ \\
\hline MODPLUS & DRV & $1976608-$ & $9: 55 p$ \\
\hline MODPLUS & MNU & $12100 \quad 08-24-94$ & $3: 38 a$ \\
\hline MODPLUS & DOC & $2352403-$ & $3: 38 a$ \\
\hline MODPLUS & 335 & 57906 & $3: 36 a$ \\
\hline MODPLUS & 336 & 74706 & $36 a$ \\
\hline GNETMON3 & GSP & 191602. & $5: 01 p$ \\
\hline DANISH & FNT & $153602-$ & $3: 27 \mathrm{a}$ \\
\hline CONFIG & SYS & $26 \quad 02-24-94$ & $3: 27 \mathrm{a}$ \\
\hline README & 372 & $8135 \quad 02-24-94$ & $3: 27 \mathrm{a}$ \\
\hline ALARM & GSP & $2219 \quad 02-24-94$ & $3: 27 a$ \\
\hline BLANK & GSP & $243 \quad 02-24-94$ & $3: 27 a$ \\
\hline EVENT & GSP & $2212 \quad 02-24-94$ & $3: 27 \mathfrak{a}$ \\
\hline RRCOMBO & GSP & $2450 \quad 02-24-94$ & $3: 27 a$ \\
\hline USER2_2 & GSP & $\begin{array}{lll}3090 & 02-24-94\end{array}$ & $3: 27 a$ \\
\hline USER2_3 & GSP & $3090 \quad 02-24-94$ & $3: 27 \mathrm{a}$ \\
\hline USER2_4 & GSP & $3090 \quad 02-24-94$ & $3: 27 \mathrm{a}$ \\
\hline USER2 5 & GSP & $\begin{array}{lll}3090 & 02-24-94\end{array}$ & $3: 27 a$ \\
\hline USER2_6 6 & GSP & $3090 \quad 02-24-94$ & $3: 27 a$ \\
\hline USER2-7 & GSP & $3090 \quad 02-24-94$ & $3: 27 a$ \\
\hline USER3 & GSP & $\begin{array}{lll}1855 & 02-24-94\end{array}$ & $3: 27 a$ \\
\hline USER3_2 & GSP & $1855 \quad 02-24-94$ & $3: 27 a$ \\
\hline USER3_3 & GSP & $\begin{array}{lll}1855 & 02-24-94\end{array}$ & $3: 27 \mathrm{a}$ \\
\hline
\end{tabular}




$\begin{array}{llrll}\text { USER3_4 } & \text { GSP } & 1855 & 02-24-94 & 3: 27 \mathrm{a} \\ \text { USER3_5 } & \text { GSP } & 1855 & 02-24-94 & 3: 27 \mathrm{a} \\ \text { USER3_6 } & \text { GSP } & 1855 & 02-24-94 & 3: 27 \mathrm{a} \\ \text { USER3_7 } & \text { GSP } & 1855 & 02-24-94 & 3: 27 \mathrm{a} \\ \text { USER_2 } & \text { GSP } & 3967 & 02-24-94 & 3: 27 \mathrm{a} \\ \text { USER_3 } & \text { GSP } & 3967 & 02-24-94 & 3: 27 \mathrm{a} \\ \text { USER_4 } & \text { GSP } & 3967 & 02-24-94 & 3: 27 \mathrm{a} \\ \text { USER_5 } & \text { GSP } & 3967 & 02-24-94 & 3: 27 \mathrm{a} \\ \text { USER_6 } & \text { GSP } & 3967 & 02-24-94 & 3: 27 \mathrm{a} \\ \text { USER77 } & \text { GSP } & 3967 & 02-24-94 & 3: 27 \mathrm{a} \\ \text { SHADOW } & \text { GSP } & 1912 & 02-18-94 & 5: 01 \mathrm{p} \\ \text { NETALMS } & \text { GSP } & 1825 & 02-18-94 & 5: 01 p \\ \text { EXPORT } & \text { OPT } & 18307 & 02-18-94 & 5: 01 p \\ \text { MODPLUS } & 338 & 60 & 09-23-94 & 3: 38 \mathrm{a} \\ \text { HPLSR4 } & \text { PRP } & 36 & 03-31-94 & 5: 12 \mathrm{p} \\ \text { HPLSR4 } & \text { PTR } & 2560 & 09-17-90 & 3: 32 \mathrm{a} \\ \text { HELP } & \text { HLS } & 1481 & 02-16-95 & 3: 01 \mathrm{p} \\ \text { HELP } & \text { HLP } & 998 & 02-16-95 & 3: 01 \mathrm{p}\end{array}$

\section{Directory of C: \TEST}

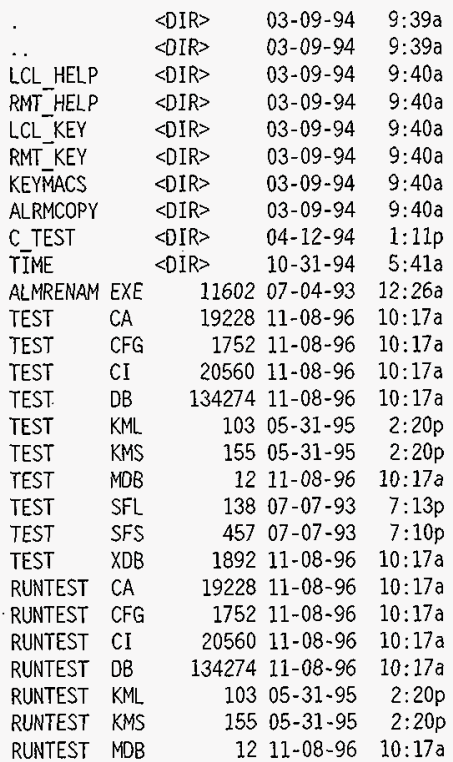




\begin{tabular}{|c|c|c|c|c|}
\hline RUNTEST & XDB & 1892 & $11-08-96$ & $10: 17 a$ \\
\hline ROLLOVER & GRP & 13928 & $04-04-96$ & $4: 51 p$ \\
\hline ABRTENAB & GRP & 44959 & $04-11-96$ & $11: 13 a$ \\
\hline ABRTNAME & GRP & 28563 & $04-11-96$ & $11: 14 a$ \\
\hline ASMAIN & GRP & 2827 & $07-28-94$ & $5: 47 p$ \\
\hline CSMAIN & GRP & 9058 & $04-24-96$ & $2: 33 p$ \\
\hline DACS & GRP & 12755 & $03-11-94$ & $10: 19 a$ \\
\hline GASSUM & GRP & 9140 & $04-08-96$ & $10: 04 a$ \\
\hline HVTALARM & GRP & 10289 & $04-24-96$ & $3: 03 p$ \\
\hline IOSTATUS & GRP & 13096 & $06-08-95$ & $2: 04 p$ \\
\hline MANABRT & GRP & 4199 & $04-16-96$ & $8: 22 a$ \\
\hline MAP & GRP & 4087 & $03-22-95$ & $1: 55 p$ \\
\hline MININ1 & GRP & 15878 & $04-12-96$ & $12: 28 p$ \\
\hline MININ2 & GRP & 12135 & $09-04-96$ & 1:04p \\
\hline MIT178 & GRP & 13092 & $3-96$ & $12: 38 p$ \\
\hline MIT17C & GRP & 11621 & $0-94$ & $8: 14 a$ \\
\hline MSMAIN & GRP & 5643 & $4-96$ & $2: 53 p$ \\
\hline NEW72HR & GRP & 5626 & -96 & $9: 43 a$ \\
\hline OLD72HR & GRP & 5631 & & $9: 46 a$ \\
\hline PUMP & GRP & 9579 & -96 & $5: 17 p$ \\
\hline PUMPALRM & GRP & 8695 & -95 & $11: 27 a$ \\
\hline PUMPOPS & GRP & 5126 & $03-29-96$ & $4: 15 p$ \\
\hline ABRTCHEK & GRP & 10487 & $04-24-96$ & $3: 08 p$ \\
\hline STRNALM & GRP & 11330 & $04-04-96$ & $5: 21 p$ \\
\hline SUMMARY & GRP & 11579 & $03-03-95$ & $9: 53 a$ \\
\hline SY101-1 & GRP & 7092 & $01-28-94$ & $12: 27 p$ \\
\hline TBSTC & GRP & 1392 & $10-26-94$ & $11: 08 a$ \\
\hline TEMPALM & GRP & 10475 & $03-29-96$ & $4: 24 p$ \\
\hline TEMPRFL & GRP & 13453 & -94 & $8: 24 a$ \\
\hline TESTEXIT & GRP & 2574 & -95 & $10: 54 a ̂ a$ \\
\hline WELCOME & GRP & 3450 & -95 & $11: 29 a$ \\
\hline BOOT & GSP & 3450 & $02-15-95$ & $11: 29 a$ \\
\hline HELP & GSP & 1217 & $06-17-92$ & $3: 54 a$ \\
\hline HELP.1 & GSP & 1217 & $03-29-94$ & $10: 40 a$ \\
\hline HELP2 & GSP & 1217 & $03-29-94$ & $10: 40 a$ \\
\hline HELP3 & GSP & 1217 & $03-29-94$ & $10: 40 a$ \\
\hline HELP4 & GSP & 1217 & $03-29-94$ & $10: 40 a$ \\
\hline HELP5 & GSP & 1217 & $03-29-94$ & $10: 40 a$ \\
\hline HELP6 & GSP & 1217 & $03-$ & $10: 40 a$ \\
\hline RSSBOOT & GSP & 3450 & $02-$ & $11: 29 a$ \\
\hline HISTCOPY & RPS & 2712 & $08-12-94$ & $3: 24 p$ \\
\hline HISTFNAM & RPS & 1243 & $08-12-94$ & $3: 23 p$ \\
\hline SETLIMS & RPS & 1423 & $04-03-96$ & $3: 17 p$ \\
\hline ALARMOO & TXT & 9108 & $03-12-97$ & $11: 03 a$ \\
\hline STORE & DT & & $03-12-97$ & $10: 00 a$ \\
\hline FN & DT & & $03-12-97$ & $10: 00 a$ \\
\hline 73CAPUMP & PRN & 1616 & ; $03-12-97$ & $11: 03 a$ \\
\hline NEW72 & PRN & 52625 & $03-12-97$ & $11: 03 a$ \\
\hline TEST & LST & & $03-12-97$ & $11: 06 a$ \\
\hline OLDFN & DT & & $03-12-97$ & $10: 0$ \\
\hline
\end{tabular}




$\begin{array}{llrlr}\text { TEST } & \text { NEW } & 134274 & 02-11-97 & 1: 37 p \\ \text { RSS } & \text { BAT } & 927 & 05-25-95 & 2: 42 p \\ \text { XXX } & \text { XXX } & 26 & 03-10-97 & 7: 08 p \\ \text { OLD72 } & \text { PRN } & 93773 & 03-10-97 & 7: 08 p \\ \text { 73CAMIT2 } & \text { PRN } & 39963 & 03-12-97 & 11: 03 a \\ \text { 73CATBS1 } & \text { PRN } & 2236 & 03-12-97 & 11: 03 a \\ \text { 73CAMIT1 } & \text { PRN } & 44981 & 03-12-97 & 11: 03 a \\ \text { 73CAGAS } & \text { PRN } & 4003 & 03-12-97 & 11: 03 a \\ \text { 73CARGA5 } & \text { PRN } & 2855 & 03-12-97 & 11: 03 a \\ \text { 73CAMIT3 } & \text { PRN } & 39715 & 03-12-97 & 11: 03 a \\ \text { 73CATBS2 } & \text { PRN } & 2236 & 03-12-97 & 11: 03 a \\ \text { 73CASTRN } & \text { PRN } & 2708 & 03-12-97 & 11: 03 a \\ \text { 73CAVOL } & \text { PRN } & 54921 & 03-12-97 & 11: 03 a\end{array}$

Directory of C: \TEST\LCL_HELP

\begin{tabular}{lllll} 
& \multicolumn{2}{c}{ CDIR> } & $03-09-94$ & $9: 40 a$ \\
STANDARD HLS & 1981 & $01-14-94$ & $4: 12 \mathrm{p}$ \\
STARD & & $03-09-94$ & $9: 40 \mathrm{a}$ \\
STANDARD & HLP & 1373 & $01-14-94$ & $4: 16 \mathrm{p}$ \\
HELP & GSP & 1217 & $06-17-92$ & $3: 54 \mathrm{a}$ \\
HELP1 & GSP & 1217 & $01-14-94$ & $4: 16 \mathrm{p}$ \\
HELP2 & GSP & 1217 & $01-14-94$ & $4: 16 \mathrm{p}$ \\
HELP3 & GSP & 1217 & $01-14-94$ & $4: 16 \mathrm{p}$ \\
HELP4 & GSP & 1217 & $01-14-94$ & $4: 16 \mathrm{p}$ \\
HELP5 & GSP & 1217 & $01-14-94$ & $4: 16 \mathrm{p}$ \\
HELP6 & GSP & 1217 & $01-14-94$ & $4: 16 \mathrm{p}$
\end{tabular}

Directory of C: $\backslash$ TEST \RMT_HELP

$\begin{array}{lllll} & & \text { CDIR> } & 03-09-94 & 9: 40 a \\ \text { STANDARD } & \text { HLS } & \text { CDIR> } & 03-09-94 & 9: 40 a \\ \text { STALP } & 2162 & 01-14-94 & 4: 09 p \\ \text { HELP } & \text { GSP } & 1217 & 06-17-92 & 3: 54 a \\ \text { HELP1 } & \text { GSP } & 1217 & 01-14-94 & 4: 17 p \\ \text { HELP2 } & \text { GSP } & 1217 & 01-14-94 & 4: 17 p \\ \text { HELP3 } & \text { GSP } & 1217 & 01-14-94 & 4: 17 p \\ \text { HELP4 } & \text { GSP } & 1217 & 01-14-94 & 4: 17 p \\ \text { HELP5 } & \text { GSP } & 1217 & 01-14-94 & 4: 17 p \\ \text { HELP6 } & \text { GSP } & 1217 & 01-14-94 & 4: 17 p \\ \text { STANDARO HLP } & 1366 & 01-14-94 & 4: 17 p\end{array}$


Directory of C: \TEST \LCL_KEY

$\begin{array}{lllrl} & & <D I R> & 03-09-94 & 9: 40 a \\ . & & \text { CIR }> & 03-09-94 & 9: 40 a \\ \text { TEST } & \text { KML } & & 5504-24-93 & 1: 40 \mathrm{p} \\ \text { TEST } & \text { KMS } & & 3204-23-93 & 5: 16 \mathrm{p}\end{array}$

Directory of C: \TEST \RMT_KEY

\begin{tabular}{|c|c|c|c|c|}
\hline & \multirow{2}{*}{\multicolumn{2}{|c|}{$\begin{array}{l}\langle D I R\rangle \\
\langle D I R\rangle\end{array}$}} & $03-09-94$ & $9: 40 a$ \\
\hline & & & $03-09-94$ & $9: 40 a$ \\
\hline STT & KML & 1437 & $01-22-94$ & $1: 57 p$ \\
\hline ST & KMS & 9293 & $01-22-94$ & $1: 57 p$ \\
\hline
\end{tabular}

Directory of $C: \backslash T E S T \backslash K E Y M A C S$

$\begin{array}{llrrr} & & \text { CDIR> } & 03-09-94 & 9: 40 a \\ \text { TEST } & \text { KML } & 103 & 05-31-95 & 2: 40 \mathrm{a} \\ \text { TEIR> } & 03-09-94 & 9: 40 \mathrm{a} \\ \text { TEST } & \text { KMS } & 155 & 05-31-95 & 2: 20 \mathrm{p} \\ \text { HELP } & \text { GSP } & 1217 & 06-17-92 & 3: 54 \mathrm{a} \\ \text { HELP1 } & \text { GSP } & 1217 & 04-24-93 & 1: 43 p \\ \text { HELP2 } & \text { GSP } & 1217 & 04-24-93 & 1: 43 p \\ \text { HELP3 } & \text { GSP } & 1217 & 04-24-93 & 1: 43 p \\ \text { HELP4 } & \text { GSP } & 1217 & 04-24-93 & 1: 43 p \\ \text { HELP5 } & \text { GSP } & 1217 & 04-24-93 & 1: 43 p \\ \text { HELP6 } & \text { GSP } & 1217 & 04-24-93 & 1: 43 p\end{array}$

Directory of C: \TEST \ALRMCOPY

\begin{tabular}{lrrrr} 
& \multicolumn{2}{c}{$<D I R>$} & $03-09-94$ & $9: 40 a$ \\
RUNTIME & BAT & LIR $>$ & $03-09-94$ & $9: 40 a$ \\
RUI & 187 & $11-14-94$ & $2: 36 \mathrm{p}$ \\
ALEXP & EXE & 11602 & $07-04-93$ & $12: 26 a$ \\
RUNTIME & OLD & 186 & $07-08-93$ & $11: 50 \mathrm{p}$ \\
ALMRENAM & EXE & 11602 & $07-04-93$ & $12: 26 a$
\end{tabular}

Directory of C:ITESTIC_TEST

\begin{tabular}{|c|c|c|c|}
\hline & $\langle Q I R\rangle$ & $04-12-94$ & $1: 11 p$ \\
\hline & $\langle D I R\rangle$ & $04-12-94$ & $1: 11 \mathrm{p}$ \\
\hline LMRENAM CPP & 1760 & $04-11-94$ & $12: 55 p$ \\
\hline COPY BAT & 87 & $12-10-93$ & $3: 46 p$ \\
\hline RENAM OBJ & 1603 & $07-04-93$ & $12: 26 a$ \\
\hline IRENAM EXE & 11602 & $07-04-93$ & 120 \\
\hline
\end{tabular}




\title{
DACS STATION 5 FILE LISTINGS
}

\author{
"ALMCOPY.BAT" on Station 5 \\ copy \testlalarm00.txt \hist\6B6029AL. TXT \\ copy Itestlalarm00.txt hist2\6B6029AL. TXT
}

"AUTOEXEC.BAT" on Station 5

aECHO OFF

PROMPT $\$ p \$ g$

C: WNETROOM XLOAD. EXE C: IMOUSEYMOUSE

goto \%config\%

:GEN354

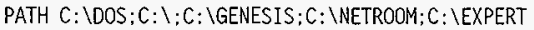

goto end

:GEN372

PATH C:\DOS:C: $\backslash: C: \backslash G E N 372 ; C: \backslash N E T R O O M ; C: \backslash E X P E R T$

SHARE

goto end

:end

"CONFIG.SYS" on Station 5

[MENU]

menui tem=GEN354.Genesis system version 3.54

menuitem $=G E N 372$, Genesis system version 3.72

menudefau $1 \mathrm{t}=\mathrm{GEN} 372[, 0]$

[COMMON]

DEVICE $=C$ : WWETROOM $\backslash$ RM 386 . EXE AUTO $X=0900$-DDFF

DEVICE $=C:$ : NETROOM $S Y S C L O A K . E X E$

DEVICE $=C: \backslash$ NETROOM XLOAD . SYS -O

BUFFERS $=20,0$

FILES $=55$

LASTDRIVE $=E$

FCBS $=4,0$

STACKS $=0.0$

SHELL=C: \NETROOM XLOAD.EXE -SDE01 -M57021 -E C: \DOSICOMMAND.COM C: \DOSI /p DEVICE $=$ C: \NETROOM \STACKS. EXE 9.256

[GEN354]

[GEN372] 
"RUNTIME.BAT" on Station 5

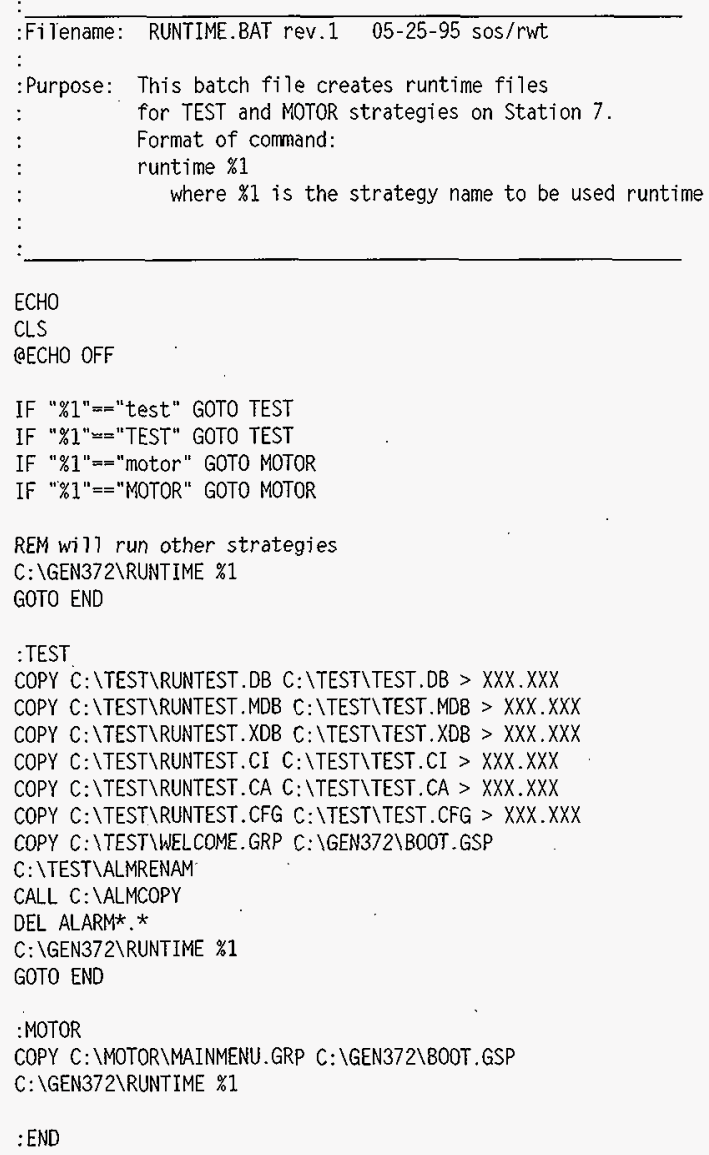

REM will run other strategies C: \GEN372\RUNTIME \%1

GOTO END

\section{:TEST}

COPY C: \TEST \RUNTEST.DB C: $\backslash T E S T \backslash T E S T . D B>X X X . X X X$

COPY C: \TEST\RUNTEST.MDB C: $\backslash T E S T \backslash T E S T . M D B>X X X . X X X$

COPY C: $\backslash T E S T \backslash R U N T E S T . X D B C: \backslash T E S T \backslash T E S T . X D B>X X X . X X X$

COPY C: \TEST \RUNTEST.CI $C: \backslash T E S T \backslash T E S T . C I>X X X . X X X$

COPY $C: \backslash \backslash T E S T \backslash R U N T E S T . C A$ C: $\backslash T E S T \backslash T E S T . C A>X X X . X X X$

COPY C: $\backslash T E S T \backslash R U N T E S T . C F G ~ C: \backslash T E S T \backslash T E S T . C F G>X X X . X X X$

COPY C: \TEST \WELCOME.GRP C: \GEN372\BOOT.GSP

C: ITEST \ALMRENAM

CALL C: \ALMCOPY

DEL ALARM***

C: IGEN372\RUNTIME $\% 1$

GOTO END

:MOTOR

COPY C: WOTORIMAINMENU.GRP C: \GEN372\BOOT.GSP

C: \GEN372\RUNTIME \%1 
HNF-SD-WM-CSDD-008

Rev. 3

Page 154

"RENAME72.BAT" on Station 5

$\begin{array}{ll}: & \\ : \text { Filename: } & \text { RENAME72.BAT } \\ : \text { Purpose: } & \text { This batch file deletes OLD72.PRN and renames } \\ \vdots & \text { NEW72.PRN to OLD72.PRN to help minimize the } \\ \vdots & \text { file size build up of NEW72. PRN } \\ \vdots & \text { Executed manually at DOS prompt when desired. }\end{array}$

DEL OLO72.PRN

REN NEW72.PRN OLD72.PRN 


\title{
DACS STATION 6 DIRECTORY LISTINGS
}

\author{
Volume in drive $C$ is MS-DOS 5 \\ Volume Serial Number is $1 \mathrm{C} 2 \overline{8}-514 E$ \\ 188358656 bytes free

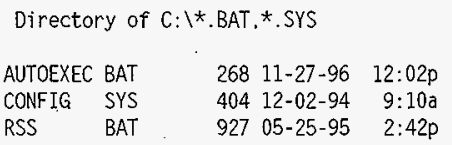

Directory of C: \GEN372

\begin{tabular}{|c|c|c|c|c|}
\hline & & $\begin{array}{l}\mathrm{IR}> \\
\mathrm{IR}>\end{array}$ & $\begin{array}{l}04-07-94 \\
04-07-94\end{array}$ & $\begin{array}{l}12: 20 \mathrm{p} \\
12: 20 \mathrm{p}\end{array}$ \\
\hline REPORT & OPT & 57547 & $05-01-90$ & $3: 21 \mathrm{a}$ \\
\hline IBMPRO & PRP & 36 & $09-17-90$ & $3: 32 a$ \\
\hline HPLSRJII & PRP & 36 & $09-17-90$ & $3: 32 a$ \\
\hline IBMPRO & PTR & 2048 & $09-17-90$ & $3: 32 a$ \\
\hline HPLSRJII & PTR & 2560 & $09-17-90$ & $3: 32 a$ \\
\hline RCOMBO & OPT & 73309 & $04-28-93$ & $3: 26 a$ \\
\hline COUNTRY & $F R$ & 4 & $10-31-91$ & $3: 52 a$ \\
\hline COUNTRY & GR & 5 & $10-31-91$ & $3: 52 a$ \\
\hline 560 & DAT & 9 & $02-24-94$ & $3: 27 a$ \\
\hline PSON_MX & PRP & 36 & $02-24-94$ & $3: 27 \mathrm{a}$ \\
\hline LISTMATIN & GSP & 363 & $02-24-94$ & $3: 27 a$ \\
\hline HCURS & GSP & 415 & $02-24-94$ & $3: 27 a$ \\
\hline PLOT & GSP & 465 & $02-24-94$ & $3: 27 a$ \\
\hline TREND & GSP & 467 & $02-24-94$ & $3: 27 \mathrm{a}$ \\
\hline STANDARD & KML & 511 & $02-24-94$ & $3: 27 a$ \\
\hline VET_OLD & KML & 510 & $02-24-94$ & $3: 27 a$ \\
\hline DBENTRY & GSP & 663 & $02-24-94$ & $3: 27 a$ \\
\hline HGREP & GSP & 781 & $02-24-94$ & $3: 27 a$ \\
\hline BREP & GSP & 1226 & $02-24-94$ & $3: 27 a$ \\
\hline EMPTY & GSP & 845 & $02-$ & $3: 27 a$ \\
\hline DISPSEC & GSP & 980 & -94 & $3: 27 a$ \\
\hline DISPSAV & GSP & 1001 & $02-24-94$ & $3: 27 a$ \\
\hline EXIT & GSP & 1021 & $02-24-94$ & $3: 27 a$ \\
\hline SORTMENU & GSP & 1128 & $02-24-94$ & $3: 27 a$ \\
\hline LISTMENU & GSP & 1657 & $02-24-94$ & $3: 27 \mathrm{a}$ \\
\hline IDBSTG & GSP & 1271 & $02-24-94$ & $3: 27 a$ \\
\hline IDBSTGO & GSP & 1309 & $02-24-94$ & $3: 27 a$ \\
\hline HGLSTMEN & GSP & 1344 & $02-24-94$ & $3: 27 a$ \\
\hline IDBDOTB & GSP & 1325 & $02-24-94$ & $3: 27 \mathrm{a}$ \\
\hline ILEUTIL & GSP & 1296 & $02-24-94$ & $3: 27 a$ \\
\hline & & 1588 & $02-24-94$ & $3: 27 a$ \\
\hline
\end{tabular}




\begin{tabular}{|c|c|c|c|}
\hline HGREPMEN & GSP & $1408 \quad 02-24-94$ & $3: 27 a$ \\
\hline IDBSIO & GSP & $1480 \quad 02-24-94$ & $3: 27 a$ \\
\hline SPULNOT & GSP & $1503 \quad 02-24-94$ & $3: 27 a$ \\
\hline IDBDINB & GSP & $157402-24-94$ & $3: 27$ a \\
\hline IDBDIOB & GSP & $1644 \quad 02-24-94$ & $3: 27 a$ \\
\hline HGREPLST & GSP & $1688 \quad 02-24-94$ & $3: 27 a$ \\
\hline ALMSUM & GSP & $2244 \quad 02-24-94$ & $3: 27 a$ \\
\hline PASSWORD & GSP & $1794 \quad 02-24-94$ & $3: 27 \mathrm{a}$ \\
\hline HISTB & GSP & $1862 \quad 02-24-94$ & $3: 27 a$ \\
\hline HDWDET & GSP & $1954 \quad 02-24-94$ & $3: 27 a$ \\
\hline SORTIDBM & GSP & $1976 \quad 02-24-94$ & $3: 27 a$ \\
\hline TRENDMEN & GSP & $1990 \quad 02-24-94$ & $3: 27 a$ \\
\hline HISTMEN1 & GSP & $2029 \quad 02-24-94$ & $3: 27 a$ \\
\hline HISTLST & GSP & $203802-24-94$ & $3: 27 a$ \\
\hline TRENDLST & GSP & $2042 \quad 02-24-94$ & $3: 27 a$ \\
\hline EPSON MX & PTR & $2048 \quad 02-24-94$ & $3: 27 a$ \\
\hline STAT2 $^{-}$ & GSP & $2053 \quad 02-24-94$ & $3: 27 a$ \\
\hline DOTDET & GSP & $2064 \quad 02-24-94$ & $3: 27 a$ \\
\hline IDBAO & GSP & $207002-24-94$ & $3: 27 a$ \\
\hline AOUTDET & GSP & $211302-24-94$ & $3: 27 a$ \\
\hline KB & TBL & $3392 \quad 02-24-94$ & $3: 27 a$ \\
\hline SEQ & GSP & $2131 \quad 02-24-94$ & $3: 27 a$ \\
\hline SORTMAIN & GSP & $2164 \quad 02-24-94$ & $3: 27 a$ \\
\hline FF1 & GSP & $2190 \quad 02-24-94$ & $3: 27 a$ \\
\hline STAT1 & GSP & $2271 \quad 02-24-94$ & $3: 27 a$ \\
\hline PULNOT & GSP & $2322 \quad 02-24-94$ & $3: 27 a$ \\
\hline SYSPERF & GSP & $2325 \quad 02-24-94$ & $3: 27 a$ \\
\hline RSYSPERF & GSP & $232502-24-94$ & $3: 27 a$ \\
\hline REMPERF & GSP & $233202-24-94$ & $3: 27 \mathrm{a}$ \\
\hline FF2 & GSP & $2335 \quad 02-24-94$ & $3: 27 \mathrm{a}$ \\
\hline SLOGIC & GSP & $2360 \quad 02-24-94$ & $3: 27 a$ \\
\hline TIMERS & GSP & $2363 \quad 02-24-94$ & $3: 27 a$ \\
\hline PLOTMEN & GSP & $2405 \quad 02-24-94$ & $3: 27 a$ \\
\hline AMBDET & GSP & $2449 \quad 02-24-94$ & $3: 27 a$ \\
\hline TUNE4 & GSP & $2432 \quad 02-24-94$ & $3: 27 a$ \\
\hline HISMON & GSP & $2463 \quad 02-24-94$ & $3: 27 a$ \\
\hline CALC3 & GSP & $250202-24-94$ & $3: 27 a$ \\
\hline MATH2 & GSP & $2506 \quad 02-24-94$ & $3: 27 a$ \\
\hline SYSCONF & GSP & $\begin{array}{lll}3011 & 02-24-94\end{array}$ & $3: 27 a$ \\
\hline CTLDET3 & GSP & $2580 \quad 02-24-94$ & $3: 27 a$ \\
\hline DTIMDET & GSP & $2588 \quad 02-24-94$ & $3: 27 a$ \\
\hline DGAP2 & GSP & $2593 \quad 02-24-94$ & $3: 27 a$ \\
\hline MATH & GSP & $2602 \quad 02-24-94$ & $3: 27 a$ \\
\hline ALM & GSP & $2649 \quad 02-24-94$ & $3: 27 \mathrm{a}$ \\
\hline IDB & GSP & $267402-24-94$ & $3: 27 a$ \\
\hline CNT & GSP & $2703 \quad 02-24-94$ & $3: 27 a$ \\
\hline IDBAIN & GSP & $273902-24-94$ & $3: 27 a$ \\
\hline IDBDOT & GSP & $2809 \quad 02-24-94$ & $3: 27 a$ \\
\hline LOGIC & GSP & $2843 \quad 02-24-94$ & $3: 27 a$ \\
\hline$S Y S C D$ & GSP & $2891 \quad 02-24-94$ & $3: 27 a$ \\
\hline
\end{tabular}


HNF-SD-WM-CSDD-008

Rev. 3

Page 157

\begin{tabular}{|c|c|c|c|}
\hline CTLDET & GSP & $2896 \quad 02-24-94$ & $3: 27 a$ \\
\hline SWCH & GSP & $292502-24-94$ & $3: 27 a$ \\
\hline TUNE3 & GSP & $293502-24-94$ & $3: 27 a$ \\
\hline DIGDET & GSP & $294602-24-94$ & $3: 27 a$ \\
\hline AINDET & GSP & $299502-24-94$ & $3: 27 a$ \\
\hline DGAP & GSP & $\begin{array}{lll}3003 & 02-24-94\end{array}$ & $3: 27 a$ \\
\hline SIM & GSP & $3038 \quad 02-24-94$ & $3: 27 a$ \\
\hline CTLDET2 & GSP & $3044 \quad 02-24-94$ & $3: 27 a$ \\
\hline TD & GSP & $\begin{array}{lll}3086 & 02-24-94\end{array}$ & $3: 27 a$ \\
\hline USER2 & GSP & $3090 \quad 02-24-94$ & $3: 27 a$ \\
\hline IDBAIO & GSP & $3137 \quad 02-24-94$ & $3: 27 a$ \\
\hline PAOUT & GSP & 31430 & $3: 27 a$ \\
\hline TUNE & GSP & 31520 & $3: 27 a$ \\
\hline TUNE2 & GSP & 315602 & $27 a$ \\
\hline TOT & GSP & 32850 & $: 27$ \\
\hline TRENDREP & GSP & $3400 \quad 02$ & $: 27$ \\
\hline PAIO1 & GSP & 345302 & $3: 27$ \\
\hline PAIO2 & GSP & 34530 & $: 27 a$ \\
\hline RAMP & GSP & 35250 & $3: 27 a$ \\
\hline$x C$ & GSP & $3543 \quad 02-24-94$ & $3: 27 a$ \\
\hline CALC & GSP & $3633 \quad 02-24-94$ & $3: 27 a$ \\
\hline TPO & GSP & $3658 \quad 02-24-94$ & $3: 27 a$ \\
\hline SEL & GSP & $\begin{array}{lll}3718 & 02-24-94\end{array}$ & $3: 27$ a \\
\hline GENESIS & GSP & $\begin{array}{lll}3776 & 02-24-94\end{array}$ & $3: 27 a$ \\
\hline PAI03 & GSP & $\begin{array}{lll}3888 & 02-24-94\end{array}$ & $3: 27$ \\
\hline USER & GSP & $3967 \quad 02-24-94$ & $3: 27 a$ \\
\hline DIR & GSP & $4139 \quad 02-24-94$ & $3: 27 a$ \\
\hline PDOUT & GSP & $4171 \quad 02-24-94$ & $3: 27 a$ \\
\hline ISPDIR & GSP & $4234 \quad 02-24-94$ & $3: 27 a$ \\
\hline IDBDIN & GSP & $438102-24-94$ & $3: 27 a$ \\
\hline CALC2 & GSP & $4408 \quad 02-24-94$ & $3: 27 a$ \\
\hline IDBDIO & GSP & $4831 \quad 02-24-94$ & $3: 27 a$ \\
\hline POIN & GSP & $\begin{array}{lll}5661 & 02-24-94\end{array}$ & $3: 27 a$ \\
\hline MOUSE & OPT & $\begin{array}{lll}4118 & 02-24-94\end{array}$ & $3: 27 a$ \\
\hline RSS & EXE & $3638 \quad 02-24-94$ & $3: 27 a$ \\
\hline LOGO_NET & DAT & $902-18-94$ & $1: 36 a$ \\
\hline GCOPY & BAT & 3301 & $3: 52 a$ \\
\hline GENCMDR & BAT & 4601 & $3: 52 a$ \\
\hline BOOT & BAT & 7902 & $5: 01 p$ \\
\hline DOSNODE & PWD & 22602 & $5: 01 p$ \\
\hline GENCFG & GNF & 26502 & $1: 36 a$ \\
\hline GENCMDR & NDX & 62502 & $5: 02 p$ \\
\hline GNETDIR & GSP & 67602 & 5:01p \\
\hline GNFXR4 & GSP & $82702-18-94$ & $5: 01 p$ \\
\hline GENCMDR2 & GSP & $860 \quad 02-18-94$ & $5: 02 p$ \\
\hline GENCEXIT & GSP & $928 \quad 02-18-94$ & $5: 02 p$ \\
\hline GENCMDR & GSP & $948 \quad 02-18-94$ & $5: 02 p$ \\
\hline DOSPWD & MNU & $959 \quad 02-18-94$ & $5: 01 p$ \\
\hline GNFXEXIT & GSP & $97202-18-94$ & 5:01p \\
\hline GNFXR3 & GSP & $102402-18-94$ & $5: 01$ \\
\hline
\end{tabular}




\begin{tabular}{|c|c|c|c|c|}
\hline GNFXR2 & GSP & 1043 & $02-18-94$ & $5: 01 p$ \\
\hline GMFXR1 & GSP & 1053 & $02-18-94$ & $5: 01 p$ \\
\hline CONFMSMI & $\mathrm{COM}$ & 1487 & $02-18-94$ & $5: 01 p$ \\
\hline GN_TIMER & SYS & 1856 & $02-18-94$ & $5: 01 \mathrm{p}$ \\
\hline GNETMON & GSP & 2073 & $02-18-94$ & $5: 01 p$ \\
\hline GNETMON2 & GSP & 2045 & $02-18-94$ & $5: 01 p$ \\
\hline GENCMDR & $D O C$ & 5912 & $02-18-94$ & $5: 02 p$ \\
\hline README & $D O C$ & 5912 & $01-15-92$ & $3: 52 a$ \\
\hline CONF104 & FNT & 7168 & $02-18-94$ & $5: 01 p$ \\
\hline GENCMDR & MNU & 7682 & $02-18-94$ & $5: 02 p$ \\
\hline GN_TIMER & EXE & 13851 & $02-18-94$ & $5: 01 p$ \\
\hline PS1̄10RST & EXE & 15259 & $02-18-94$ & 5:01p \\
\hline EGA & DEV & 13450 & $02-18-94$ & 5:01p \\
\hline EENMON & EXE & 16487 & $02-18-94$ & 5 \\
\hline SHOW_OPT & EXE & 15931 & $02-18-94$ & 5:01p \\
\hline$\overline{B E N C F} G$ & MNU & 33934 & $02-18-94$ & 5: \\
\hline AENCMER & HLP & 23280 & $02-18-94$ & $5: 02 p$ \\
\hline UNPACK & EXE & 29378 & $02-18-94$ & $1: 36 a$ \\
\hline GENCFGB & MNU & 24190 & $01-15-92$ & 3: \\
\hline GN_INTF & OPT & 32731 & $02-18-94$ & $5: 02 p$ \\
\hline GN_COMM & OPT & 35453 & $02-18-94$ & $5: 02 p$ \\
\hline GENTCMOR & OPT & 43487 & $02-18-94$ & $5: 02 p$ \\
\hline GENCOMP & EXE & 44069 & $02-18-94$ & 5:01p \\
\hline GN_FTP & OPT & 52219 & $02-18-94$ & $5: 02 p$ \\
\hline GN DRVR & OPT & 67307 & -94 & $5: 02 p$ \\
\hline GN_INTFB & OPT & 56305 & $5-92$ & $3: 52 a$ \\
\hline GEÑ_NET & OPT & 61551 & -92 & $3: 52 a$ \\
\hline GN $\bar{C} A$ & OPT & 66311 & -92 & $3: 52 a$ \\
\hline DOS̄PWO. & EXE & 113849 & 94 & $5: 01 p$ \\
\hline GN_DCA & OPT & 77441 & $01-1$ & $3: 52 a$ \\
\hline GN_DB & $\mathrm{OPT}$ & 86329 & $01-15-92$ & $3: 52 a$ \\
\hline$G N \_C B$ & OPT & 91089 & $01-15-92$ & $3: 52 a$ \\
\hline GENCONF & EXE & 91957 & $02-18-94$ & 5:01p \\
\hline GN_DFA & OPT & 94991 & $01-15-92$ & $3: 52 a$ \\
\hline AN_CFA & OPT & 99255 & $01-15-92$ & $3: 52 a$ \\
\hline GN_DCB & OPT & 102235 & $01-15-92$ & $3: 52 a$ \\
\hline GN_DCFA & OPT & 110897 & $01-15-92$ & $3: 52 a$ \\
\hline GN DFB & OPT & 119273 & $01-15-92$ & $3: 52 a$ \\
\hline GN_CFB & OPT & 124033 & $01-15-92$ & $3: 52 a$ \\
\hline GN_DCFB & OPT & 135675 & $01-15-92$ & $3: 52 a$ \\
\hline GCOPY & EXE & 145747 & $02-18-94$ & 5:01p \\
\hline BCOPY & EXE & 165287 & $01-15-92$ & $3: 52 a$ \\
\hline GENCMOR & EXE & 260257 & $02-18-94$ & $5: 02 p$ \\
\hline BENCMDR & EXE & 279813 & $01-15-92$ & $3: 52 a$ \\
\hline MODICON & DES & 2418 & $04-03-92$ & $3: 50 a$ \\
\hline MODICON & DRV & 7038 & $04-03-92$ & $3: 50 \mathrm{a}$ \\
\hline AF 5000 & DES & 448 & $05-06-92$ & $3: 52 a$ \\
\hline AF5000 & DRV & 35066 & $04-29-94$ & $3: 52 a$ \\
\hline HELS & GSP & 1217 & $06-17-92$ & $3: 54 a$ \\
\hline & IVBC & 1015 & $09-03-92$ & \\
\hline
\end{tabular}


HNF-SD-WM-CSDD-008

Rev. 3

Page 159

\begin{tabular}{|c|c|c|c|}
\hline$\$ \$ R E M C$ & DIR & $959109-10-92$. & $9: 12 a$ \\
\hline BOOT & GSP & $3450 \quad 02-15-95$ & $11: 29 a$ \\
\hline SSBOOT & GSP & $3450 \quad 02-15-95$ & $11: 29 a$ \\
\hline ELP3 & GSP & $1217 \quad 02-16-95$ & $3: 01 p$ \\
\hline LP2 & GSP & $1217 \quad 02-16-95$ & $3: 01 p$ \\
\hline ELP1 & GSP & $1217 \quad 02-16-95$ & $3: 01 p$ \\
\hline LLP5 & GSP & $121703-29-94$ & $10: 40 \mathrm{a}$ \\
\hline LP6 & GSP & $1217 \quad 03-29-94$ & $10: 40 a$ \\
\hline ELP4 & GSP & $1217 \quad 02-16-95$ & $3: 01 p$ \\
\hline NNET & NDB & $17105-09-95$ & $10: 34 a$ \\
\hline GENCFG & NCF & $276 \quad 05-09-95$ & $10: 34 a$ \\
\hline GENNET & DNL & $44205-09-95$ & $10: 34 a$ \\
\hline GENCMDRO & HLP & $23280^{\prime} 01-15-92$ & $3: 52 a$ \\
\hline TANDARD & HLP & $1373 \quad 01-14-94$ & $4: 16 p$ \\
\hline ANDARD & HLS & $198101-14-94$ & $4: 12 p$ \\
\hline GNETMON3 & GSP & $191602-18-94$ & $5: 01 p$ \\
\hline AF5000 & AIF & $1695905-12-92$ & $3: 52 a$ \\
\hline SHADOW & GSP & $191202-18-94$ & $5: 01 p$ \\
\hline NETALMS & GSP & $1825 \quad 02-18-94$ & $5: 01 p$ \\
\hline AF5000 & $D O C$ & $31716 \quad 05-12-92$ & $3: 52 a$ \\
\hline DANISH & FNT & $1536 \quad 02-24-94$ & $3: 27 a$ \\
\hline EXTASCII & FNT & $1536 \quad 02-24-94$ & $3: 27 a$ \\
\hline ALARM & GSP & $2219 \quad 02-24$ & $3: 27 a$ \\
\hline BLANK & GSP & 243 & $3: 27 a$ \\
\hline EVENT & GSP & 2212 & $3: 27 a$ \\
\hline RRCOMBO & GSP & $2450 \quad 02-24-94$ & $3: 27 a$ \\
\hline SER2_2 & GSP & $3090 \quad 02-24-94$ & $3: 27 a$ \\
\hline USER2_3 & GSP & $3090 \quad 02-24-94$ & $3: 27 a$ \\
\hline USER2_4 & GSP & $3090 \quad 02-24-94$ & $3: 27 a$ \\
\hline USER2_5 & GSP & $3090 \quad 02-24-94$ & $3: 27 a$ \\
\hline USER2 6 & GSP & $3090 \quad 02-24-94$ & $3: 27 a$ \\
\hline USER2 7 & GSP & $3090 \quad 02-24-94$ & $3: 27 a$ \\
\hline USER3 & GSP & $1855 \quad 02-24-94$ & $3: 27 a$ \\
\hline USER3_2 & GSP & $1855 \quad 02-24-94$ & $3: 27 a$ \\
\hline USER3 3 & GSP & $1855 \quad 02-24-94$ & $3: 27 a$ \\
\hline USER3_4 & GSP & $1855 \quad 02-24-94$ & $3: 27 a$ \\
\hline USER3_5 & GSP & $1855 \quad 02-24-94$ & $3: 27 a$ \\
\hline USER3_6 & GSP & $1855 \quad 02-24-94$ & $3: 27 a$ \\
\hline USER3 $3{ }^{-} 7$ & GSP & $1855 \quad 02-24-94$ & $3: 27 a$ \\
\hline USER_ $\overline{2}$ & GSP & $3967 \quad 02-24-94$ & $3: 27 a$ \\
\hline USER_3 & GSP & $3967 \quad 02-24-94$ & $3: 27 a$ \\
\hline USER_4 & GSP & $3967 \quad 02-24-94$ & $3: 27 a$ \\
\hline USER_5 & GSP & $396702-24-94$ & $3: 27 a$ \\
\hline USER_ 6 & GSP & $3967 \quad 02-24-94$ & $3: 27 a$ \\
\hline USER_7 & GSP & $3967 \quad 02-24-94$ & $3: 27 a$ \\
\hline EXPORT & OPT & $18307 \quad 02-18-94$ & $5: 01 p$ \\
\hline AF5000 & MNU & $81205-06-92$ & $3: 52 a$ \\
\hline MODPLUS & DES & $448 \quad 06-03-93$ & $3: 36 a$ \\
\hline MODPLUS & DRV & $19130 \quad 06-03-93$ & $3: 36 a$ \\
\hline MODPLUS & MNU & $12100 \quad 06-03-93$ & $3: 36 a$ \\
\hline
\end{tabular}




$\begin{array}{llrll}\text { MODPLUS } & \text { DOC } & 2418806-03-93 & 3: 36 a \\ \text { MODPLUS } & 335 & 579 & 06-03-93 & 3: 36 a \\ \text { MODPLUS } & 336 & 747 & 06-03-93 & 3: 36 a \\ \text { HPLSR4 } & \text { PRP } & 36 & 03-31-94 & 5: 12 p \\ \text { HPLSR4 } & \text { PTR } & 2560 & 09-17-90 & 3: 32 a \\ \text { HELP } & \text { HLS } & 148102-16-95 & 3: 01 p \\ \text { HELP } & \text { HLP } & 998 & 02-16-95 & 3: 01 p\end{array}$

Directory of C: $\backslash$ TEST

\begin{tabular}{|c|c|c|c|c|}
\hline & & $\langle\mathrm{DIR}>$ & $12-07-93$ & $2: 14 p$ \\
\hline & & $\langle D I R\rangle$ & $12-07-93$ & $2: 14 p$ \\
\hline KEYMACS & & $<D I R>$ & $12-07-93$ & $2: 15 p$ \\
\hline BATFILES & & $\langle\mathrm{DIR}\rangle$ & $12-07-93$ & $2: 15 p$ \\
\hline LCL_HELP & & $\langle$ DIR $\rangle$ & $12-07-93$ & $2: 15 p$ \\
\hline LCL_KEY & & $\langle D I R\rangle$ & $12-07-93$ & $2: 15 p$ \\
\hline TEST & $C A$ & 19228 & $09-04-96$ & $1: 15 p$ \\
\hline TEST & CFG & 1752 & $09-04-96$ & $1: 15 p$ \\
\hline TEST & CI & 20560 & $09-04-96$ & $1: 15 p$ \\
\hline TEST & $\mathrm{DB}$ & 134274 & $09-0$ & $1: 15 p$ \\
\hline TEST & $\mathrm{MDB}$ & 12 & & $1: 15 p$ \\
\hline TEST & $X D B$ & 1892 & 09 & $1: 15 p$ \\
\hline RSSTEST & $C A$ & 19228 & 09 - & $1: 15 p$ \\
\hline RSSTEST & CFG & 1752 & -96 & $1: 15 p$ \\
\hline RSSTEST & $C I$ & 20560 & -96 & $1: 15 p$ \\
\hline RSSTEST & $\mathrm{DB}$ & 134274 & $09-$ & $1: 15 p$ \\
\hline RSSTEST & MDB & 12 & 96 & $1: 15 p$ \\
\hline STEST & XDB & 1892 & -96 & $1: 15 p$ \\
\hline LLOVER & GRP & 13928 & -96 & 4:51p \\
\hline SRTENAB & GRP & 44959 & -96 & $11: 13 a$ \\
\hline ABRTNAME & GRP & 28563 & $1-96$ & $11: 14 a$ \\
\hline ASMAIN & GRP & 2827 & -94 & $5: 47 p$ \\
\hline CSMAIN & GRP & 9058 & $04-2$ & $2: 33 p$ \\
\hline DACS & GRP & 12755 & $03-11-94$ & $10: 19 a$ \\
\hline GASSUM & GRP & 9140 & $3-96$ & $10: 04 a$ \\
\hline HVTALARM & GRP & 10289 & $04-24-96$ & $3: 03 p$ \\
\hline IOSTATUS & GRP & 13096 & $06-($ & $2: 04 p$ \\
\hline MANABRT & GRP & 4199 & $04-16-96$ & $8: 22 a$ \\
\hline MAP & GRP & 4087 & $03-22-95$ & $1: 55 p$ \\
\hline MININ1 & GRP & 15878 & $04-12-96$ & $12: 28 p$ \\
\hline MININ2 & GRP & 12135 & $09-04-96$ & $1: 04 p$ \\
\hline MIT17B & GRP & 13092 & $04-03-96$ & $12: 38 p$ \\
\hline MITI7C & GRP & 11621 & $03-$ & $8: 14 a$ \\
\hline MSMAIN & GRP & 5643 & $4-96$ & $: 53 p$ \\
\hline NEW72HR & GRP & 5626 & $04-$ & $9: 43 a$ \\
\hline OLD72HR & GRP & 5631 & $04-05-96$ & $9: 46 a$ \\
\hline PUMP & GRP & 9579 & $04-04-96$ & $5: 17 p$ \\
\hline PUMPALRM & GRP & 8695 & $02-15-95$ & $11: 27 a$ \\
\hline PUMPOPS & GRP & 5126 & $03-29-96$ & $4: 15$ \\
\hline
\end{tabular}




$\begin{array}{llrrr}\text { ABRTCHEK } & \text { GRP } & 10487 & 04-24-96 & 3: 08 p \\ \text { STRNALM } & \text { GRP } & 11330 & 04-04-96 & 5: 21 p \\ \text { SUMMARY } & \text { GRP } & 11579 & 03-03-95 & 9: 53 a \\ \text { SY101-1 } & \text { GRP } & 7092 & 01-28-94 & 12: 27 p \\ \text { TBSTC } & \text { GRP } & 7392 & 10-26-94 & 11: 08 a \\ \text { TEMPALM } & \text { GRP } & 10475 & 03-29-96 & 4: 24 p \\ \text { TEMPRFL } & \text { GRP } & 13453 & 03-10-94 & 8: 24 a \\ \text { TESTEXIT GRP } & 2574 & 06-05-95 & 10: 54 a \\ \text { WELCOME } & \text { GRP } & 3450 & 02-15-95 & 11: 29 a \\ \text { BOOT } & \text { GSP } & 3450 & 02-15-95 & 11: 29 a \\ \text { HELP } & \text { GSP } & 1217 & 06-17-92 & 3: 54 a \\ \text { HELP1 } & \text { GSP } & 1217 & 03-29-94 & 10: 40 a \\ \text { HELP2 } & \text { GSP } & 1217 & 03-29-94 & 10: 40 a \\ \text { HELP3 } & \text { GSP } & 1217 & 03-29-94 & 10: 40 a \\ \text { HELP4 } & \text { GSP } & 1217 & 03-29-94 & 10: 40 a \\ \text { HELP5 } & \text { GSP } & 1217 & 03-29-94 & 10: 40 a \\ \text { HELPS } & \text { GSP } & 1217 & 03-29-94 & 10: 40 a \\ \text { RSSBOOT } & \text { GSP } & 3450 & 02-15-95 & 11: 29 a \\ \text { HISTCOPY } & \text { RPS } & 2712 & 08-12-94 & 3: 24 p \\ \text { HISTFNAM } & \text { RPS } & 1243 & 08-12-94 & 3: 23 p \\ \text { SETLIMS } & \text { RPS } & 1423 & 04-03-96 & 3: 17 p \\ \text { TEST } & \text { KML } & 103 & 05-31-95 & 2: 20 \mathrm{p} \\ \text { TEST } & \text { KMS } & 155 & 05-31-95 & 2: 20 p \\ \text { RSSTEST } & \text { KML } & 103 & 05-31-95 & 2: 20 p \\ \text { RSSTEST } & \text { KMS } & 155 & 05-31-95 & 2: 20 p\end{array}$

Directory of C: \TEST \KEYMACS

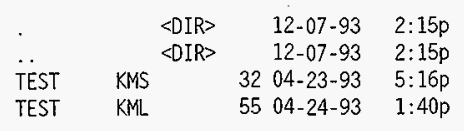

Directory of $\mathrm{C}: \backslash$ TEST $\backslash$ BATFILES

\begin{tabular}{|c|c|c|c|c|}
\hline & & $\langle D I R\rangle$ & $12-07-93$ & $2: 15 p$ \\
\hline & & & & \\
\hline & BAT & & $3106-18-93$ & $4: 39$ \\
\hline
\end{tabular}


Directory of C:ITESTILCL_HELP

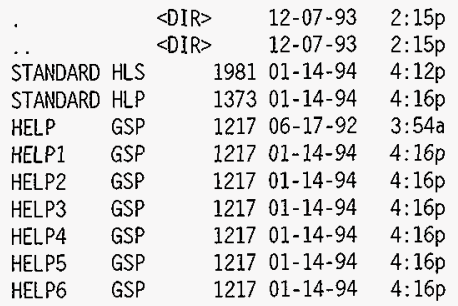

Directory of C: \TESTYLCL_KEY

$\begin{array}{lllrl} & & <\text { DIR }> & 12-07-93 & 2: 15 p \\ . & & <D I R> & 12-07-93 & 2: 15 p \\ \text { TEST } & \text { KML } & & 5504-24-93 & 1: 40 p \\ \text { TEST } & \text { KMS } & & 3204-23-93 & 5: 16 p\end{array}$




\section{DACS STATION 6 FILE LISTINGS}

"AUTOEXEC.BAT" on Station 6

DECHO OFF

PROMPT \$P\$G

C: \NETROOM \XLOAD. EXE -SB001 -M23248 C: \EXPERTIMOUSE

goto \%config\%

:GEN354

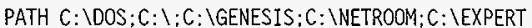

goto end

:GEN372

PATH C: \DOS:C: $: C: \backslash G E N 372: C:$ WETROOM:C: $\backslash$ EXPERT

SHARE

goto end

:end

CD \TEST

RSS TEST

"CONFIG.SYS" on Station 6

[MENU]

menuitem=GEN354, Genesis system version 3.54

menuitem $=\mathrm{GEN} 372$, Genesis system version 3.72

menudefau $t=G E N 372[, 0]$

[COMMON]

DEVICE $=C$ : \NETROOM $\backslash$ RM386 . EXE AUTO X=D900-DDFF

DEVICE $=C$ : \NETROOM SYSCLOAK. EXE

DEVICE $=C: \backslash N E T R O O M \backslash X L O A D$. SYS -0

BUFFERS $=20,0$

FILES $=55$

LASTDRIVE $=E$

$\mathrm{FCBS}=4,0$

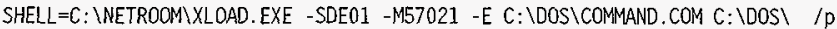
STACKS $=0.0$

[GEN354]

[GEN372] 
HNF-SD-WM-CSDD-008

Rev. 3

Page 164

"RSS.BAT" on Station 6

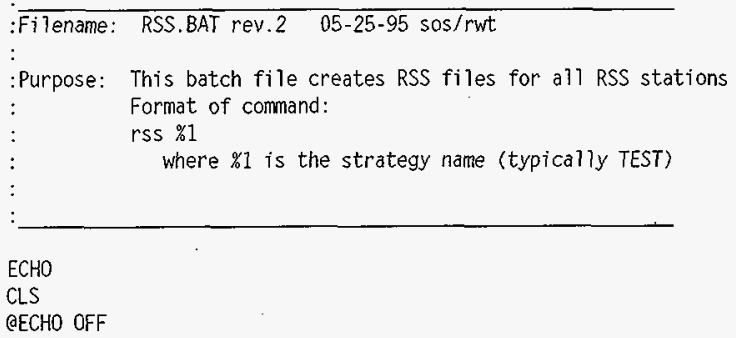

ECHO

CLS

AECHO OFF

IF "\%1"=="test" GOTO TEST

IF "\%1"=="TEST" GOTO TEST

f: \GEN372\RSS \%1

GOTO END

:TEST

COPY $f: \backslash T E S T \backslash$ RSSTEST.DB $f: \backslash T E S T \backslash T E S T . D B>X X X . X X X$

COPY $f: \backslash T E S T \backslash R S S T E S T . C I$ I $: \backslash T E S T \backslash T E S T . C I>X X X . X X X$

COPY $f: \backslash T E S T \backslash R S S T E S T . X D B$ f: $\backslash T E S T \backslash T E S T . X D B>X X X . X X X$

COPY $f: \backslash T E S T \backslash$ RSSTEST.CA $f: \backslash T E S T \backslash T E S T . C A>X X X . X X X X$

COPY $f: \backslash T E S T \backslash R S S T E S T$.CFG $f: \backslash T E S T \backslash T E S T . C F G>X X X . X X X$

COPY $f: \backslash T E S T \backslash R S S T E S T . M D B$ $f: \backslash T E S T \backslash T E S T . M D B>X X X . X X X$

COPY WELCOME.GRP $f: \backslash G E N 372 \backslash B O 0 T$.GSP

COPY WELCOME.GRP $f: \backslash G E N 372 \backslash R S S B O O T . G S P$

COPY WELCOME.GRP RSSBOOT.GSP

$f: \backslash G E N 372 \backslash R S S \% 1$

:END 


\title{
DACS STATION 7 DIRECTORY LISTINGS
}

\author{
Volume in drive $C$ has no label \\ Volume Serial Number is 1C49-3EBC \\ 167182336 bytes free \\ Directory of $C: \backslash^{\star}$. BAT, *.SYS

$\begin{array}{llrlr}\text { AUTOEXEC } & \text { BAT } & 285 & 11-27-96 & 12: 02 p \\ \text { RUNTIME } & \text { BAT } & 1357 & 04-26-96 & 10: 26 a \\ \text { CONFIG } & \text { SYS } & 404 & 12-03-94 & 8: 47 a \\ \text { RSS } & \text { BAT } & 927 & 05-25-95 & 2: 42 p\end{array}$

Directory of C: \GEN372

\begin{tabular}{|c|c|c|c|c|}
\hline & & & $12-03-94$ & $9: 02 a$ \\
\hline & & & $12-03-94$ & $9: 02 a$ \\
\hline REPORT & OPT & 57547 & $05-01-90$ & $3: 21 a$ \\
\hline HPLSRJII & PRP & 36 & $09-17-90$ & $3: 32 a$ \\
\hline IBMPRO & PRP & 36 & $09-17-90$ & $3: 32 a$ \\
\hline IBMPRO & PTR & 2048 & $09-17-90$ & $3: 32 a$ \\
\hline APLSRJII & PTR & 2560 & $09-17-90$ & $3: 32 a$ \\
\hline COMBO & OPT & 73309 & $04-28-93$ & $3: 26 a$ \\
\hline UNTRY & $\mathrm{FR}$ & 4 & $10-31-91$ & $3: 52 a$ \\
\hline UNTRY & GR & 5 & $10-31-91$ & $: 52 a$ \\
\hline OGO & DAT & 9 & $02-24-94$ & $3: 27 a$ \\
\hline EPSON MX & PRP & 36 & $02-24-94$ & $3: 27 a$ \\
\hline LISTMĀIN & GSP & 363 & $02-24-94$ & $3: 27 a$ \\
\hline HCURS & GSP & 415 & $02-24-94$ & $3: 27 a$ \\
\hline PLOT & GSP & 465 & $02-24-94$ & $3: 27 a$ \\
\hline TREND & GSP & 467 & $02-24-94$ & $3: 27 a$ \\
\hline TANDARD & KMiL & 511 & $02-24-94$ & $3: 27 \mathrm{a}$ \\
\hline ET OLD & KML & 510 & $02-24-94$ & $3: 27 a$ \\
\hline IDBEN̄TRY & GSP & 663 & $02-24-94$ & $3: 27 a$ \\
\hline REP & GSP & 781 & $02-24-94$ & $3: 27 a$ \\
\hline BREP & GSP & 1226 & $02-24-94$ & $3: 27 a$ \\
\hline PTY & GSP & 845 & $02-24-94$ & $3: 27 a$ \\
\hline SPSEC & GSP & 980 & $02-24-94$ & $3: 27 a$ \\
\hline ISPSAV & GSP & 1001 & $02-24-94$ & $3: 27 a$ \\
\hline EXIT & GSP & 1021 & $02-24-94$ & $3: 27 a$ \\
\hline SORTMENU & GSP & 1128 & $02-24-94$ & $3: 27 a$ \\
\hline LISTMENU & GSP & 1657 & $02-24-94$ & $3: 27 a$ \\
\hline IDBSTG & GSP & 1271 & $02-24-94$ & $3: 27 a$ \\
\hline IDBSTGO & GSP & 1309 & $02-24-94$ & $3: 27 a$ \\
\hline HGLSTMEN & GSP & 1344 & $02-24-94$ & $3: 27$ a \\
\hline DBDOTB & GSP & 1325 & $02-24-94$ & $3: 27 \mathrm{a}$ \\
\hline LEUTIL & GSP & 1296 & $02-24-94$ & $3: 27 a$ \\
\hline HISREP & GSP & 1588 & $02-24-94$ & $3: 27 a$ \\
\hline
\end{tabular}


HNF-SD-WM-CSDD-008

Rev. 3

Page 166

\begin{tabular}{|c|c|c|c|}
\hline HGREPMEN & GSP & $1408 \quad 02-24-94$ & $3: 27 a$ \\
\hline IDBSIO & GSP & $1480 \quad 02-24-94$ & $3: 27 a$ \\
\hline SPULNOT & GSP & $1503 \quad 02-24-94$ & $3: 27 a$ \\
\hline IDBDINB & GSP & $\begin{array}{lll}1574 & 02-24-94\end{array}$ & $3: 27 \mathrm{a}$ \\
\hline IDBDIOB & GSP & $1644 \quad 02-24-94$ & $3: 27 a$ \\
\hline HGREPLST & GSP & $\begin{array}{lll}1688 & 02-24-94\end{array}$ & $3: 27 a$ \\
\hline ALMSUM & GSP & $2244 \quad 02-24-94$ & $3: 27 a$ \\
\hline PASSWORD & GSP & $1794 \quad 02-24-94$ & $3: 27 a$ \\
\hline HISTB & GSP & $186202-24-94$ & $3: 27 a$ \\
\hline HDWDET & GSP & $1954 \quad 02-24-94$ & $3: 27 a$ \\
\hline SORT IOBM & GSP & $1976 \quad 02-24-94$ & $3: 27 a$ \\
\hline TRENDMEN & GSP & $1990 \quad 02-24-94$ & $3: 27 a$ \\
\hline HISTMEN1 & GSP & $202902-24-94$ & $3: 27 a$ \\
\hline HISTLST & GSP & $2038 \quad 02-24-94$ & $3: 27 a$ \\
\hline TRENDLST & GSP & $2042 \quad 02-24-94$ & $3: 27 a$ \\
\hline EPSON MX & PTR & $2048 \quad 02-24-94$ & $3: 27 a$ \\
\hline STAT2 & GSP & $2053 \quad 02-24-94$ & $3: 27 a$ \\
\hline DOTDET & GSP & $2064 \quad 02-24-94$ & $3: 27 a$ \\
\hline IDBA0 & GSP & $2070.02-24-94$ & $3: 27 a$ \\
\hline AOUTDET & GSP & $2113.02-24-94$ & $3: 27 a$ \\
\hline$K B$ & TBL & $3392 \quad 02-24-94$ & $3: 27 a$ \\
\hline SEQ & GSP & $2131 \quad 02-24-94$ & $3: 27 a$ \\
\hline SORTMAIN & GSP & $2164 \quad 02-24-94$ & $3: 27 a$ \\
\hline FFI & GSP & $2190 \quad 02-24-94$ & $3: 27 a$ \\
\hline STAT1 & GSP & $2271 \quad 02-24-94$ & $3: 27 a$ \\
\hline PULNOT & GSP & $2322 \quad 02-24-94$ & $3: 27 a$ \\
\hline RSYSPERF & GSP & $2325 \quad 02-24-94$ & $3: 27 a$ \\
\hline SYSPERF & GSP & $2325 \quad 02-24-94$ & $3: 27 a$ \\
\hline REMPERF & GSP & $2332 \quad 02-24-94$ & $3: 27 a$ \\
\hline FF2 & GSP & $233502-24-94$ & $3: 27 a$ \\
\hline SLOGIC & GSP & $2360 \quad 02-24-94$ & $3: 27 a$ \\
\hline TIMERS & GSP & $2363 \quad 02-24-94$ & $3: 27 a$ \\
\hline PLOTMEN & GSP & $2405 \quad 02-24-94$ & $3: 27 a$ \\
\hline AMBDET & GSP & $2449 \quad 02-24-94$ & $3: 27 a$ \\
\hline TUNE4 & GSP & $2432 \quad 02-24-94$ & $3: 27 a$ \\
\hline HISMON & GSP & $2463 \quad 02-24-94$ & $3: 27 a$ \\
\hline CALC3 & GSP & $2502 \quad 02-24-94$ & $3: 27 a$ \\
\hline MATH2 & GSP & $2506 \quad 02-24-94$ & $3: 27 a$ \\
\hline SYSCONF & GSP & $3011 \quad 02-24-94$ & $3: 27 a$ \\
\hline CTLDET3 & GSP & $2580 \quad 02-24-94$ & $3: 27 a$ \\
\hline DTIMDET & GSP & $2588 \quad 02-24-94$ & $3: 27 a$ \\
\hline DGAP2 & GSP & $2593 \quad 02-24-94$ & $3: 27 a$ \\
\hline MATH & GSP & $2602 \quad 02-24-94$ & $3: 27 \mathrm{a}$ \\
\hline ALM & GSP & $2649 \quad 02-24-94$ & $3: 27 a$ \\
\hline IDB & GSP & $2674 \quad 02-24-94$ & $3: 27 a$ \\
\hline CNT & GSP & $2703 \quad 02-24-94$ & $3: 27 a$ \\
\hline IDBAIN & GSP & $273902-24-94$ & $3: 27 a$ \\
\hline IDBDOT & GSP & $2809 \quad 02-24-94$ & $3: 27 a$ \\
\hline LOGIC & GSP & $2843 \quad 02-24-94$ & $3: 27 a$ \\
\hline SYSCONF2 & GSP & $289102-24-94$ & $3: 27 \mathrm{a}$ \\
\hline
\end{tabular}




\begin{tabular}{|c|c|c|c|}
\hline CTLDET & GSP & $2896 \quad 02-24-94$ & $3: 27 a$ \\
\hline SWCH & GSP & $292502-24-94$ & $3: 27 a$ \\
\hline TUNE3 & GSP & $2935 \quad 02-24-94$ & $3: 27 a$ \\
\hline DIGDET & GSP & $294602-24-94$ & $3: 27 a$ \\
\hline AINDET & GSP & $299502-24-94$ & $3: 27 a$ \\
\hline DGAP & GSP & $300302-24-94$ & $3: 27 a$ \\
\hline SIM & GSP & $\begin{array}{lll}3038 & 02-24-94\end{array}$ & $3: 27 a$ \\
\hline CTLDET2 & GSP & $3044 \quad 02-24-94$ & $3: 27 a$ \\
\hline TD & GSP & $308602-24-94$ & $3: 27 a$ \\
\hline USER2 & GSP & $3090 \quad 02-24-94$ & $3: 27 a$ \\
\hline IDBAIO & GSP & $3137 \quad 02-24-94$ & $3: 27 a$ \\
\hline PAOUT & GSP & $314302-24-94$ & $3: 27 a$ \\
\hline TUME & GSP & $3152 \quad 02-24-94$ & $3: 27 a$ \\
\hline TUNE2 & GSP & $3156 \quad 02-24-94$ & $3: 27 a$ \\
\hline TOT & GSP. & $328502-24-94$ & $3: 27 a$ \\
\hline TRENDREP & GSP & $3400 \quad 02-24-94$ & $3: 27 a$ \\
\hline PAIO2 & GSP & $3453 \quad 02-24$ & $3: 27 a$ \\
\hline PAI01 & GSP & $3453 \quad 02-24-94$ & $3: 27 a$ \\
\hline RAMP & GSP & $3525 \quad 02-24-94$ & $3: 27 a$ \\
\hline$X C$ & GSP & $3543 \quad 02-24-94$ & $3: 27 a$ \\
\hline CALC & GSP & $363302-24-94$ & $3: 27 a$ \\
\hline TPO & GSP & $3658 \quad 02-24-94$ & $3: 27 a$ \\
\hline SEL & GSP & $3718 \quad 02-24-94$ & $3: 27 a$ \\
\hline GENESIS & GSP & $3776 \quad 02-24-94$ & $3: 27 a$ \\
\hline PAIO3 & GSP & $3888 \quad 02-24-94$ & $3: 27 a$ \\
\hline USER & GSP & $3967 \quad 02-24-94$ & $3: 27 a$ \\
\hline DIR & GSP & $4139 \quad 02-24-94$ & $3: 27 a$ \\
\hline PDOUT & GSP & $417102-24-94$ & $3: 27 a$ \\
\hline DISPDIR & GSP & $4234 \quad 02-24-94$ & $3: 27 a$ \\
\hline IDBDIN & GSP & $4381 \quad 02-24-94$ & $3: 27 a$ \\
\hline CALC2 & GSP & $4408 \quad 02-24-94$ & $3: 27 a$ \\
\hline IDBDIO & GSP & $4831 \quad 02-24-94$ & $3: 27 \mathrm{a}$ \\
\hline PDIN & GSP & $\begin{array}{lll}5661 & 02-24-94\end{array}$ & $3: 27 a$ \\
\hline MOUSE & OPT & $4118 \quad 02-24-94$ & $3: 27 a$ \\
\hline RSS & EXE & $343638 \quad 02-24-94$ & $3: 27 a$ \\
\hline LOGO_NET & DAT & $902-18-94$ & $1: 36 a$ \\
\hline GCOPY & BAT & $3301-15-92$ & $3: 52 a$ \\
\hline GENCMDR & BAT & $46 \quad 01-15-92$ & $3: 52 a$ \\
\hline BOOT & BAT & $7902-18-94$ & $5: 01 p$ \\
\hline DOSNODE & PWD & $226 \quad 02-18-94$ & $5: 01 p$ \\
\hline GENCFG & GNF & $26502-18-94$ & $1: 36 a$ \\
\hline GENCMDR & NDX & $625 \quad 02-18-94$ & $5: 02 p$ \\
\hline GNETDIR & GSP & $676 \quad 02-18-94$ & $5: 01 p$ \\
\hline GNFXR4 & GSP & $827 \quad 02-18-94$ & $5: 01 p$ \\
\hline GENCMDR2 & GSP & $\begin{array}{lll}860 & 02-18-94\end{array}$ & $5: 02 p$ \\
\hline GENCEXIT & GSP & $928 \quad 02-18-94$ & $5: 02 p$ \\
\hline GENCMDR & GSP & $948 \quad 02-18-94$ & $5: 02 p$ \\
\hline DOSPWD & MNU & $959 \quad 02-18-94$ & $5: 01 p$ \\
\hline GNFXEXIT & GSP & $97202-18-94$ & $5: 01 p$ \\
\hline GNFXR3 & GSP & $1024 \quad 02-18-94$ & $5: 01 p$ \\
\hline
\end{tabular}


HNF-SD-WM-CSDD-008

Rev. 3

Page 168

\begin{tabular}{|c|c|c|c|}
\hline NFXR2 & GSP & $1043 \quad 02-18-94$ & $5: 01$ \\
\hline NFXR1 & GSP & $105302-18-94$ & $: 01$ \\
\hline DNFMSMI & $\mathrm{COM}$ & $1487 \quad 02-18-94$ & $5: 01$ \\
\hline I_TIMER & SYS & $185602-18-94$ & $: 01$ \\
\hline NETMON & GSP & $207302-18-94$ & .0 \\
\hline NETMON2 & GSP & $204502-18-94$ & $5: 0$ \\
\hline EDME & $D O C$ & 5912 01-15-92 & \\
\hline ENCMDR & DOC & $591202-18-94$ & $5: 0$ \\
\hline JNF104 & FNT & $7168 \quad 02-18-94$ & $5: 0$ \\
\hline NCMDR & MNU: & $\begin{array}{lll}7682 & 02-18-94\end{array}$ & $5: 0$ \\
\hline __ TIMER & EXE & $13851 \quad 02-18-94$ & $5: 0$ \\
\hline 5110RST & EXE & $1525902-$ & 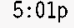 \\
\hline EGA & DEV & $\begin{array}{lll}13450 & 02-18-94\end{array}$ & 0 \\
\hline ENMON & EXE & $16487 \quad 02-18-94$ & . \\
\hline HOW_OPT & EXE & $15931 \quad 02-18-94$ & \\
\hline ENCFG & MNU & $33934 \quad 02-$ & 0. \\
\hline NCMDR & HLP & $23280 \quad 02-$ & 5: \\
\hline SPACK & EXE & $2937802-$ & 1.8 \\
\hline NCFGB & MNU & $2419001-$ & \\
\hline IINTF & OPT & $3273102-$ & 5: \\
\hline COMM & OPT & $3545302-$ & 5: \\
\hline NCMOR & OPT & $43487 \quad 02-$ & 5: \\
\hline NCOMP & EXE & $44069 \quad 02$ & \\
\hline N_FTP & OPT & $5221902-$ & \\
\hline N_DRVR & OPT & $\begin{array}{lll}67307 & 02-\end{array}$ & \\
\hline N_INTFB & OPT & $530501-$ & \\
\hline N_NET & OPT & 5101 & $3: 52$ \\
\hline$\_$CA & OPT & 31101 & $3: 52$ \\
\hline PWD & EXE & 02 & \\
\hline & OPT & 2 & \\
\hline$D B$ & OPT & 2 & \\
\hline CB & OPT & 2 & \\
\hline ICONF & EX & 4 & \\
\hline DFA & OPT & 991 & \\
\hline CFA & $\mathrm{OP}$ & 2 & \\
\hline$B$ & OP & 2 & \\
\hline DCFA & $O P$ & 2 & \\
\hline DFB & $\mathrm{OP}$ & 2 & \\
\hline CFB & OPT & 2 & \\
\hline DCFB & OPT & 2 & \\
\hline$O P Y$ & EXE & 74702 & \\
\hline COPY & EXE & $528701-1$ & $3: 5$ \\
\hline NCMDR & EXE & $0257 \quad 02-$ & 5: \\
\hline NCMDR & EXE & $27981301-15-92$ & $3: 5$ \\
\hline DICON & DES & $2418 \quad 04-03-92$ & $3: 5$ \\
\hline DDICON & DRV & $7038 \quad 04-03-92$ & $3: 5$ \\
\hline 5000 & DES & $448 \quad 05-1$ & \\
\hline 5000 & DRV & $35386 \quad 09-16-94$ & $3: 5$ \\
\hline INCR & RP & $46 \quad 06-08-92$ & $2 .{ }^{2}$ \\
\hline OVFRI & $\mathrm{RP}$ & $14106-09-92$ & $10: 30$ \\
\hline
\end{tabular}


HNF-SD-WM-CSDD-008

Rev. 3

Page 169

\begin{tabular}{|c|c|c|c|c|}
\hline NEXT & RPS & 115 & $06-10-92$ & $7: 44 p$ \\
\hline PREV & RPS & 108 & $06-10-92$ & $7: 47 p$ \\
\hline DISMOVE & RPS & 21 & $06-11-92$ & $3: 26 p$ \\
\hline RESMOVE & RPS & 32 & $06-12-92$ & $7: 47 a$ \\
\hline HELP & GSP & 1217 & $06-17-92$ & $3: 54 a$ \\
\hline CTREPT & RPS & 7628 & $07-29-92$ & $9: 54 a$ \\
\hline EXTRA & KMS & 62 & $07-29-92$ & $10: 33 a$ \\
\hline EXTRA & KML & 84 & $07-29-92$ & $10: 33 a$ \\
\hline BACKUP1 & BAT & 121 & $07-29-92$ & $3: 35 p$ \\
\hline UNLOADI & BAT & 96 & $07-29-92$ & $3: 37 p$ \\
\hline BACKUP2 & BAT & 57 & $07-29-92$ & $3: 38 p$ \\
\hline TEST & GIF & 24682 & $06-05-93$ & $12: 23 p$ \\
\hline GENCFG & NBC & 1015 & $01-26-93$ & $1: 29 a$ \\
\hline CONFIG & SYS & 160 & $01-26-93$ & $2: 09 p$ \\
\hline AUTOEXEC & BAT & 159 & $01-31-93$ & $4: 31 p$ \\
\hline RSSBOOT & GSP & 3450 & $02-15-95$ & $11: 29 a$ \\
\hline BOOT & GSP & 3450 & $02-15-95$ & $11: 29 a$ \\
\hline HELP4 & GSP & 1217 & $02-16-95$ & $3: 01 p$ \\
\hline HELP6 & GSP & 1217 & $03-29-94$ & $10: 40 \mathrm{a}$ \\
\hline HELP3 & GSP & 1217 & $02-16-95$ & $3: 01 p$ \\
\hline HELP1 & GSP & 1217 & $02-16-95$ & $3: 01 \mathrm{p}$ \\
\hline HELP2 & GSP & 1217 & $02-16-95$ & $3: 01 p$ \\
\hline HELP5 & GSP & 1217 & $03-29-94$ & $10: 40 a$ \\
\hline GENNET & NOB & 171 & $05-09-95$ & $10: 33 a$ \\
\hline GENCFG & NCF & 276 & $05-09-95$ & $10: 33 a$ \\
\hline GENNET & ONL & 442 & $05-09-95$ & $10: 33 a$ \\
\hline GENCMORO & HLP & 23280 & $01-15-92$ & $3: 52 a$ \\
\hline STANDARD & HLP & 1373 & $01-14-94$ & $4: 16 p$ \\
\hline STANDARD & HLS & 1981 & $01-14-94$ & $4: 12 p$ \\
\hline AF5000 & AIF & 17103 & $09-16-94$ & $3: 53 a$ \\
\hline AF5000 & DOC & 31716 & $05-12-92$ & $3: 53 a$ \\
\hline AF5000 & MNU & 912 & $09-16-94$ & $3: 53 a$ \\
\hline MODPLUS & DES & 448 & $02-09-94$ & $3: 38 a$ \\
\hline MODPLUS & DRV & 19750 & $09-29-94$ & $4: 59 p$ \\
\hline MODPLUS & MNU & 12100 & $08-24-94$ & $3: 38 a$ \\
\hline MODPLUS & $D O C$ & 23524 & $03-29-93$ & $3: 38 \mathrm{a}$ \\
\hline MODPLUS & 335 & 579 & $06-03-93$ & $3: 36 a$ \\
\hline MODPLUS & 336 & 747 & $06-03-93$ & $3: 36 a$ \\
\hline GNETMON3 & GSP & 1916 & $02-$ & $5: 01 p$ \\
\hline SHADOW & GSP & 1912 & $02-18-94$ & 5:01p \\
\hline NETALMS & GSP & 1825 & $02-18-94$ & 5:01p \\
\hline DANISH & FNT & 1536 & $02-24-94$ & $3: 27 a$ \\
\hline EXTASCII & FNT & 1536 & $02-24-94$ & $3: 27 a$ \\
\hline ALARM & GSP & 2219 & $02-24-94$ & $3: 27 a$ \\
\hline BLAAK & GSP & 243 & $02-24-94$ & $3: 27 a$ \\
\hline EVENT & GSP & 2212 & $02-24-94$ & $3: 27 a$ \\
\hline RRCOMBO & GSP & 2450 & $02-24-94$ & $3: 27$ a \\
\hline USER2_2 & GSP & 3090 & $02-24-94$ & $3: 27 \mathrm{a}$ \\
\hline USER2_3 3 & GSP & 3090 & $02-24-94$ & $3: 27 a$ \\
\hline USER2_4 & GSP & 3090 & $02-24-94$ & $3: 27$ a \\
\hline
\end{tabular}




$\begin{array}{llrll}\text { USER2_5 } & \text { GSP } & 3090 & 02-24-94 & 3: 27 a \\ \text { USER2_6 } & \text { GSP } & 3090 & 02-24-94 & 3: 27 a \\ \text { USER2_7 } & \text { GSP } & 3090 & 02-24-94 & 3: 27 a \\ \text { USER3 } & \text { GSP } & 1855 & 02-24-94 & 3: 27 a \\ \text { USER3_2 } & \text { GSP } & 1855 & 02-24-94 & 3: 27 a \\ \text { USER3_3 } & \text { GSP } & 1855 & 02-24-94 & 3: 27 a \\ \text { USER3_4 } & \text { GSP } & 1855 & 02-24-94 & 3: 27 a \\ \text { USER3_5 } & \text { GSP } & 1855 & 02-24-94 & 3: 27 a \\ \text { USER3_6 } & \text { GSP } & 1855 & 02-24-94 & 3: 27 a \\ \text { USER3_7 } & \text { GSP } & 1855 & 02-24-94 & 3: 27 a \\ \text { USER_2 } & \text { GSP } & 3967 & 02-24-94 & 3: 27 a \\ \text { USER_3 } & \text { GSP } & 3967 & 02-24-94 & 3: 27 a \\ \text { USER_4 } & \text { GSP } & 3967 & 02-24-94 & 3: 27 a \\ \text { USER_5 } & \text { GSP } & 3967 & 02-24-94 & 3: 27 a \\ \text { USER_6 } & \text { GSP } & 3967 & 02-24-94 & 3: 27 a \\ \text { USER_7 } & \text { GSP } & 3967 & 02-24-94 & 3: 27 a \\ \text { EXPORT } & \text { OPT } & 18307 & 02-18-94 & 5: 01 p \\ \text { MODPLUS } & 338 & 60 & 09-23-94 & 3: 38 a \\ \text { RUNTIME } & \text { EXE } & 401424 & 02-24-94 & 3: 27 a \\ \text { HPLSR4 } & \text { PRP } & 36 & 03-31-94 & 5: 12 p \\ \text { HPLSR4 } & \text { PTR } & 2560 & 09-17-90 & 3: 32 a \\ \text { HELP } & \text { HLS } & 1481 & 02-16-95 & 3: 01 p \\ \text { HELP } & \text { HLP } & 998 & 02-16-95 & 3: 01 p\end{array}$

Directory of C: \TEST

$\begin{array}{llrrr} & & \text { CDIR> } & 10-05-93 & 9: 56 a \\ \text { LCL_KEY } & & \text { CDIR> } & 10-05-93 & 9: 56 a \\ \text { LEIR> } & 12-14-93 & 11: 56 a \\ \text { KEYMACS } & & \text { CDIR> } & 10-05-93 & 9: 58 a \\ \text { BATFILES } & \text { CDIR> } & 10-05-93 & 9: 58 a \\ \text { TEST } & \text { CA } & 19228 & 09-04-96 & 1: 15 p \\ \text { TEST } & \text { CFG } & 1752 & 09-04-96 & 1: 15 p \\ \text { TEST } & \text { CI } & 20560 & 09-04-96 & 1: 15 p \\ \text { TEST } & \text { DB } & 134274 & 09-04-96 & 1: 15 p \\ \text { TEST } & \text { MDB } & 12 & 09-04-96 & 1: 15 p \\ \text { TEST } & \text { XDB } & 1892 & 09-04-96 & 1: 15 p \\ \text { RSSTEST } & \text { CA } & 19228 & 09-04-96 & 1: 15 p \\ \text { RSSTEST } & \text { CFG } & 1752 & 09-04-96 & 1: 15 p \\ \text { RSSTEST } & \text { CI } & 20560 & 09-04-96 & 1: 15 p \\ \text { RSSTEST } & \text { OB } & 134274 & 09-04-96 & 1: 15 p \\ \text { RSSTEST } & \text { MDB } & 12 & 09-04-96 & 1: 15 p \\ \text { RSSTEST } & \text { XDB } & 1892 & 09-04-96 & 1: 15 p \\ \text { ROLLOVER } & \text { GRP } & 13928 & 04-04-96 & 4: 51 p \\ \text { ABRTENAB } & \text { GRP } & 44959 & 04-11-96 & 11: 13 a \\ \text { ABRTNAME GRP } & 28563 & 04-11-96 & 11: 14 a \\ \text { ASMAIN } & \text { GRP } & 2827 & 07-28-94 & 5: 47 p \\ \text { CSMAIN } & \text { GRP } & 9058 & 04-24-96 & 2: 33 p \\ \text { DACS } & \text { GRP } & 12755 & 03-11-94 & 10: 19 a\end{array}$


HNF-SD-WM-CSDD-008

Rev. 3

Page 171

$\begin{array}{llrrr}\text { GASSUM } & \text { GRP } & 9140 & 04-08-96 & 10: 04 a \\ \text { HVTALARM GRP } & 10289 & 04-24-96 & 3: 03 p \\ \text { IOSTATUS GRP } & 13096 & 06-08-95 & 2: 04 p \\ \text { MANABRT } & \text { GRP } & 4199 & 04-16-96 & 8: 22 a \\ \text { MAP } & \text { GRP } & 4087 & 03-22-95 & 1: 55 p \\ \text { MININ1 } & \text { GRP } & 15878 & 04-12-96 & 12: 28 p \\ \text { MININ2 } & \text { GRP } & 12135 & 09-04-96 & 1: 04 p \\ \text { MIT17B } & \text { GRP } & 13092 & 04-03-96 & 12: 38 p \\ \text { MIT17C } & \text { GRP } & 11621 & 03-10-94 & 8: 14 a \\ \text { MSMAIN } & \text { GRP } & 5643 & 04-24-96 & 2: 53 p \\ \text { NEW72HR } & \text { GRP } & 5626 & 04-05-96 & 9: 43 a \\ \text { OLD72HR } & \text { GRP } & 5631 & 04-05-96 & 9: 46 a \\ \text { PUMP } & \text { GRP } & 9579 & 04-04-96 & 5: 17 p \\ \text { PUMPALRM } & \text { GRP } & 8695 & 02-15-95 & 11: 27 a \\ \text { PUMPOPS } & \text { GRP } & 5126 & 03-29-96 & 4: 15 p \\ \text { ABRTCHEK } & \text { GRP } & 10487 & 04-24-96 & 3: 08 p \\ \text { STRNALM } & \text { GRP } & 11330 & 04-04-96 & 5: 21 p \\ \text { SUMMMARY } & \text { GRP } & 11579 & 03-03-95 & 9: 53 a \\ \text { SYI01-1 } & \text { GRP } & 7092 & 01-28-94 & 12: 27 p \\ \text { TBSTC } & \text { GRP } & 7392 & 10-26-94 & 11: 08 a \\ \text { TEMPALM } & \text { GRP } & 10475 & 03-29-96 & 4: 24 p \\ \text { TEMPRFL } & \text { GRP } & 13453 & 03-10-94 & 8: 24 a \\ \text { TESTEXIT } & \text { GRP } & 2574 & 06-05-95 & 10: 54 a \\ \text { WELCOME } & \text { GRP } & 3450 & 02-15-95 & 11: 29 a \\ \text { BOOT } & \text { GSP } & 3450 & 02-15-95 & 11: 29 a \\ \text { HELP } & \text { GSP } & 1217 & 06-17-92 & 3: 54 a \\ \text { HELP1 } & \text { GSP } & 1217 & 03-29-94 & 10: 40 a \\ \text { HELP2 } & \text { GSP } & 1217 & 03-29-94 & 10: 40 a \\ \text { HELP3 } & \text { GSP } & 1217 & 03-29-94 & 10: 40 a \\ \text { HELP4 } & \text { GSP } & 1217 & 03-29-94 & 10: 40 a \\ \text { HELP5 } & \text { GSP } & 1217 & 03-29-94 & 10: 40 a \\ \text { HELP6 } & \text { GSP } & 1217 & 03-29-94 & 10: 40 a \\ \text { RSSBOOT } & \text { GSP } & 3450 & 02-15-95 & 11: 29 a \\ \text { HISTCOPY } & \text { RPS } & 2712 & 08-12-94 & 3: 24 p \\ \text { HISTFNAM RPS } & 1243 & 08-12-94 & 3: 23 p \\ \text { SETLIMS } & \text { RPS } & 1423 & 04-03-96 & 3: 17 p \\ \text { TEST } & \text { KML } & 103 & 05-31-95 & 2: 20 p \\ \text { TEST } & \text { KMS } & 155 & 05-31-95 & 2: 20 p \\ \text { RSSTEST } & \text { KML } & 103 & 05-31-95 & 2: 20 p \\ \text { RSSTEST } & \text { KMS } & 155 & 05-31-95 & 2: 20 p \\ & & & & \end{array}$

Directory of C:ITESTULL_KEY

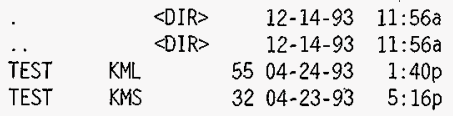


HNF-SD-WM-CSDD-008

Rev. 3

Page 172

Directory of $C: \backslash T E S T \backslash K E Y M A C S$

\begin{tabular}{lllll} 
& & CDIR> & $10-05-93$ & $9: 58 a$ \\
H. & \multicolumn{2}{c}{ COIR> } & $10-05-93$ & $9: 58 a$ \\
HELP & GSP & 1217 & $06-17-92$ & $3: 54 a$ \\
TEST & KMS & 32 & $04-23-93$ & $5: 16 p$ \\
TEST & KML & 55 & $04-24-93$ & $1: 40 p$ \\
HELP1 & GSP & 1217 & $04-24-93$ & $1: 43 p$ \\
HELP2 & GSP & 1217 & $04-24-93$ & $1: 43 p$ \\
HELP3 & GSP & 1217 & $04-24-93$ & $1: 43 p$ \\
HELP4 & GSP & 1217 & $04-24-93$ & $1: 43 p$ \\
HELP5 & GSP & 1217 & $04-24-93$ & $1: 43 p$ \\
HELP6 & GSP & 1217 & $04-24-93$ & $1: 43 p$
\end{tabular}

Directory of C: \TEST \BATFILES

\begin{tabular}{|c|c|c|c|c|c|}
\hline & & $<D I R>$ & & $10-05-93$ & $9: 58 a$ \\
\hline & & $\langle D I R>$ & & $10-05-93$ & $9: 58 a$ \\
\hline & BAT & & 348 & $06-16-93$ & $4: 11 p$ \\
\hline & BA & & 405 & $02-09-94$ & $8: 51 a$ \\
\hline UPP7 & BAT & & 123 & $06-19-93$ & $5: 08$ \\
\hline
\end{tabular}


HNF-SD-WM-CSDD-008

Rev. 3

Page 173

\section{DACS STATION 7 FILE LISTINGS}

"AUTOEXEC.BAT" on Station 7

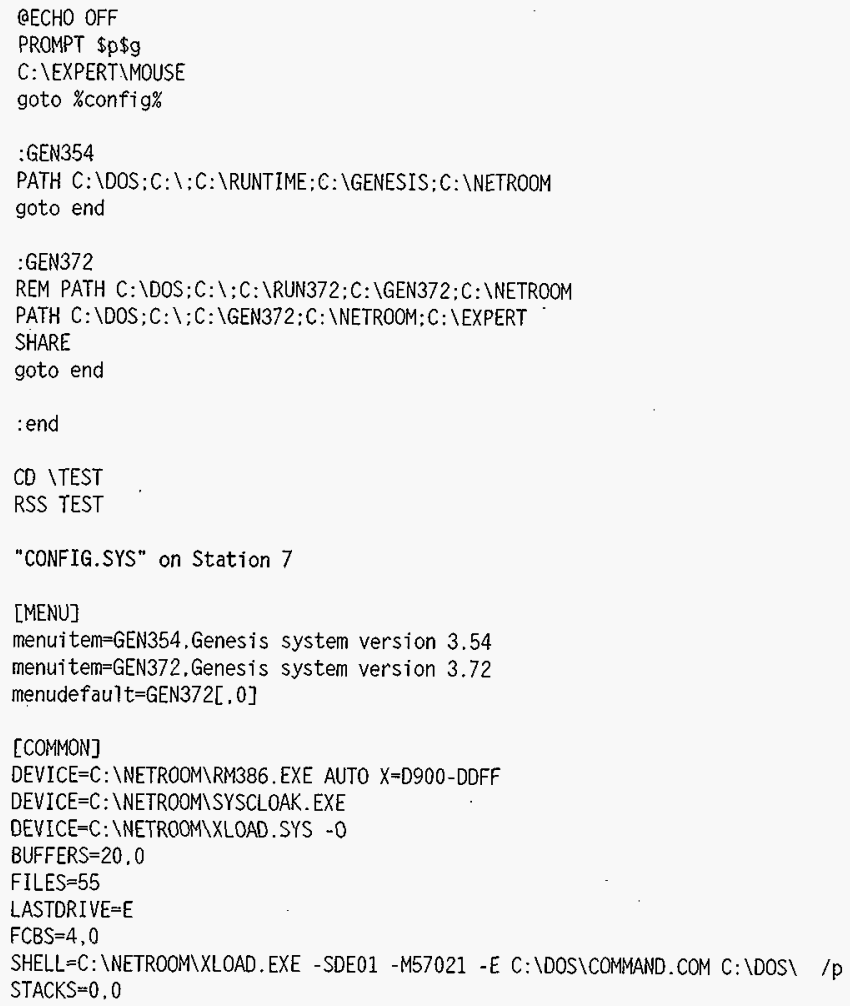


HNF-SD-WM-CSDD-008

Rev. 3

Page 174

"RUNTIME.BAT" on Station 7

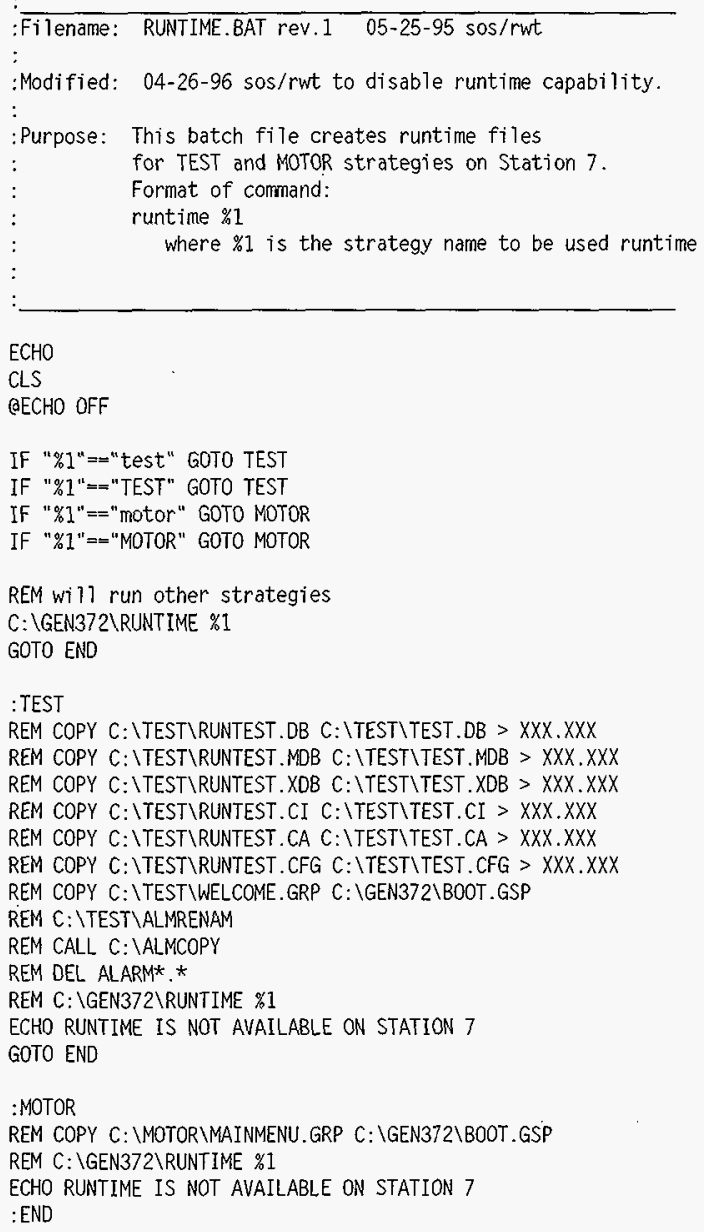




\section{HNF-SD-WM-CSDD-008}

Rev. 3

Page 175

"RSS.BAT" on Station 7

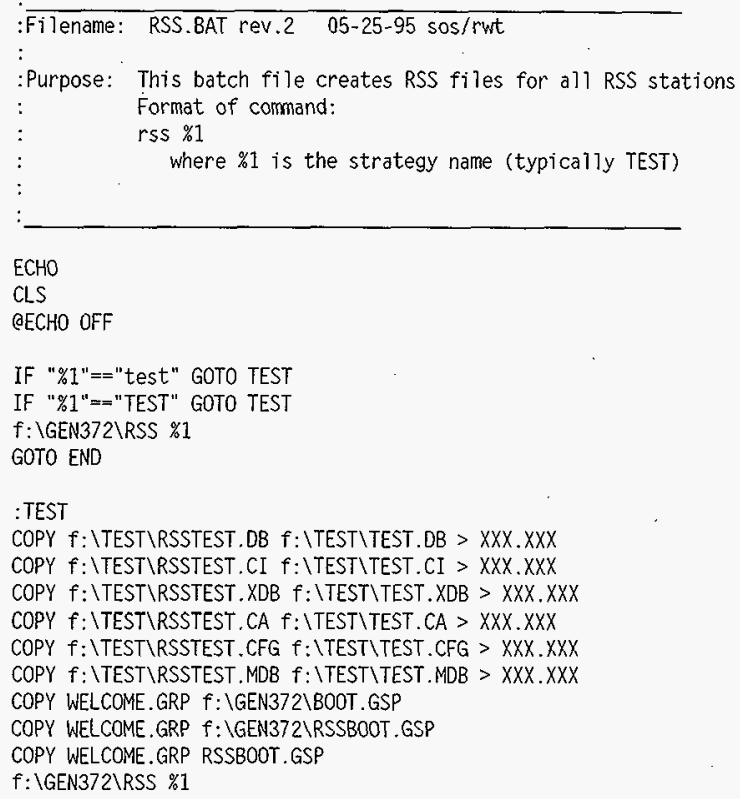


HNF-SD-WM-CSDD-008

Rev. 3

Page 176

\title{
DACS STATION 8 DIRECTORY LISTINGS
}

\author{
Volume in drive $C$ has no label \\ Volume Serial Number is 1 C90-4760 \\ 186703872 bytes free \\ Directory of $C: \backslash^{*}$. BAT, *. SYS

$\begin{array}{llrll}\text { AUTOEXEC } & \text { BAT } & 190 & 11-28-94 & 1: 03 p \\ \text { CONFIG } & \text { SYS } & 390 & 12-13-94 & 8: 41 a \\ \text { RUNTIME } & \text { BAT } & 1155 & 05-25-95 & 2: 12 p\end{array}$

Directory of C: \GEN372

\begin{tabular}{|c|c|c|c|c|}
\hline & & $\langle O I R>$ & $08-01-94$ & $5: 37 p$ \\
\hline & & $\langle D I R\rangle$ & $08-01-94$ & $5: 37 p$ \\
\hline _OGO NET & DAT & 9 & $02-18-94$ & $1: 36 a$ \\
\hline UNPAC̄K & EXE & 29378 & $02-18-94$ & $1: 36 a$ \\
\hline GENNET & DNL & 442 & $08-03-94$ & $12: 50 p$ \\
\hline CONF104 & FNT & 7168 & $02-18-94$ & $5: 01 p$ \\
\hline EXTASCI I & FNT & 1536 & $02-24-94$ & $3: 27 a$ \\
\hline CONFIG & PRM & 407 & $08-01-94$ & $5: 49 p$ \\
\hline EGA & DEV & 13450 & $02-18-94$ & $5: 01 p$ \\
\hline XLATE & EXE & 78445 & $02-24-94$ & $3: 27 a$ \\
\hline OLDBOOT & GSP & 4245 & $12-06-93$ & $10: 16 a$ \\
\hline GENESIS & GSP & 1109 & $02-24-94$ & $3: 27 a$ \\
\hline LOGO & DAT & 9 & $02-24-94$ & $3: 27$ \\
\hline EPSON_MX & PRP & 36 & $02-24-94$ & $3: 27$ \\
\hline EPSON MX & PTR & 2048 & $02-24-94$ & $3: 27$ \\
\hline GENESIS & BAT & 19 & $08-01-94$ & $5: 49$ \\
\hline CONFMSMI & COM & 1487 & $02-18-94$ & $5: 01$ \\
\hline ICONS & ICN & 66267 & $02-24-94$ & $3: 27 a$ \\
\hline README & 354 & 7611 & $06-17-92$ & $3: 54 a$ \\
\hline ELECTRIC & SMB & 2837 & $02-24-94$ & $3: 27 a$ \\
\hline HEATEXCH & SMB & 846 & $02-24-94$ & $3: 27 \mathrm{a}$ \\
\hline LOGIC & SMB & 1353 & $02-24-94$ & $3: 27 a$ \\
\hline IISC & SMB & 1680 & $02-24-94$ & $3: 27 a$ \\
\hline MOTORS & SMB & 396 & $02-24-94$ & $3: 27 a$ \\
\hline TANKS & SMB & 1890 & $02-24-94$ & $3: 27$ \\
\hline VALVES & SMB & 2364 & $02-24-94$ & $3: 27$ \\
\hline KEYHELP & EXE & 39261 & $02-24-94$ & $3: 27$ \\
\hline STANDARD & HLS & 1908 & $02-24-94$ & $3: 27$ \\
\hline KEYMAC & EXE & 34201 & $02-24-94$ & $3: 27$ \\
\hline MOUSE & OPT & 4118 & $02-24-94$ & $3: 27 a$ \\
\hline STATECMP & EXE & 28561 & $02-24-94$ & $3: 27 \mathrm{a}$ \\
\hline STATES & SFL & 642 & $02-24-94$ & $3: 27 a$ \\
\hline STATES & SFS & 913 & $02-24-94$ & $3: 2$ \\
\hline
\end{tabular}


HNF-SD-WM-CSDD-008

Rev. 3

Page 177

\begin{tabular}{|c|c|c|c|}
\hline BUTTONS & SMB & $1320 \quad 02-24-94$ & $3: 27 a$ \\
\hline CART & SMB & $245 \quad 02-24-94$ & $3: 27$ a \\
\hline CIRCUITS & SMB & $44898 \quad 02-24-94$ & $3: 27 a$ \\
\hline FACEPLAT & SMB & $15558 \quad 02-24-94$ & $3: 27 a$ \\
\hline MACHINE & SMB & $184102-24-94$ & $3: 27 a$ \\
\hline PRESS & SMB & $1755 \quad 02-24-94$ & $3: 27 a$ \\
\hline VATS & SMB & $3741 \quad 02-24-94$ & $3: 27$ \\
\hline AUTOCAD & DOC & $998410-31-91$ & $1: 31 a$ \\
\hline DXFTOGRP & EXE & 58777 10-31-91 & $1: 31 a$ \\
\hline GRPTODXF & EXE & 3966 & $1: 31$ \\
\hline SPACE & GRP & 33622 & $31 a$ \\
\hline STAIR & DXF & $46932 \quad 10-31-91$ & $31 a$ \\
\hline PUMP & GRP & $1270310-31-91$ & $1: 31 \mathrm{a}$ \\
\hline STAIR & GRP & $2062510-31-91$ & $1: 31 a$ \\
\hline SHUTTLE & SMB & $4841910-31-91$ & $1: 31$ \\
\hline CONFIG & EXE & $637000 \quad 02-24-94$ & $3: 27 a$ \\
\hline METACONF & EXE & $69599 \quad 02-24-94$ & $3: 27 a$ \\
\hline METACONF & MNU & $3859 \quad 02-24-94$ & $3: 27 \mathrm{a}$ \\
\hline ST.ANDARD & CFN & $18899 \quad 02-24-94$ & $3: 27$ \\
\hline ANALOG & MNU & $337702-24-94$ & $3: 27 \mathrm{a}$ \\
\hline CONTROL & MNU & $10065 \quad 02-24-94$ & $3: 27 a$ \\
\hline DIGITAL & MNU & $4434 \quad 02-$ & $3: 2$ \\
\hline DVNAMIC & MNU & $14019 \quad 02-24-94$ & $3: 27 a$ \\
\hline GRAPHIC & MASU & $2627 \quad 02-24-94$ & $3: 27 a$ \\
\hline HIST & MNU & $15746 \quad 02-24-94$ & $3: 27 a$ \\
\hline LIBRARY & MNU & $\begin{array}{lll}3471 & 02-24-94\end{array}$ & $3: 27 a$ \\
\hline MACROS & MNU & $2282 \quad 02-24-94$ & $3: 27 a$ \\
\hline MEMSYS & MNU & $863 \quad 02-24-94$ & $3: 27 a$ \\
\hline MNEMONIC & MNU & $8335 \quad 02-24-94$ & $3: 27$ a \\
\hline STRING & MNU & $1027 \quad 02-24-94$ & $3: 27 a$ \\
\hline SUPMAC & MNU & $2461 \quad 02-24-94$ & $3: 27 a$ \\
\hline SYSCONF & MNU & $15280 \quad 02-24-94$ & $3: 27 a$ \\
\hline RUNT IME & EXE & $401424 \quad 02-24-94$ & $3: 27 a$ \\
\hline AINDET & GSP & 94 & $3: 27$ \\
\hline ALM & GSP & $264902-24-94$ & $7 a$ \\
\hline ALMSUM & GSP & $224402-24-94$ & $3: 27 a$ \\
\hline AMBDET & GSP & $244902-24-94$ & $3: 27 a$ \\
\hline AOUTDET & GSP & $211302-24-94$ & $3: 27 a$ \\
\hline CALC & GSP & $363302-24-94$ & $3: 27 a$ \\
\hline CALC2 & GSP & $4408 \quad 02-24-94$ & $3: 27 a$ \\
\hline CALC3 & GSP & $2502 \quad 02-24-94$ & $3: 27 a$ \\
\hline CNT & GSP & $2703 \quad 02-24-94$ & $3: 27 a$ \\
\hline CTLDET & GSP & $289602-24-94$ & $3: 27 a$ \\
\hline CTLDET2 & GSP & $3044 \quad 02-24-94$ & 27 \\
\hline CTLDET3 & GSP & $2580 \quad 02-24-94$ & $3: 27 a$ \\
\hline DGAP & GSP & $300302-24-94$ & $3: 27 a$ \\
\hline DGAP2 & GSP & $259302-24-94$ & $3: 27 a$ \\
\hline DIGDET & GSP & $294602-24-94$ & $3: 27 a$ \\
\hline DIR & GSP & $413902-24-94$ & $3: 27 a$ \\
\hline OISPDIR & GSP & $4234 \quad 02-24-94$ & $3: 27 a$ \\
\hline
\end{tabular}


HNF-SD-WM-CSDD-008

Rev. 3

Page 178

$\begin{array}{llrll}\text { DISPSAV } & \text { GSP } & 1001 & 02-24-94 & 3: 27 a \\ \text { DISPSEC } & \text { GSP } & 980 & 02-24-94 & 3: 27 a \\ \text { DOTDET } & \text { GSP } & 2064 & 02-24-94 & 3: 27 a \\ \text { DTIMDET } & \text { GSP } & 2588 & 02-24-94 & 3: 27 a \\ \text { EMPTY } & \text { GSP } & 845 & 02-24-94 & 3: 27 a \\ \text { EXIT } & \text { GSP } & 1021 & 02-24-94 & 3: 27 a \\ \text { FF1 } & \text { GSP } & 2190 & 02-24-94 & 3: 27 a \\ \text { FF2 } & \text { GSP } & 2335 & 02-24-94 & 3: 27 a \\ \text { FILEUTIL } & \text { GSP } & 1296 & 02-24-94 & 3: 27 a \\ \text { HCIRS } & \text { GSP } & 415 & 02-24-94 & 3: 27 a \\ \text { HBWDET } & \text { GSP } & 1954 & 02-24-94 & 3: 27 a \\ \text { HELP } & \text { GSP } & 1217 & 02-24-94 & 3: 27 a \\ \text { HELP1 } & \text { GSP } & 1124 & 02-24-94 & 3: 27 a \\ \text { HELP2 } & \text { GSP } & 1217 & 02-24-94 & 3: 27 a \\ \text { HELP3 } & \text { GSP } & 1217 & 02-24-94 & 3: 27 a \\ \text { HELP4 } & \text { GSP } & 1214 & 02-24-94 & 3: 27 a \\ \text { HELP5 } & \text { GSP } & 1210 & 02-24-94 & 3: 27 a \\ \text { HELP6 } & \text { GSP } & 1156 & 02-24-94 & 3: 27 a \\ \text { HGLSTMEN } & \text { GSP } & 1344 & 02-24-94 & 3: 27 a \\ \text { HGREP } & \text { GSP } & 781 & 02-24-94 & 3: 27 a \\ \text { HGREPLST GSP } & 1688 & 02-24-94 & 3: 27 a \\ \text { HGREPMEN } & \text { GSP } & 1408 & 02-24-94 & 3: 27 a \\ \text { HISMON } & \text { GSP } & 2463 & 02-24-94 & 3: 27 a \\ \text { HISREP } & \text { GSP } & 1588 & 02-24-94 & 3: 27 a \\ \text { HISTB } & \text { GSP } & 1862 & 02-24-94 & 3: 27 a \\ \text { HISTLST } & \text { GSP } & 2038 & 02-24-94 & 3: 27 a \\ \text { HISTMEN1 } & \text { GSP } & 2029 & 02-24-94 & 3: 27 a \\ \text { HTBREP } & \text { GSP } & 1226 & 02-24-94 & 3: 27 a \\ \text { IDB } & \text { GSP } & 2674 & 02-24-94 & 3: 27 a \\ \text { IDBAIN } & \text { GSP } & 2739 & 02-24-94 & 3: 27 a \\ \text { IDBAIO } & \text { GSP } & 3137 & 02-24-94 & 3: 27 a \\ \text { IOBAO } & \text { GSP } & 2070 & 02-24-94 & 3: 27 a \\ \text { IDBDIN } & \text { GSP } & 4381 & 02-24-94 & 3: 27 a \\ \text { IDBDINB } & \text { GSP } & 1574 & 02-24-94 & 3: 27 a \\ \text { IOBDIO } & \text { GSP } & 4831 & 02-24-94 & 3: 27 a \\ \text { IDBDIOB } & \text { GSP } & 1644 & 02-24-94 & 3: 27 a \\ \text { IDBDOT } & \text { GSP } & 2809 & 02-24-94 & 3: 27 a \\ \text { IDBDOTB } & \text { GSP } & 1325 & 02-24-94 & 3: 27 a \\ \text { IDBENTRY GSP } & 663 & 02-24-94 & 3: 27 a \\ \text { IDBSIO } & \text { GSP } & 1480 & 02-24-94 & 3: 27 a \\ \text { IOBSTG } & \text { GSP } & 1271 & 02-24-94 & 3: 27 a \\ \text { IDBSTGO } & \text { GSP } & 1309 & 02-24-94 & 3: 27 a \\ \text { LISTMAIN } & \text { GSP } & 363 & 02-24-94 & 3: 27 a \\ \text { LISTMENU GSP } & 1657 & 02-24-94 & 3: 27 a \\ \text { LOGIC } & \text { GSP } & 2843 & 02-24-94 & 3: 27 a \\ \text { MATH } & \text { GSP } & 2602 & 02-24-94 & 3: 27 a \\ \text { MATH2 } & \text { GSP } & 2506 & 02-24-94 & 3: 27 a \\ \text { PAIOP } & 3453 & 02-24-94 & 3: 27 a \\ 3453 & 02-24-94 & 3: 27 a \\ 3888 & 02-24-94 & 3: 27 a\end{array}$


HNF-SD-WM-CSDD-008

Rev. 3

Page 179

\begin{tabular}{|c|c|c|c|}
\hline PAOUT & GSP & $3143 \quad 02-24-94$ & $3: 27 a$ \\
\hline PASSWORD & GSP & $1794 \quad 02-24-94$ & $3: 27 a$ \\
\hline PDIN & GSP & $5661 \quad 02-24-94$ & $3: 27 \hat{a}$ \\
\hline PDOUT & GSP & $\begin{array}{lll}4171 & 02-24-94\end{array}$ & $3: 27 a$ \\
\hline PLOT & GSP & $465 \quad 02-24-94$ & $3: 27 a$ \\
\hline PLOTMEN & GSP & $2405 \quad 02-24-94$ & $3: 27 a$ \\
\hline PULNOT & GSP & $2322 \quad 02-24-94$ & $3: 27 a$ \\
\hline RAMP & GSP & $3525 \quad 02-24-94$ & $3: 27 \mathrm{a}$ \\
\hline SEL & GSP & $3718 \quad 02-24-94$ & $3: 27 a$ \\
\hline SEQ & GSP & $213102-24-94$ & $3: 27 a$ \\
\hline SIM & GSP & $3038 \quad 02-24-94$ & $3: 27 a$ \\
\hline SLOGIC & GSP & $2360 \quad 02-24-94$ & $3: 27 a$ \\
\hline SORTIDBM & GSP & 1976 & $3: 27 a$ \\
\hline SORTMAIN & GSP & 21640 & $3: 27 a$ \\
\hline SORTMENU & GSP & $1128 \quad 02-2$ & $3: 27 a$ \\
\hline SPULNOT & GSP & 503 & $3: 27 a$ \\
\hline STAT1 & GSP & 271 & $3: 27 a$ \\
\hline STAT2 & GSP & $2053 \quad 02-24-94$ & $3: 27 a$ \\
\hline SWCH & GSP & $292502-24-94$ & $3: 27 a$ \\
\hline SYSCONF & GSP & $3011 \quad 02-24-94$ & $3: 27 \mathrm{a}$ \\
\hline SYSCONF2 & GSP & $289102-24-94$ & $3: 27 a$ \\
\hline SYSPERF & GSP & $2325 \quad 02-24-94$ & $3: 27 a$ \\
\hline TO & GSP & $3086 \quad 02-24-94$ & $3: 27 a$ \\
\hline TIMERS & GSP & $2363 \quad 02-24-94$ & $3: 27 a$ \\
\hline ТОТ & GSP & $3285 \quad 02-24-94$ & $3: 27 a$ \\
\hline TPO & GSP & $3658 \quad 02-24-94$ & $3: 27 a$ \\
\hline TREND & GSP & $\begin{array}{lll}467 & 02-24-94\end{array}$ & $3: 27 a$ \\
\hline TRENDLST & GSP & $2042 \quad 02-24-94$ & $3: 27 a$ \\
\hline TRENDMEN & GSP & $1990 \quad 02-24-94$ & $3: 27 a$ \\
\hline TRENDREP & GSP & $3400 \quad 02-2$ & $3: 27 a$ \\
\hline TUNE & GSP & $3152 \quad 02-24-94$ & $3: 27 a$ \\
\hline TUNE2 & GSP & $3156 \quad 02-24-94$ & $3: 27 a$ \\
\hline TUNE3 & GSP & $2935 \quad 02-24-94$ & $3: 27 a$ \\
\hline TUNE4 & GSP & $243202-24-94$ & $3: 27 a$ \\
\hline USER & GSP & $3967 \quad 02-24-94$ & $3: 27 a$ \\
\hline USER2 & GSP & $3090 \quad 02-24-94$ & $3: 27 a$ \\
\hline$X C$ & GSP & $3543 \quad 02-24-94$ & $3: 27 a$ \\
\hline$K B$ & TBL & $3392 \quad 02-24-94$ & $3: 27 a$ \\
\hline STANDARD & KML & $\begin{array}{lll}544 & 02-24-94\end{array}$ & $3: 27 a$ \\
\hline GNET_OLD & KML & $\begin{array}{lll}510 & 02-24-94\end{array}$ & $3: 27 a$ \\
\hline GENCFG & GNF & $265 \quad 02-18-94$ & $1: 36 a$ \\
\hline GENCFG & NCF & $276 \quad 08-03-94$ & $12: 50 p$ \\
\hline GENNET & NDB & 8-03-94 & $12: 50 p$ \\
\hline GENCMDR & $\mathrm{DOC}$ & $591202-$ & $: 02 p$ \\
\hline HPLSRJI I & PRP & $\begin{array}{lll}36 & 09-17-90\end{array}$ & $3: 32 a$ \\
\hline GN_COMM & OPT & $35453 \quad 02-18-94$ & $5: 02 p$ \\
\hline DOSPWD & EXE & $11384902-18-94$ & 5:01p \\
\hline GEN_NET & OPT & $6155101-15-92$ & $3: 52 a$ \\
\hline GN_DFA & OPT & $9499101-15-92$ & $3: 52 a$ \\
\hline GN_CA & OPT & $6631101-15-92$ & $3: 52 a$ \\
\hline
\end{tabular}


HNF-SD-WM-CSDD-008

Rev. 3

Page 180

\begin{tabular}{|c|c|c|c|c|}
\hline GN_CFA & OPT & 99255 & $01-15-92$ & $3: 528$ \\
\hline GN DCA & OPT & 77441 & $01-15-92$ & $3: 520$ \\
\hline GNDCFA & OPT & 110897 & $01-15-92$ & $3: 52$ \\
\hline GN_DRVR & OPT & 67307 & $02-18-94$ & $5: 02 p$ \\
\hline GN_FTP & OPT & 52219 & $02-18-94$ & $5: 02 p$ \\
\hline GN_INTF & OPT & 32731 & $02-18-94$ & $5: 02 p$ \\
\hline GCOOPY & EXE & 145747 & $02-18-94$ & $5: 01 p$ \\
\hline GENCOMP & EXE & 44069 & $02-18-94$ & $5: 01 p$ \\
\hline GENCONF & EXE & 91957 & $02-18-94$ & $5: 01 p$ \\
\hline GENMON & EXE & 16487 & $02-18-94$ & $5: 01 p$ \\
\hline GN_TIMER & EXE & 13851 & $02-18-94$ & $5: 01 p$ \\
\hline PSI10RST & EXE & 15259 & $02-18-94$ & $5: 01 p$ \\
\hline SHOW OPT & EXE & 15931 & $02-18-94$ & $5: 01 p$ \\
\hline DOSPWD & MNU & 959 & $02-18-94$ & $5: 01 p$ \\
\hline GNETDIR & GSP & 676 & $02-18-94$ & $5: 01 p$ \\
\hline GNETMON & GSP & 2073 & $02-18-94$ & $5: 01 p$ \\
\hline GNETMON2 & GSP & 2045 & $02-18-94$ & $5: 01 p$ \\
\hline GNFXEXIT & GSP & 972 & $02-18-94$ & $5: 01 p$ \\
\hline GNFXR1 & GSP & 1053 & $02-18-94$ & $5: 01 p$ \\
\hline GNFXR2 & GSP & 1043 & $02-18-94$ & $5: 01 p$ \\
\hline GNFXR3 & GSP & 1024 & $02-18-94$ & $5: 01 p$ \\
\hline GNFXR4 & GSP & 827 & $02-18-94$ & $5: 01 p$ \\
\hline GENCFG & MNU & 33934 & $02-18-94$ & $5: 01 p$ \\
\hline GN_TIMER & SYS & 1856 & $02-18-94$ & $5: 01 p$ \\
\hline DOS̄NODE & PWD & 226 & $02-18-94$ & 5:01p \\
\hline BOOT & BAT & 79 & $02-18-94$ & $5: 01 p$ \\
\hline GENCMDR & EXE & 260257 & $02-18-94$ & $5: 02 p$ \\
\hline GENCEXIT & GSP & 928 & $02-18-94$ & $5: 02 p$ \\
\hline GENCMDR & GSP & 948 & $02-18-94$ & $5: 02 p$ \\
\hline GENCMDR2 & GSP & 860 & $02-18-94$ & $5: 02 p$ \\
\hline GENCMDR & MNU & 7682 & $02-18-94$ & $5: 02 p$ \\
\hline GENCMDR & OPT & 43487 & $02-18-94$ & $5: 02 p$ \\
\hline GENCMDR & HLP & 23280 & $02-18-94$ & $5: 02 p$ \\
\hline GENCMDR & NDX & 625 & $02-18-94$ & $5: 02 p$ \\
\hline HPLSRJII & PTR & 2560 & $09-17-90$ & $3: 32 a$ \\
\hline RRCOMBO & OPT & 73309 & $04-28-93$ & $3: 26 a$ \\
\hline AF5000 & DES & 448 & $05-06-92$ & $3: 53 a$ \\
\hline AF5000 & DOC & 31716 & $05-12-92$ & $3: 53 a$ \\
\hline AF5000 & DRV & 35386 & $09-16-94$ & $3: 53 a$ \\
\hline AF5000 & AIF & 17103 & $09-16-94$ & $3: 53 a$ \\
\hline AF5000 & MNU & 912 & $09-16-94$ & $3: 53 a$ \\
\hline TEST & GIF & 24682 & $06-05-93$ & $12: 23 p$ \\
\hline STANDARD & HLP & 1373 & $01-14-94$ & $4: 16 p$ \\
\hline MODICON & DES & 2418 & $04-03-92$ & $3: 50 a$ \\
\hline RSSBOOT & GSP & 4245 & $12-06-93$ & $10: 16 a$ \\
\hline MODICON & 350 & 282 & $04-03-92$ & $3: 50 a$ \\
\hline MODICON & DRV & 7038 & $04-03-92$ & $3: 50 a$ \\
\hline MODICON & MNU & 14762 & $04-03-92$ & $3: 50 a$ \\
\hline $300 T$ & GSP & 2505 & $02-15-95$ & 11:07a \\
\hline MODPLUS & DES & 448 & $02-09-94$ & $3: 38 a$ \\
\hline
\end{tabular}


HNF-SD-WM-CSDD-008

Rev. 3

Page 181

\begin{tabular}{|c|c|c|c|}
\hline MOOPLUS & DRV & $19750 \quad 09-29-94$ & $4: 59 p$ \\
\hline DANISH & ·FNT & $1536 \quad 02-24-94$ & $27 a$ \\
\hline CONFIG & SYS & $26 \quad 02-24-94$ & $3: 27 a$ \\
\hline README & 372 & $8135 \quad 02-24-94$ & $3: 27 a$ \\
\hline ALARM & GSP & $2219 \quad 02-24-94$ & $3: 27 a$ \\
\hline BLANK & GSP & $243 \quad 02-24-94$ & $3: 27$ \\
\hline EVENT & GSP & $2212 \quad 02-24-94$ & $3: 27$ \\
\hline RRCOMBO & GSP & $2450 \quad 02-24-94$ & $3: 27 a$ \\
\hline USER2 2 & GSP & $3090 \quad 02-24-94$ & $3: 27 a$ \\
\hline USER2 3 & GSP & $\begin{array}{lll}3090 & 02-24-94\end{array}$ & $3: 27 a$ \\
\hline USER2_4 & GSP & $3090 \quad 02-24-94$ & $3: 27 a$ \\
\hline USER2_5 & GSP & $\begin{array}{lll}3090 & 02-24-94\end{array}$ & $3: 27 a$ \\
\hline USER2 26 & GSP & $\begin{array}{lll}3090 & 02-24-94\end{array}$ & $3: 27 a$ \\
\hline USER2 $2^{-7}$ & GSP & $\begin{array}{lll}3090 & 02-24-94\end{array}$ & $3: 27 a$ \\
\hline USER $3^{-}$ & GSP & $\begin{array}{lll}1855 & 02-24-94\end{array}$ & $3: 27 a$ \\
\hline USER3 2 & GSP & $\begin{array}{lll}1855 & 02-24-94\end{array}$ & $3: 27 a$ \\
\hline USER 33 & GSP & $1855 \quad 02-24-94$ & $3: 27$ \\
\hline USER $3-4$ & GSP & $\begin{array}{lll}1855 & 02-24-94\end{array}$ & $3: 27$ \\
\hline USER3 5 & GSP & $\begin{array}{lll}1855 & 02-24-94\end{array}$ & $3: 27 a$ \\
\hline USER3 6 & GSP & $\begin{array}{lll}1855 & 02-24-94\end{array}$ & $3: 27 a$ \\
\hline USER3 7 & GSP & $\begin{array}{lll}1855 & 02-24-94\end{array}$ & $3: 27 a$ \\
\hline USER_ $\overline{2}$ & GSP & $3967 \quad 02-24-94$ & $3: 27 a$ \\
\hline USER_3 & GSP & $3967 \quad 02-24-94$ & $3: 27 a$ \\
\hline USER_4 & GSP & $3967 \quad 02-24-94$ & $3: 27$ a \\
\hline USER-5 & GSP & $3967 \quad 02-24-94$ & $3: 27 a$ \\
\hline USER 6 & GSP & $\begin{array}{lll}3967 & 02-24-94\end{array}$ & $3: 27 a$ \\
\hline USER 7 & GSP & $\begin{array}{lll}3967 & 02-24-94\end{array}$ & $3: 27 a$ \\
\hline MODPLUUS & MNU & $12100 \quad 08-24-94$ & $3: 38 a$ \\
\hline MODPLUS & $\mathrm{DOC}$ & $2352403-29-93$ & $3: 38 a$ \\
\hline MODPLUS & 335 & $57906-03-93$ & $3: 36 a$ \\
\hline MODPLUS & 336 & $747 \quad 06-03-93$ & $3: 36 a$ \\
\hline GNETMON3 & GSP & $1916 \quad 02-18-94$ & $5: 01 p$ \\
\hline SHADOW & GSP & $1912 \quad 02-18-94$ & $5: 01 p$ \\
\hline NETALMS & GSP & $\begin{array}{lll}1825 & 02-18-94\end{array}$ & $5: 01 p$ \\
\hline EXPORT. & OPT & $18307 \quad 02-18-94$ & $5: 01 p$ \\
\hline HPLSR4 & PRP & $36 \quad 03-31-94$ & $5: 12 p$ \\
\hline MODPLUS & 338 & $\begin{array}{lll}60 & 09-23-94\end{array}$ & $3: 38 a$ \\
\hline HPLSR4 & PTR & $2560 \quad 09-17-90$ & $3: 32 a$ \\
\hline AF5000 & RWT & $35386 \quad 09=16-94$ & $3: 5$ \\
\hline
\end{tabular}




\section{HNF-SD-WM-CSDD-008}

Rev. 3

Page 182

Directory of C: IMOTOR

\begin{tabular}{llrrr} 
& & \multicolumn{1}{c}{$<$ DIR> } & $06-01-94$ & $3: 45 p$ \\
USERET & TDF & 2886 & $05-01-94$ & $3: 45 p$ \\
USERSET & TDI & & $06-47 a$ \\
NEWSET & TDF & 2886 & $05-04-95$ & $9: 47 a$ \\
KMLEXTRA OLD & 278 & $06-10-94$ & $10: 29 a$ \\
KMSEXTRA & OLD & 324 & $06-10-94$ & $10: 29 a$ \\
MOTOR & DB & 50363 & $11-06-96$ & $9: 05 a$ \\
MOTOR & CI & 13956 & $11-06-96$ & $9: 05 a$ \\
MOTOR & XDB & 676 & $11-06-96$ & $9: 05 a$ \\
MOTOR & CA & 19228 & $11-06-96$ & $9: 05 a$ \\
MOTOR & CFG & 1752 & $01-02-97$ & $8: 28 p$ \\
MOTOR & MDB & 10070 & $11-06-96$ & $9: 05 a$ \\
MAINMENU & GRP & 2505 & $02-15-95$ & $11: 07 a$ \\
PBENPROB & GRP & 3298 & $02-15-95$ & $11: 07 a$ \\
POSPROB & GRP & 2963 & $02-15-95$ & $11: 07 a$ \\
PSPROB & GRP & 3056 & $02-15-95$ & $11: 08 a$ \\
PUMPRUN & GRP & 9256 & $02-15-95$ & $11: 10 a$ \\
SETPROB & GRP & 2600 & $02-15-95$ & $11: 10 a$ \\
TESTSET & GRP & 6255 & $02-26-95$ & $10: 01 a$ \\
EXIT & GRP & 2674 & $02-15-95$ & $11: 06 a$ \\
DMPROB & GRP & 2921 & $02-15-95$ & $11: 06 a$ \\
CLRMESS & RPS & 38 & $05-26-94$ & $1: 34 p$ \\
DELETE & RPS & 2028 & $08-23-94$ & $4: 12 p$ \\
ILOAD & RPS & 1088 & $08-24-94$ & $10: 33 a$ \\
NEXT & RPS & 2845 & $08-24-94$ & $10: 33 a$ \\
PBSETVAL & RPS & 4857 & $08-24-94$ & $10: 06 a$ \\
PREV & RPS & 2263 & $08-24-94$ & $10: 34 a$ \\
SAVE & RPS & 5687 & $08-23-94$ & $4: 18 p$ \\
SETOLD & RPS & 226 & $06-13-94$ & $10: 33 a$ \\
ULOAD & RPS & 1260 & $08-24-94$ & $10: 34 a$ \\
INITENAB & RPS & 1260 & $07-12-95$ & $9: 57 a$ \\
STATES & SFS & 4231 & $12-06-93$ & $10: 07 a$ \\
STATES & SFL & 2771 & $12-06-93$ & $10: 08 a$ \\
BOOT & GSP & 2505 & $02-15-95$ & $11: 07 a$ \\
EXTRA & KMS & 659 & $10-16-95$ & $10: 23 a$ \\
EXTRA & KML & 246 & $10-17-95$ & $7: 36 a$ \\
MOTOR & NEW & 50363 & $01-02-97$ & $8: 28 p$
\end{tabular}


HNF-SD-WM-CSDD-008

Rev. 3

Page 183

\title{
DACS STATION 8 FILE LISTINGS
}

\author{
"AUTOEXEC.BAT" on Station 8 \\ QECHO OFF \\ PROMPT $\$ p \$ g$ \\ C: IEXPERT \MOUSE \\ goto \%config\% \\ :GEN354 \\ PATH C: \DOS:C: $\backslash: C: \backslash$ GENESIS:C: WNETROOM \\ goto end \\ :GEN372

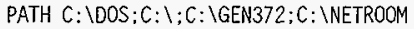 \\ SHARE \\ goto end \\ :end
}

"CONFIG.SYS" on Station 8

\section{[MENU]}

menui tem $=G E N 354$, Genes is version 3.54

menuitem=GEN372, Genesis version 3.72

menudef aul $t=G E N 372[, 0]$

[COMMON]

DEVICE $=C$ : $\backslash$ NETROOMIRM386. EXE AUTO $X=0900$-DDFF

DEVICE $=\mathrm{C}:$ WNETROOMSYSCLOAK. EXE

DEVICE $=C: \backslash N E T R O O M \backslash X L O A D$. SYS - 0

BUFFERS $=20.0$

FILES $=55$

LASTDRIVE $=E$

$\mathrm{FCBS}=4.0$

SHELL=C: WNETROOMYXLOAD. EXE -SDE01 -M57021 -E C:IDOSICOMMANO.COM C:IDOSI /P STACKS $=0,0$

[GEN354]

[GEN372] 
"RUNTIME.BAT" on Station 8

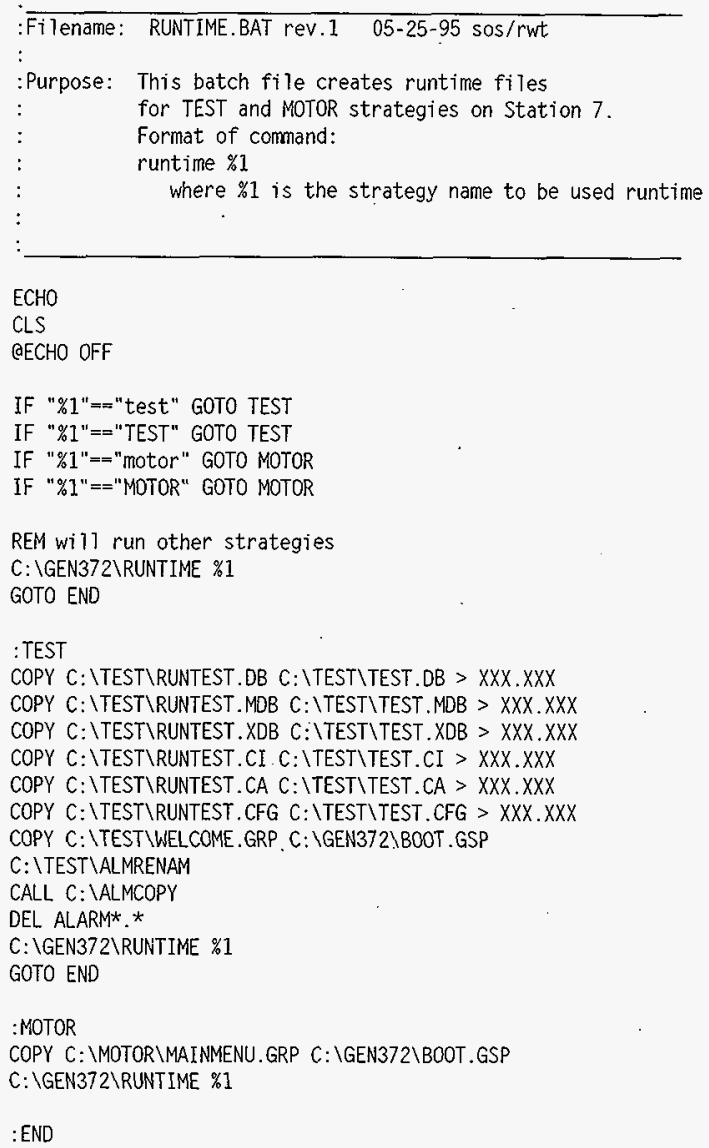




\title{
DACS STATION 9 DIRECTORY LISTINGS
}

\author{
Volume in drive $C$ is MS-DOS 5 \\ Volume Serial Number is 1C99:5306 \\ 175628288 bytes free \\ Directory of $C: I^{*}$. BAT, *.SYS \\ $\begin{array}{lllll}\text { AUTOEXEC BAT } & 892 & 04-26-96 & 10: 53 a \\ \text { CONFIG SYS } & 760 & 04-26-96 & 10: 51 a\end{array}$
}

Directory of C: \GEN372

\begin{tabular}{|c|c|c|c|c|}
\hline & & $\begin{array}{l}I R> \\
I R>\end{array}$ & $\begin{array}{l}08-03-94 \\
08-03-94\end{array}$ & $\begin{array}{l}9: 52 a \\
9: 52 a\end{array}$ \\
\hline MODICON & DES & 2418 & $04-03-92$ & $3: 50 \mathrm{a}$ \\
\hline UNPACK & EXE & 29378 & $02-18-94$ & $1: 36 a$ \\
\hline MODICON & MNU & 14762 & $04-03-92$ & $3: 50 \mathrm{a}$ \\
\hline CONF104 & FNT & 7168 & $02-18-94$ & \\
\hline EXTASCI I & FNT & 1536 & $02-24-94$ & \\
\hline CONFIG & SYS & 26 & $02-$ & \\
\hline CONFIG & PRM & 407 & $08-c$ & \\
\hline EGA & DEV & 13450 & $02-18-94$ & $5: 01 p$ \\
\hline XLATE & EXE & 78445 & $02-24-94$ & 3: \\
\hline B00T & GSP & 1492 & $02-24-94$ & $3: 27 a$ \\
\hline GENESIS & GSP & $1109^{\circ}$ & $02-24-94$ & 3: \\
\hline LOGO & DAT & 9 & $02-24-94$ & $3: 27 a$ \\
\hline EPSON_MX & PRP & 36 & $02-24-94$ & $3: 27 a$ \\
\hline EPSON_MX & PTR & 2048 & $02-24-94$ & $3: 27 a$ \\
\hline GENESIS & BAT & 19 & $08-03-94$ & 9: \\
\hline CONFMSMI & $\operatorname{COM}$ & 1487 & $02-18-94$ & $5: 01 p$ \\
\hline ICONS & $I C N$ & 66267 & $02-24-94$ & $3: 27 a$ \\
\hline README & 354 & 7611 & $06-17-92$ & $3: 54 a$ \\
\hline ELECTRIC & SMB & 2837 & $02-24-94$ & $3: 27 a$ \\
\hline HEATEXCH & SMB & 846 & $02-24-94$ & $27 a$ \\
\hline LOGIC & SMB & 1353 & $02-24-94$ & $3: 27 a$ \\
\hline MISC & SMB & 1680 & $02-24-94$ & $3: 27 a$ \\
\hline MOTORS & SMB & 396 & $02-24-94$ & $3: 27 a$ \\
\hline TANKS & SMB & 1890 & $02-24-94$ & $3: 27 a$ \\
\hline VALVES & SMB & 2364 & $02-24-94$ & $3: 27 a$ \\
\hline KEYHELP & EXE & 39261 & $02-24-94$ & $3: 27 a$ \\
\hline STANDARD & HLS & 1908 & $02-24-94$ & $3: 27 a$ \\
\hline KEYMAC & EXE & 34201 & $02-24-94$ & $3: 27 a$ \\
\hline 1OUSE & OPT & 4118 & $02-24-94$ & $3: 27 \mathrm{a}$ \\
\hline PJET & PRP & 36 & $06-17-92$ & $3: 54$ \\
\hline JET & PTR & 2560 & $06-17-92$ & \\
\hline & PRP & 36 & $06-17$ & 3.5 \\
\hline
\end{tabular}




\begin{tabular}{|c|c|c|c|c|}
\hline IBMPRO & PTR & 2048 & $06-17-92$ & $3: 54 a$ \\
\hline NEWJET & PRP & 82 & $06-17-92$ & $3: 54 a$ \\
\hline NEWJET & PTR & 2560 & $06-17-92$ & $3: 54 a$ \\
\hline XROX 4020 & PRP & 82 & $06-17-92$ & $3: 54 a$ \\
\hline XROX 4020 & PTR & 2560 & $06-17-92$ & $3: 54 a$ \\
\hline READPTR & ME & 562 & $06-17-92$ & $3: 54 a$ \\
\hline STATECMP & EXE & 28561 & $02-24-94$ & $3: 27 a$ \\
\hline STATES & SFL & 642 & $02-24-94$ & $3: 27 \mathrm{a}$ \\
\hline STATES & SFS & 913 & $02-24-94$ & $3: 27 a$ \\
\hline BUTTONS & SMB & 1320 & $02-24-94$ & $3: 27 a$ \\
\hline CART & SMB & 245 & $02-24-94$ & $3: 27 a$ \\
\hline CIRCUITS & SMB & 44898 & $02-24-94$ & $3: 27 \hat{a}$ \\
\hline FACEPLAT & SMB & 15558 & $02-24-94$ & $3: 27 a$ \\
\hline MACHINE & $S M B$ & 1841 & $02-24-94$ & $3: 27 a$ \\
\hline PRESS & $S M B$ & 1755 & $02-24-94$ & $3: 27 \mathrm{a}$ \\
\hline VATS & SMB & 3741 & $02-24-94$ & $3: 27 a$ \\
\hline AUTOCAD & DOC & 9984 & $10-31-91$ & $1: 31 a$ \\
\hline DXFTOGRP & EXE & 58777 & $10-31-91$ & 1:31a \\
\hline GRPTODXF & EXE & 39665 & $10-31-91$ & 1:31a \\
\hline SPACE & GRP & 33622 & $10-31-91$ & $1: 31 a$ \\
\hline STAIR & DXF & 46932 & $10-31-91$ & 1:31a \\
\hline PUMP & GRP & 12703 & $10-31-91$ & $1: 31 a$ \\
\hline STAIR & GRP & 20625 & $10-31-91$ & 1:31a \\
\hline SHUTTLE & SMB & 48419 & $10-31-91$ & 1:31a \\
\hline CONFIG & EXE & 637000 & $02-24-94$ & $3: 27 a$ \\
\hline METACONF & EXE & 69599 & $02-24-94$ & $3: 27 a$ \\
\hline METACONF & MNU & 3859 & $02-24-94$ & $3: 27 a$ \\
\hline STANDARD & CFN & 18899 & $02-24-94$ & $3: 27 a$ \\
\hline ANALOG & MNU & 3377 & $02-24-94$ & $3: 27 a$ \\
\hline CONTROL & MNU & 10065 & $02-24-94$ & $3: 27 a$ \\
\hline OIGITAL & MNU & 4434 & $02-24-94$ & $3: 27 a$ \\
\hline DYNAMIC & MNU & 14019 & $02-24-94$ & $3: 27 a$ \\
\hline GRAPHIC & MNU & 2627 & $02-24-94$ & $3: 27 a$ \\
\hline HIST & MNU & 15746 & $02-24-94$ & $27 a$ \\
\hline LIBRARY & MNU & 3471 & $02-24-94$ & $3: 27 a$ \\
\hline MACROS & MNU & 2282 & $02-24-94$ & $3: 27 a$ \\
\hline MEMSYS & MNU & 863 & $02-24-94$ & $3: 27 a$ \\
\hline MNEMONIC & MNU & 8335 & $02-24-94$ & $3: 27 a$ \\
\hline STRING & MNU & 1027 & $02-24-94$ & $3: 27 a$ \\
\hline SUPMAC & MNU & 2461 & $02-24-94$ & $3: 27 a$ \\
\hline SYSCONF & MNU & 15280 & $02-24-94$ & $3: 27 a$ \\
\hline RUNTIME & EXE & 401424 & $02-24-94$ & $3: 27 a$ \\
\hline AINDET & GSP & 2995 & $02-24-94$ & $3: 27 a$ \\
\hline ALM & GSP & 2649 & $02-24-94$ & $3: 27 a$ \\
\hline ALMSUM & GSP & 2244 & $02-24-94$ & $3: 27 a$ \\
\hline AMBDET & GSP & 2449 & $02-24-94$ & $3: 27 a$ \\
\hline AOUTDET & GSP & 2113 & $02-24-94$ & $3: 27 \mathrm{a}$ \\
\hline CALC & GSP & 3633 & $02-24-94$ & $3: 27 a$ \\
\hline CALC2 & GSP & 4408 & $02-24-94$ & $3: 27 a$ \\
\hline CALC3 & GSP & 2502 & $02-24-94$ & $3: 27 a$ \\
\hline
\end{tabular}




\begin{tabular}{|c|c|c|c|}
\hline CNT & GSP & $2703 \quad 02-24-94$ & $3: 27 a$ \\
\hline CTLDET & GSP & $2896 \quad 02-24-94$ & $3: 27 a$ \\
\hline CTLDET2 & GSP & $3044 \quad 02-24-94$ & $3: 27 a$ \\
\hline CTLDET3 & GSP & $2580 \quad 02-24-94$ & $3: 27 a$ \\
\hline DGAP & GSP & $3003 \quad 02-24-94$ & $3: 27 a$ \\
\hline DGAP2 & GSP & $2593 \quad 02-24-94$ & $3: 27 \mathrm{a}$ \\
\hline DIGDET & GSP & $294602-24-94$ & $3: 27 a$ \\
\hline DIR & GSP & $\begin{array}{lll}4139 & 02-24-94\end{array}$ & $3: 27 a$ \\
\hline DISPDIR & GSP & $\begin{array}{lll}4234 & 02-24-94\end{array}$ & $3: 27 a$ \\
\hline DISPSAV & GSP & $1001 \quad 02-24-94$ & $3: 27 \mathrm{a}$ \\
\hline DISPSEC & GSP & $980 \quad 02-24-94$ & $3: 27 a$ \\
\hline DOTDET & GSP & $206402-24-94$ & $3: 27 a$ \\
\hline DTIMDET & GSP & $2588 \quad 02-24-94$ & $3: 27 a$ \\
\hline EMPTY & GSP & $845 \quad 02-24-94$ & $3: 27 \mathrm{a}$ \\
\hline EXIT & GSP & $1021 \quad 02-24-94$ & $3: 27 a$ \\
\hline FF1 & GSP & $2190 \quad 02-24-94$ & $3: 27 a$ \\
\hline FF2 & GSP & $233502-24-94$ & $3: 27 a$ \\
\hline FILEUTIL & GSP & $1296 \quad 02-24-94$ & $3: 27 a$ \\
\hline HCURS & GSP & $\begin{array}{lll}415 & 02-24-94\end{array}$ & $3: 27 a$ \\
\hline HDWDET & GSP & $1954 \quad 02-24-94$ & $3: 27 a$ \\
\hline HELP & GSP & $1217 \quad 02-24-94$ & $3: 27 a$ \\
\hline HELP1 & GSP & $1124 \quad 02-24-94$ & $3: 27 a$ \\
\hline HELP2 & GSP & $1217 \quad 02-24-94$ & $3: 27 a$ \\
\hline HELP3 & GSP & $\begin{array}{lll}1217 & 02-24-94\end{array}$ & $3: 27 a$ \\
\hline HELP4 & GSP & $1214 \quad 02-24-94$ & $3: 27 a$ \\
\hline HELP5 & GSP & $1210 \quad 02-24-94$ & $3: 27 a$ \\
\hline HELP6 & GSP & $1156 \quad 02-24-94$ & $3: 27 \mathrm{a}$ \\
\hline HGLSTMEN & GSP & $1344 \quad 02-24-94$ & $3: 27 a$ \\
\hline HGREP & GSP & $\begin{array}{lll}781 & 02-24-94\end{array}$ & $3: 27 a$ \\
\hline HGREPLST & GSP & $\begin{array}{lll}1688 & 02-24-94\end{array}$ & $3: 27 a$ \\
\hline HGREPMEN & GSP & $1408 \quad 02-24-94$ & $3: 27 a$ \\
\hline HISMON & GSP & $246302-24-94$ & $3: 27 a$ \\
\hline HISREP & GSP & $1588 \quad 02-24-94$ & $3: 27 a$ \\
\hline HISTB & GSP & $1862 \quad 02-24-94$ & $3: 27 a$ \\
\hline HISTLST & GSP & $2038 \quad 02-24-94$ & $3: 27 a$ \\
\hline HISTMEN1 & GSP & $2029 \quad 02-24-94$ & $3: 27$ \\
\hline HTBREP & GSP & $1226 \quad 02-24-94$ & $3: 27 a$ \\
\hline IDB & GSP & $2674 \quad 02-24-94$ & $3: 27 a$ \\
\hline IDBAIN & GSP & $2739 \quad 02-24-94$ & $3: 27 a$ \\
\hline IDBAIO & GSP & $3137 \quad 02-24-94$ & $3: 27 \mathrm{a}$ \\
\hline IOBA0 & GSP & $.2070 \quad 02-24-94$ & $3: 27 a$ \\
\hline IDBDIN & GSP & $4381 \quad 02-24-94$ & $3: 27 a$ \\
\hline IDBDINB & GSP & $\begin{array}{lll}1574 & 02-24-94\end{array}$ & $3: 27 a$ \\
\hline IDBDIO & GSP & $4831 \quad 02-24-94$ & $3: 27 a$ \\
\hline IOBOIOB & GSP & $1644 \quad 02-24-94$ & $3: 27 a$ \\
\hline IDBDOT & GSP & $2809 \quad 02-24-94$ & $3: 27 a$ \\
\hline IDBDOTB & GSP & $\begin{array}{lll}1325 & 02-24-94\end{array}$ & $3: 27$ \\
\hline IDBENTRY & GSP & $\begin{array}{lll}663 & 02-24-94\end{array}$ & $3: 27 a$ \\
\hline IDBSIO & GSP & $\begin{array}{lll}1480 & 02-24-94\end{array}$ & $3: 27$ \\
\hline ID & GSP & $24-94$ & $3: 27$ \\
\hline
\end{tabular}


HNF-SD-WM-CSDD-008

Rev. 3

Page 188

\begin{tabular}{|c|c|c|c|}
\hline IDBSTGO & GSP & $1309 \quad 02-24-94$ & $3: 27 a$ \\
\hline LISTMAIN & GSP & $\begin{array}{lll}363 & 02-24-94\end{array}$ & $3: 27 a$ \\
\hline LISTMENU & GSP & $165702-24-94$ & $3: 27 \mathrm{a}$ \\
\hline LOGIC & GSP & $2843 \quad 02-24-94$ & $3: 27 \mathrm{a}$ \\
\hline MATH & GSP & $2602 \cdot 02-24-94$ & $3: 27 \mathrm{a}$ \\
\hline МАTH2 & GSP & $2506 \quad 02-24-94$ & $3: 27 a$ \\
\hline PAI01 & GSP & $3453 \quad 02-24-94$ & $3: 27 a$ \\
\hline PAIO2 & GSP & $\begin{array}{lll}3453 & 02-24-94\end{array}$ & $3: 27 a$ \\
\hline PAI03 & GSP & $3888 \quad 02-24-94$ & $3: 27 \mathrm{a}$ \\
\hline PAOUT & GSP & $3143 \quad 02-24-94$ & $3: 27 a$ \\
\hline PASSWORD & GSP & $1794 \quad 02-24-94$ & $3: 27 a$ \\
\hline PDIN & GSP & $\begin{array}{lll}5661 & 02-24-94\end{array}$ & $3: 27 \mathrm{a}$ \\
\hline PDOUT & GSP & $4171 \quad 02-24-94$ & $3: 27 a$ \\
\hline PLOT & GSP & $465 \quad 02-24-94$ & $3: 27 \mathrm{a}$ \\
\hline PLOTMEN & GSP & $2405 \quad 02-24-94$ & $3: 27 a$ \\
\hline PULNOT & GSP & $2322 \quad 02-24-94$ & $3: 27 a$ \\
\hline RAMP & GSP & $3525 \quad 02-24-94$ & $3: 27 a$ \\
\hline SEL & GSP & $\begin{array}{lll}3718 & 02-24-94\end{array}$ & $3: 27 a$ \\
\hline SEQ & GSP & $2131 \quad 02-24-94$ & $3: 27 a$ \\
\hline SIM & GSP & $\begin{array}{lll}3038 & 02-24-94\end{array}$ & $3: 27 a$ \\
\hline SLOGIC & GSP & $2360 \quad 02-24-94$ & $3: 27 a$ \\
\hline SORTIDBM & GSP & $1976 \quad 02-24-94$ & $3: 27 a$ \\
\hline SORTMAIN & GSP & $2164 \quad 02-24-94$ & $3: 27 a$ \\
\hline SORTMENU & GSP & $1128 \quad 02-24-94$ & $3: 27 a$ \\
\hline SPULNOT & GSP & $1503 \quad 02-24-94$ & $3: 27 \mathrm{a}$ \\
\hline STATI & GSP & $227102-24-94$ & $3: 27 a$ \\
\hline STAT2 & GSP & $2053 \quad 02-24-94$ & $3: 27 a$ \\
\hline $\mathrm{SWCH}$ & GSP & $2925 \quad 02-24-94$ & $3: 27 a$ \\
\hline SYSCONF & GSP & $301102-24-94$ & $3: 27 a$ \\
\hline SYSCONF2 & - GSP & $2891 \quad 02-24-94$ & $3: 27 a$ \\
\hline SYSPERF & GSP & $2325 \quad 02-24-94$ & $3: 27 a$ \\
\hline TD & GSP & $\begin{array}{lll}3086 & 02-24-94\end{array}$ & $3: 27 a$ \\
\hline TIMERS & GSP & $2363 \quad 02-24-94$ & $3: 27 a$ \\
\hline TOT & GSP & $3285 \quad 02-24-94$ & $3: 27 a$ \\
\hline TPO & GSP & $3658 \quad 02-24-94$ & $3: 27 a$ \\
\hline TREND & GSP & $467 \quad 02-24-94$ & $3: 27 a$ \\
\hline TRENDLST & GSP & $2042 \quad 02-24-94$ & $3: 27 a$ \\
\hline TRENDMEN & GSP & $1990 \quad 02-24-94$ & $3: 27 a$ \\
\hline TRENDREP & GSP & $3400 \quad 02-24-94$ & $3: 27 a$ \\
\hline TUNE & GSP & $\begin{array}{lll}3152 & 02-24-94\end{array}$ & $3: 27 a$ \\
\hline TUNE2 & GSP & $3156 \quad 02-24-94$ & $3: 27 a$ \\
\hline TUNE3 & GSP & $293502-24-94$ & $3: 27 a$ \\
\hline TUNE4 & GSP & $2432 \quad 02-24-94$ & $3: 27 a$ \\
\hline USER & GSP & $3967 \quad 02-24-94$ & $3: 27 \mathrm{a}$ \\
\hline USER2 & GSP & $\begin{array}{lll}3090 & 02-24-94\end{array}$ & $3: 27 a$ \\
\hline$X C$ & GSP & $3543 \quad 02-24-94$ & $3: 27 a$ \\
\hline K8 & TBL & $3392 \quad 02-24-94$ & $3: 27 a$ \\
\hline STANDARD & KML & $544 \quad 02-24-94$ & $3: 27 a$ \\
\hline MODICON & DRV & $7038 \quad 04-03-92$ & $3: 50 \mathrm{a}$ \\
\hline & 50 & $28204-03-92$ & $3: 50 a$ \\
\hline
\end{tabular}




\begin{tabular}{|c|c|c|c|}
\hline LOGO NET & DAT & $902-18-94$ & $1: 36 a$ \\
\hline GENNET & DNL & $44205-09-95$ & $10: 39 a$ \\
\hline GENCFG & GNF & $26502-18-94$ & $1: 36 a$ \\
\hline GENCFG & NCF & $27605-09-95$ & $10: 39 a$ \\
\hline GENNET & NDB & $17105-09-95$ & $10: 39 a$ \\
\hline GENCMDR & $D O C$ & $5912 \quad 02-18-94$ & $5: 02 p$ \\
\hline GN_INTF & OPT & $32731 \quad 02-18-94$ & $5: 02 p$ \\
\hline DOSPWD & EXE & $11384902-18-94$ & $5: 01 p$ \\
\hline GEN NET & OPT & $6155101-15-92$ & $3: 52 a$ \\
\hline GN_CA & OPT & $6631101-15-92$ & $3: 52 a$ \\
\hline GN CFA & OPT & $99255 \quad 01-15-92$ & $3: 52$ \\
\hline GN DCA & OPT & $7744101-15-92$ & $3: 5$ \\
\hline GN_DCFA & OPT & $11089701-15-92$ & $3: 52 a$ \\
\hline$G_{N} D F A$ & OPT & $9499101-15-92$ & $3: 52 a$ \\
\hline GN_DRVR & OPT & $\begin{array}{lll}67307 & 02-18-94\end{array}$ & $5: 02 p$ \\
\hline GN_COMM & OPT & $\begin{array}{lll}35453 & 02-18-94\end{array}$ & 5: \\
\hline GN FTP & OPT & $52219 \quad 02-18-94$ & $5: 02 p$ \\
\hline GCOPY & EXE & $145747 \quad 02-18-94$ & $5: 01 p$ \\
\hline GENCOMP & EXE & $4406902-18-94$ & $5: 01 p$ \\
\hline GENCONF & EXE & $9195702-18-94$ & $: 01 p$ \\
\hline GENMON & EXE & $1648702-1$ & $01 p$ \\
\hline GN_TIMER & EXE & $\begin{array}{lll}13851 & 02-18-94\end{array}$ & $5: 01 p$ \\
\hline PS1110RST & EXE & $\begin{array}{lll}15259 & 02-18-94\end{array}$ & $5: 01 p$ \\
\hline SHOW OPT & EXE & $15931 \quad 02-18-94$ & $5: 01 p$ \\
\hline DOSPW̄D & MNU & $959 \quad 02-18-94$ & $5: 01 p$ \\
\hline GNETDIR & GSP & $676 \quad 02-18-94$ & $5: 01 p$ \\
\hline GNETMON & GSP & $2073 \quad 02-18-94$ & $5: 01 p$ \\
\hline GNETMON2 & GSP & $2045 \quad 02-18-94$ & $5: 01 p$ \\
\hline GNFXEXIT & GSP & $972 \quad 02-18-94$ & $5: 01 p$ \\
\hline GNFXR1 & GSP & $\begin{array}{lll}1053 & 02-18-94\end{array}$ & 5: \\
\hline GNFXR2 & GSP & $1043 \quad 02-18-94$ & $5: 01 p$ \\
\hline GNFXR3 & GSP & $1024 \quad 02-18-94$ & 5: \\
\hline GNFXR4 & GSP & $82702-18-94$ & $5: 01 p$ \\
\hline GENCFG & MNU & $33934 \quad 02-18-94$ & $.01 \mathrm{p}$ \\
\hline GN_TIMER & SYS & $1856 \quad 02$ & $01 \mathrm{p}$ \\
\hline DOSNODE & PWO & $226 \quad 02-18-94$ & $5: 01 p$ \\
\hline BOOT. & BAT & $79 \quad 02-18-94$ & $5: 01 p$ \\
\hline GENCMDR & EXE & $26025702-18-94$ & $5: 02 p$ \\
\hline GENCEXIT & GSP & $928 \quad 02-18-94$ & $5: 02 p$ \\
\hline GENCMDR & GSP & $948 \quad 02-18-94$ & $5: 02 p$ \\
\hline GENCMDR2 & GSP & $860 \quad 02-18-94$ & $5: 02 p$ \\
\hline GENCMDR & MNU & $\begin{array}{lll}7682 & 02-18-94\end{array}$ & $5: 02 p$ \\
\hline GENCMDR & OPT & $43487 \quad 02-18-94$ & $5: 02 p$ \\
\hline GENCMDR & HLP & $23280 \quad 02-18-94$ & $5: 02 p$ \\
\hline GENCMDR & NDX & $\begin{array}{lll}625 & 02-18-94\end{array}$ & $5: 02 p$ \\
\hline RRCOMBO & OPT & $6523310-07-91$ & $3: 41 a$ \\
\hline RRTEST & EXE & $68794 \quad 10-07-91$ & $3: 41 a$ \\
\hline $\mathrm{FL}$ & & $28091808-06-93$ & $7: 02 p$ \\
\hline GNE & GSP & $1916 \quad 02-18-94$ & $5: 01 p$ \\
\hline DANISH & FNT & $1536 \quad 02-24-94$ & $3: 27$ \\
\hline
\end{tabular}




$\begin{array}{llrll}\text { README } & 372 & 8135 & 02-24-94 & 3: 27 a \\ \text { ALARM } & \text { GSP } & 2219 & 02-24-94 & 3: 27 a \\ \text { BLANK } & \text { GSP } & 243 & 02-24-94 & 3: 27 a \\ \text { EVENT } & \text { GSP } & 2212 & 02-24-94 & 3: 27 a \\ \text { RRCOMB0 } & \text { GSP } & 2450 & 02-24-94 & 3: 27 a \\ \text { USER2_2 } & \text { GSP } & 3090 & 02-24-94 & 3: 27 a \\ \text { USER2_3 } & \text { GSP } & 3090 & 02-24-94 & 3: 27 a \\ \text { USER2_4 } & \text { GSP } & 3090 & 02-24-94 & 3: 27 a \\ \text { USER2_5 } & \text { GSP } & 3090 & 02-24-94 & 3: 27 a \\ \text { USER2_6 } & \text { GSP } & 3090 & 02-24-94 & 3: 27 a \\ \text { USER2_7 } & \text { GSP } & 3090 & 02-24-94 & 3: 27 a \\ \text { USER3 } & \text { GSP } & 1855 & 02-24-94 & 3: 27 a \\ \text { USER3_2 } & \text { GSP } & 1855 & 02-24-94 & 3: 27 a \\ \text { USER3_3 } & \text { GSP } & 1855 & 02-24-94 & 3: 27 a \\ \text { USER3_4 } & \text { GSP } & 1855 & 02-24-94 & 3: 27 a \\ \text { USER3_5 } & \text { GSP } & 1855 & 02-24-94 & 3: 27 a \\ \text { USER3_6 } & \text { GSP } & 1855 & 02-24-94 & 3: 27 a \\ \text { USER3_7 } & \text { GSP } & 1855 & 02-24-94 & 3: 27 a \\ \text { USER_2 } & \text { GSP } & 3967 & 02-24-94 & 3: 27 a \\ \text { USER_3 } & \text { GSP } & 3967 & 02-24-94 & 3: 27 a \\ \text { USER_4 } & \text { GSP } & 3967 & 02-24-94 & 3: 27 a \\ \text { USER_5 } & \text { GSP } & 3967 & 02-24-94 & 3: 27 a \\ \text { USER_6 } & \text { GSP } & 3967 & 02-24-94 & 3: 27 a \\ \text { USER_7 } & \text { GSP } & 3967 & 02-24-94 & 3: 27 a \\ \text { GNET_OLD } & \text { KML } & 510 & 02-24-94 & 3: 27 a \\ \text { SHADOW } & \text { GSP } & 1912 & 02-18-94 & 5: 01 p \\ \text { NETALMS } & \text { GSP } & 1825 & 02-18-94 & 5: 01 \mathrm{p} \\ \text { EXPORT } & \text { OPT } & 18307 & 02-18-94 & 5: 01 p\end{array}$




\section{DACS STATION 9 FILE LISTINGS}

"AUTOEXEC.BAT" on Station 9

C: IDOSISETVER SCPLUS.EXE 5.00

REM OECHO OFF

SET OAD_DRIVER $=C: \backslash O A D O O S$

C: $\backslash$ NETROOOM XLOAD. EXE -C -AB001.27664 -AC156.12496 -ACE01.47232 C: $\backslash$ OADDOSISCPLUSISCPLUS INSTALL SET OAD UTILITY $=C: \backslash O A D O O S$

PROMPT $\$ \mathrm{p} \$ \mathrm{~g}$

goto \%config\%

:GEN354

PATH C: \DOS:C: $\backslash ; \mathrm{C}: \backslash$ GENESIS:C: WMOUSE;C: $\backslash$ BAT:

goto finish

:GEN372

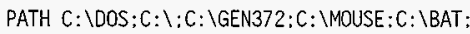

SHARE

goto finish

:finish

C: INETROOM XLOAD. EXE -SCE01 -M23248 -X C: IMOUSEIMOUSE

QREM $====$ LANMAN $2.1 \mathrm{a}===$ DO NOT MODIFY BETWEEN THESE LINES $===$ LANMAN $2.1 \mathrm{a}=m=$

PATH C: IDOS;C: ILMINETPROG:\%PATH\%

C: WNETROOM XLOAD. EXE -C -AB001,4448 -AC156,13488 -AF001.35520 NET START WORKSTATION

NET LOGON DACCS9 DACCS9 /DOMAIN:STANDALONE

net use $f:$ IIwhc324\dpu strength

QREM $====$ LANMAN $2.1 \mathrm{a}===$ DO NOT MODIFY BETWEEN THESE LINES $===$ LANMAN $2.1 \mathrm{a}===$

guest

$f$ :

cd Irawtransfer

REM $======$ GENESIS $==0=====$

GENCMDR

REM $======$ GENESIS $=========$ 
HNF-SD-WM-CSDD-008

Rev. 3

Page 192

"CONFIG.SYS" on Station 9

[MENU]

menuitem=GEN354, Genes is system version 3.54

menui tem $=G E N 372$. Genesis system version 3.72

menudefau $\mathrm{t}=\mathrm{GEN} 372[$, 0]

[COMMON]

DEVICE $=C: \backslash N E T R O O M \backslash R M 386$. EXE AUTO $X=C 800-$ CBFF $X=0900-D D F F$

rem DEVICE $=$ C: WNETROOM VIDCLOAK. EXE /PMBIOS

rem DEVICE $=C$ : $\backslash$ NETTROOMISYSCLOAK. EXE

DEVICE $=C: \backslash$ WETROOM $\backslash X L O A D$. SYS -O

REM DOS $=H I G H$

BUFFERS $=17,0$

FILES $=55$

LASTDRIVE $=P$

$\mathrm{FCBS}=4,0$

DEVICE $=$ C: WWETROOMIXLOAD. SYS -SC156 -M13728 C: IDOSISETVER. EXE

DEVICE $=C: \backslash$ OADDOS $\backslash D O S C F G$. EXE /M1 $/ V$

DEVICE-C: \NETROCM XLOAD. SYS -SF001 -M51376 C: IOADDOSIDOSOAD.SYS

SHELL=C: \NETROOMIXLOAD. EXE -SCE01 -M57021 -E C: IDOSICOMMAND.COM C:IDOSI/P

STACKS $=0,0$

DEVICE-C: \NETROOMIXLOAD.SYS -SF001 -M2832 C: INETROOMISTACKS. EXE 9,256

device $=\mathrm{c}$ : $\backslash$ scsi $\backslash$ aspipc2. sys

[GEN354]

[GEN372] 


\section{Appendix J: ASCU/BASIC Listings}

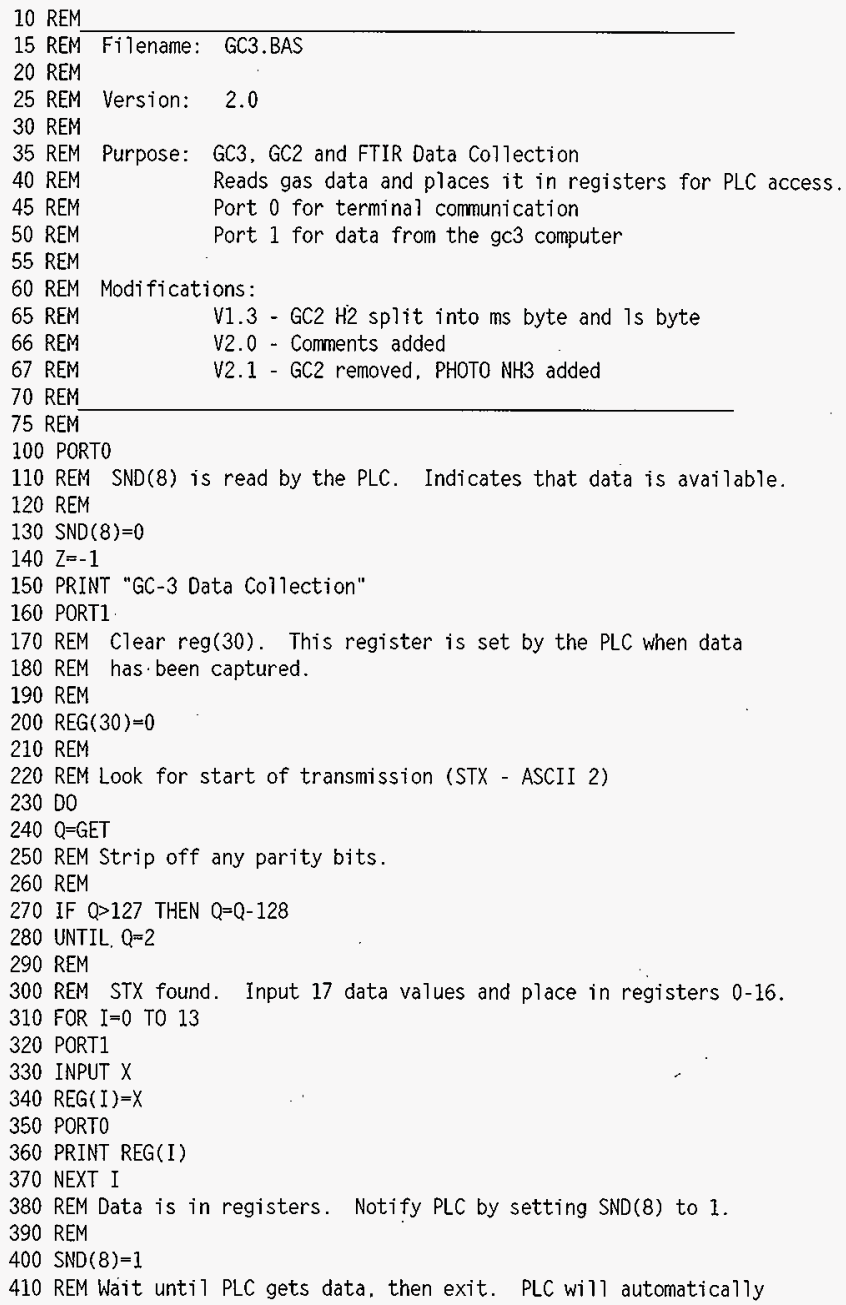


HNF-SD-WM-CSDD-008

Rev. 3

Page 194

420 REM Re-run program.

430 REM

440 IF (REG(30)=0) THEN 440

$450 \mathrm{SND}(8)=0$

460 END 
HNF-SD-WM-CSDD-008

Rev. 3

Page 195

10 REM

15 REM Fi7ename: RGA5.BAS

20 REM Author: Jeff Martin

25 REM Version: 1.0

30 REM

35 REM

40 REM

Purpose: RGA-5 Data Collection

Extract Data from RGA-5 ASCII stream and send it to

45 REM

50 REM

55 REM

Notes: Port 0 is for terminal communication.

60 REM

65 REM

70 REM

75 REM

80 REM

85 REM

90 REM

95 REM

100 REM

105 REM

110 REM

115 REM

120 REM

125 REM

130 REM

135 REM

140 REM

145 REM

150 REM

155 REM

160 REM

165 REM

170 REM

175 REM

180 REM

185 REM the PLC.

Port 1 receives the RGA-5 data stream.

The following ASCII formats are used by the program

RMSG1: SO,D3

RMSG2: S1,A1

RMSG3: S2

RMSG4: S2,D2,D2

RMSG5: $\$ 4, F 6.1$

RMSG6: S6,D1,04,D4

RMSG7: S9,D3

RMSG8: $\$ 10$

RMSG9: S10, F6.1

RMSG10:S12,01.04.04

RMSG11:S15,03

RMSG12:S16

These ASCII formats need to be loaded into the ASCII section of the ASCII/Basic module.

In addition, the ASCII/Basic module must be set for no

delimeter (DL\# 0) and for a prefix string of " $="$ (PR\# 3Dh).

XON/XOFF should be enabled (XI\# 1). The communications

parameters are 1200 baud. 8 bits, no parity. 1 stop bit.

The program should be loaded into RAM: 2 of the Basic module.

190 REM

195 REM

280 ONERR 6000

285 PORTO

290 REM SND(8) is sent when data has been collected. PLC uses this

295 REM to determine when to grab data.

300 REM

305 SND $(8)=0$

310 REM " $Z$ " is a constant used in Subroutine at line 1390

315 REM

$320 \mathrm{Z}=-1$

325 PRINT "RGA-5 Data Collection"

330 REM Search ASCII stream for the word "Run"

335 REM Reg( 30$)$ is set to 1 by the PLC when it has read the data

340 REM

$345 \operatorname{REG}(30)=0$

350 portl

35500 


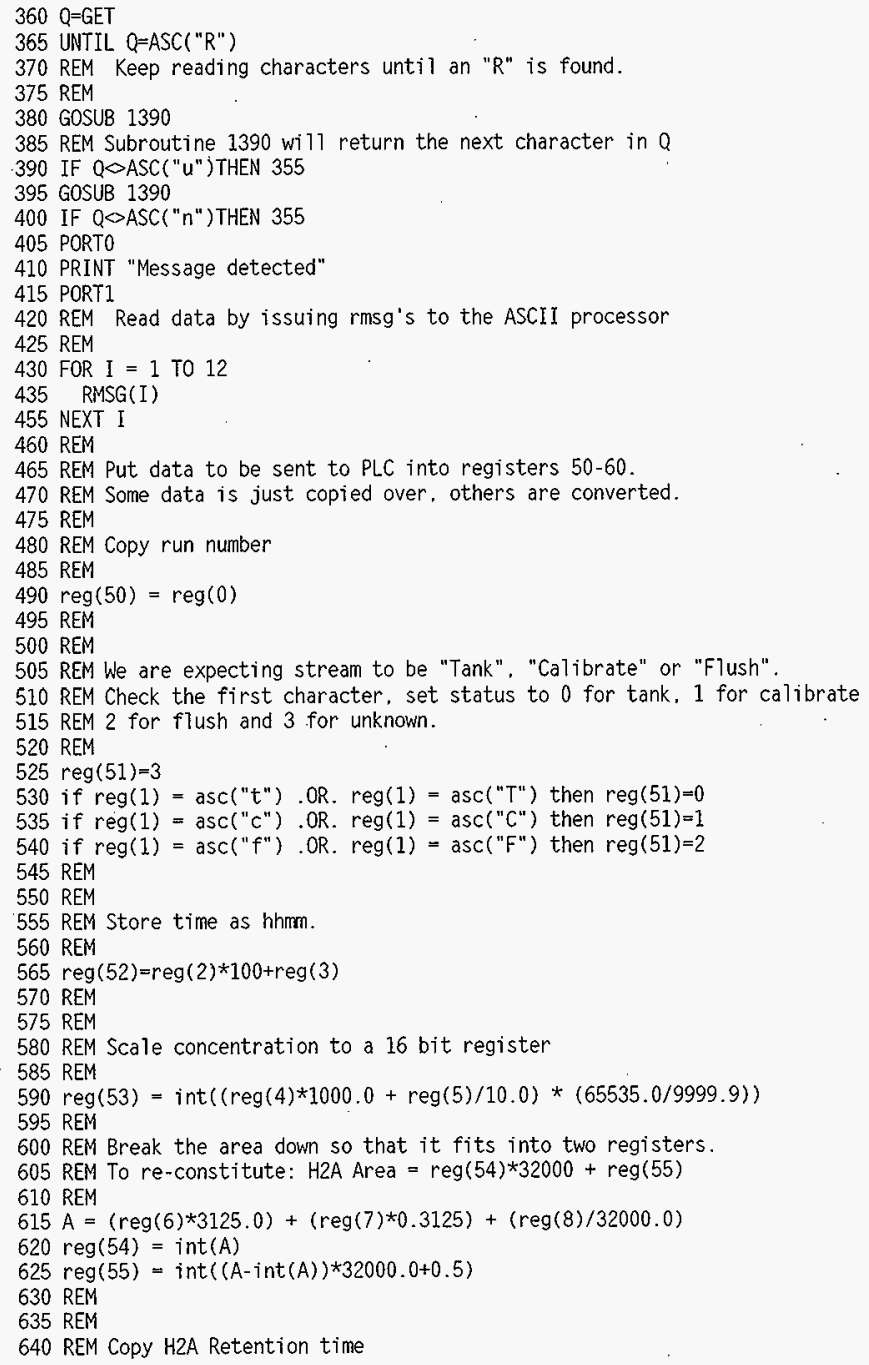


HNF-SD-WM-CSDD-008

Rev. 3

Page 197

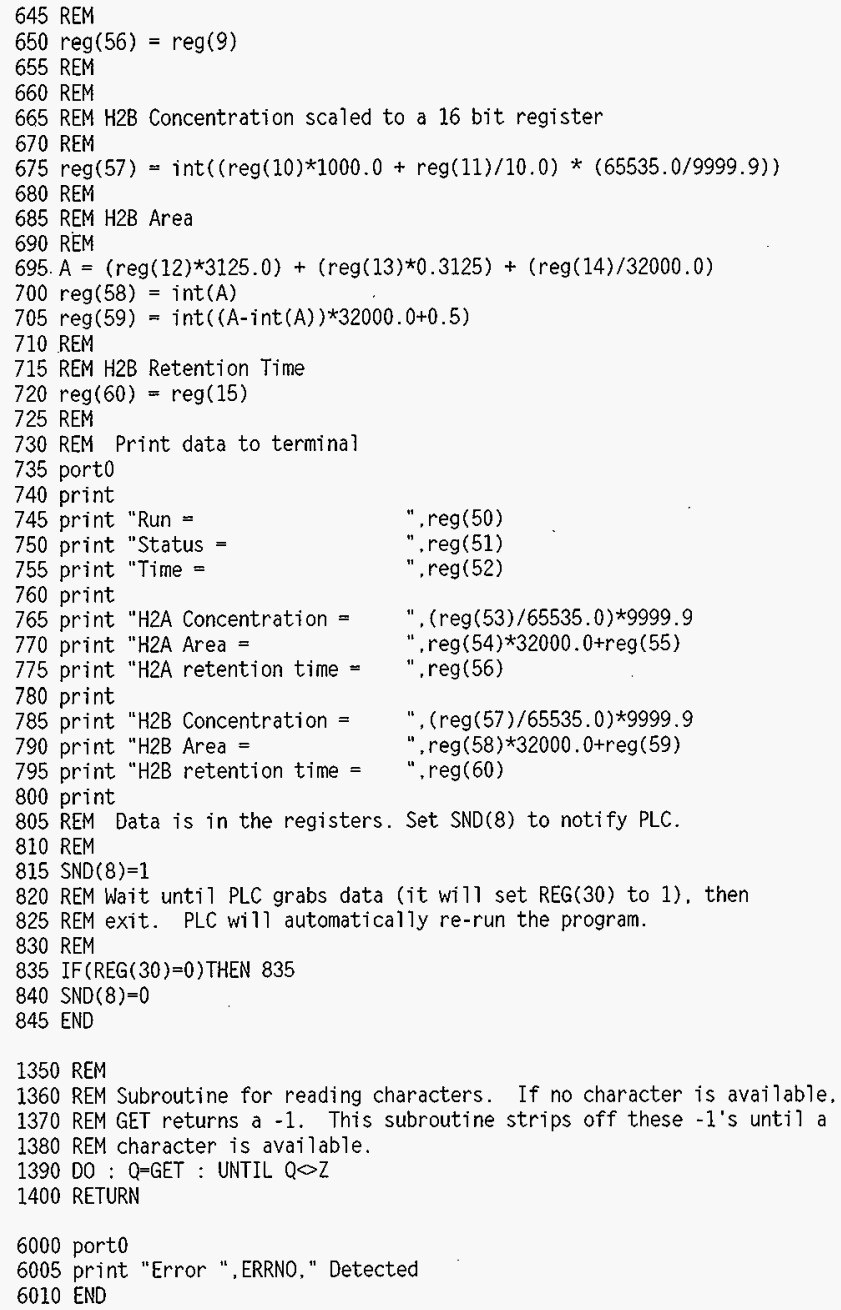


HNF-SD-WM-CSDD-008

Rev. 3

Page 198

\section{Appendix K: Software License Agreements}

The following is a list of the commercial software that is used in the DACS system.

\begin{tabular}{|l|l|l|}
\hline \multicolumn{1}{|c|}{ Company } & \multicolumn{1}{|c|}{ Software } & \multicolumn{1}{c|}{ Version } \\
\hline \hline Helix & Netroom3 & 3.02 \\
\hline Kensington Microware, Ltd. & Expert Mouse & $\mathrm{n} / \mathrm{a}$ \\
\hline Iconics, Inc. & Genesis Control Series & 3.72 \\
\hline Iconics, Inc. & GEN-NET & 3.64 \\
\hline Iconics, Inc. & Remote Supervisory Station & 3.72 \\
\hline Modicon, Inc & Modsoft & 2.1 \\
\hline Microsoft Corp. & MS-DOS & 6.0 \\
\hline Microsoft Corp. & Windows & 3.1 \\
\hline Nicolet Instrument Corp. & FAMOS & $\mathrm{n} / \mathrm{a}$ \\
\hline Symantec Corp. & Norton DiskLock & 3.5 \\
\hline
\end{tabular}


HNF-SD-WM-CSDD-008

Rev. 3

Page 199

\section{Appendix L: DeCipher Plus and DeTerminal Software}

The DeCipher Plus software and DeTerminal software are used with the Datataker 50 data logger in support of the tank 241SY101 mixer pump removal. Descriptions of the software are summarized as follows:

DeCipher Plus Program Disk, version 1.1, July 1, 1992

Volume in drive A is DCP11_1

Directory of A:I

\begin{tabular}{llrrr} 
READ & ME & 12,709 & $06-30-92$ & $9: 37 \mathrm{a}$ \\
README & BAT & 22 & $06-26-92$ & $1: 01 \mathrm{p}$ \\
INSTALL & EXE & 104.645 & $02-26-92$ & $11: 34 \mathrm{p}$ \\
DCP01100 & 001 & 448,830 & $06-30-92$ & $9: 51 \mathrm{a}$ \\
\multicolumn{1}{c}{4 file(s) } & \multicolumn{3}{c}{566,206 bytes } \\
& & 160,768 bytes free
\end{tabular}

"READ.ME" File Listing

DeCipher Plus Release 1.1 - Release Notes

Contents

1. How to install version 1.1

2. Running the DeCipher Plus demonstration

3. Vital hints for getting started

4. Known software problems

5. Known documentation problems

6. What to do when you have problems

7. Revision History

1. How to install version 1.1

To install DeCipher Plus :-

- the DeCipher Plus program disk contains the installation program: -

INSTALL.EXE

- execute this program either by 
drive_name:INSTALL <Enter>

(e.g. $>a$ : INSTALL)

or

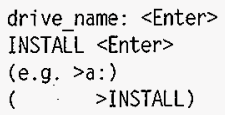

where drive_name should be replaced by the letter denoting the drive in which the program disk now resides.

- as the INSTALL program executes, it

* creates the DeCipher Plus directory structure

* copies the DeCipher Plus files

* manages any changes to CONFIG.SYS and AUTOEXEC.BAT which may be required (with your permission)

2. Running the DeCipher Plus Demonstration

The IDCP directory on the installation drive contains the demonstration program

DEMO.BAT

To run the demonstration, enter the DOS cormand

cd IOCP<Enter >

DEMO<Enter>

The Decipher Plus demonstration will execute various application displays using data previously acquired already installed onto your computer.

3. Vital Hints for Getting Started

* DeCipher Plus requires a very specific directory structure to be set up on disk in order for it to run. When this directory structure is not present DeCipher Plus will not run. This directory structure begins at the root directory level with the IDCP directory. The IDCP directory must aiways be at root directory level. By default the database is found on the drive on which DeCipher Plus is executing. although the DB command line parameter allows this to be modified. 
* Decipher Plus file connections can only be made to files with the extension DCP. These files are in a very special format and can only be generated through the File application of DeCipher Plus. The .DCP files are very different in format to any data saved in the top window of the Command application.

IT IS NOT POSSIBLE to connect, plot or translate any data saved using Alt-S in the Command application, nor is it possible to connect to any data saved in the $\$$ Session.DAT file.

The correct sequence of actions to save data from a logger into a disk file, which can then be used by Decipher. Plus is as follows

- Connect to the logger

- Select the desired retrieval mode (real time or logged) in the data window.

- Select the desired channels in the File application

- Select DECIPHER format in the File application (indicated by *)

- Select a file name for the disk file (e.g. DATA)

- Use the Run menu to select and run the File application

As a result the file DATA.DCP will be created in the LDCPIDCP_DATA directory.

To access this data file. we must now create a connection to the file as follows

- Enter the Connect menu

- Highlight Filedata

- Press Alt $N$ to create a new connection

- Select the Datafile type

- Tab to the Datafile tile

- Ensure that the path is set for IDCPIDCP_DATA

- Change the filename to DATA

- Tab to the top menu

- Press Alt-S to save

- Name the connection DATA

As a result a connection definition named DATA wi 11 now be listed in the connection list. Connect to the DATA connection as by pressing <Enter> or Alt $C$. The original data from the logger is now available for use within DeCipher Plus.

* Note that the files created by the File application are for IMPORTing into the spreadsheets only. They are NOT worksheet files.

* The inbuilt context sensitive help system is extensive and is available throughout DeCipher Plus. It may prove useful to browse the help files 
before using the product. These files and other useful information can be accessed through the ? window. Simply highlight the desired subject and press <Enter>.

\section{Known Software Problems with Version 1.1}

* DeCipher Plus does not exit gracefully to DOS if it cannot find a database structure with which to execute (either by default or as specified on the comand line). Reboot the machine to restart DOS. Investigate why no database ( $D C P$ directory structure) exists where DeCipher Plus was executed.

* There are some memory problems associated with running DeCipher Plus under Windows as a DOS application. If the EMM386 expanded memory manager is being used with the NOEMS parameter. DeCipher Plus will crash on initialization. It is not compatible with this expanded memory arrangement. Run EMM386 without the NOEMS parameter.

* We have had reports of DeCipher Plus crashes in the plot appiication connected to use of the axis changing keys and non-standard graphics hardware. As yet no problems have been reported with VGA systems but we have received one report each for Hercules and EGA. It should be stressed that in general DeCipher Plus does work with these graphics adaptors. In cases where the axis change facility causes problems, it should not be used. Check that there are no TSRs loaded which may be making sophisticated or unusual use of the graphics adaptor.

* Some problems have been reported when a DeCipher Plus connection is made to a COM port on which a serial mouse driver is resident. Some mouse drivers have been found to interfere with DeCipher Plus, which causes various phenomena such as no communications when running applications. We have found this to be a problem especially with

Genius Mouse driver Agi ler Mouse driver

The Microsoft mouse driver seems to function correctly. As a rule don't insta 17 mouse drivers installed on any COM port which you intend to use to connect to loggers.

* A sma11 number of problems have been found with the saving of tasks

- File application special date and time format are not saved (The first three for all file formats except DECIPHER). Use Date and Time from logger channels.

- Tasks which include channels which have been deselected in the Data window will not load correctly. Ensure all deselection is managed within the individual application windows. 
* The Lotus default file formats are incorrect for date and time. You should select .dddd format for time and ddd elapsed format for date manually. Once in Lotus it is necessary to import these as numbers and to convert them to TIME_VALUE and DATE_VALUE with a formula. The TIME VALUE converts directly but the DATTE_VALUE must be adjusted by adding 32509 to the imported number (converts to the Lotus date offset from $01 \backslash 01 \backslash 1900)$.

* It is possible to receive an alarm or an error message during the transmission of a response to DeCipher Pius program query. However this results in eventual loss of connection after a period displaying the Waiting window. Try using protacol mode if this is a problem. otherwise just reconnect as this is only likely to be a problem in situations where large numbers of alarms or errors are being returned continuously or frequentiy.

* On entering the File application after a task load, the file destination may be selected but the filename may not be visible. To display the filename simply toggle the file destination selection.

* The Setup window always shows the default graphics printer after restart. even after another printer has been selected and saved. In fact the correct printer driver is active, the problem is that it has not been displayed correctly.

* Creation of a connection file with the name NEW CON prevents creation of any other connection. The connections may be defined but they cannot be saved. The NEW CON.CON should be deleted from IOCP\CON_DB\CCT. Unfortunately NEW_CON is the default connection name suggested on a new connection save.

* The available data range for a connection which includes an internal memory card (as displayed in the data window) is not visible. The data still exists on the card, but DeCipher Plus cannot access its range. Any applications executed can define any timeldate range for retrieved data as required without problem.

* It is possible to select any format for date and time channels in the DECIPHER file format. However these have no effect, and will be forced to integer days and integer seconds due to the requirements for reconnection. This will be apparent by returning to the File application window.

* The units for date and time channels are inconsistent between different applications. However this does not affect running of the applications in any way.

* $Y$ axis labeling on some plots is not quite correct. On occasion the largest $Y$ axis label is not displayed. 
* When connecting to a Datataker using an address not directly attached to the COM port of the computer, the 'Connected to' message is issued once DeCipher Plus has contacted the network and NOT the logger itself. If no logger with the specified address exists on the network. the first communication to that logger will be the first failure. This occurs on an attempt to agree on the program map with the Waiting window displayed. A network error is displayed on the Alarm line. At this point use Alt $R$ to release the connection.

$+$

5. Omissions from the Manual in version 1.1

Three sections are missing from the manua?.

- 6.3.8 Setup Module

- 6.3 .9 Help overview

- A2 System messages

Exiting DeCipher Plus should be section 6.3.10

Synopsis

\subsubsection{Setup Module}

The setup module al lows definition and saving of the contents of the OCP_CFG.CFG file. All overall system parameters can be set here.

It also allows loading and saving of task files. A task file is a complete copy of all DeCipher Plus menu definitions. Loading a task file results in DeCipher Plus menus being configured to the contents of the task file.

Examples are provided in the demonstration.

- DEMO $1.00 T$

- DEMO_2.DDT

etc...

6.3.9 Help overview

A11 DeCipher Plus help files (and other useful text files provided by Data Electronics) can be browsed within the help overview menu. Simply highlight the desired file and press <Enter>.

The filename is provided on the right hand side of the list to allow access to the text files for printing. The files can be found in IDCP\HELP.

The file KEY HELP.HLP provides on line access to the manual section 6.2 Keyboard Usage. 
6. What to do when you have Problems

* Please check both the manual appendix and help files for possible solutions to the problem.

* If that fails, fill out the problem report sheet as fully as possible. In particular describe the sequence of DeCipher Plus operations that highlighted the problem, and details of the Datataker program and configuration you were using. These are of paramount importance.

* Fax the information to us as follows Within Australia (03)-764-8997 Outside Australia 61-3-764-8997

* For Telephone support you can contact us as follows Within Australia (03) $-764-8600$ Outside Australia 61-3-764-8600

6. Revision History

24-Apri1-1992 (JPM) Original Version

01-Juily-1992 (JPM) Upgrade Revision

Enjoy using Decipher Plus! 


\section{DeTerminal Software, version 2., Science/Electronics Part \#71025}

\begin{tabular}{|c|c|c|c|c|}
\hline BLOKSCAN & CMD & 1,098 & $09-16-93$ & $2: 46 p$ \\
\hline DEPOLY & EXE & 37.254 & $06-25-93$ & $11: 07 a$ \\
\hline DOWNTIME & $C M D$ & 2.732 & $09-16-93$ & $2: 46 p$ \\
\hline DT & $C F G$ & 374 & $03-$ & $11: 14 p$ \\
\hline DT & EXE & 292.984 & $03-11-94$ & $3: 28 p$ \\
\hline OT & HLP & 61,964 & $03-13-94$ & $11: 07 p$ \\
\hline EXAMPLE & CMD & 2.283 & $01-20-94$ & $5: 01 p$ \\
\hline FUELFLOW & CMO & 1.767 & $09-16-93$ & $2: 46 p$ \\
\hline LOGSCAN & CMD & 1,247 & $09-16-93$ & $2: 46 p$ \\
\hline LSQ & DOC & 2.176 & $04-14-88$ & $2: 31 p$ \\
\hline LSQ & EXE & 85,585 & $04-19-88$ & $4: 16 p$ \\
\hline PROGRAM & CMD & 1,138 & $11-09-93$ & $4: 24 p$ \\
\hline READ & ME & 4.958 & $03-16-94$ & $12: 19 p$ \\
\hline README & BAT & 44 & $02-09-94$ & $12: 07 a$ \\
\hline STEPSCAN & CMD & 1,355 & $09-16-93$ & $2: 46 p$ \\
\hline TEMPLATE & $C M D$ & 1.218 & $11-09-93$ & $4: 23 p$ \\
\hline UNLD_100 & CMD & 1,050 & $03-16-94$ & $11: 55 a$ \\
\hline UNLD_200 & CMD & 1.348 & $03-16-94$ & $11: 56 a$ \\
\hline SET & CMD & 3.632 & $09-16-93$ & $2: 46 p$ \\
\hline & 19 file(s) & & 504,207 by & tes \\
\hline & & & . & s fr \\
\hline
\end{tabular}

"READ.ME" File Listing

DeTerminal Command Files

Introduction

DeTerminal is a terminal type program which provides an easy to use interface to the Datataker data loggers from IBM-PC and compatible computers.

DeTerminal is used to create and edit command files, to send commands and command files to the Datataker, and to view and save data returned by the Datataker.

This DeTerminal distribution disc contains the following files

DT.EXE

DT. HLP

DT.CFG

READ.ME
- DeTerminal program file

- DeTerminal help file. accessed via F1

- Last used configuration of the DeTerminal system

- This information file 
PROGRAM.CMD - A suggested layout for Datataker programs

TEMPLAT.CMD

\begin{abstract}
- A template for Datataker programs, based on the suggested layout. A simple program can be quickly developed by entering details into the template.
\end{abstract}

\title{
Command Files
}

The distribution disc also contains a number of Datataker command files which provide a guide to using DeTerminal to program the Datataker, and some useful applications programs, as follows

\author{
BLOKSCAN .CMD - Demonstrates programming of the Datataker to scan \\ input channels for short periods of time, at longer \\ regular intervals of time. \\ STEPSCAN.CMD - Demonstrates programming of the Datataker to scan \\ input channels at increasing intervals as the data \\ logging session proceeds. This technique can be used \\ to collect data for a parameter which asymptotes \\ with time, such that data is collected more slowly \\ as the parameter changes more slowly. \\ LOGSCAN.CMO - Demonstrates programming of the Datataker to scan \\ input channels at logarithmic intervals as the data \\ logging session proceeds. This technique can also be \\ used to collect data for a parameter which asymptotes \\ with time. \\ DOWNTIME.CMD - Demonstrates programming of the Datataker to perform \\ calculations based on time. Operator buttons are \\ monitored to indicate reason for machine downtime, \\ which provide triggers for measuring total elapsed \\ time for each cause of downtime. \\ FUELFLOW.CMD - Demonstrates the use of Datataker expressions to \\ combine data from two related measurements, to \\ provide corrected results in real time. \\ WINDSET.CMD - Demonstrates use of Datataker expressions to \\ calculate average wind direction and wind sigma \\ from a wind direction and wind speed sensor. \\ UNED_100.CMD - Provides assistance in unloading the DT100 family \\ of loggers, by stepping the user through the \\ decisions to be made about data delimiters, time \\ formats, and filenames. The logger is then set as \\ desired and unloaded automatically.
}


Note that UNLO 100.CMD is supplied for DT100 users as DeTerminal's Alt Unload feature is specifically for supporting DT500's and DT50's.

UNLD_200.CMD

- Provides assistance in unloading the DT200 family of loggers, by stepping the user through the decisions to be made about data delimiters, time and date formats, and filenames. The logger is then set as desired and unloaded automatically.

Note that UNLD 200.CMD is supplied for DT200 users as DeTerminal's Ait Unload feature is specifically for supporting DT500's and DT50's.

\section{Utilities}

There are also two utility programs on the distribution disc, for extracting polynomials from data sets of sensor calibrations. These polynomials can then be programmed into the Datataker to return data in engineering units from sensors with simple analog or digital outputs.

DEPOLY.EXE

- Calculates polynomials mathematically from selected data points from a data set.

LSQ.EXE

- Calculates polynomials for data sets using the least squares method. 


\section{DISTRIBUTION SHEET}

\begin{tabular}{|c|c|c|c|c|c|}
\hline \multirow{2}{*}{$\begin{array}{l}\text { To } \\
\text { Distribution }\end{array}$} & \multirow{2}{*}{\multicolumn{3}{|c|}{$\begin{array}{l}\text { From } \\
\text { Remote Sensing and Sampling } \\
\text { Equipment Engineering }\end{array}$}} & \multicolumn{2}{|l|}{ Page 1 of 1} \\
\hline & & & & \multicolumn{2}{|c|}{ Date May 20, 1997} \\
\hline \multirow{2}{*}{\multicolumn{4}{|c|}{$\begin{array}{l}\text { Project Title/Work Order } \\
\text { Computer System Design Description for SY-101 Hydrogen Mitigation Test } \\
\text { Project Data Acquisition and Control System (DACS-1) - Rev. } 3\end{array}$}} & \multirow{2}{*}{\multicolumn{2}{|c|}{$\begin{array}{l}\text { EDT No. } \\
\text { ECN No. } 637502\end{array}$}} \\
\hline & & & & & \\
\hline Name & MSIN & $\begin{array}{l}\text { Text } \\
\text { With All } \\
\text { Attach. }\end{array}$ & Text Only & $\begin{array}{l}\text { Attach./ } \\
\text { Appendix } \\
\text { Only }\end{array}$ & $\begin{array}{c}\text { EDT/ECN } \\
\text { Only }\end{array}$ \\
\hline W. G. Brown & T4-07 & $\mathrm{x}$ & & & \multirow{5}{*}{$\mathrm{X}$} \\
\hline D. W. Crass & H6-11 & & & & \\
\hline J. A. Ellingsworth & $\mathrm{R} 2-87$ & $x$ & & & \\
\hline A. M. Ermi (5) & L6-37 & $\mathrm{X}$ & & & \\
\hline G. J. Gauck & $\mathrm{T} 4-07$ & $\mathrm{x}$ & & & \\
\hline C. E. Hanson & S7-12 & & & & $\mathrm{X}$ \\
\hline G. D. Johnson & S7-14 & & & & $\mathrm{x}$ \\
\hline L. S. Krogsrud & T4-07 & $\mathrm{X}$ & & & \multirow{6}{*}{$\mathrm{X}$} \\
\hline D. C. Larsen & T4-08 & $\mathrm{X}$ & & & \\
\hline S. O. Smith & L6-37 & $\mathrm{X}$ & & & \\
\hline D. D. Tate & L6-37 & & & & \\
\hline R. W. Truitt & L6-37 & $\mathrm{x}$ & & & \\
\hline R. R. True & T4-07 & $\mathrm{x}$ & & & \\
\hline DACS Project File & L6-37 & $\mathrm{X}$ & & & \\
\hline Central Files (1) & A3-88 & $\mathrm{x}$ & & & \\
\hline
\end{tabular}

